\title{
TECHNOLOGY DEVELOPMENT PROGRAM FOR AN ADVANCED POTASSIUM RANKINE POWER CONVERSION SYSTEM COMPATIBLE WITH SEVERAL SPACE REACTOR DESIGNS
}

\author{
FINAL PHASE I REPORT \\ COMPLETED SEPTEMBER 2004 \\ PUBLISHED SEPTEMBER 2005
}

\author{
G. L. Yoder, Jr. \\ J. J. Carbajo \\ R. W. Murphy \\ A. L. Qualls \\ C. D. Sulfredge \\ Oak Ridge National Laboratory \\ Oak Ridge, TN \\ M. P. Moriarty \\ F. J. Widman \\ K. J. Metcalf \\ Pratt \& Whitney Rocketdyne \\ Canoga Park, CA
}

\author{
M. Nikitkin \\ Swales Aerospace \\ Beltsville, MD
}

\begin{abstract}
This report was prepared as an account of work sponsored by an agency of the United States Government. Neither the United States Government nor any agency thereof, nor any of their employees, makes any warranty, express or implied, or assumes any legal liability or responsibility for the accuracy, completeness, or usefulness of any information, apparatus, product, or process disclosed, or represents that its use would not infringe privately owned rights. Reference herein to any specific commercial product, process or service by trade name, trademark, manufacturer, or otherwise, does not necessarily constitute or imply its endorsement, recommendation, or favoring by the united States Government or any agency thereof. The views and opinions of authors expressed herein do not necessarily state or reflect those of the United States Government or any agency thereof.
\end{abstract}




\title{
DOCUMENT AVAILABILITY
}

Reports produced after January 1, 1996, are generally available free via the U.S. Department of Energy (DOE) Information Bridge:

Web site: http://www.osti.gov/bridge

Reports produced before January 1, 1996, may be purchased by members of the public from the following source:

\author{
National Technical Information Service \\ 5285 Port Royal Road \\ Springfield, VA 22161 \\ Telephone: 703-605-6000 (1-800-553-6847) \\ TDD: $703-487-4639$ \\ Fax: 703-605-6900 \\ E-mail: info@ntis.fedworld.gov \\ Web site: http://www.ntis.gov/support/ordernowabout.htm
}

Reports are available to DOE employees, DOE contractors, Energy Technology Data Exchange (ETDE) representatives, and International Nuclear Information System (INIS) representatives from the following source:

Office of Scientific and Technical Information

P.O. Box 62

Oak Ridge, TN 37831

Telephone: 865-576-8401

Fax: 865-576-5728

E-mail: reports@adonis.osti.gov

Web site: http://www.osti.gov/contact.htm

\begin{abstract}
This report was prepared as an account of work sponsored by an agency of the United States Government. Neither the United States government nor any agency thereof, nor any of their employees, makes any warranty, express or implied, or assumes any legal liability or responsibility for the accuracy, completeness, or usefulness of any information, apparatus, product, or process disclosed, or represents that its use would not infringe privately owned rights. Reference herein to any specific commercial product, process, or service by trade name, trademark, manufacturer, or otherwise, does not necessarily constitute or imply its endorsement, recommendation, or favoring by the United States Government or any agency thereof. The views and opinions of authors expressed herein do not necessarily state or reflect those of the United States Government or any agency thereof.
\end{abstract}




\section{CONTENTS}

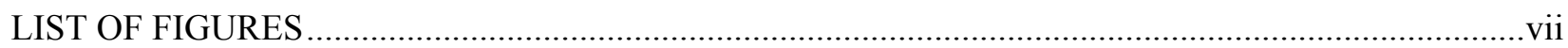

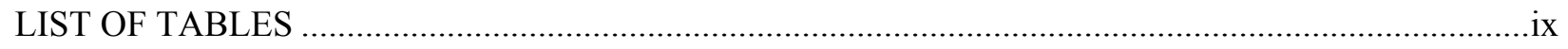

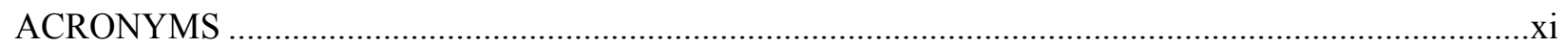

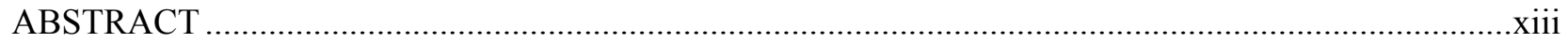

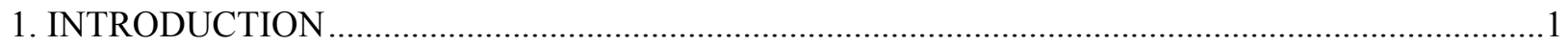

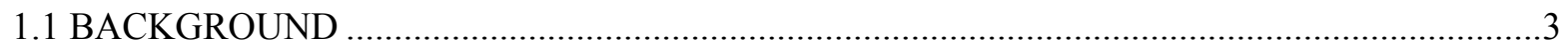

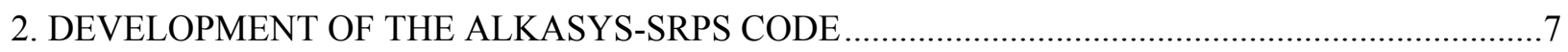

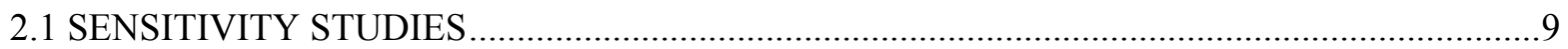

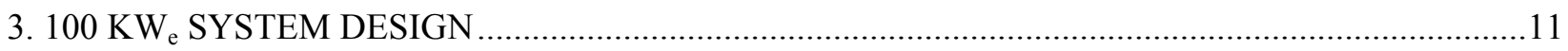

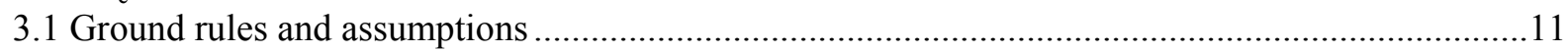

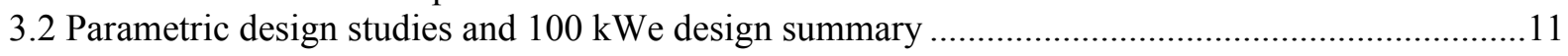

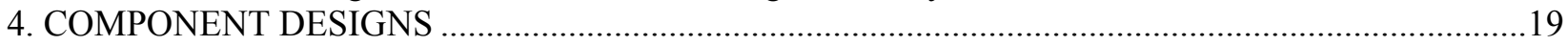

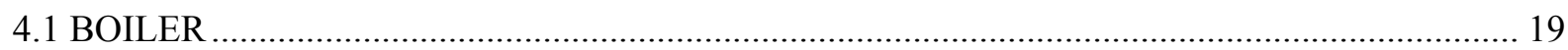

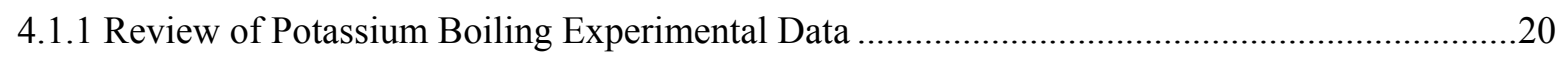

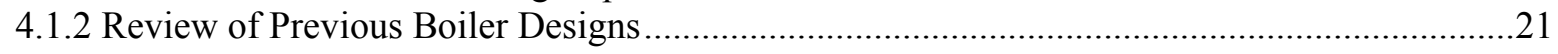

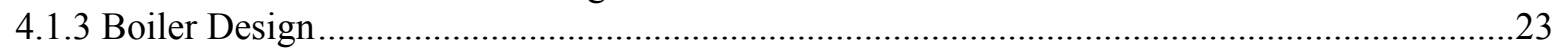

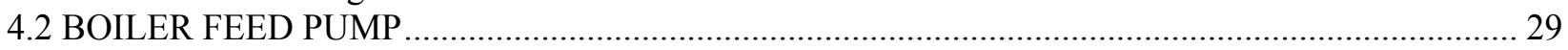

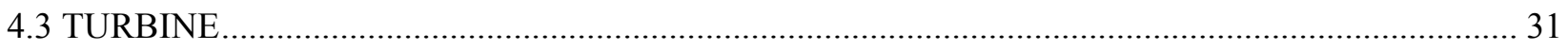

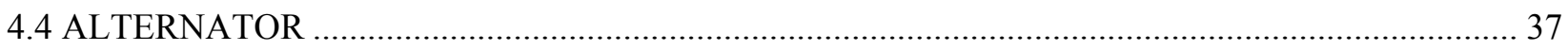

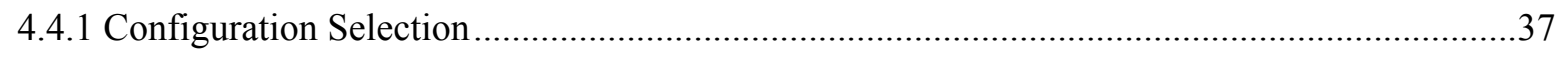

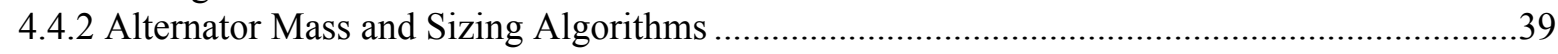

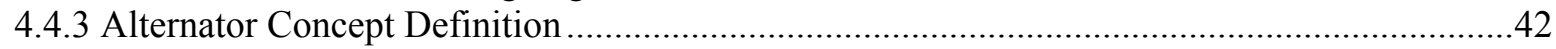

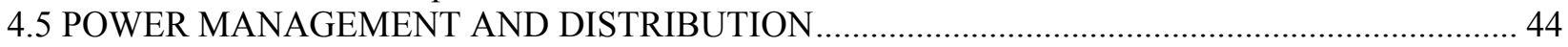

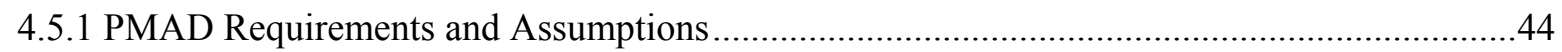

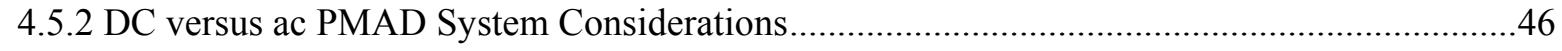

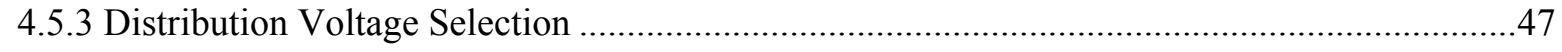

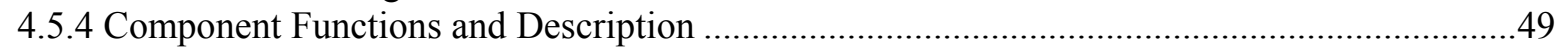

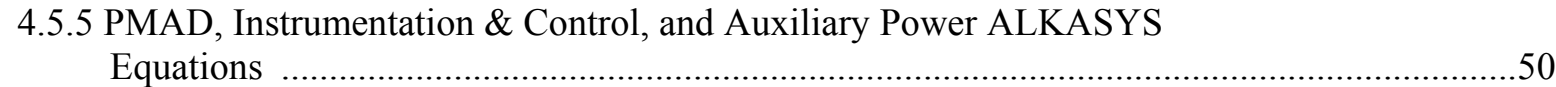

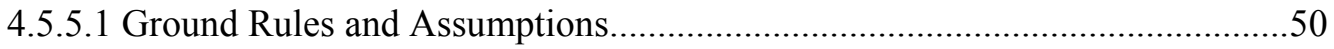

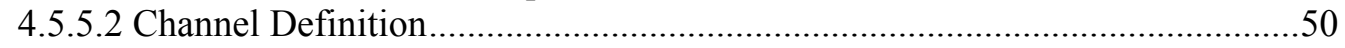

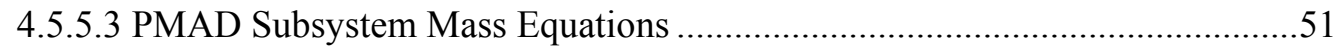

4.5.5.4 Instrumentation and Control Subsystem Mass Equation ...............................51

4.5.5.5 Auxiliary Power Subsystem Mass Equations …............................................51

4.5.5.6 PMAD Efficiency and Input Power Equations ...........................................51

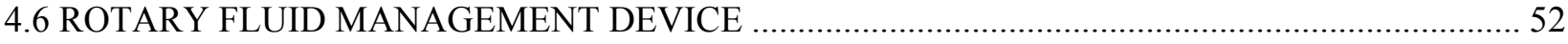

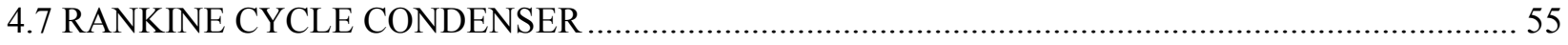

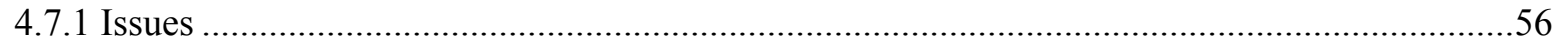

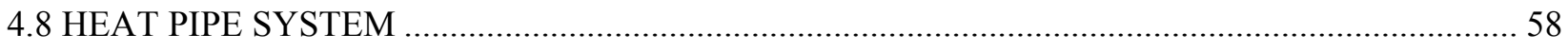

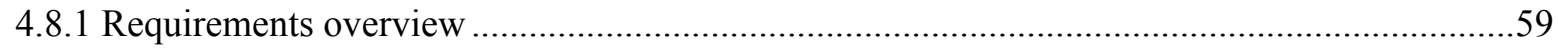

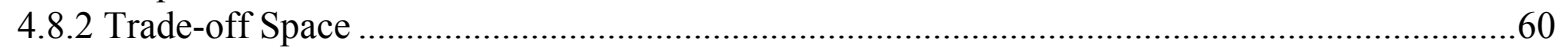

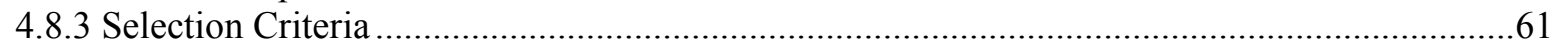

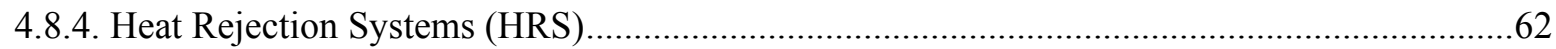

4.8.4.1 Heat Pipe Design and Operation ............................................................62

4.8.4.2 Loop Heat Pipe Design and Operation ........................................................64

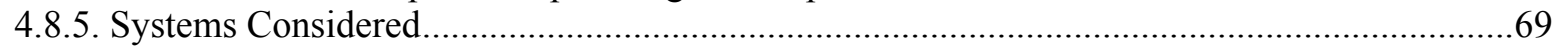

4.8.5.1 HRS Based on a Conventional HPs (System 1) ............................................70

4.8.5.2 HRS Based on a Single Phase Loop (System 2) ............................................73

4.8.5.3 HRS Based on a Loop Heat Pipe with Direct Condensation 


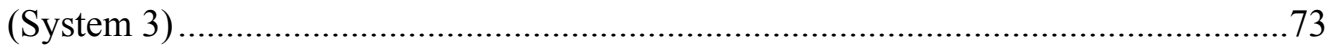

4.8.5.4 HRS Based on a Loop Heat Pipe with Indirect Condensation

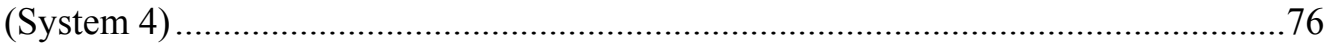

4.8.5.5 HRS Based on a Multiple Evaporator LHP with a Mechanical

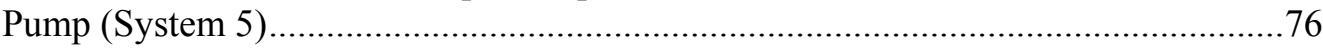

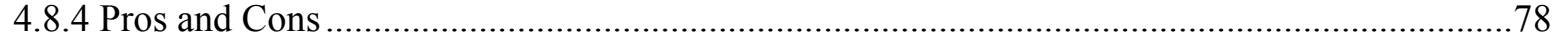

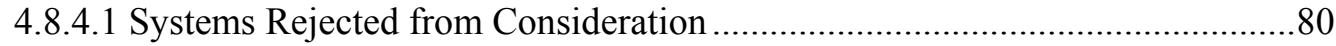

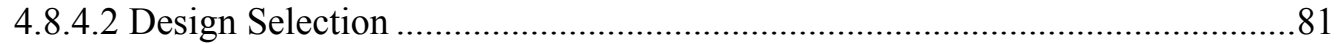

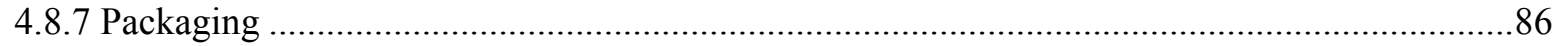

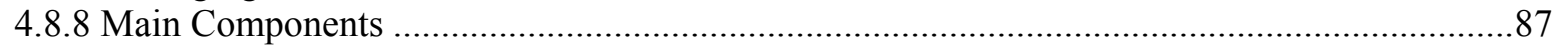

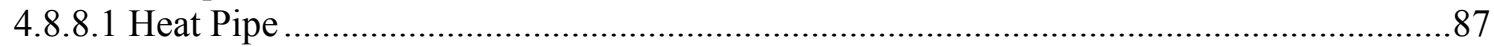

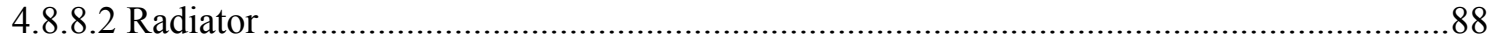

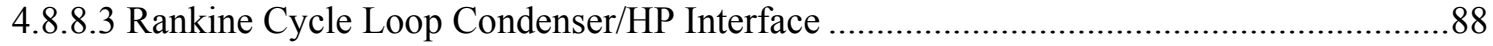

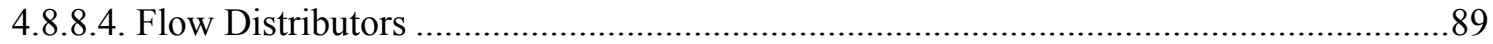

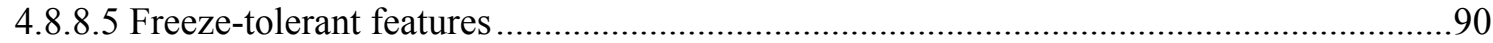

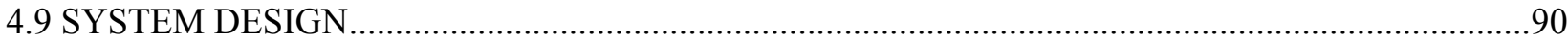

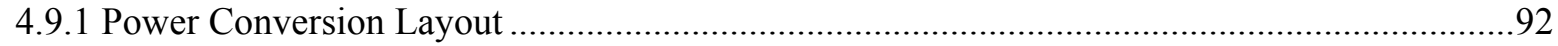

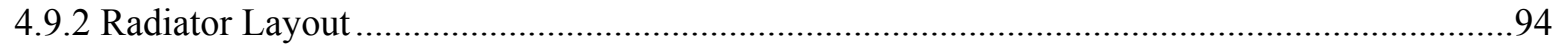

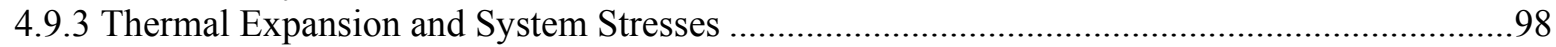

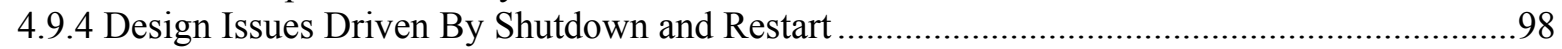

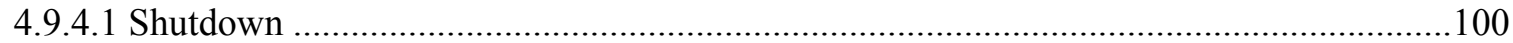

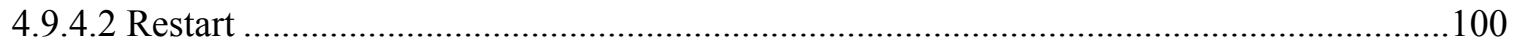

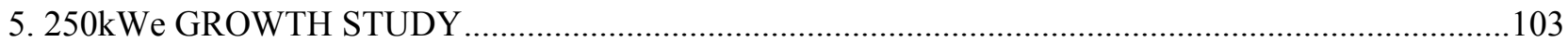

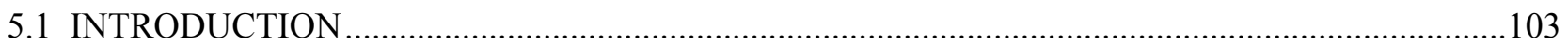

5.2 PARAMETRIC DESIGN EVALUATION AND DESIGN SUMMARY ........................................103

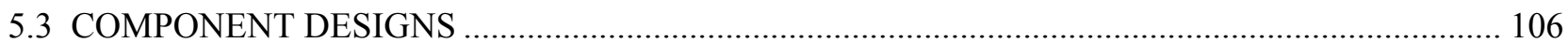

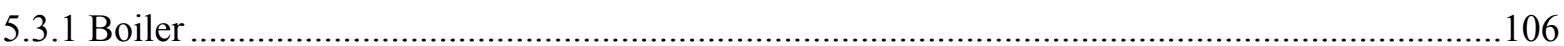

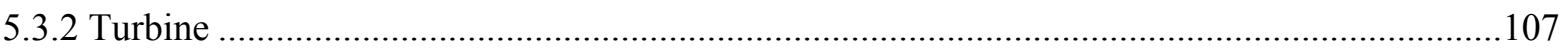

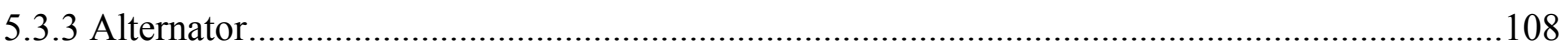

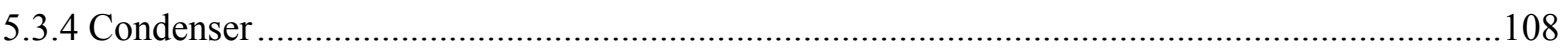

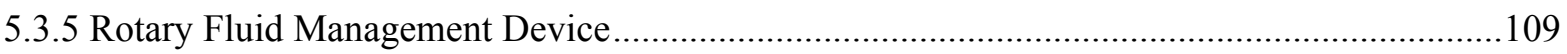

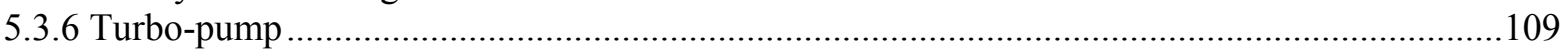

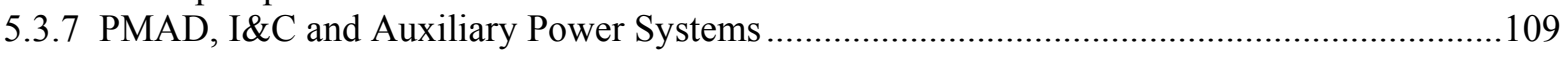

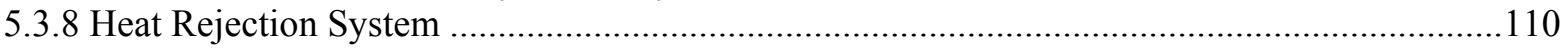

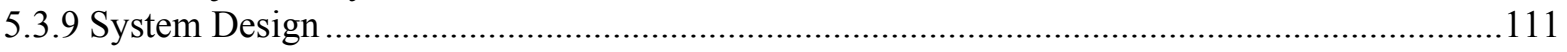

6. MICROGRAVITY ISSUES AND EXPERIMENT SCALING.......................................................113

6.1 MICROGRAVITY PHENOMENOLOGY AS IT APPLIES TO THE RANKINE

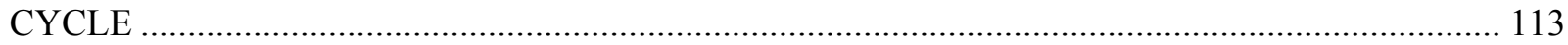

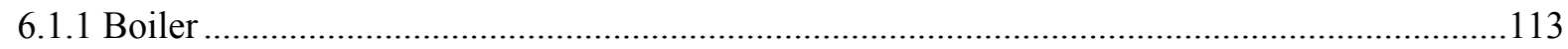

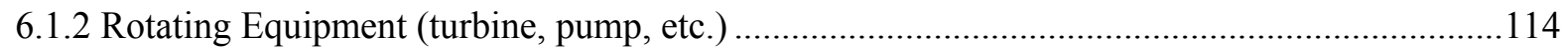

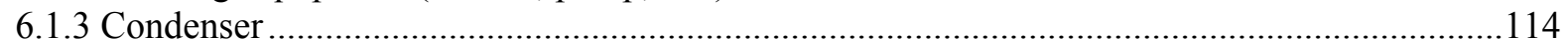

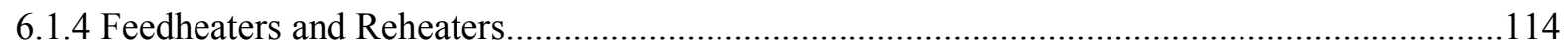

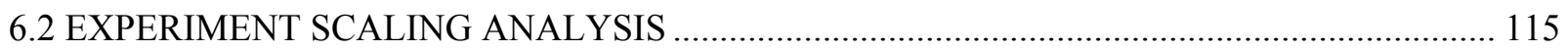

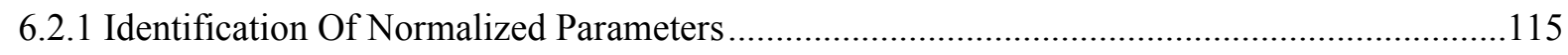

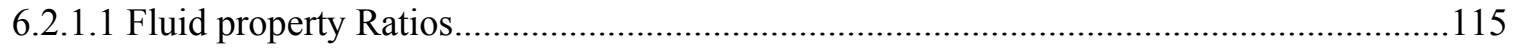

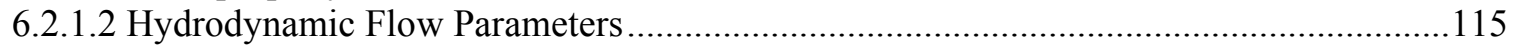

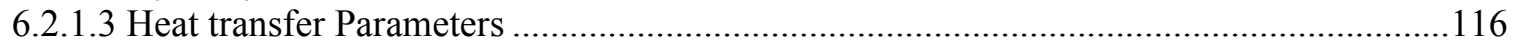

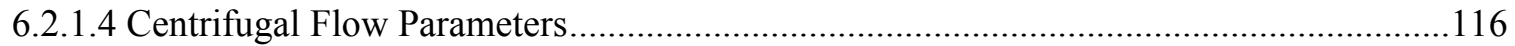

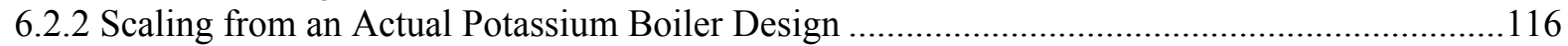

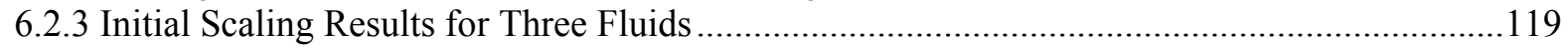

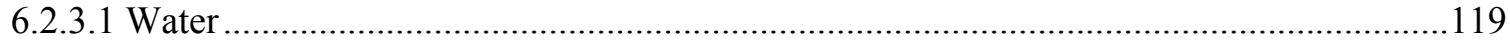




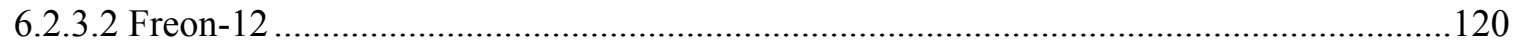

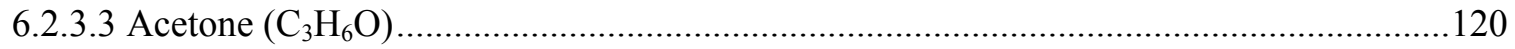

7. TECHNOLOGY DEVELOPMENT PLAN FOR ACHIEVING A TECHNOLOGY

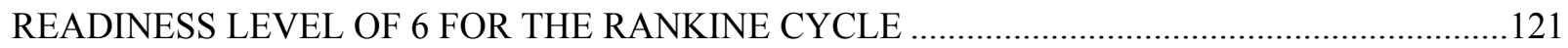

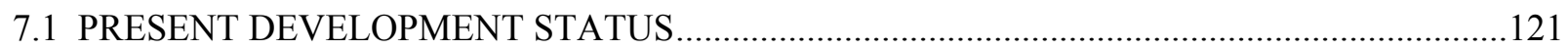

7.2 DEVELOPMENT CONSIDERATIONS AND DEVELOPMENT PROGRAM.............................121

7.2.1 Structural Materials .........................................................................................................12

7.2.1.1 Development Program ..........................................................................................121

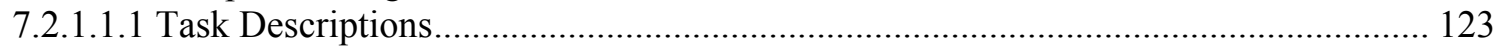

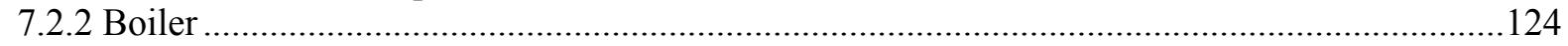

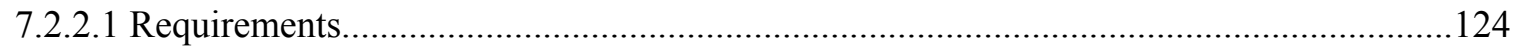

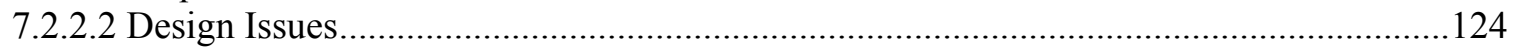

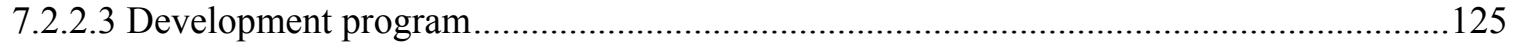

7.2.3 Turboalternator and turbopump ......................................................................................126

7.2.3.1 Development Requirements ..............................................................................126

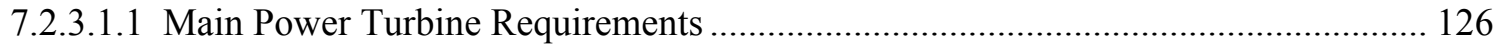

7.2.3.1.2 Alternator Requirements ................................................................................ 127

7.2.3.1.3 Boiler Feed Turbopump Requirements................................................................. 128

7.2.3.1.4 Bearing Requirements.................................................................................... 129

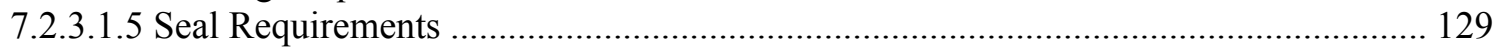

7.2.3.1.6 Coupling Requirements................................................................................. 130

7.2.3.2 Development Program Objectives ..............................................................................130

7.2.3.3 Development Program .........................................................................................131

7.2.3.3.1 Development Issues ....................................................................................... 131

7.2.3.3.2 Program implementation to achieve "nearly TRL-6 ………………………………... 134

7.2.3.3.3 Test Article fabrication .................................................................................... 137

7.2.3.4 Development Risk and Its Mitigation .....................................................................137

7.2.3.5 Conclusions and Recommendations.......................................................................138

7.2.4 PMAD Development .........................................................................................138

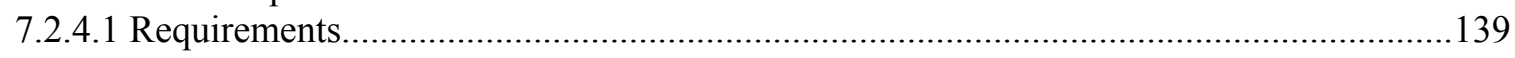

7.2.4.1.1 Wide Bandgap Devices....................................................................................... 140

7.2.4.1.2 Silicon Devices ...................................................................................... 141

7.2.4.1.3 Cables, Connectors, and Electronics Parts ............................................................... 141

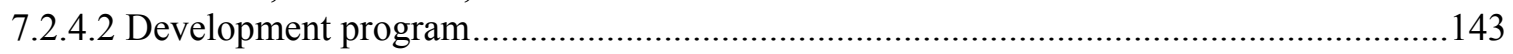

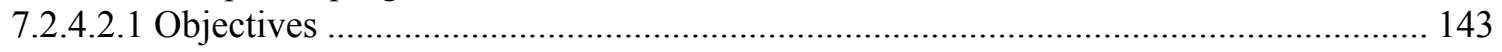

7.2.4.2.2 Ground rules and assumptions …………………………………………….... 143

7.2.4.2.3 Current State of the Art ....……………………………………………………... 144

7.2.4.2.4 Development Plan and Schedule..................................................................... 145

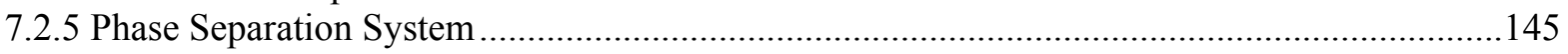

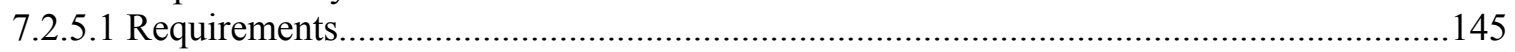

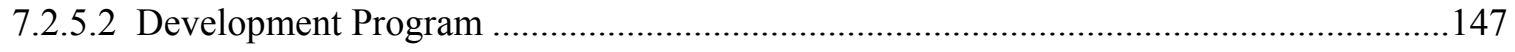

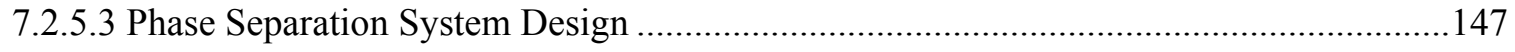

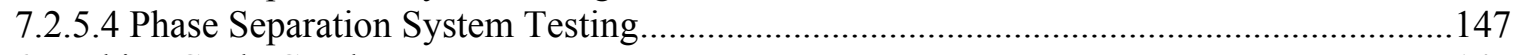

7.2.6 Rankine Cycle Condenser ................................................................................................147

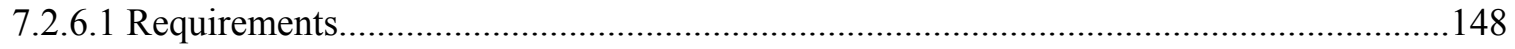

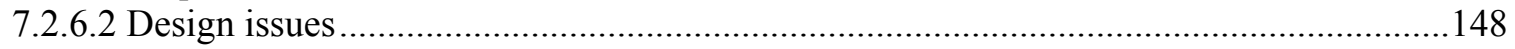

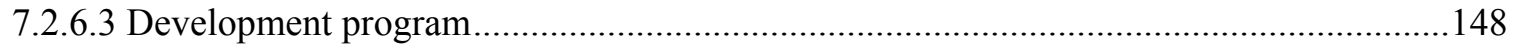

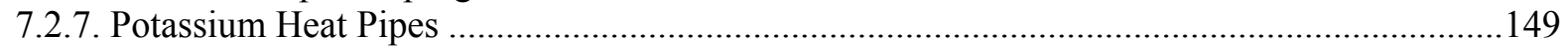

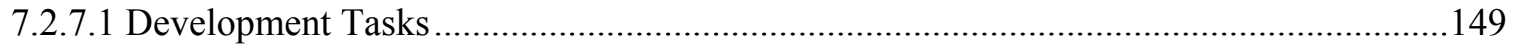

7.2.7.1.1 Wick Structure ………………………………………………………………... 149

7.2.7.1.2 Material Compatibility Studies ............................................................................ 150 
7.2.7.1.3 Design of the HP

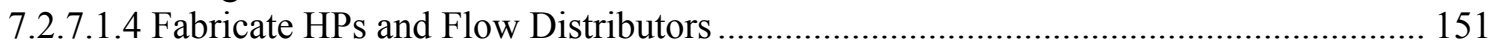

7.2.7.1.5 Charging and testing of the potassium heat pipe .................................................... 151

7.2.7.1.6 Charging and testing of the surrogate fluid heat pipe .............................................. 151

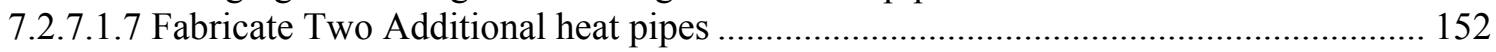

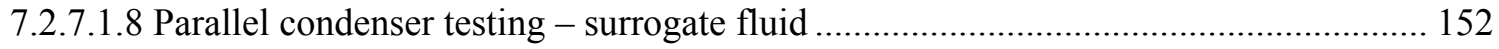

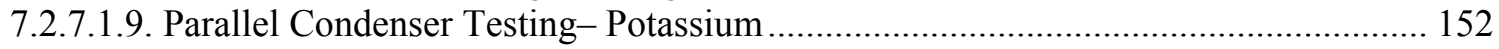

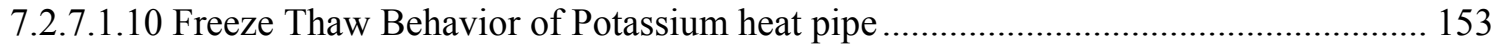

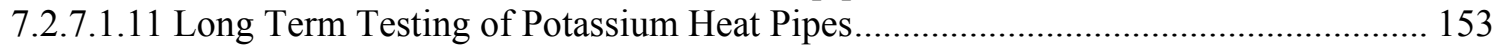

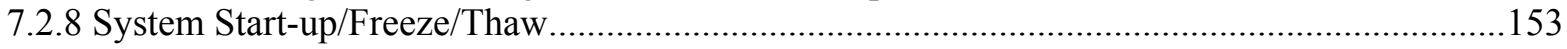

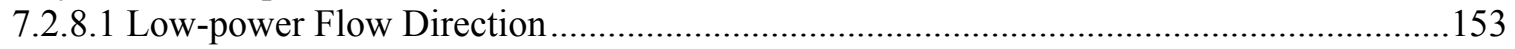

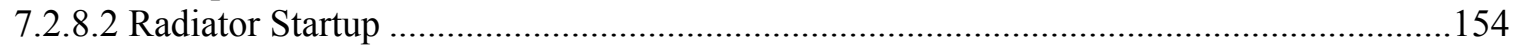

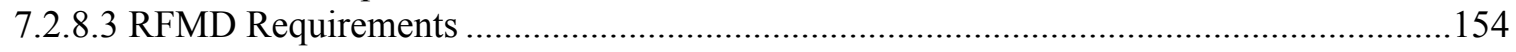

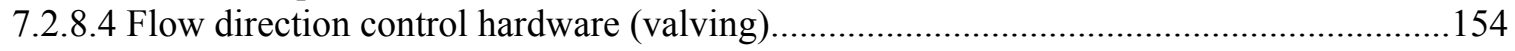

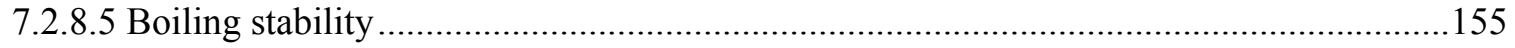

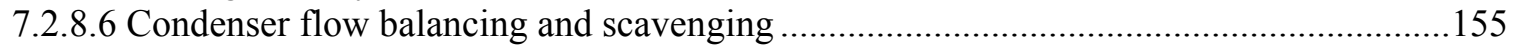

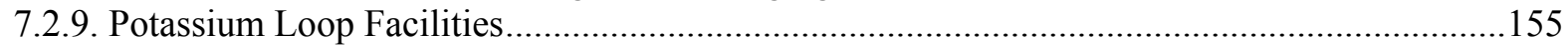

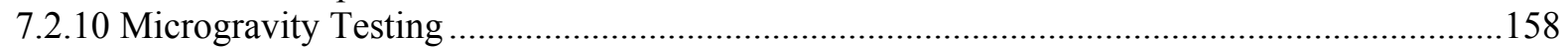

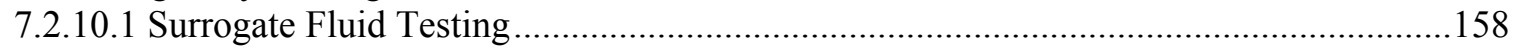

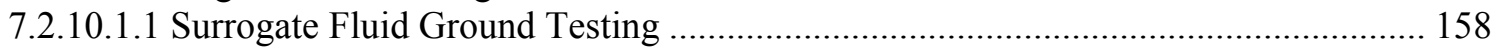

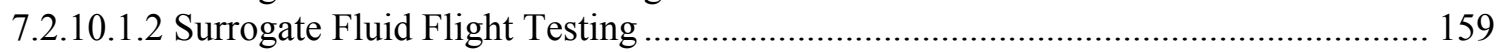

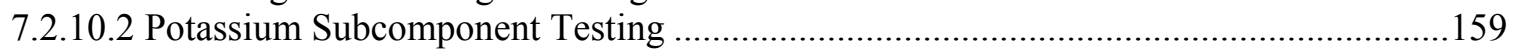

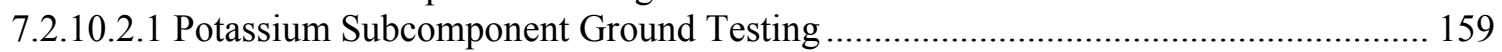

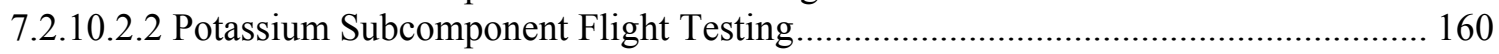

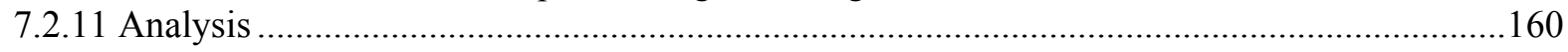

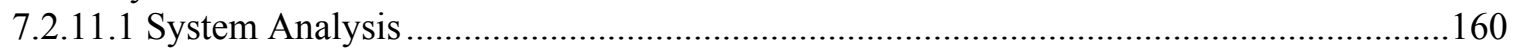

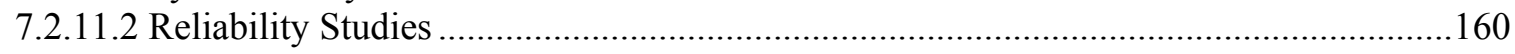

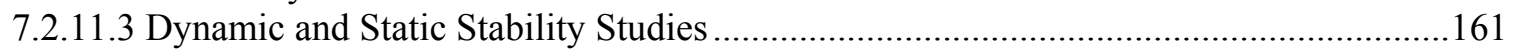

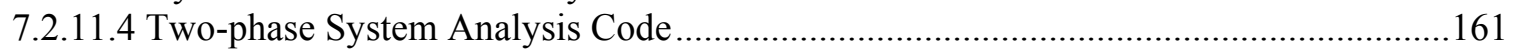

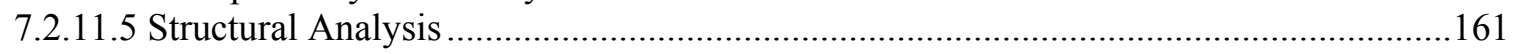

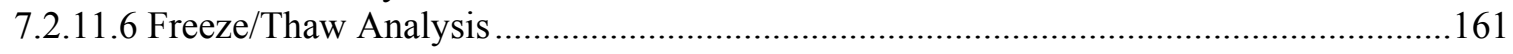

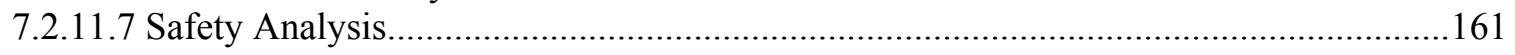

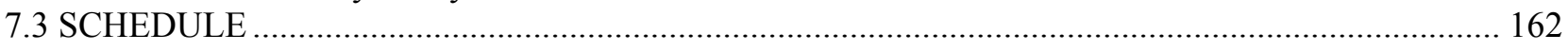

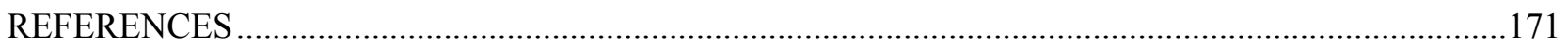

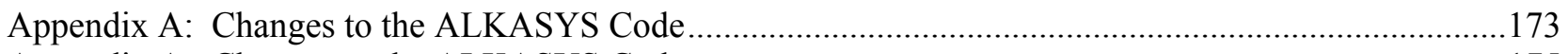

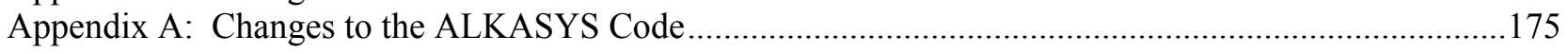

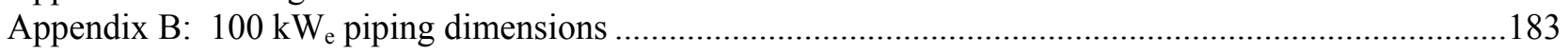

APPENDIX C: Listing of possible system connections of the integrated.............................................187

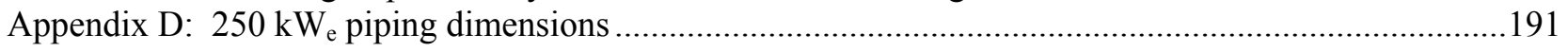

Appendix E: Design stress equations used in ALKASYS-SRPS .....................................................195 


\section{LIST OF FIGURES}

Figure

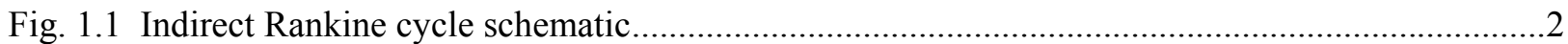

Fig. 1.2 Direct boiling Rankine cycle ..........................................................................................

Fig. 2.1 Diagram showing modular components of ALKASYS-SRPS …............................................

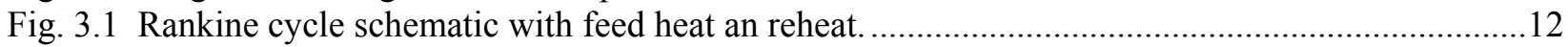

Fig. 3.2 Baseline Rankine cycle schematic chosen for the 100-kWe system .......................................14

Fig. 3.3 System mass predicted for three different structural materials: stainless steel, ........................15

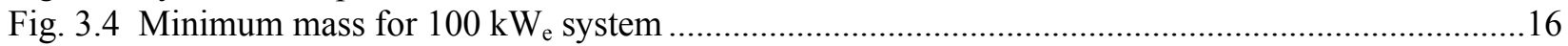

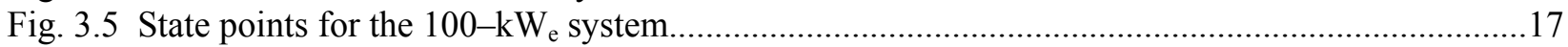

Fig. 3.6 The estimated masses $(\mathrm{kg})$ of a $100-\mathrm{kW}_{\mathrm{e}}$ (to the thrusters) potassium Rankine nuclear..............18

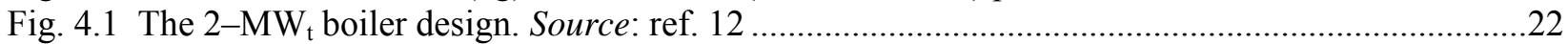

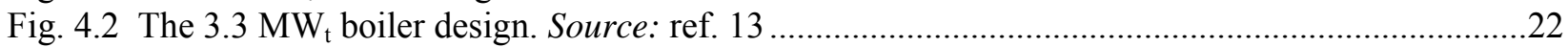

Fig. 4.3 Temperature distribution in 3.3 MWt boiler design (a) and heat flux and heat transfer...............23

Fig. 4.4 Temperatures in a boiler tube as calculated with the ATHENA code. ......................................25

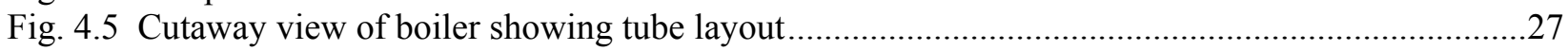

Fig. 4.6 Boiler isometric showing potassium and lithium inlets and outlets .........................................2

Fig. 4.7 Boiler header cutaway showing tube sheet and boiler tubes...............................................28

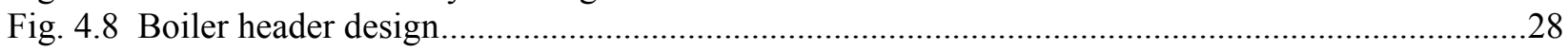

Fig. 4.9 Feed turbopump efficiency is driven by system power output ..............................................29

Fig. 4.10 Turbopump optimum speed is driven by the system power output. .........................................30

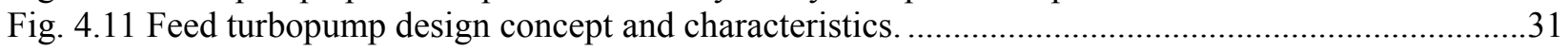

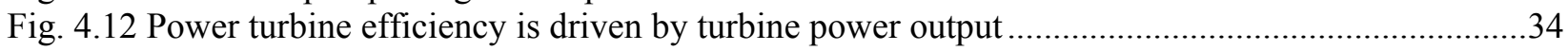

Fig. 4.13 Power turbine optimum speed is driven by shaft output power...............................................35

Fig. 4.14 Number of turbine stages is driven by maximum allowable tip speed......................................36

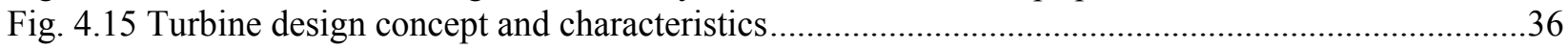

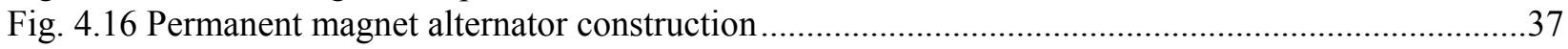

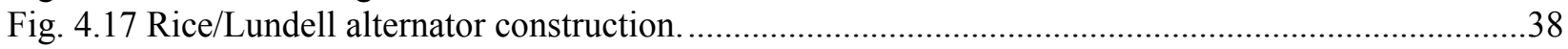

Fig. 4.18 Homopolar inductor alternator concept for $100-\mathrm{kW}_{\mathrm{e}}$ Power to thruster PPUs. .........................43

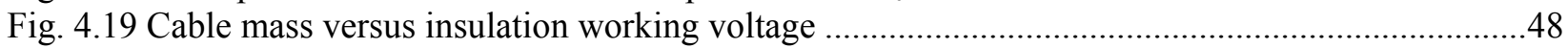

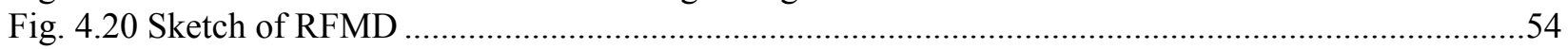

Fig. 4.21 Exploded view of Rankine cycle condenser (dimensions in inches). ....................................57

Fig. 4.22 Rankine cycle condenser and heat pipe module ...................................................................5

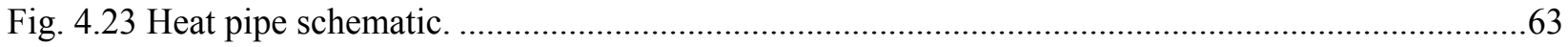

Fig. 4.24 The classical LHP with the direct condensation condenser .....................................................64

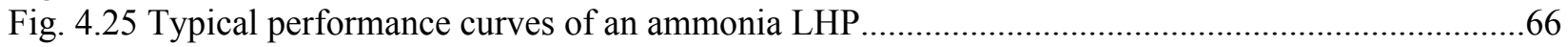

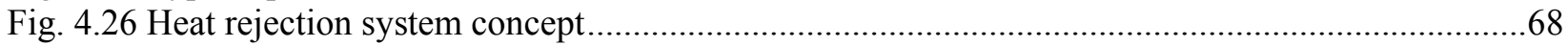

Fig. 4.27 HRS based on conventional heat pipes. System 1 schematic................................................. 70

Fig. 4.28 System 1 with potassium total heat rejection system mass ....................................................71

Fig. 4.29 System 1 with potassium total radiator system area................................................................71

Fig. 4.30 System 1 with mercury total heat rejection system mass........................................................ 72

Fig. 4.31 System 1 with mercury total radiator system area. …..............................................................72

Fig. 4.32 HRS based on mechanically pumped loop (System 2) .........................................................73

Fig. 4.33 HRS based on loop heat pipe with direct condensation (System 3) ...........................................74

Fig. 4.34 System 3 with mercury total heat rejection system mass....................................................... 75

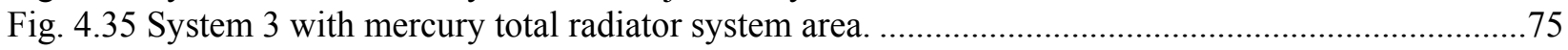

Fig. 4.36 HRS radiator based on loop heat pipe with indirect condensation (System 4) ..........................76

Fig. 4.37 HRS radiator based on multiple-evaporator, multiple condenser loop heat pipe with..................77 
Fig. 4.38 System 1 with potassium and Nb-1\%Zr. Total reject heat system mass...................................82

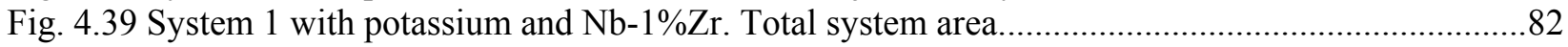

Fig. 4.40 System 1 (optimization). Number of heat pipes required (one PCU). .....................................8

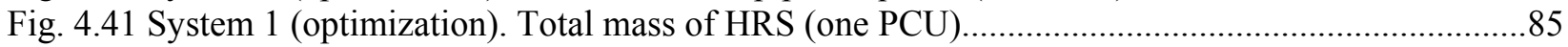

Fig. 4.42 System 1 (optimization). Total area of HRS (one PCU) ..........................................................85

Fig. 4.43 Nuclear electric power HRS suggested packaging approach ....................................................86

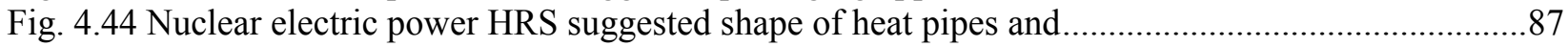

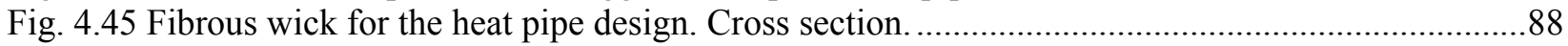

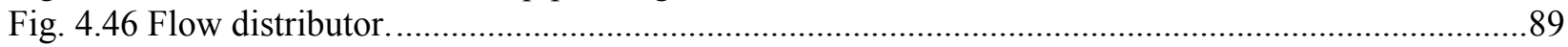

Fig. 4.47 Flow schematic of the 115-kW(e) Rankine system (from alternator to PMAD).......................91

Fig. 4.48 Rendering of the arrangement of the $115 \mathrm{~kW}(\mathrm{e})$ rankine system components ..........................93

Fig. 4.49 Rendering of a potential layout (not optimal) of a reactor within a shield connected to ..............94

Fig. 4.50 Rendering of a system layout for two 115-kWe systems (from the alternator to the ................96

Fig. 4.51 Possible layout of the 115-kWe system (from the alternator to the PMAD) using a ..................97

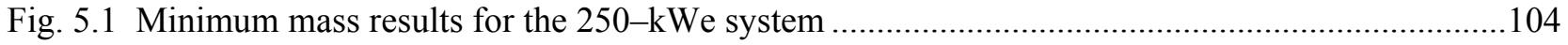

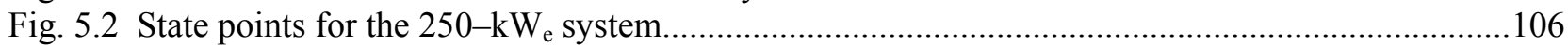

Fig. 6.1 Schematic of the potassium boiler design chosen for scaling purposes. Source: ref. 4 ...............117

Fig. 6.2 Channel helical insert used in the original potassium boiler design. Source: ref. 4.....................117

Fig. 6.3 Temperature profile from potassium boiler experiment on Oct. 12, 1964. Source: ref. 4 ............118

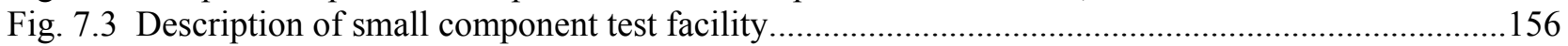

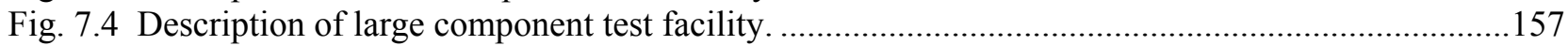

Fig. 7.5 shows the yearly spending plan for completing the outlined Technology .................................163 


\section{LIST OF TABLES}

Table

Page

Table 1.1 Boiling-potassium Rankine system and component testing ..............................................4

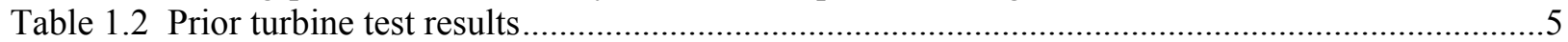

Table 3.1 Effect of feedheat and reheat on 100-kWe system efficiency and mass..................................13

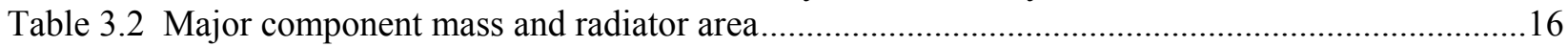

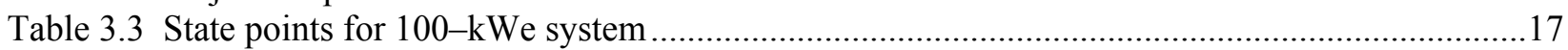

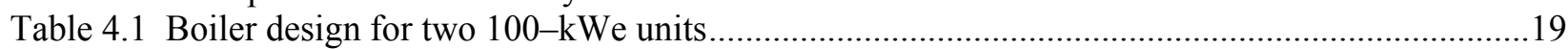

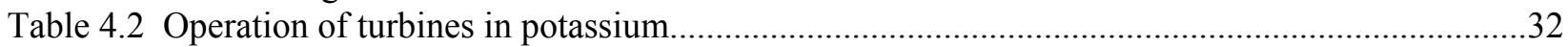

Table 4.3 Alternator configuration comparison indicates the homopolar inductor ..................................39

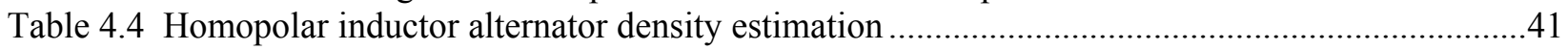

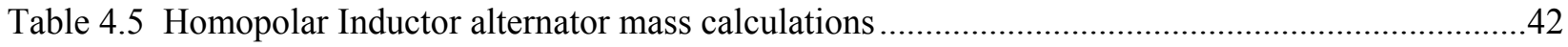

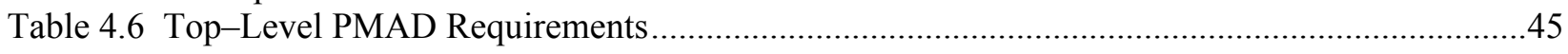

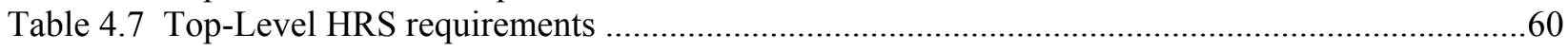

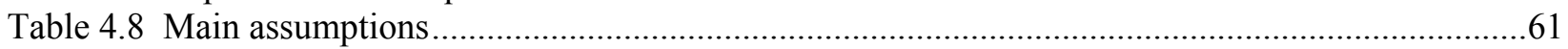

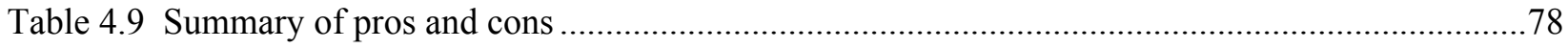

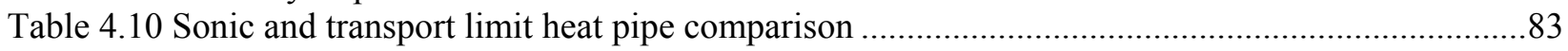

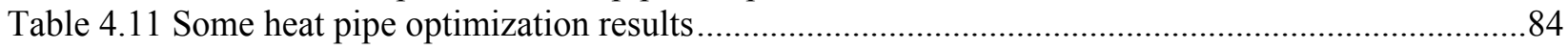

Table 5.1 Effect of feed and reheat on 250-kWe system efficiency and mass .......................................103

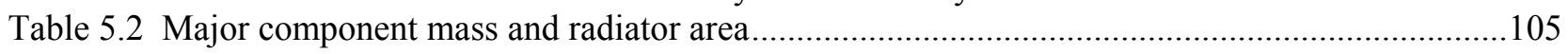

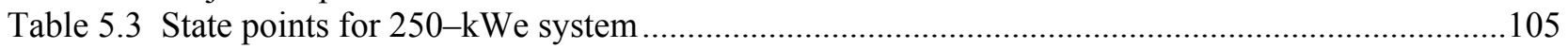

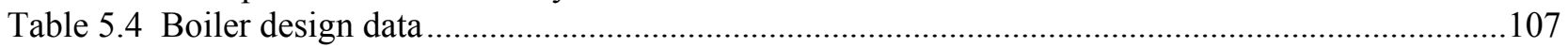

Table 7.1 Present Rankine power conversion technology readiness levels.............................................122

Table 7.2 Major tasks in the development of $\mathrm{Nb}-1 \% \mathrm{Zr}$ for space application.........................................123

Table 7.3 Candidate semiconductor material properties …..................................................................140

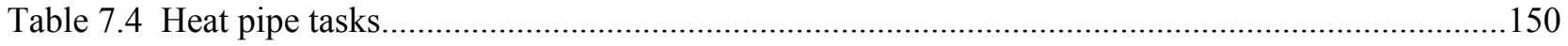




\section{ACRONYMS}

$\begin{array}{ll}\text { APS } & \text { auxiliary power system } \\ \text { ASIC } & \text { application-specific integrated circuit } \\ \text { BJT } & \text { bipolar junction transistor } \\ \text { C\&DH } & \text { command and data handling } \\ \text { CCHP } & \text { constant conductance heat pipe } \\ \text { CDR } & \text { critical design review } \\ \text { CDRL } & \text { contract data requirements list } \\ \text { CHF } & \text { critical heat flux } \\ \text { CoDR } & \text { conceptual design review } \\ \text { CrDR } & \text { critical design review } \\ \text { DWV } & \text { design working voltage } \\ \text { EM } & \text { electromagnetic } \\ \text { GN\&C } & \text { guidance navigation \& control } \\ \text { GTO } & \text { gate turn-off } \\ \text { HP } & \text { heat pipe } \\ \text { HRS } & \text { heat rejector system } \\ \text { IC } & \text { integrated circuit } \\ \text { ID } & \text { internal diameter } \\ \text { IGBT } & \text { insulated gate bipolar transistor } \\ \text { ISS } & \text { International Space Station } \\ \text { JIMO } & \text { Jupiter Icy Moons Orbiter } \\ \text { LHP } & \text { loop heat pipe } \\ \text { L-L } & \text { line to line } \\ \text { MMRTG } & \text { multi mission RTG } \\ \text { MOSFET } & \text { metal oxide semiconductor field effect transistor } \\ \text { MPRE } & \text { Medium Power Reactor Experiment } \\ \text { NASA } & \text { National Aeronautics and Space Administration } \\ \text { NCG } & \text { non-condensable gas } \\ \text { NEP } & \text { nuclear electric power } \\ \text { NPSH } & \text { net positive suction head } \\ \text { NRA } & \text { NASA Research Announcement } \\ \text { NRC } & \text { Nuclear Regulatory Commission } \\ \text { OD } & \text { outside diameter } \\ \text { ORNL } & \text { Oak Ridge National Laboratory } \\ \text { PCS } & \text { power conversion system } \\ \text { PCU } & \text { power conversion unit } \\ \text { PDR } & \text { preliminary design review } \\ \text { PHTS } & \text { primary heat transport system } \\ \text { PLR } & \text { parasitic load radiator } \\ \text { PMAD } & \text { power management and distribution } \\ \text { PM } & \text { permanent magnet } \\ \text { PPU } & \text { power processing unit } \\ \text { Q } & \text { heat flow rate } \\ \text { RPM } & \text { revolutions per minute } \\ & \end{array}$


RFMD rotary fluid management device

RTG radioisotope thermal electric generators

SCR switch control rectifier

SI

silicon

$\mathrm{SiC}$

silicon carbide

SNAP

space nuclear auxiliary power

SPUR

space power unit reactor

SRPS

Space Reactor Power System

TEM

thermoelectric module

TRL technology readiness level

VCHP

variable conductance heat pipe 


\begin{abstract}
This report documents the work performed during the first phase of the National Aeronautics and Space Administration (NASA), National Research Announcement (NRA) Technology Development Program for an Advanced Potassium Rankine Power Conversion System Compatible with Several Space Reactor Designs. The document includes an optimization of both $100-\mathrm{kW}_{\mathrm{e}}$ and $250-\mathrm{kW}_{\mathrm{e}}$ (at the propulsion unit) Rankine cycle power conversion systems. In order to perform the mass optimization of these systems, several parametric evaluations of different design options were investigated. These options included feed and reheat, vapor superheat levels entering the turbine, three different material types, and multiple heat rejection system designs. The overall masses of these $\mathrm{Nb}-1 \% \mathrm{Zr}$ systems are approximately $3100 \mathrm{~kg}$ and $6300 \mathrm{~kg}$ for the $100-\mathrm{kW}_{\mathrm{e}}$ and $250-\mathrm{kW}_{\mathrm{e}}$ systems, respectively, each with two totally redundant power conversion units, including the mass of the single reactor and shield.

Initial conceptual designs for each of the components were developed in order to estimate component masses. In addition, an overall system concept was presented that was designed to fit within the launch envelope of a heavy lift vehicle.

A technology development plan is presented in the report that describes the major efforts that are required to reach a technology readiness level of 6. A 10-year development plan was proposed.
\end{abstract}


PAGE INTENTIONALLY LEFT BLANK 


\section{INTRODUCTION}

One promising power conversion cycle for application in space is based on a liquid metal Rankine operating cycle. The Rankine cycle is the basis of most of the operating commercial power conversion systems on Earth, and all of the nuclear- reactor-based power conversion systems. This system relies on a phase change from liquid to vapor in the working fluid (i.e., water for terrestrial reactors and liquid metals such as potassium for space reactors) and extraction of energy from the vapor phase via a turbine/alternator for production of electricity. The saturated turbine exhaust vapor is condensed into a liquid and then pumped back through the heat generator (or exchanger) to repeat the cycle. Rankine power conversion technology is applicable over a wide range of power levels, from tens of kilowatts-electric to multimegawatt levels. Cycle efficiencies range up to $30 \%$. The use of a liquid metal working fluid allows low system pressure with high-and constant-temperature heat rejection; Rankine system waste heat radiators are therefore modest in size and mass compared to lower rejection temperature systems. Thus, the use of Rankine cycle technology using liquid metals can lead to extremely attractive system-specific masses that improve as the system power output increases.

Earth-based nuclear power Rankine system configurations vary, with the most common being a two-loop (or indirect) system where the heat source is in the primary loop and the boiling-power extraction-condensing portion of the cycle is in the secondary loop. Figure 1.1 shows the schematic of the two-loop system. Almost as common (in terrestrial nuclear power plants and fossil-fired steam plants) is a direct-cycle (singleloop system) where the vapor phase is generated directly at the primary heat source. Space-based Rankine cycle systems could be configured similarly but would use alkali liquid metals as the working fluid. Generally, potassium is considered optimal for the power conversion system working fluid (both in the direct and the indirect designs), with liquid lithium used in the primary loop of an indirect cycle. The most attractive features of space-based Rankine systems include these:

-High thermodynamic efficiency (up to $30 \%$ )

-Small radiators

-Compact components

-Demonstrated capability with refractory metals

-High amenability to nonnuclear testing/qualification

-Large experimental and industrial database on materials and components

-Extremely favorable scaling performance to multimegawatt levels 


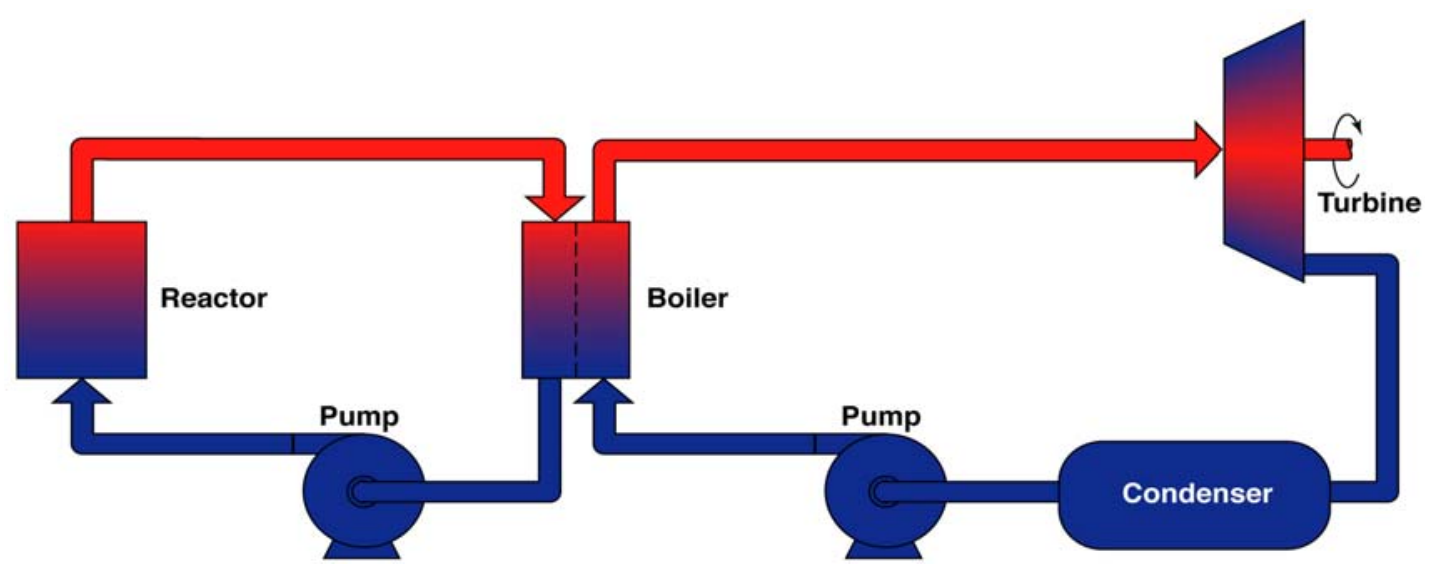

Fig. 1.1 Indirect Rankine cycle schematic.

The two-loop (or indirect) system uses a pumped, single-phase, lithium primary loop to extract heat from a fast-spectrum nuclear reactor core (Fig. 1.1). The heated lithium is then circulated through the primary side of a heat exchanger where potassium is boiled in the secondary side to near $100 \%$ vapor quality and then used as the working fluid in the Rankine power conversion cycle.

In this design, the reactor core is cooled by single-phase convection using liquid lithium, and significant margin is available between normal operating conditions and the critical heat flux (CHF) or dryout point that is typically used to establish reactor operating limits.

Typical operating conditions for a $100-\mathrm{kW}_{\mathrm{e}}$ indirect system are as follows:

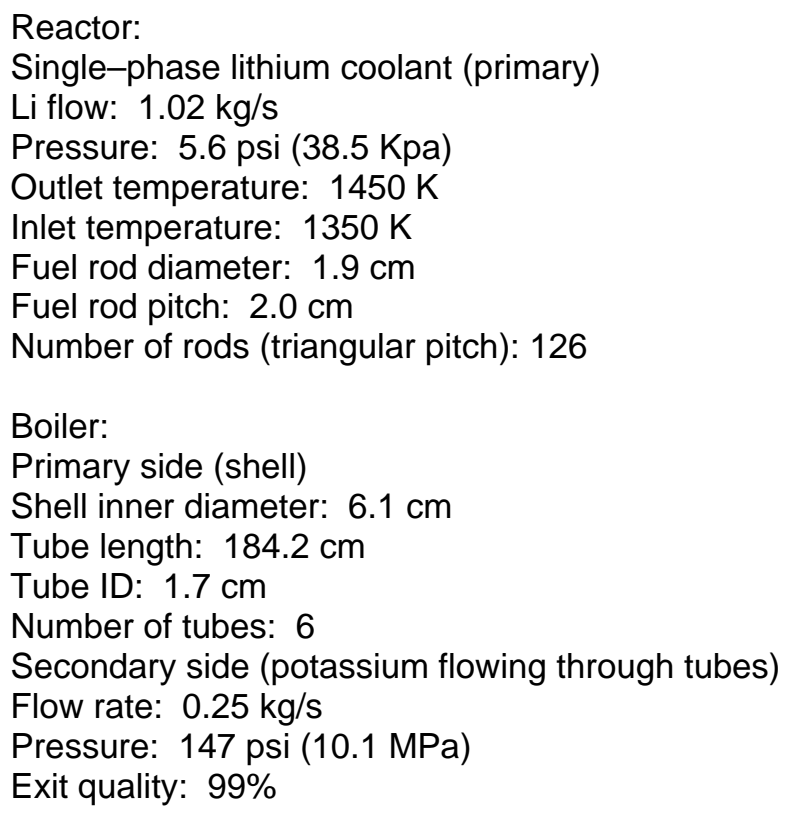

The second system boils potassium directly in the reactor core (Fig. 1.2). This design is mechanically simpler, has fewer components, and has less mass than the 
indirect system. Because of boiling and the potential for flow instabilities in the reactor core, an upper vapor quality limit of about $25 \%$ to $30 \%$ is imposed on the reactor core design. The vapor-liquid mixture exiting the reactor must be separated into liquid and vapor streams, with the vapor entering the turbine and the liquid recycled to the core inlet. In both the direct and indirect concepts, the two-phase mixture that leaves the turbine is condensed to liquid by a radiator; and a feed pump returns the condensed liquid to the reactor core.

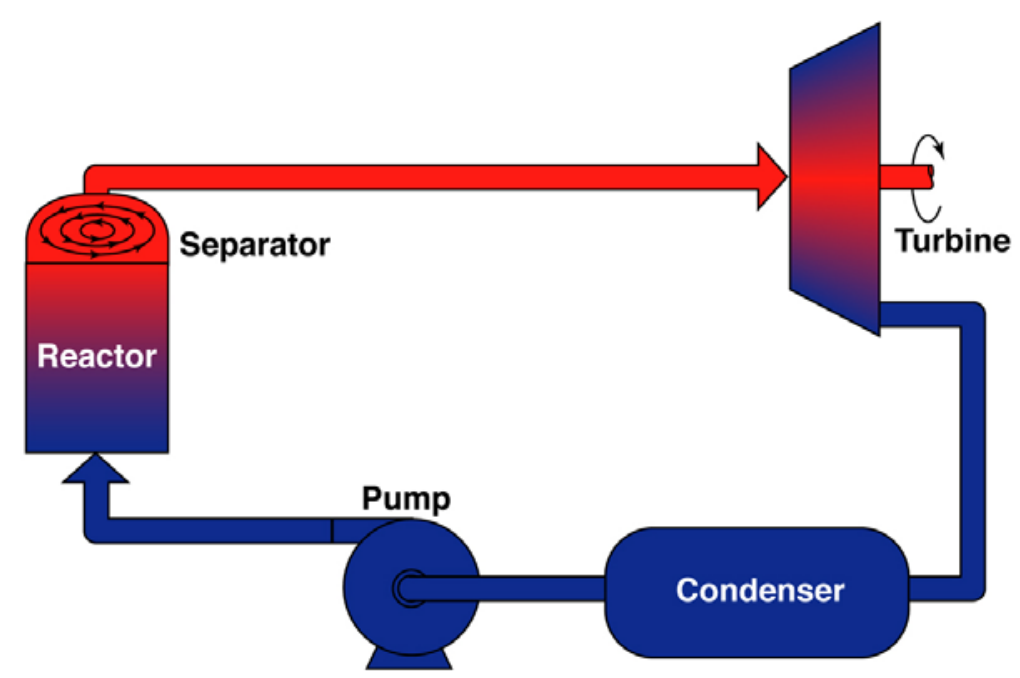

Fig. 1.2. Direct boiling Rankine cycle

\subsection{BACKGROUND}

Extensive development of liquid-metal (primarily potassium) Rankine cycle technology was carried out from 1959 through 1972 under the SNAP-50 Space Power Unit Reactor (SPUR) program and in the Medium Power Reactor Experiment (MPRE), at Oak Ridge National Laboratory (ORNL). Pratt and Whitney Aircraft Company designed the SNAP-50/SPUR system and conducted development work on the reactor, shield, boiler, and condenser. ${ }^{1}$ General Electric Company conducted development work on the boiler, turbine, and condenser. Boilers, pumps, turbines, and condensers were designed, fabricated, and tested to support development of SNAP systems designed to produce $100-300 \mathrm{~kW}_{\mathrm{e}}$. A substantial technology base relating to materials and small components was developed during that time.

The MPRE system was designed by ORNL. ${ }^{2}$ This system consisted of a boilingpotassium fast reactor connected directly to a turbine generator. It included a turbinedriven liquid feed pump and a direct condenser-radiator. Development work was conducted on electrically heated boilers designed to simulate a scale model of the reactor, with associated turbine-pumps and condensers. A potassium vapor temperature of approximately $1100 \mathrm{~K}$ was chosen so that stainless steel could be used as the major construction material. A condensing temperature of $833 \mathrm{~K}$ was selected, which yielded the minimum weight of the system for a turbine inlet temperature of $1110 \mathrm{~K}$. 
Potassium Rankine cycle technology development was terminated before a complete power system was tested. As a result, the technical status of the various component technologies is somewhat inconsistent (Tables 1.1 and 1.2). Corrosion test loops using niobium and tantalum alloys (with potassium working fluid) were operated for tens of thousands of hours at temperatures of 1300-1500 K, and potassium boiling tests were run in small boilers at temperatures of up to $1400 \mathrm{~K}$. However, the longest turbine test was 5000 hours at a temperature of approximately $1100 \mathrm{~K}$ (in a stainless steel loop). The development work demonstrated that cycle components (i.e., boilers, turbines, condensers, and pumps) fabricated from stainless steel would operate successfully, with negligible corrosion or turbine blade erosion, at temperatures of $1100 \mathrm{~K}$ for up to several thousand hours. ${ }^{2}$ The most noteworthy results were achieved in two successful 5000-h tests of $150-\mathrm{kW}$ potassium turbines operated at $1100 \mathrm{~K}$ by General Electric. ${ }^{3}$ Boiling and materials tests in refractory metal alloy tubes $(\mathrm{Nb}-1 \mathrm{Zr}$ and $\mathrm{T}-111)$ demonstrated successful operation with potassium temperatures of up to $1450 \mathrm{~K}$. ${ }^{4,6}$ These results indicate a high probability that turbines fabricated from tantalum alloys would also operate successfully at temperatures of up to $1450-1500 \mathrm{~K}$.

Technology issues common to Rankine and Brayton power conversion systems include the fabrication and use of high-temperature components and operational issues associated with the use of dynamic components such as turbines, compressors, and pumps. Other common areas include the power management and distribution (PMAD) subsystems. A unique technology issue associated with a space-based Rankine system is the control and management of two-phase liquids. While many aspects of two-phase management have been demonstrated for short periods of time in zero-gravity with water and organic working fluids, the lack of a demonstration of liquid-metal two-phase systems in space remains a fundamental obstacle to their use.

Table 1.1. Boiling-potassium Rankine system and component testing

\begin{tabular}{cccc} 
Test type/component & $\begin{array}{c}\text { Total accumulated } \\
\text { test duration (h) }\end{array}$ & Test type/component & $\begin{array}{c}\text { Total accumulated } \\
\text { test duration (h) }\end{array}$ \\
\hline Corrosion test loops & & Component tests & \\
Thermal convection & 66,100 & Boilers & 137,300 \\
Forced convection & 51,000 & Boiler feed pumps & 73,500 \\
Boiling test loops & 20,200 & Radiators & 58,500 \\
& & Condensers & 137,300 \\
& & Turbines & 13,300 \\
& & Seals & 8,200 \\
& & Bearings & 94,000 \\
\hline
\end{tabular}


Table 1.2. Prior turbine test results

\begin{tabular}{llccccccc}
\hline Organization & $\begin{array}{c}\text { Number of } \\
\text { stages and } \\
\text { turbine } \\
\text { type }\end{array}$ & $\begin{array}{c}\text { Blade } \\
\text { tip } \\
\text { speed } \\
\text { (ft/s) }\end{array}$ & $\begin{array}{c}\text { Blade } \\
\text { material }\end{array}$ & $\begin{array}{c}\text { Operating } \\
\text { hours }\end{array}$ & $\begin{array}{c}\text { Nozzle } \\
\text { inlet temp. } \\
\left({ }^{\circ} \mathbf{F}\right)\end{array}$ & $\begin{array}{c}\text { Exhaust } \\
\text { temp. }\left({ }^{\circ} \mathbf{F}\right)\end{array}$ & $\begin{array}{c}\text { Outlet } \\
\text { vapor } \\
\text { quality }\end{array}$ & Erosion \\
\hline Aeroneutronics & 1- Impulse & 350 & TZM & 100 & 1250 & 960 & 96 & all blades \\
AirResearch & 1- Impulse & 760 & Inconel-X & 3000 & 1350 & 1076 & 96 & None \\
AirResearch & 1- Reaction & 670 & Waspalloy & 50 & & & & \\
General Electric & 2- Reaction & 750 & Udimet & 5100 & 1500 & 1240 & 92 & Negligible \\
& & & 700, & & & & & \\
& & & TZM, & & & & & \\
ORNL & & & TZC & 360 & 1400 & 1040 & 96 & None \\
ORNL & 1- Impulse & 220 & TZM & 2600 & 1250 & 1040 & 96 & None \\
ORNL & 1- Impulse & 220 & TZM & 1020 & 1250 & 1040 & 96 & \\
ORNL & 1- Impulse & 220 & TZM & 1040 & & & \\
Rocketdyne & 1- Impulse & 220 & TZM & 3970 & 1250 & 1040 & 96 & \\
\hline
\end{tabular}

This report discusses the design of a $100-\mathrm{kW}_{\mathrm{e}}$ potassium Rankine cycle power conversion system. This discussion includes the analysis tools used in this exercise, the assumptions used to design each component, and the results of those analyses. In addition, a description is provided of a scaling exercise that can be used to help develop an experiment to study two-phase issues important to the Rankine cycle operating under micro-gravity conditions. A section of the report is also devoted to describing the analysis of a $250-\mathrm{kW}_{\mathrm{e}}$ potassium Rankine cycle studied as a growth exercise. The final portion of the report describes a technology development plan required to get the potassium Rankine cycle to a technology readiness level (TRL) of 6. 
PAGE INTENTIONALLY LEFT BLANK 


\section{DEVELOPMENT OF THE ALKASYS-SRPS CODE}

The ALKASYS code was originally developed at ORNL in 1987 by Moyers and Nichols ${ }^{7}$. ALKASYS is a computer code developed specifically to analyze Rankine cycles employing alkali metals. The code was originally written in BASIC and later converted to FORTRAN.

The code estimates masses for the complete space nuclear power system, including the reactor, shield, turbine, generator, piping, pumps, and radiator. Rankine cycles with potassium in either a direct (single-loop) or indirect (two-loop) configuration can be analyzed by this code. The single-loop configuration produces potassium vapor in a boiling reactor. The two-loop configuration is the configuration to be studied in this National Aeronautics and Space Administration (NASA) project. The output from the code includes weights of each component and temperatures and pressures at different points in the cycle.

The ALKASYS code was developed for multi-megawatt power systems (powers over $\left.1 \mathrm{MW}_{\mathrm{e}}\right)$. Consequently, when applied to small systems $(100 \mathrm{kWe})$, the code did not run, or yielded erroneous results. In particular, the mass of uranium in the core was calculated based on burnup considerations, and for low-power systems, the calculated masses did not result in a critical reactor. Therefore, the program was modified to analyze low-power Rankine systems.

New versions of the code were developed at ORNL in 2003 and 2004, written in FORTRAN 77 and fully modular, with separate modules to calculate the power conversion system (PCS), the radiator, the reactor, and the shield (Fig. 2.1). The PCS module calculates the thermodynamic cycle points and masses for the turbine, generator, feedheaters and reheaters, condenser, and piping. The radiator module calculates the masses of the radiators (high and low temperature). The reactor module calculates the masses of the reactor and the boiler for the indirect cycle. Finally, the shield module calculates the masses and dimensions of the shield, based on user inputs of dose requirements and distance to the payload. 


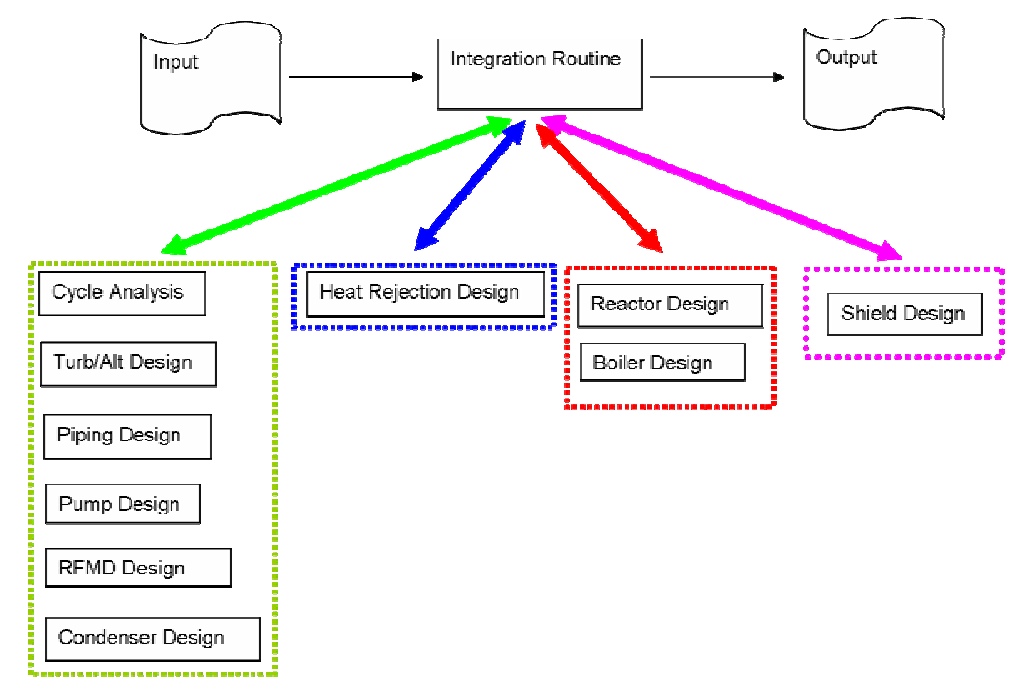

Fig. 2.1 Diagram showing modular components of ALKASYS-SRPS

Version 1 of the new code, named ALKASYS-SRPS (Space Reactor Power System), employed the same models as the original ALKASYS (BASIC) program for the radiator, the shield, and the PCS. The reactor model was modified extensively to calculate low-power $\left(\sim 100-\mathrm{kW}_{\mathrm{e}}\right)$ systems. The uranium mass is now calculated iteratively, first based on burnup considerations; if the system is not critical, the mass is increased until a critical system with $95 \%$ maximum enrichment is achieved. The rod diameter is calculated based on a maximum allowed heat flux and a peaking factor that are input by the user. Rod diameters are constrained between a maximum of $1.9 \mathrm{~cm}$ and a minimum of $0.635 \mathrm{~cm}$. The calculation of assemblies and fuel rods per assembly for a particular core has also been modified. The original ALKASYS code used a minimum of 18 assemblies with 61 rods per assembly, for a total of 1098 fuel rods. This number of rods is excessive for small reactors; thus solutions could not be found. A minimum of 6 assemblies with 7 fuel rods per assembly, for a total of 42 fuel rods, is now possible in the new version. A central reactivity control assembly can also be eliminated in this new version, since it is not necessary for small cores (radial control drums provide sufficient negative reactivity for small reactor systems, and smaller cores result).

The modular architecture of ALKASYS-SRPS allows for easy replacement or modification of the modules as new models became available. Advanced radiator models have been implemented in addition to the original model, and improved generator/turbine models have been implemented into version 2 of the ALKASYS-SRPS code. A complete description of modifications made to the code versions 1 and 2 is presented in Appendix A and can be used as an addendum to the original ALKASYS manual. ${ }^{7}$ 


\subsection{SENSITIVITY STUDIES}

ALKASYS-SRPS has been used extensively to perform sensitivity studies and to calculate the optimum condenser temperature for minimum total system mass. The results are dependent on the models used and the constraints input by the user (e.g., superheat, reheat, feed heaters, radiator, material of primary or secondary loops, alternator and turbine model, total system power, number of PCS units considered). 
PAGE INTENTIONALLY LEFT BLANK 


\section{100-KW ${ }_{\mathrm{e}}$ SYSTEM DESIGN}

\subsection{GROUND RULES AND ASSUMPTIONS}

A requirements definition document ${ }^{8}$ was developed early in the project to guide the Phase I work. Some of the major requirements and assumptions are restated here in order to place the work in the appropriate perspective. Several power system requirements were dictated by reference mission needs and were the major goals in the optimization process.

- $100 \mathrm{~kW}_{\mathrm{e}}\left(250 \mathrm{~kW}_{\mathrm{e}}\right.$ as a growth study) to the thrusters of the electric propulsion system

- $\quad<3000 \mathrm{~kg}$ (entire system - including reactor, radiator and shield)

- Lifetime-15 years: 10 years at $100 \%$ power, 5 years at $20 \%$ power

- Thrust for 2 to 4 years - coast for 2 to 4 years - thrust for 2 to 4 years - science missions

o Thrust $-100 \mathrm{~kW}_{\mathrm{e}}$

o Coast -1 to $5 \mathrm{~kW}_{\mathrm{e}}$

o Mission -1 to $20 \mathrm{~kW}_{\mathrm{e}}$

- Must be responsive to system transients (sudden drop in power requirements)

- Must be capable of restarting after a planned/unplanned shutdown at great distances from the sun ( $>10 \mathrm{AU})$

- Must be capable of operating under Zero-gravity conditions

- Must be able to withstand launch loads and vehicle imposed accelerations

- Must not impose unacceptable noise and vibration signatures on the scientific payload

- Must be able to withstand natural radiation fields encountered during the mission

Some assumptions were made and were not considered as part of the optimization process:

- Power was assumed to be supplied by a fast-spectrum nuclear reactor cooled by single-phase lithium.

- Two independent power conversion systems were assumed in order to provide redundancy and single fault tolerance.

- Three structural materials were considered: stainless steel, $\mathrm{Nb}-1 \% \mathrm{Zr}$ and T-111.

- The system would be launched in a heavy lift vehicle.

These assumptions were used during the optimization and design process. They dictate major features of the design and influence the technology development plan that is necessary to achieve a TRL of 6 for the Rankine cycle.

\subsection{PARAMETRIC DESIGN STUDIES AND 100-KW e $_{\mathrm{e}}$ DESIGN SUMMARY}

The $100-\mathrm{kW}_{\mathrm{e}}$ system design uses a single fast-spectrum reactor fueled with highly enriched uranium in the form of uranium nitride. A total of 703 fuel pins, 0.635 $\mathrm{cm}$ in diameter and $30.22 \mathrm{~cm}$ long, are arranged on a $0.673 \mathrm{~cm}$ triangular pitch. A mass 
of $60 \mathrm{~kg}$ of uranium is used in the present design with a fuel burn-up limit of $6.3 \%$. Ten control drums located outside the reactor pressure vessel are used for reactivity control. A 13- year full-power lifetime was used in the design. The reactor shadow shield is constructed of layered tungsten and lithium hydride to control gamma and neutron fluence at the payload. The tungsten layer is $5.87 \mathrm{~cm}$ thick, and the lithium hydride is $45.0 \mathrm{~cm}$ thick, limiting gamma dose levels at the payload to $10^{6}$ rads and neutron dose to $10^{13} \mathrm{n} / \mathrm{cm}^{2}$ at a distance of $15 \mathrm{~m}$ from the reactor. The shield tapers in diameter from 50 $\mathrm{cm}$ at the core to $97 \mathrm{~cm}$ facing the payload. The reactor is cooled by single-phase lithium circulated by two redundant electromagnetic pumps.

The arc-shaped boiler, located behind the shield, feeds potassium vapor to both redundant power conversion system loops. A $30-\mathrm{m}^{2}$ radiator surface area is used to reject waste heat from each power conversion unit. Each unit has its own set of heat pipes with condensers and an independent radiator. This configuration allows the $100-\mathrm{kWe}$ system to be launched within a single heavy lift cargo volume.

The basic design of the two-loop Rankine cycle used as the basis of this study was presented in Fig. 1.1; however, additional cycle components are typically added to the basic diagram that improves cycle performance. Two such devices are feedheaters and reheaters.

A Rankine cycle that incorporates both feedheat and reheat is presented in Fig. 3.1. In the diagram, both high-pressure and low-pressure turbines are incorporated in the design, connected to the same shaft. After expansion through the high-pressure turbine, the vapor/liquid mixture is returned to a reheater located in the lithium line that exits the boiler. The reheater design is similar to that of the boiler, with single phase lithium flowing on the shell side, and two-phase potassium flowing on the tube side. The potassium is reheated to a temperature somewhat below the boiler lithium exit temperature to a quality of near $100 \%$. The reheated potassium is input to the lowpressure turbine where it is further expanded to the condenser inlet pressure.

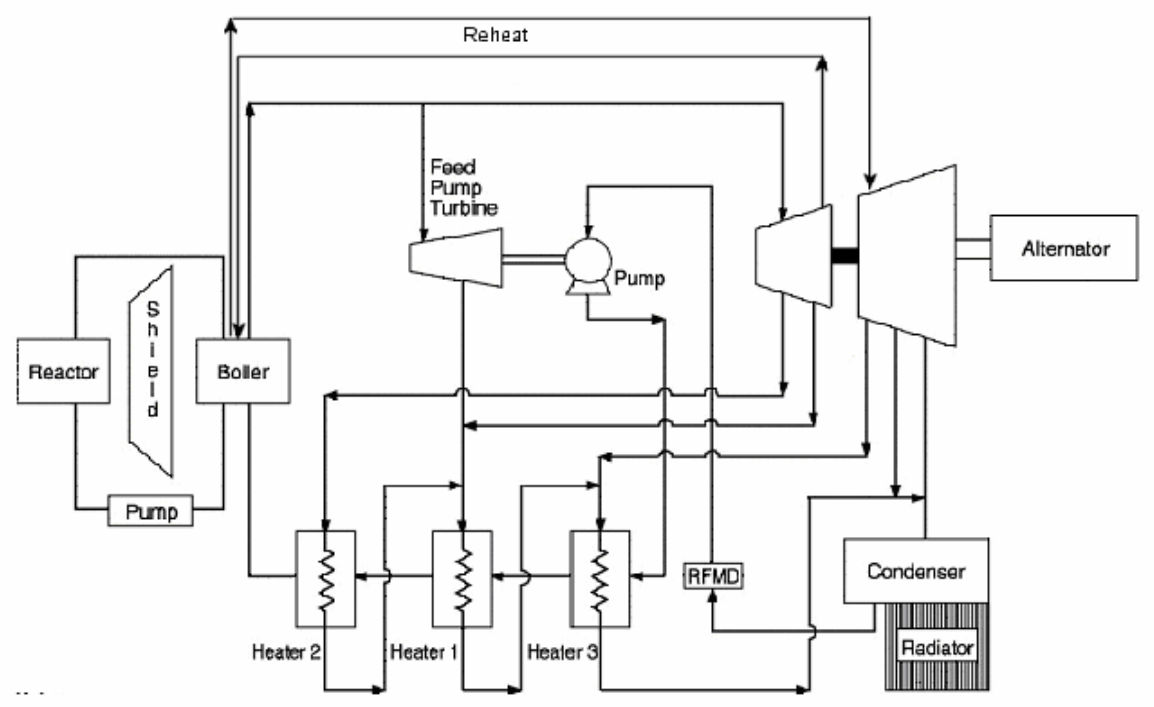

Fig. 3.1. Rankine cycle schematic with feed heat an reheat. 
Feedheaters can be located in the boiler feed stream and used to extract heat from the turbo-pump exhaust and the liquid extraction streams from the power turbine, and to preheat potassium before it enters the boiler inlet. Both feedheat and reheat increase cycle efficiencies.

A study was conducted using ALKASYS-SRPS Version 2 to evaluate the performance of the $100-\mathrm{kW}_{\mathrm{e}}$ system using feedheaters and reheaters in the cycle. The analysis examined the impact of using 3 feedheaters and one reheater, both separately and in combination, on the system efficiency and overall system mass. The results of these calculations are listed in Table 3.1.

Table 3.1 Effect of feedheat and reheat on 100-kWe system efficiency and mass

\begin{tabular}{ccccc}
\hline $\begin{array}{c}\text { No. of feed } \\
\text { heaters }\end{array}$ & $\begin{array}{c}\text { Reheat Temperature } \\
(\mathrm{K})\end{array}$ & $\begin{array}{c}\text { Cycle efficiency } \\
(\%)\end{array}$ & $\begin{array}{c}\text { Relative mass } \\
0\end{array}$ & $\begin{array}{c}\Delta \text { mass } \\
(\mathrm{kg})\end{array}$ \\
\hline 0 & 0 & 23.6 & 1.0 & 0 \\
3 & 0 & 28.8 & 0.97 & -88 \\
0 & 160 & 31.5 & 0.92 & -256 \\
3 & 160 & & 0.86 & -436 \\
\hline
\end{tabular}

The base case with no feedheaters and reheaters shown in Table 3.1 is for a reactor outlet temperature of $1350 \mathrm{~K}$. Masses and efficiencies shown are for the minimum mass point of the design. For the base case, a cycle efficiency of $23.6 \%$ and a system mass of $3071 \mathrm{~kg}$ are calculated. For the case that uses three feedheaters and no reheat, efficiency is improved to $24.8 \%$ and system mass decreases by approximately $88 \mathrm{~kg}$. The reheat temperature given in the table is the temperature increase of the vapor stream going through the reheater. In the cases with reheat, it was assumed that the turbine mass increases by $80 \%$ above that of a turbine without reheat. This increase is due to the added complexity that is required to extract the vapor stream from the high-pressure turbine stages and then reintroduce it in the low-pressure turbine stages. Additionally, the reheater mass was assumed to be $50 \%$ of the boiler mass in these calculations. Feed heater masses were calculated explicitly. Offsetting these mass increases are decreases in the masses of both the radiator and reactor/shield system because of increased cycle efficiency. The reheat reduces more mass (about three times) than the feedheaters. More mass is reduced when both feedheaters and reheat are employed together; a total of 436 $\mathrm{kg}$ is saved in this case. However, it was decided to eliminate feedheaters and reheaters from the baseline design in order to simplify the system, since components are still small at this power level. The optimized system schematic is shown in Fig. 3.2. 


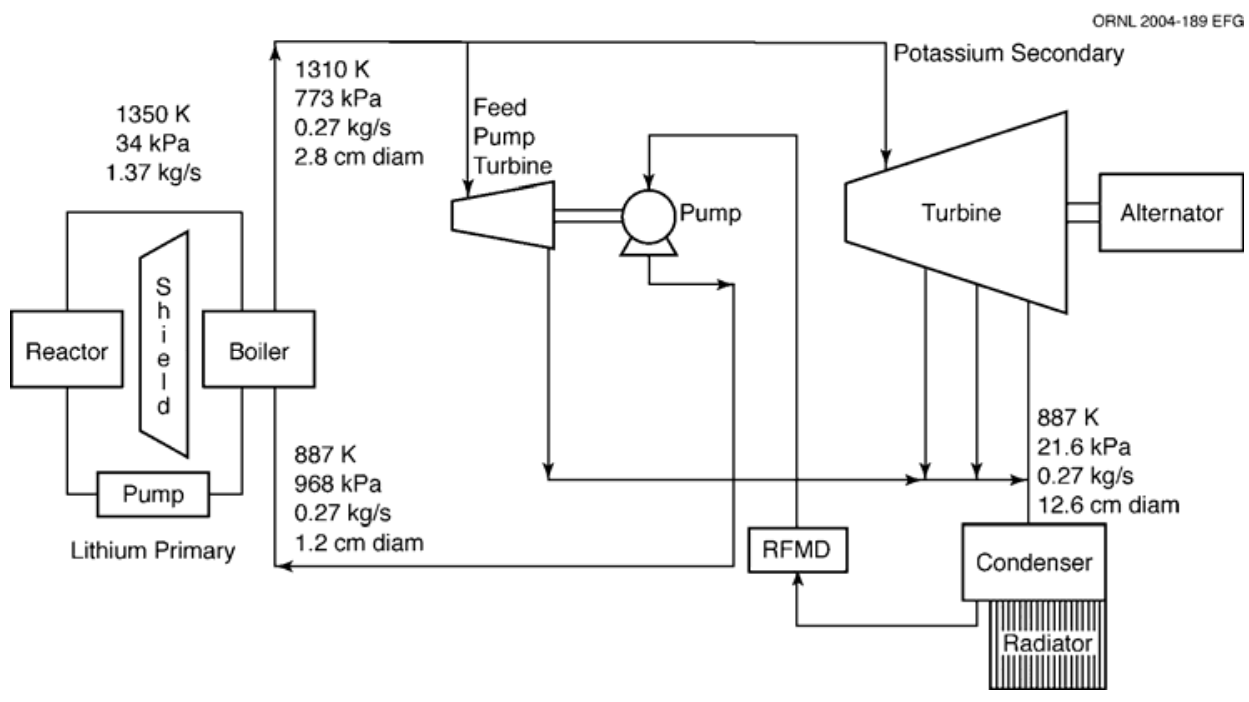

Fig. 3.2. Baseline Rankine cycle schematic chosen for the 100-kWe system

Stainless steel, $\mathrm{Nb}-1 \% \mathrm{Zr}$, and $\mathrm{T}-111$ were all examined to determine the impact of structural material choice on system mass. The material choice essentially establishes the upper limit of system operation because of material strength limitations. These temperatures, therefore, establish the maximum reactor lithium outlet temperature. Based on strength limitations, it was assumed that the maximum material temperatures were $1000 \mathrm{~K}$ for stainless steel, $1350 \mathrm{~K}$ for $\mathrm{Nb}-1 \% \mathrm{Zr}$, and $1500 \mathrm{~K}$ for $\mathrm{T}-111$. For the stainless steel system, the primary system uses $\mathrm{Nb}-1 \% \mathrm{Zr}$ with a maximum temperature of around $1100 \mathrm{~K}$. The secondary system is stainless steel, with a maximum temperature of $1000 \mathrm{~K}$. Increased materials development cost would be associated with increasing system temperature. An optimization using radiator temperature as the independent variable was performed, assuming that all components that require welding to maintain the primary pressure boundary in the Rankine cycle were made of the same material. The results of these calculations are shown in Fig. 3.3. These calculations were performed with ALKASYS-SRPS Version 1 and do not reflect the upgrades of Version 2. In addition, the final, optimized design used a higher turbine inlet temperature resulting from additional boiler analysis. However, the trends shown by these results are correct and can be used to reach these conclusions. 


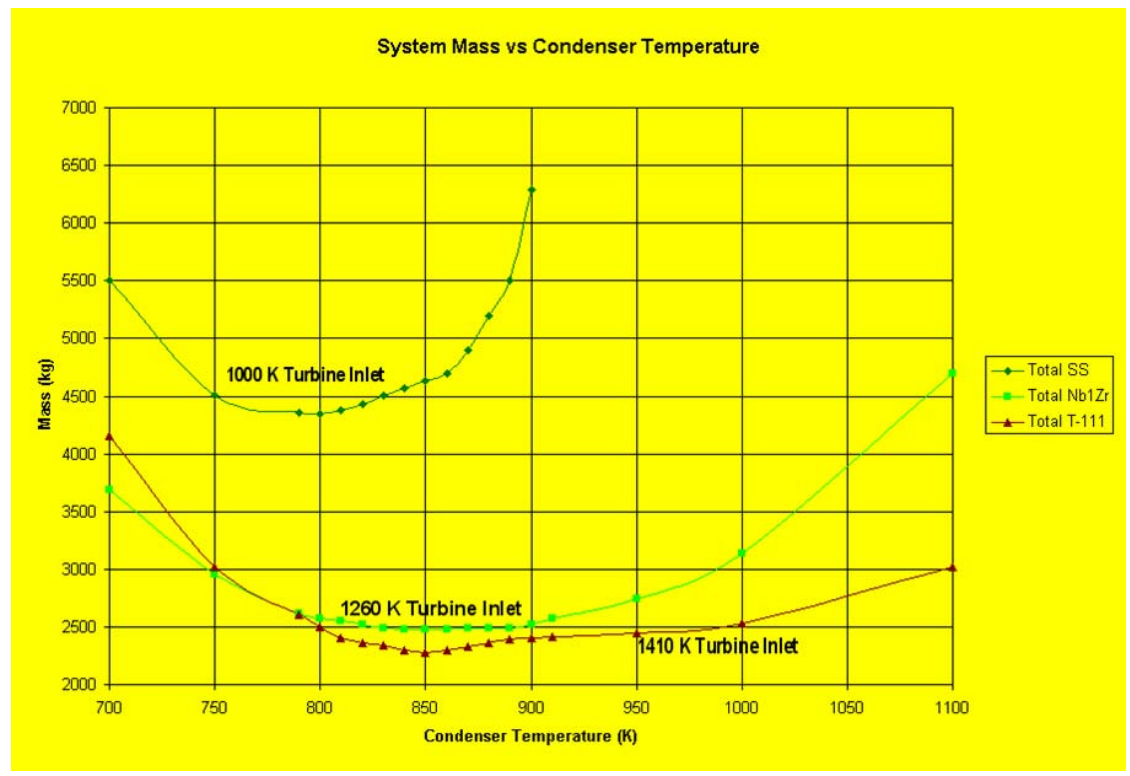

Fig. 3.3. System mass predicted for three different structural materials: stainless steel, NB-1\%Zr, and T-111

These calculations indicate that a stainless steel system could not meet the $3000-\mathrm{kg}$ system mass target. The T-111 system has the lowest mass; however, it was decided that the development issues associated with the use of T-111 would outweigh the benefits of using this material. $\mathrm{Nb}-1 \% \mathrm{Zr}$ was therefore chosen for further design optimization.

Parametric calculations were performed for a $\mathrm{Nb}-1 \% \mathrm{Zr}$ system as the baseline material using PCS radiator temperature as the independent variable to determine minimum system mass. The results are shown in Fig. 3.4. As radiator temperatures increase, cycle efficiencies decrease for the same reactor outlet temperature. However, as radiator temperatures increase, the heat rejection capability per unit area of radiator also increases. These two competing effects cause a minimum in the mass vs. rejection temperature curve. For the $100-\mathrm{kW}_{\mathrm{e}} \mathrm{Nb}-1 \% \mathrm{Zr}$ system being studied, a minimum system mass was found at a radiator temperature of $887 \mathrm{~K}$. 


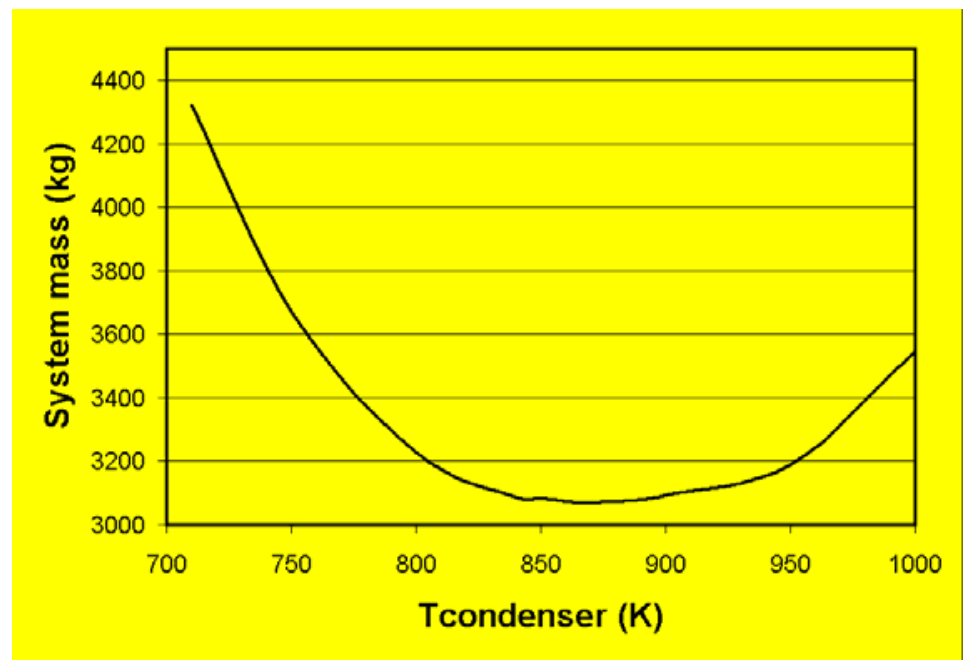

Fig. 3.4. Minimum mass for $100 \mathrm{~kW}_{\mathrm{e}}$ system

An overall system mass of $3071 \mathrm{~kg}$ is predicted for the $100-\mathrm{kW}_{\mathrm{e}}$ system, which corresponds to a value of $30.7 \mathrm{~kg} / \mathrm{kW}_{\mathrm{e}}$. The major system mass breakdown is presented in Table 3.2. As noted in the table, the components highest in mass are the reactor and shield, the heat pipes (HPs) and radiator, and the power management and conditioning system (PMAD), comprising 34\%, 33\%, and $23 \%$ of the overall system mass respectively. A $60-\mathrm{m}^{2}$ radiator is needed to reject the waste heat from the dynamic PCSs, $30 \mathrm{~m}^{2}$ for each of the two redundant units. A detailed mass breakdown and piping dimensions are presented in Appendix B. PCS state points are shown in Fig. 3.5, and the corresponding pressure and thermodynamic values are shown in Table 3.3

Table 3.2. Major component mass and radiator area

\begin{tabular}{lcc}
\hline Component & Mass (kg) & \% of total mass \\
\hline Reactor & 221 & 7.2 \\
Shield & 831 & 27.0 \\
Boiler (2) & 20 & 0.7 \\
Turbo-alternator (2) & 116 & 3.8 \\
HP + Radiator (2) & 868 & 28.3 \\
Low temp. radiators (2) & 160 & 5.2 \\
Power conditioning & 704 & 22.9 \\
Remainder of PCS & 151 & 4.9 \\
Total & 3071 & 100
\end{tabular}




\begin{tabular}{lcc}
\hline & Area $\mathbf{1}$ unit $\left(\mathbf{m}^{2}\right)$ & 2 units $\left(\mathbf{m}^{2}\right)$ \\
\hline PCS radiator & 27 & 54 \\
Low-temp. & 3 & 6 \\
Radiators & & \\
\hline
\end{tabular}

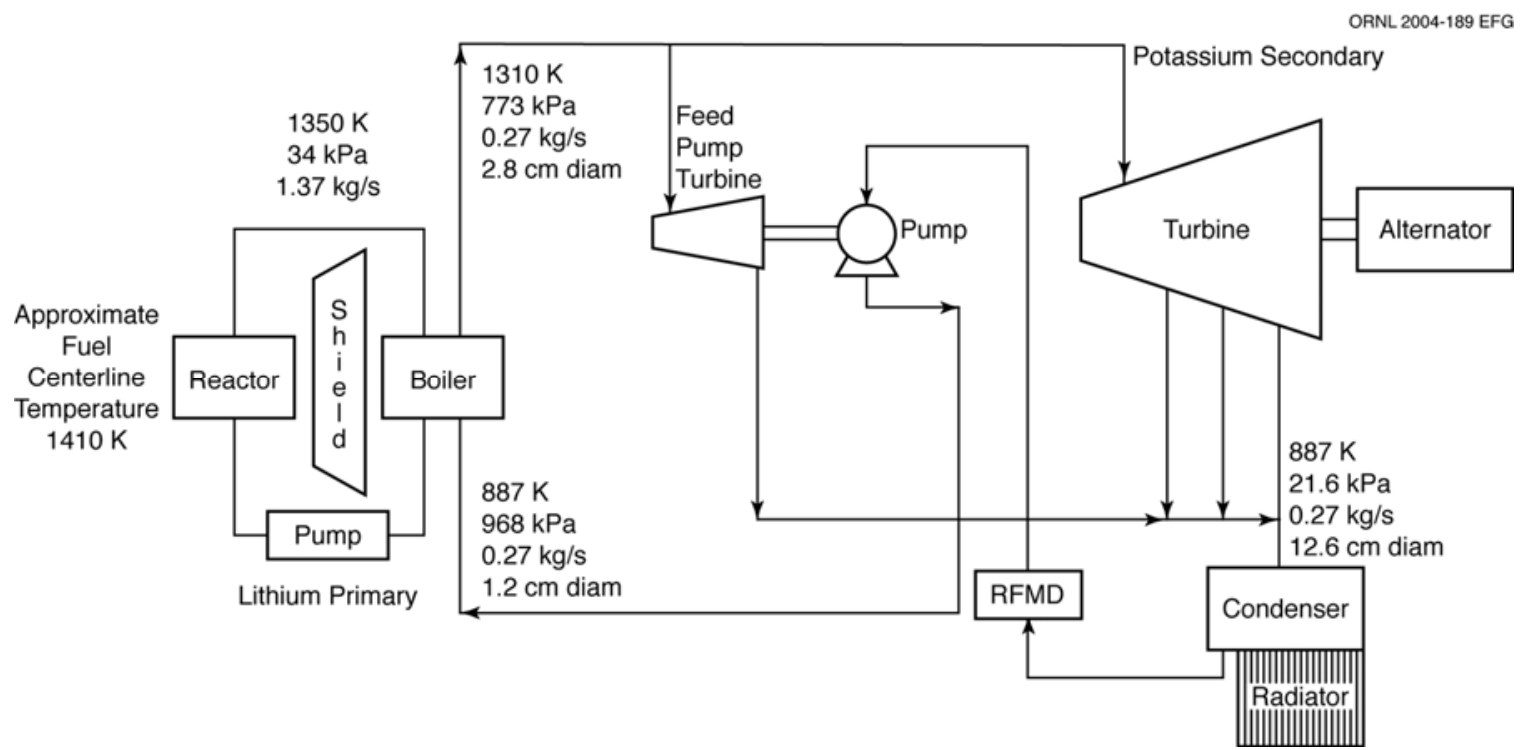

Fig. 3.5. State points for the $100-\mathrm{kW}_{\mathrm{e}}$ system

Table 3.3. State points for $100-\mathrm{kWe}$ system

Typical Potassium Rankine Cycle Operating State Points

\begin{tabular}{cllrcrcc}
\hline Number & Description & Temp (R) & Temp $(\mathrm{K})$ & $\begin{array}{l}\text { Pressure } \\
(\mathrm{psi})\end{array}$ & $\begin{array}{c}\text { Pressure } \\
(\mathrm{MPa})\end{array}$ & $\begin{array}{c}\text { Mass flow } \\
\text { rate }(\mathrm{lbm} / \mathrm{s})\end{array}$ & $\begin{array}{c}\text { Mass flow } \\
\text { rate }(\mathrm{Kg} / \mathrm{s})\end{array}$ \\
\hline & & & & & & & \\
1 & Boiler outlet & 2358 & 1310 & 112.1 & $7.729 \mathrm{E}-01$ & 0.6 & $2.724 \mathrm{E}-01$ \\
2 & Turbine inlet & 2358 & 1310 & 112.1 & $7.729 \mathrm{E}-01$ & 0.58 & $2.633 \mathrm{E}-01$ \\
3 & Turbine outlet & 1596 & 886.67 & 3.13 & $2.158 \mathrm{E}-02$ & 0.5 & $2.270 \mathrm{E}-01$ \\
4 & Condenser inlet & 1596 & 886.67 & 3.13 & $2.158 \mathrm{E}-02$ & 0.6 & $2.724 \mathrm{E}-01$ \\
5 & Condenser outlet & 1587 & 881.67 & 3.13 & $2.158 \mathrm{E}-02$ & 0.6 & $2.724 \mathrm{E}-01$ \\
5 & RFMD inlet & 1587 & 881.67 & 3.13 & $2.158 \mathrm{E}-02$ & 0.6 & $2.724 \mathrm{E}-01$ \\
6 & RFMD outlet & 1587 & 881.67 & 18.3 & $1.262 \mathrm{E}-01$ & 0.6 & $2.724 \mathrm{E}-01$ \\
6 & Boiler pump inlet & 1587 & 881.67 & 18.3 & $1.262 \mathrm{E}-01$ & 0.6 & $2.724 \mathrm{E}-01$ \\
7 & Boiler pump exit & 1587 & 881.67 & 140.34 & $9.676 \mathrm{E}-01$ & 0.6 & $2.724 \mathrm{E}-01$ \\
8 & Stage 5 extraction & & & & & 0.06 & $2.724 \mathrm{E}-02$ \\
9 & Stage 9 extraction & & & & & 0.02 & $9.080 \mathrm{E}-03$ \\
10 & Boiler inlet & 1593 & 885 & 140.34 & $9.676 \mathrm{E}-01$ & 0.6 & $2.724 \mathrm{E}-01$ \\
11 & Pump turbine inlet & 2358 & 1310 & 112.1 & $7.729 \mathrm{E}-01$ & 0.02 & $9.080 \mathrm{E}-03$ \\
12 & Pump Trubine outlet & 2008 & 115.56 & 30.638 & $2.112 \mathrm{E}-01$ & 0.02 & $9.080 \mathrm{E}-03$ \\
\hline
\end{tabular}

The optimized cycle operates between a high temperature of $1310 \mathrm{~K}$ and a low temperature at the condenser of $887 \mathrm{~K}$ with corresponding pressures of 773 and $21.6 \mathrm{kPa}$. A $105-\mathrm{kPa}$ pressure rise is provided by the rotary fluid management device (RFMD) in order to meet the net positive suction head (NPSH) requirement of the centrifugal boiler feed pump. The boiler pump provides an $841-\mathrm{kPa}$ pressure rise while the pressure drop through the boiler is $194 \mathrm{kPa}$. The pressure drop across the turbine is $752 \mathrm{kPa}$. Two moisture extractions from the nine-stage turbine are performed, one after stage four that uses an external separator and one after stage nine that uses an interstage separator, in 
order to maintain the moisture content within the turbine below $10 \%$. The extraction streams, along with the pump turbine exhaust stream, are routed to the inlet of the condenser. Overall system efficiency is $20.1 \%$.

A summary of the estimated masses of a $100-\mathrm{kW}_{\mathrm{e}}$ system using a layout with conical and cylindrical radiators is shown in Fig. 3.6. The mass of the start loop components have not been explicitly calculated, but $50 \mathrm{~kg}$ for this system is included in the estimated mass.

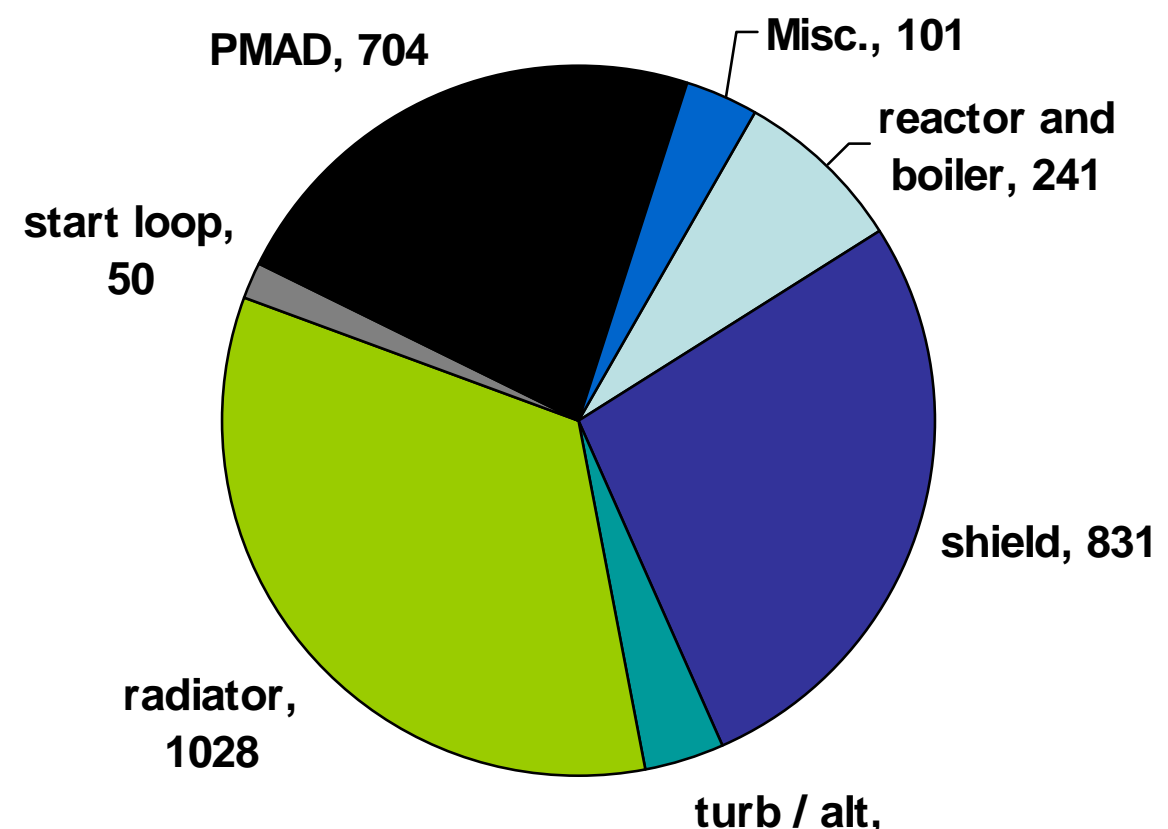

116

Fig. 3.6. The estimated masses (kg) of a $100-\mathrm{kW}_{\mathrm{e}}$ (to the thrusters) potassium Rankine nuclear reactor power system 


\section{COMPONENT DESIGNS}

\subsection{BOILER}

The boiler is a once-through shell-and-tube design with single-phase liquid lithium flowing through the shell side of the boiler and potassium flowing on the tube side. The potassium is vaporized to approximately $100 \%$ quality. In the present design, which uses two independent dynamic PCSs, a sufficient number of boiler tubes are incorporated for both systems (i.e., double the number of tubes that would be used for a single unit). The two PCSs are separated by using two nozzles each in the boiler inlet and outlet heads, one for each unit. The heads are separated in two sections that partition the tube sheet as well. In this way, the the two PCSs remain independent. Baffles in the shell side of the boiler ensure sufficient mixing to provide heat to either unit.

Twisted tapes internal to the boiler tubes are incorporated to provide sufficient swirl flow in the boiling potassium to de-entrain any liquid flow in the vapor stream, preventing liquid carryover in the boiler exit vapor. Typical boiler geometry and operating conditions are shown in Table 4.1. The boiler has a rectangular cross section with the tubes arranged in a square pitch, and it is shaped in a circular arc from inlet to outlet in order fit behind the reactor shield.

\section{Table 4.1. Boiler design for two 100-kWe units}

\begin{tabular}{ll}
\hline Number of tubes & 24 \\
Tube diameter $(\mathrm{cm})$ & 1 \\
Tube length $(\mathrm{cm})$ & 250 \\
Tube pitch $(\mathrm{cm})$ & 1.74 \\
Tube wall thickness $(\mathrm{cm})$ & 0.08 \\
Twisted tape pitch & 2 \\
Boiler dimensions $(\mathrm{cm})$ & $7.6 \times 11$ \\
Boiler wall thickness $(\mathrm{cm})$ & 0.12 \\
Number of inlet nozzles & 2 \\
Inlet nozzle diameter $(\mathrm{cm})$ & 2 \\
Number of outlet nozzles & 2 \\
Outlet nozzle diameter $(\mathrm{cm})$ & 2.8 \\
Potassium flow rate $(\mathrm{kg} / \mathrm{s}-1$ unit) & 0.27 \\
Lithium flow rate $(\mathrm{kg} / \mathrm{s})$ & 1.37 \\
\hline
\end{tabular}

This section reviews potassium boiling data, potassium boilers, and the design of the $100-$ $\mathrm{kW}_{\mathrm{e}}$ boiler. 


\subsubsection{Review of Potassium Boiling Experimental Data}

There is a significant amount of potassium boiling data in the open literature generated more than 30 years ago. A review of selected references follows.

Reference 4 describes data of potassium boiling in vertical tubes, 91.5 in. $(232 \mathrm{~cm})$ long, with two different IDs, 0.67 and 0.92 in. $(1.7$ and $2.337 \mathrm{~cm})$, and with and without helical inserts. The helical inserts employed pitch-to-diameter (P/D) ratios of 2.2 and 6. Potassium flowed upward inside the tube, and the tube was heated by sodium flowing downward outside the tube (in counter-current flow). Potassium saturation temperatures were varied between 1500 and $1750^{\circ} \mathrm{F}(1088$ and $1227 \mathrm{~K})$.

These experiments showed that superheated vapor could be obtained only when inserts were used inside the tubes. Very long tubes would be needed to produce dry vapor without inserts. The maximum amount of superheated vapor that could be produced in the 0.92 in.-ID $(2.337 \mathrm{~cm})$ tube was $0.053 \mathrm{~kg} / \mathrm{s}$, and in the smaller, 0.67 in.-ID $(1.7 \mathrm{~cm})$ tube, the maximum amount of superheated vapor was $0.055 \mathrm{~kg} / \mathrm{s}$.

The original ALKASYS code used one of these tests as a baseline. The test that had a potassium flow rate of $\mathrm{G}=34.1 \mathrm{lb} / \mathrm{ft}^{2} \cdot \mathrm{s}(0.0835 \mathrm{lb} / \mathrm{s}$ per tube or $0.038 \mathrm{~kg} / \mathrm{s}$ per tube $)$ with 0.67 -in ID $(1.7 \mathrm{~cm})$ was used as the basis to size the boiler. The number of tubes in the boiler was calculated by dividing the required potassium vapor flow rate by the flow of this test.

Reference 6 describes potassium boiling data at temperatures up to $2100^{\circ} \mathrm{F}(1422$ $\mathrm{K})$ in vertical tubes, $30 \mathrm{in}$. $(76.2 \mathrm{~cm})$ long and with five different IDs: $0.432,0.738,0.74$, 0.742 , and 0.762 in. $(1.10,1.87,1.88,1.88$ and $1.94 \mathrm{~cm})$ Tests were performed with and without helical inserts of $\mathrm{P} / \mathrm{Ds}$ of 2 and 6 . The potassium tube (or test section) was heated by external radiative heaters, making the results of these tests not directly applicable to the design of the boiler of this project. Superheated vapor was generated in some of these tests, with test sections that were only 30 in. long.

Reference 9 describes data of potassium boiling in a horizontal tube 0.311 in. (0.79 $\mathrm{cm})$ in ID and 60 in. $(152 \mathrm{~cm})$ long with twisted ribbons (P/D of 2.16) and helical inserts (P/D of 3.42). The tube was heated by sodium flowing outside co-currently at a maximum temperature of $1600^{\circ} \mathrm{F}(1144 \mathrm{~K})$. These tests showed that the pressure drop when twisted ribbons were employed was much larger (34 psi [0.23MPa] for a mass flow rate of $30 \mathrm{lb} / \mathrm{h}[0.0038 \mathrm{~kg} / \mathrm{s}]$ ) than when helical inserts were employed (about $12 \mathrm{psi}$ $[0.083 \mathrm{MPa}]$ for a flow rate of $30 \mathrm{lb} / \mathrm{h}[0.0038 \mathrm{~kg} / \mathrm{s}])$. These tests also showed that superheated vapor could be produced at mass flow rates of up to $30.7 \mathrm{lb} / \mathrm{h}(0.0039 \mathrm{~kg} / \mathrm{s})$. These mass flow rates are much smaller (by a factor of 10) than the values reported in ref. 4 for similar tubes (but with larger diameters, 0.67 and 0.92 in. ID[1.70 and $2.34 \mathrm{~cm}]$ ). This large difference may be due to a combination of factors: the smaller-diameter tube $(0.311$ in. [0.79 cm] vs. 0.67 and 0.92 in. [1.70 and $2.34 \mathrm{~cm}])$, the shorter length $(60$ in. [152.4 cm] vs. $91.5 \mathrm{in} .[232.4 \mathrm{~cm}]$ ), the efficiency of the inserts (ribbons vs. helical inserts), the orientation of the tube (horizontal vs. vertical), and the co-current sodium/potassium flow in these tests vs. the countercurrent flow of ref. 4 . 


\subsubsection{Review of Previous Boiler Designs}

All boiler designs with liquid metals reviewed from the open literature are oncethrough boilers.

Reference 4 has examples of boiler designs for powers of 10 and $8.3 \mathrm{MW}_{\mathrm{t}}$. Both boilers produced potassium vapor inside the tubes and are heated by sodium or lithium circulated in counter-flow outside the tubes. Helical inserts are required for tube lengths of under $3 \mathrm{~m}$. The $10 \mathrm{MW}_{\mathrm{t}}$ boiler requires 130 tubes, $90 \mathrm{in}$. $(228.6 \mathrm{~cm})$ long, $0.92 \mathrm{in}$. $(2.33 \mathrm{~cm})$ in ID with helical inserts $(\mathrm{P} / \mathrm{D}=2)$. The $8.3 \mathrm{MW}_{\mathrm{t}}$ boiler requires 254 tubes, 68 in $(172.7 \mathrm{~cm})$ long, 0.75 in $(1.9 \mathrm{~cm})$ ID, with helical insets of $\mathrm{P} / \mathrm{D}=1$. The power per tube for each boiler is 76.92 and $32.7 \mathrm{~kW}_{\mathrm{t}} /$ tube, respectively.

Reference 10 compares different boiler designs employing cesium or potassium as the boiling fluid and employing two different approaches to obtain superheated vapor: vortex generators or a low-entrainment approach. The report concludes that potassium boilers are lighter than cesium boilers, and the low-entrainment boilers are lighter than the vortex generator boilers. However, boilers employing the low-entrainment approach are more complex, as they require tapered tubes and two flows into the primary side (cocurrent flow up to the CHF point, and counter-current flow in the superheating region).

Reference 11 compares different tube designs to be used as superheaters. Water and potassium were used as the fluids. The experiments were performed using a preheater and a boiler before the superheater tube was tested. Heat was provided by electrical heaters. The boiler and the superheater were oriented vertically, while the preheater was horizontal. Six different superheaters were tested with water and four different superheaters with potassium. The water superheaters were all $118 \mathrm{in} .(300 \mathrm{~cm})$ long with IDs varying between 0.591 and 0.625 in. $(1.5-1.59 \mathrm{~cm})$. The potassium test sections were 106 in. long $(269 \mathrm{~cm})$ with IDs of between 0.591 and 0.628 in. $(1.5-1.6 \mathrm{~cm})$. Different inserts were employed to produce swirl flow and superheated vapor. Heat transfer coefficients, vapor superheat, and pressure drops were measured for the different test sections. The maximum temperature employed was $1800^{\circ} \mathrm{F}(1255 \mathrm{~K})$, and the mass flow rates were under $0.02 \mathrm{~kg} / \mathrm{s}$. The inserts were evaluated based on the pressure drop and superheat obtained.

Reference 12 is a study of a $2-\mathrm{MW}_{\mathrm{t}}$ potassium boiler using lithium as the heating fluid in counter-current flow. The boiler consists of 31 tubes, each 90 in. $(230 \mathrm{~cm})$ long, contained within a cylindrical shell, shaped into an arc of a circle (Fig 4.1). The diameter of the tubes ranged from 0.5 to $0.75 \mathrm{in}$. $(1.27$ to $1.9 \mathrm{~cm})$ with a $0.03 \mathrm{in}$. $(0.076 \mathrm{~cm})$ wall thickness. The boiler produced $2.08 \mathrm{lb} / \mathrm{s}(0.94 \mathrm{~kg} / \mathrm{s})$ of superheated potassium vapor at a temperature of $2100^{\circ} \mathrm{F}(1420 \mathrm{~K})$ and at a pressure of $163 \mathrm{psia}(1.13 \mathrm{MPa})$. Potassium liquid enters the boiler at a temperature of $1211^{\circ} \mathrm{F}(929 \mathrm{~K})$. The lithium temperatures are $2200^{\circ} \mathrm{F}(1480 \mathrm{~K})$ at the inlet and $2100^{\circ} \mathrm{F}(1420 \mathrm{~K})$ at the exit of the boiler.

Reference 13 describes the design of a $3.3-\mathrm{MW}_{\mathrm{t}}$ potassium boiler employing lithium as the heating fluid in counter-current flow. This boiler is very similar to the one of ref. 12 but has more tubes (55 tubes) as it supplies more power. Fig. 4.2, taken from ref. 13, shows the similarity between this design and the one of ref. 12 (Fig. 4.1). The 


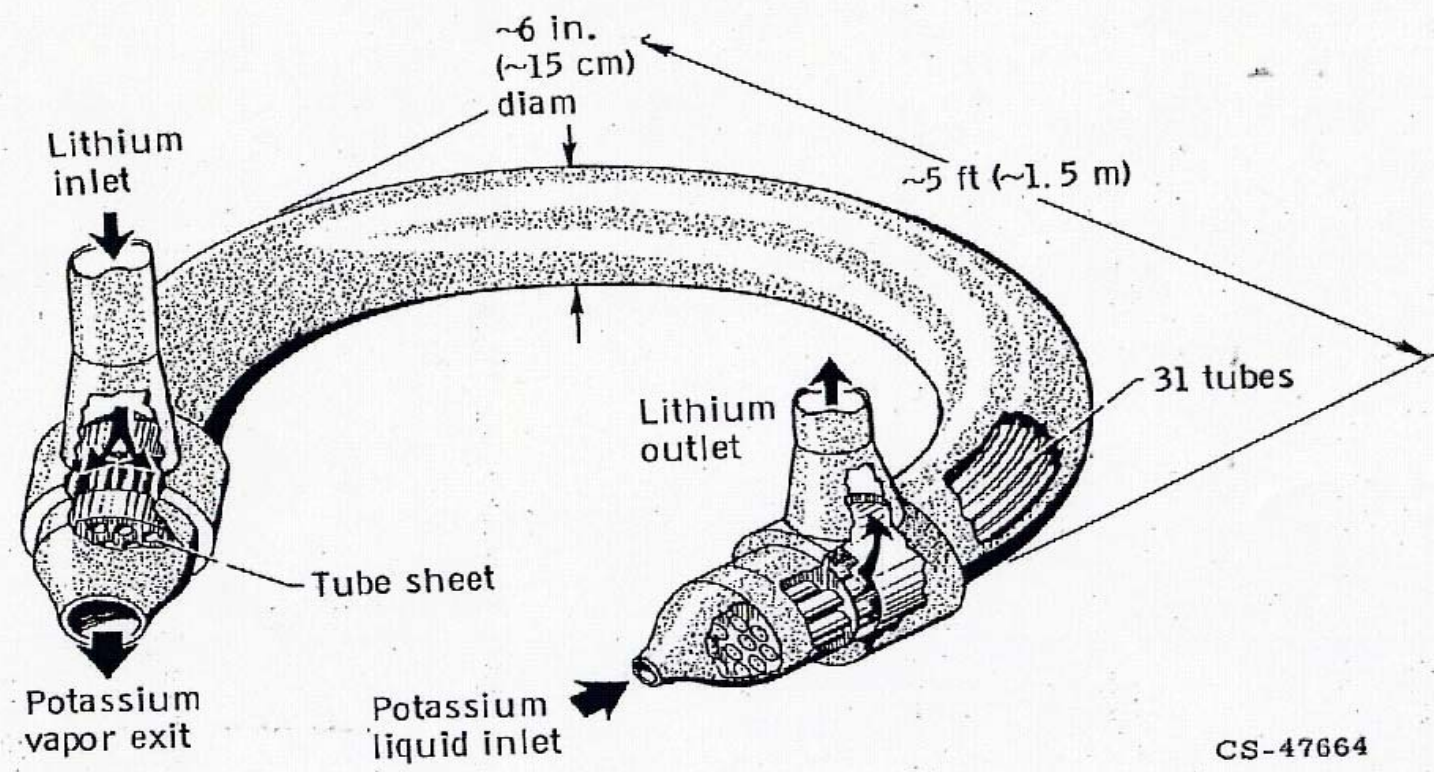

Fig. 4.1. The 2-MW ${ }_{t}$ boiler design. Source: ref. 12

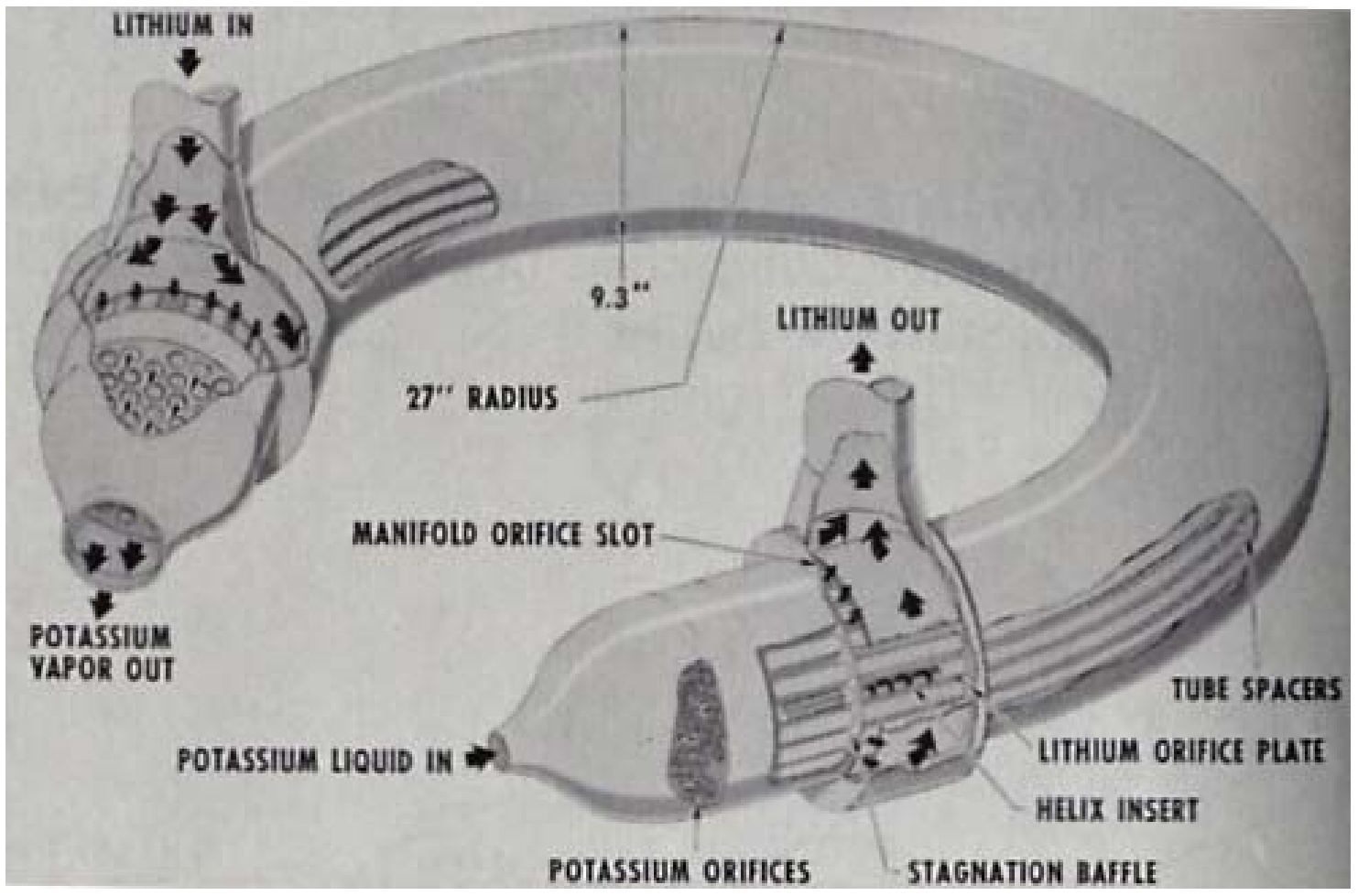

Fig. 4.2 The 3.3 MW $\mathrm{MW}_{\mathrm{t}}$ boiler design. Source: ref. 13 
tubes are 89 in. $(226 \mathrm{~cm})$ long, $0.75 \mathrm{in.}(1.9 \mathrm{~cm})$ in ID, shaped into an arc, and $0.04 \mathrm{in.}$ $(0.1 \mathrm{~cm})$ in wall thickness. The temperatures of the lithium are $2200^{\circ} \mathrm{F}(1477 \mathrm{~K})$ inlet and $2100^{\circ} \mathrm{F}(1422 \mathrm{~K})$ exit. The temperatures of the potassium are $1100^{\circ} \mathrm{F}(866 \mathrm{~K})$ inlet and $2150^{\circ} \mathrm{F}(1450 \mathrm{~K})$ vapor outlet (Fig. 4.3).

There were other boiler designs employing mercury (SNAP-2 for $55 \mathrm{~kW}_{\mathrm{t}}$ and SNAP-8 for $600 \mathrm{~kW}_{\mathrm{t}}$ in ref. 14) and one in ref. 13 for $72 \mathrm{~kW}_{\mathrm{t}}$.
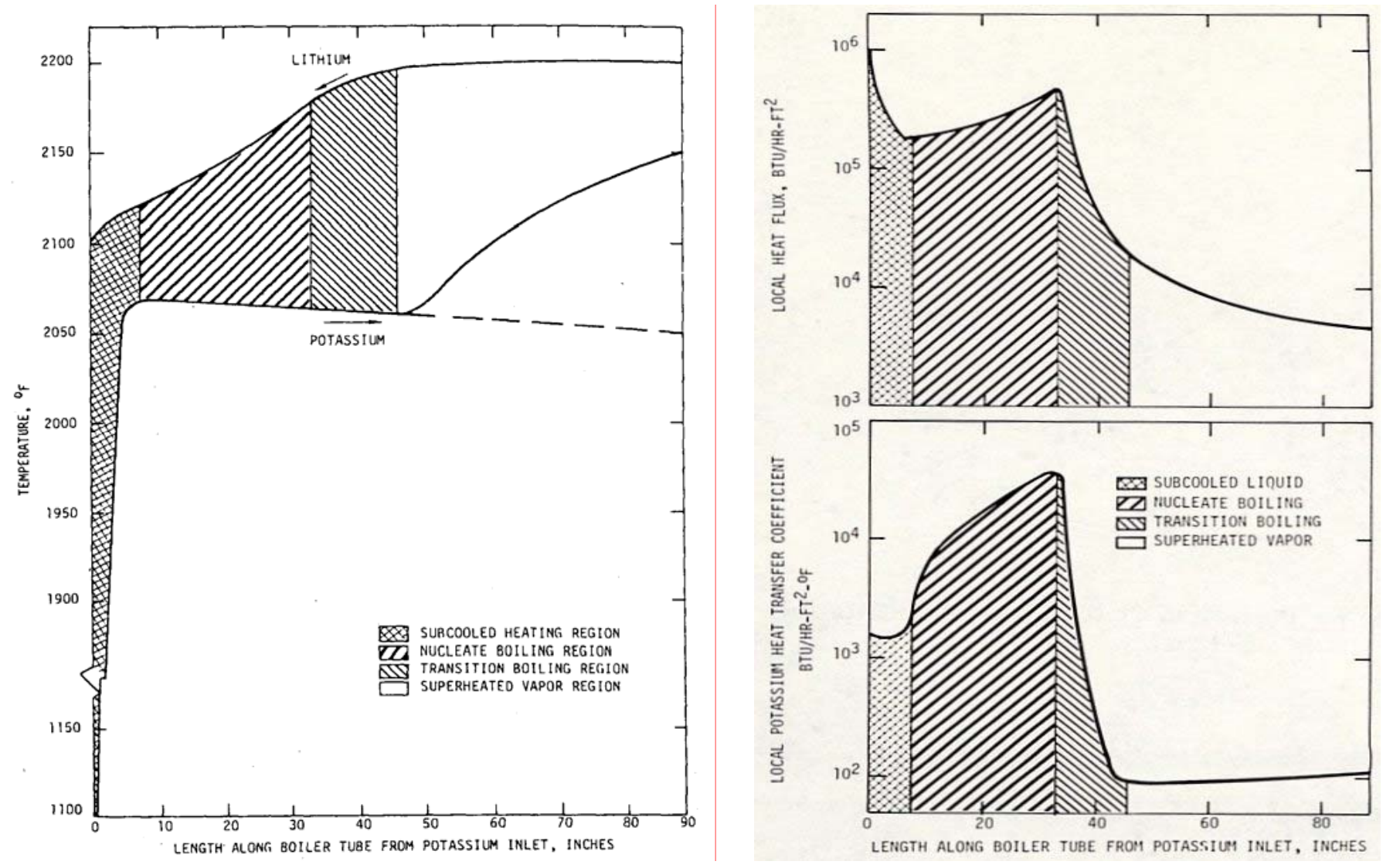

Fig. 4.3. Temperature distribution in 3.3 MWt boiler design (a) and heat flux and heat transfer coefficient distribution (b). Source: ref. 13

\subsubsection{Boiler Design}

Potassium boilers can be either recirculating or once-through. Once-through boilers usually have inserts inside the tubes to improve the vaporization of the potassium drops (by centrifuging the drops to the tube wall where they get vaporized) and to generate dry or superheated vapor. Based on the designs reviewed in the open literature, the once- 
through boiler with tube inserts and counter-current flow appears to be the preferred option. This option results in a simple boiler that requires less control than the recirculating boiler, which needs a vapor/liquid separator at the exit. The counter-current flow shell and tube design, with helical inserts inside the tubes, is the most efficient way to obtain superheated vapor. The boiler must produce dry saturated vapor or superheated vapor to reduce erosion problems in the turbine.

The experimental data and relevant boiler designs reviewed have been summarized in Table 4.2, showing parameter values for a single tube of each boiler.

Table 4.2. Comparison of different boiler designs producing superheated vapor

\begin{tabular}{lllccl}
\hline Reference & 4 & 4 & 12 & 13 & $4^{a}$ \\
Number of tubes & 1 & 1 & 31 & 55 & 1 \\
Tube ID, in. & 0.67 & 0.92 & $0.5-0.75$ & 0.75 & 0.67 \\
$\quad \mathrm{~cm}$ & 1.7 & 2.34 & $1.27-1.9$ & 1.9 & 1.7 \\
Tube length, in. & 91.5 & 91.5 & 90 & 89 & 91.5 \\
$\quad \mathrm{~cm}$ & 232 & 232 & 230 & 226 & 232 \\
Vapor temp, K & 1227 & 1227 & 1420 & 1450 & 1140 \\
Tube flow, kg/s & 0.055 & 0.0835 & 0.03 & - & 0.038 \\
$\mathrm{~kW}_{\mathrm{t}}$ /tube & & & 64.5 & 60 & \\
\hline
\end{tabular}

${ }^{a}$ ALKASYS boiler design value

This table shows that boilers with tubes about 90 in. $(230 \mathrm{~cm})$ long and 0.67 in. $(1.7 \mathrm{~cm})$ in ID can supply about $0.03-0.04 \mathrm{~kg} / \mathrm{s}$ of superheated potassium vapor, or about $60 \mathrm{~kW}_{\mathrm{t}}$ of power. The $100-\mathrm{kW}_{\mathrm{e}}$ system requires about $500 \mathrm{~kW}_{\mathrm{t}}$ and $0.272 \mathrm{~kg} / \mathrm{s}$ of potassium vapor, which can be supplied with eight or nine of these boiler tubes.

Boiler design calculations were also performed with the thermal hydraulic code ATHENA. This code is a one-dimensional, two-fluid, non-homogeneous, nonequilibrium, six-equation transient thermal-hydraulic analysis code that is based on the Nuclear Regulatory Commission (NRC) licensing code RELAP5 Mod 3.2 (ref. 15). The code can be used to model transients of the complete reactor system, including the primary with the reactor and the secondary with the turbine, or to model single components, like the boiler.

While RELAP5 uses water as the main fluid, ATHENA can employ a variety of fluids, including cryogenic liquids and liquid metals. The properties of lithium and potassium are in the code, but the heat transfer correlations are primarily for water and steam and were replaced with correlations that applied to liquid metals. There are many correlations in the open literature that can be used with liquid metals. The selection was made following the recommendations of Peterson. ${ }^{13}$ Therefore, the following correlations have been implemented into the code:

Maresca and Dwyer for the lithium side (liquid forced convection)

Lubarsky and Kaufman for the potassium side under liquid forced convection

Bonilla and Rohsenow equations for nucleate boiling

Peterson for transition boiling 
Dittus and Boelter (that is already in the code) for superheated potassium vapor A Peterson empirical equation ${ }^{13}$ for CHF transition.

An ATHENA model was developed to help design the boiler. The boiler modeled is a once-through shell and tube design, with the potassium flowing inside the tubes and lithium flowing counter-currently outside the tubes. Different heat transfer regimes are calculated by the code as the potassium boils. At the entrance to the boiler, there is a single-phase forced-convection liquid region where the potassium is heated to the saturation temperature. The second region is the nucleate boiling region, where the potassium gets converted into vapor. A transition region follows, after the critical heat flux point is reached. In the transition region, potassium liquid and vapor coexist on the tube wall. In the last region of the boiler, single-phase potassium vapor is superheated.

Calculations with the ATHENA code were completed for a single horizontal tube with different diameters, lengths, lithium inlet temperatures and mass flow rates, and different potassium inlet temperatures, outlet pressures, and mass flow rates. Two different lithium inlet temperatures were examined, $1500 \mathrm{~K}$ (for the T-111) system and $1350 \mathrm{~K}$ (for the $\mathrm{Nb}-1 \% \mathrm{Zr}$ system).

ATHENA-calculated temperatures for the lithium and potassium along the tube are shown in Fig. 4.4. Lithium enters at $1500 \mathrm{~K}$ (right side of the figure.) and leaves at 1450 $\mathrm{K}$ (left side of the figure). Potassium liquid enters at $1240 \mathrm{~K}$ (left side of the figure for counter-current flow), heats up to saturation, starts boiling, and as it travels down inside the tube, separates into a liquid portion at saturation conditions and a vapor portion that is superheated. The liquid portion eventually vaporizes completely, and only superheated vapor at $1460 \mathrm{~K}$ leaves the boiler (right side of the figure). Based on these calculations, a $\Delta \mathrm{T}$ of $40 \mathrm{~K}$ between the hot inlet lithium and the potassium exit vapor exists in the hot side of the boiler. A value of $40 \mathrm{~K}$ was therefore used as the minimum temperature difference in version 2 of the ALKASYS-SRPS code.

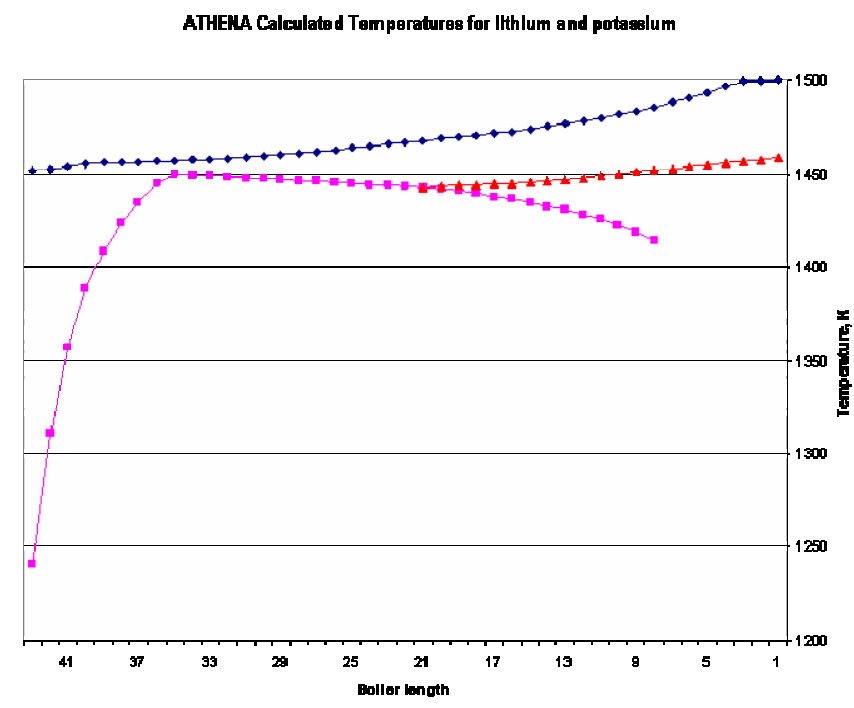

Fig. 4.4. Temperatures in a boiler tube as calculated with the ATHENA code. 
A significant number of ATHENA calculations have been completed. These calculations have been very useful in understanding the conditions of the lithium and potassium in the boiler; the limits of operation; and the size (tube length and diameter), temperatures, and pressures that produce dry or superheated vapor. Results have been used to design the boiler for the systems considered.

ATHENA calculations for tubes $240 \mathrm{~cm}$ (95 in.) long and 1 and 1.7-cm (0.4 and 0.67 in.) ID with internal inserts $(\mathrm{P} / \mathrm{D}=2)$ are summarized. The small tube (1-cm-ID) can produce up to $0.024 \mathrm{~kg} / \mathrm{s}$ of superheated potassium vapor and the large tube (1.7-cm-ID) up to $0.035 \mathrm{~kg} / \mathrm{s}$ of superheated vapor. The vapor superheat is at least $50 \mathrm{~K}$. If larger mass flow rates are used, the vapor conditions at the boiler exit have reduced superheat; and, for sufficiently larger flows, dry saturated vapor or a mixture of saturated vapor with some liquid droplets is predicted. Since wet vapor cannot be used in the turbine, it is important not to use mass flow rates above the calculated limits. These calculated values are in good agreement with the experimental values of ref. 10 for the 0.67 in. $(1.7-\mathrm{cm})$ tubes.

For the boiler design, a conservative value of $0.022 \mathrm{~kg} / \mathrm{s}$ was set as the maximum potassium flow in this project for the $1-\mathrm{cm}-$ ID tube and a value of $0.03 \mathrm{~kg} / \mathrm{s}$ as the maximum flow for the 1.7-cm-ID tube. These conservative limits ensure superheated vapor conditions at the boiler exit.

The $100-\mathrm{kW}_{\mathrm{e}}$ system requires approximately $0.272 \mathrm{~kg} / \mathrm{s}$ of potassium vapor that can be supplied by 12 small (1-cm-ID) or by 9 large $(1.7-\mathrm{cm}-\mathrm{ID})$ tubes. The latter number ( 9 ) agrees with the estimated tube number based on the experimental/design data of Table 4.2. For dual $(2 \times 100 \mathrm{kWe})$ units, twice the number of tubes are needed: 24 small tubes or 18 large tubes. The small tubes can be arranged in a square pitch inside a rectangular shell section (e.g., six rows of four tubes each). The large tubes can be arranged in a triangular/hexagonal pitch inside a circular shell, and a total of 19 tubes can be used ( 9 for one unit and 10 for the other unit) with a hexagonal configuration incorporating 3 rings. Using a pitch of $1.74 \mathrm{~cm}$ for the small tubes, a rectangular shell of $7.6 \times 11 \mathrm{~cm}$ results. For the large tubes, a pitch of $2.1 \mathrm{~cm}$ can be used that results in a shell diameter of $10.2 \mathrm{~cm}$. Based on structural considerations, the tube wall thickness is 0.8 $\mathrm{mm}$, and the shell thickness is $1.2 \mathrm{~mm}$, if $\mathrm{Nb}-1 \% \mathrm{Zr}$ at temperatures below $1350 \mathrm{~K}$ is used.

The boiler with small tubes ( $1 \mathrm{~cm}$ ID) and with internal inserts $(\mathrm{P} / \mathrm{D}=2)$ has been selected over the boiler with the large tubes. The small tubes with the inserts provide larger radial acceleration of the liquid than the large tubes. This is important not only in the two-phase flow region but also at the entrance of the boiler where low liquid potassium velocities exist.

Conceptual drawings of the 24-tube boiler have been completed and are shown in Figs. 4.5-4.8. Figure 4.5 shows a view of the boiler with an the inlet and outlet for the lithium flow from and to the reactor and two inlets and two outlets for the potassium flow (for the two PCSs). The piping diameter is approximately $1.2 \mathrm{~cm}$ for the potassium liquid inlets, $2.5 \mathrm{~cm}$ for the potassium outlets, and $2.5 \mathrm{~cm}$ for both the lithium inlet and outlet. Figs. 4.6-4.8 show additional details of the boiler.

Stress analyses of the boiler tubes have been initiated at the potassium entrance to the boiler, where the temperature difference between the potassium side (liquid at about 
$850 \mathrm{~K}$ ) and the lithium side (at $1310 \mathrm{~K}$ ) is $460 \mathrm{~K}$, with a total radial $\Delta \mathrm{T}$ across the boiler tube wall of over $100 \mathrm{~K}$.

An axial temperature difference of $30 \mathrm{~K}$ has been calculated at the potassium wet front, where the CHF point is. This temperature difference moves slightly down the tube, as the boiling/vaporization process is a transient process. Based on the stress calculations performed at the boiler inlet, this temperature difference does not appear to cause stress problems; however, additional evaluation is needed to determine fatigue limits.

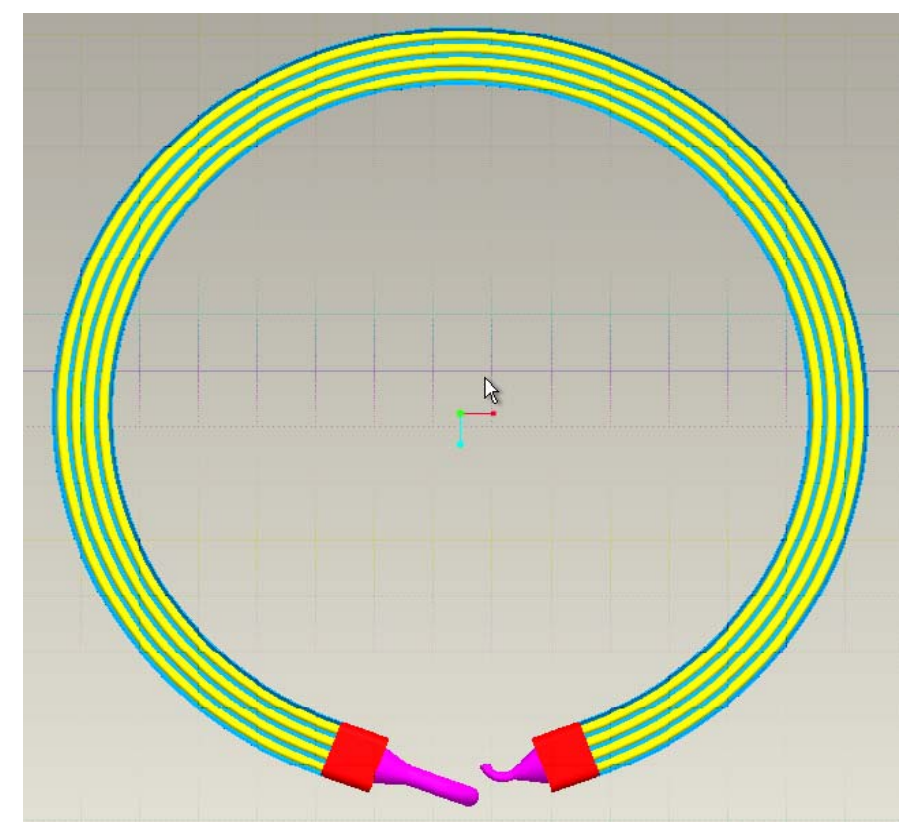

Fig. 4.5. Cutaway view of boiler showing tube layout.

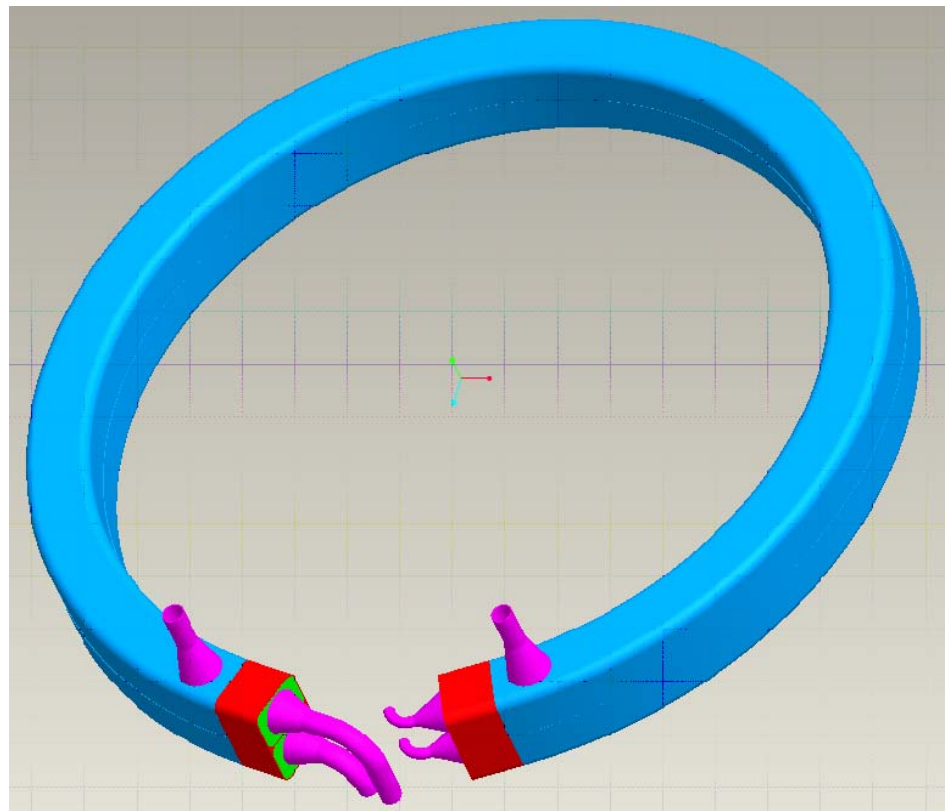

Fig. 4.6. Boiler isometric showing potassium and lithium inlets and outlets. 


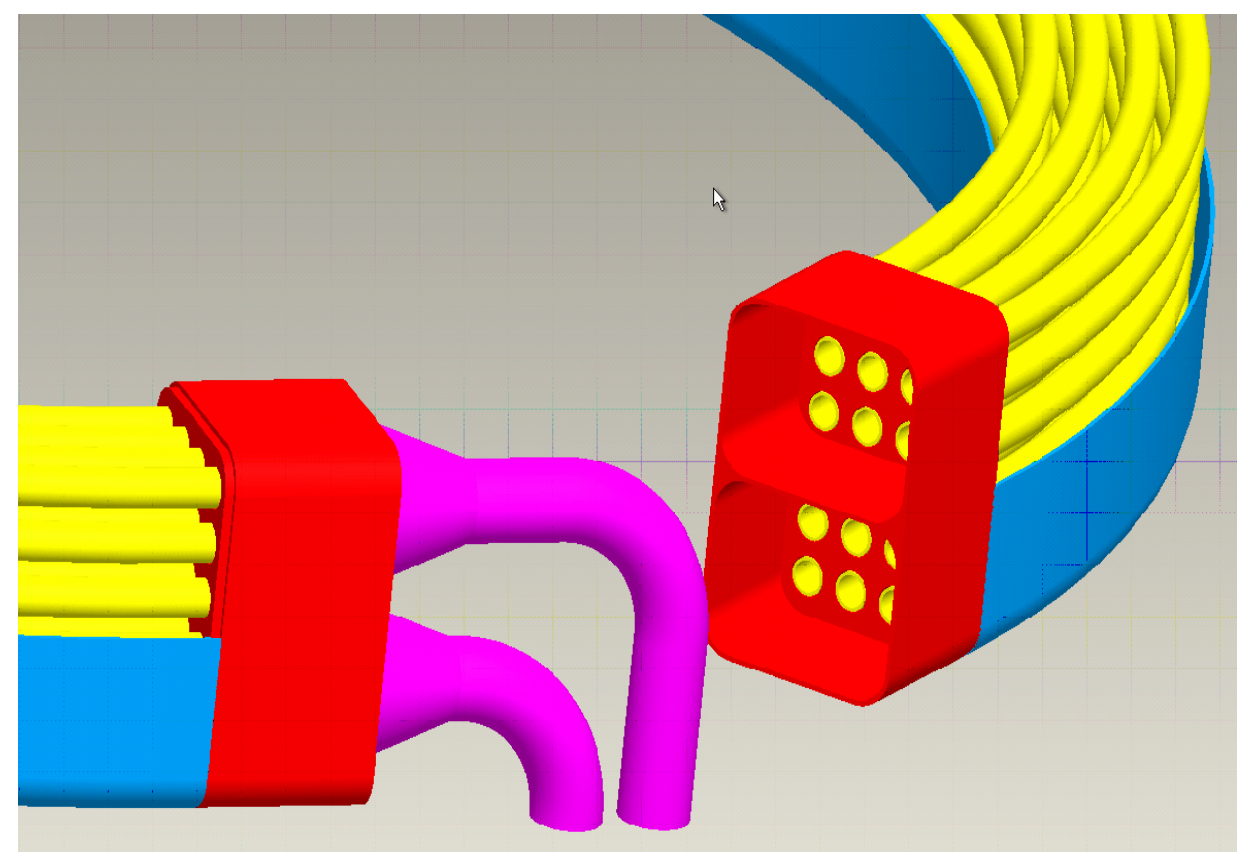

Fig. 4.7. Boiler header cutaway showing tube sheet and boiler tubes.

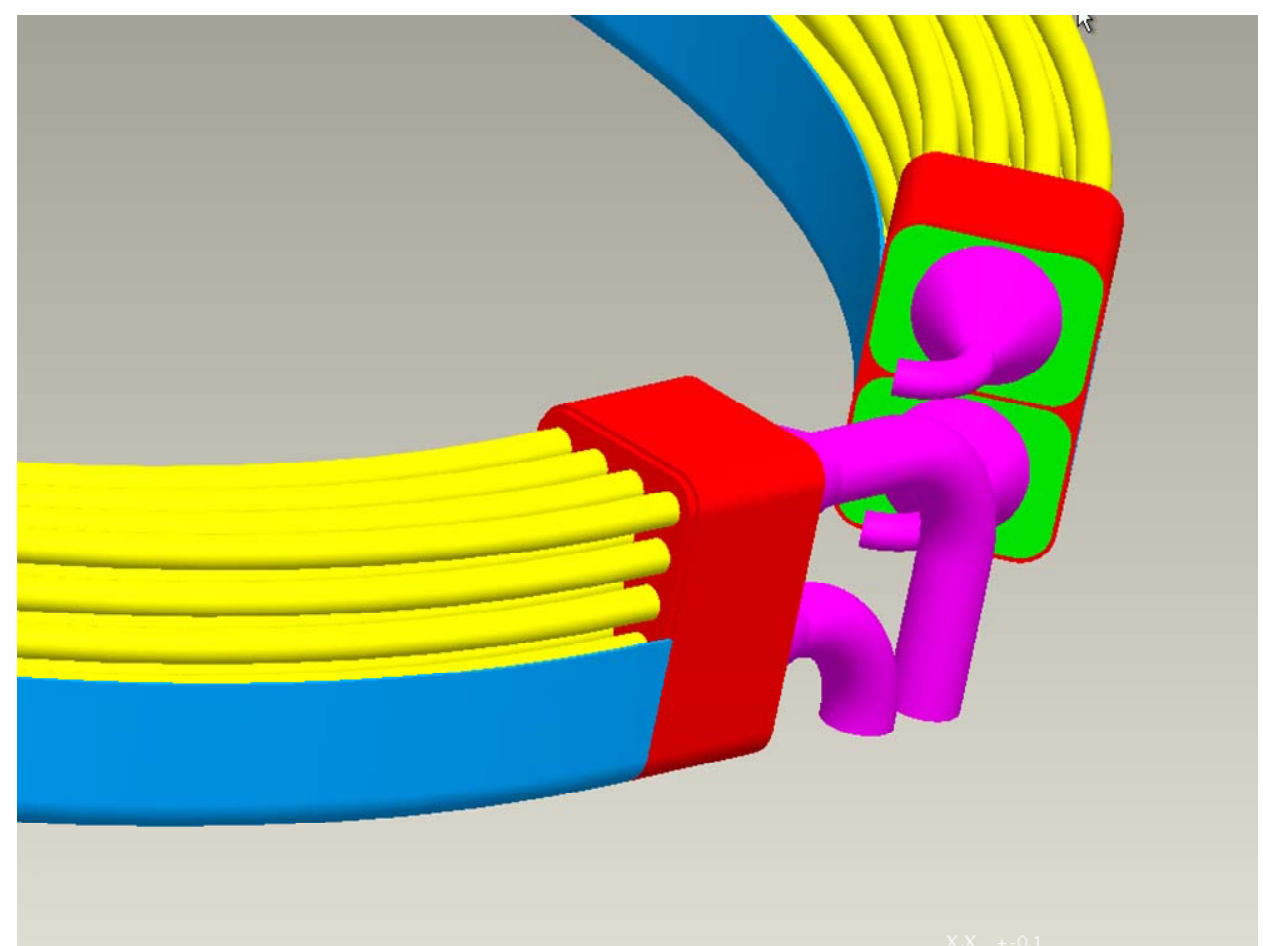

Fig. 4.8. Boiler header design. 


\subsection{BOILER FEED PUMP}

The turbopump consists of a single-stage, partial admission turbine coupled to a single-stage centrifugal pump. The two components are enclosed in a common, canned housing eliminating any external rotating seals. The turbine rotor diameter is approximately $11 \mathrm{~cm}$, and the pump impeller diameter is approximately $2.7 \mathrm{~cm}$ for the $100-\mathrm{kW}_{\mathrm{e}}$ unit. Expected pump efficiency is $47 \%$ and turbine efficiency is $13 \%$ for this system. The turbo-pump operates at approximately 24,000 rpm.

The turbine is supplied with $0.009 \mathrm{~kg} / \mathrm{s}$ of potassium vapor directly from the boiler exit at $1310 \mathrm{~K}$ and $0.77 \mathrm{MPa}$ pressure. The potassium is expanded through the turbine to a pressure of $0.21 \mathrm{MPa}$. Boiler pump flow is $0.27 \mathrm{~kg} / \mathrm{s}$, and the pump provides a pressure rise of $0.84 \mathrm{MPa}$.

Detailed design analysis of the boiler feed pump and turbine were performed using Rocketdyne design codes. Parametric analyses allowed the results to be condensed into performance curves that could be used in ALKASYS-SRPS to predict turbopump characteristics.

The performance of small axial-flow partial admission turbopumps operating on potassium vapor can be estimated using Fig. 4.9. Figure 4.9 shows that for small partial admission turbopumps, operating on potassium vapor and pumping liquid potassium, the turbine efficiency is a function of turbine size. Figure 4.10 shows that the optimum turbopump operating speed is also primarily a function of turbine size. These two parameters are the only ones required for system optimization studies, since along with turbopump size, efficiency may be estimated; and if turbopump speed is set, then the size and mass of the turbopump can be determined.

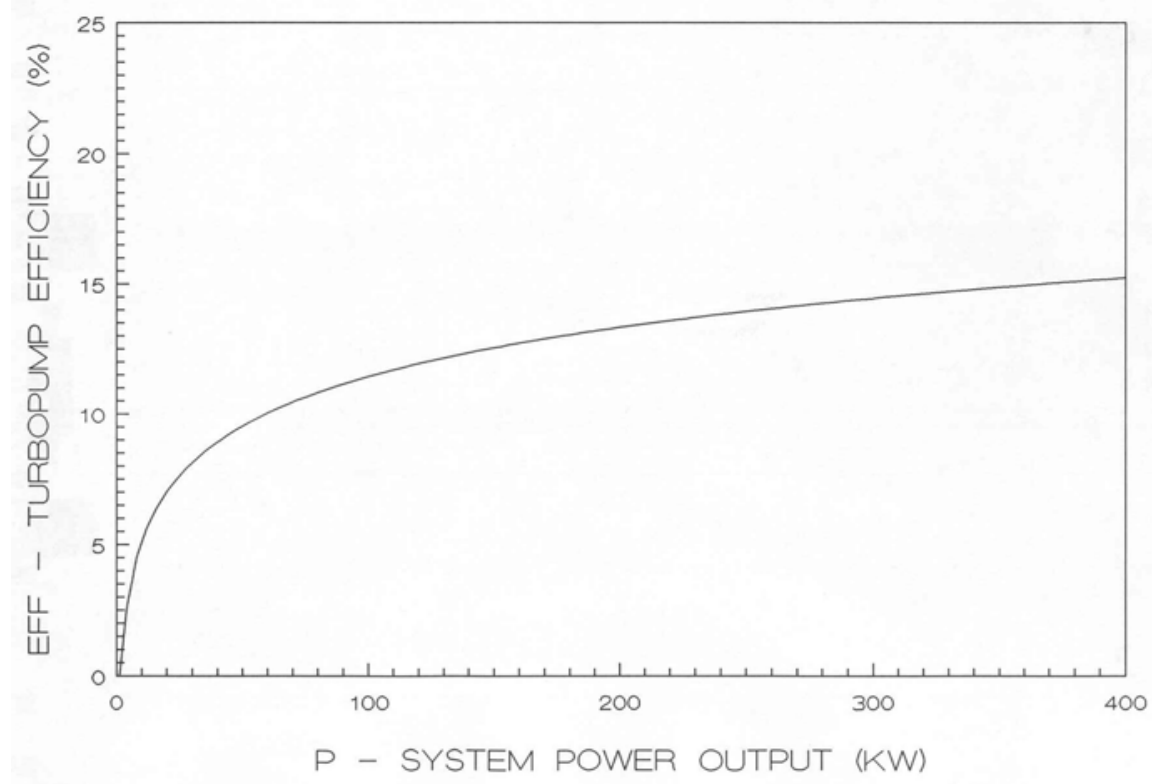

Fig. 4.9. Feed turbopump efficiency is driven by system power output

Turbopump mass was found to be well represented by the simple expression given 


$$
\mathrm{Wp}=22.0 * \mathrm{Tp}^{* *} 0.6
$$

Where

$$
\begin{aligned}
& \mathrm{Wp}=\text { turbopump mass }(\mathrm{lb}) \\
& \mathrm{Tp}=\text { turbopump torque }(\mathrm{ft}-\mathrm{lb})
\end{aligned}
$$

Since

$$
\mathrm{Tp}=5252.0 * \mathrm{Phyd} / \mathrm{N}
$$

Where

Phyd $=$ pump hydraulic power $=0.2618 *$ Wdot $*$ Delta-P/Rho

$\mathrm{Wdot}=$ turbopump drive flowrate $(\mathrm{lb} / \mathrm{s})$

Delta-P = turbopump pressure rise (psid)

Rho $=$ local pumped fluid density $\left(\mathrm{lb} / \mathrm{ft}^{3}\right)$

$\mathrm{N}=$ turbine rpm

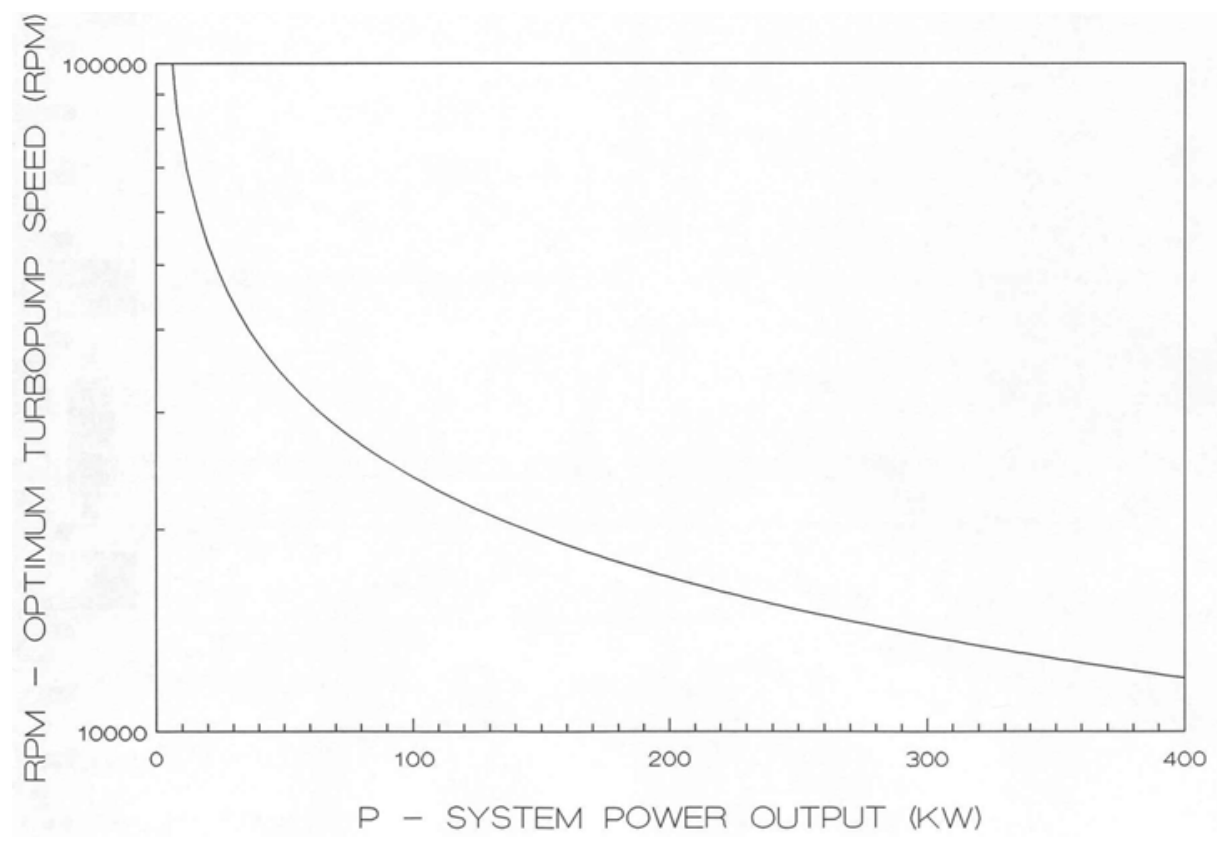

Fig. 4.10. Turbopump optimum speed is driven by the system power output.

These relationships do not define a turbopump design, but they do provide sufficient information to proceed with system optimization and a design specification for the detailed design of the turbine. Note that these relations were developed for a single-stage centrifugal pump driven by a partial admission turbine with $10 \%$ admission.

Figure 4.11 shows the conceptual design of a potassium turbopump designed to be used in a system that delivers $100-\mathrm{kW}_{\mathrm{e}}$ system power. The turbine uses a single, partial admission expansion stage and an inducer-type centrifugal pump. The unit is very compact and should be easily integrated into the overall power system. 


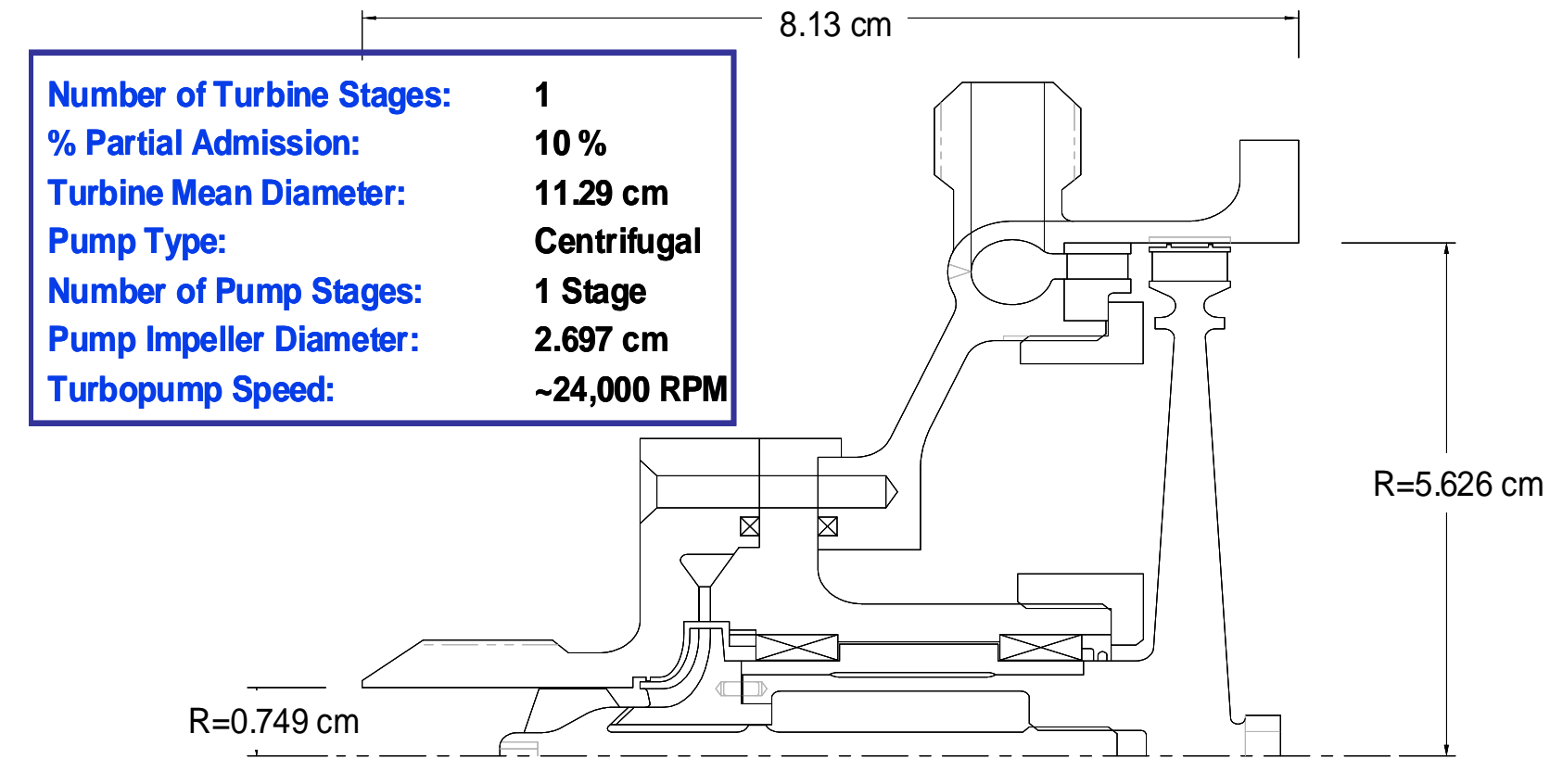

Fig. 4.11. Feed turbopump design concept and characteristics.

\subsection{TURBINE}

Considerable test and development work was accomplished on potassium turbines prior to 1970. Table 4.2 summarizes this work. Note from Table 4.2 that the maximum operating temperature attempted to date was $1144 \mathrm{~K}$ and that two test rigs were operated for over $5000 \mathrm{~h}$ with negligible erosion. One of the long-duration tests featured an inlet temperature of $1088 \mathrm{~K}$ and an outlet vapor quality of $92 \%$. This indicates that there is a good chance that potassium vapor turbines can be designed to operate with reasonable amounts of wet potassium in the vapor stream. 


\begin{tabular}{|c|c|c|c|c|c|c|c|c|c|c|}
\hline 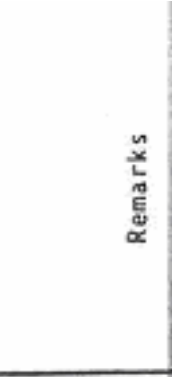 & 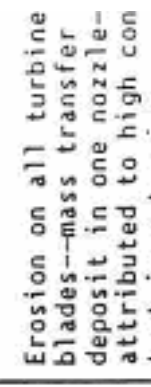 & 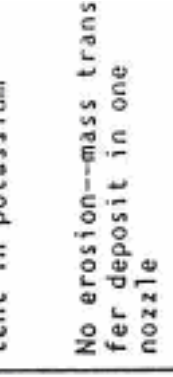 & & 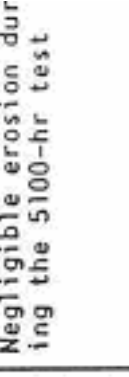 & 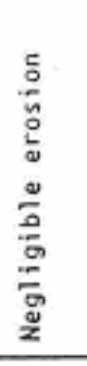 & 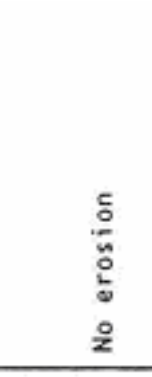 & 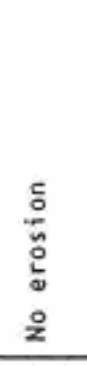 & 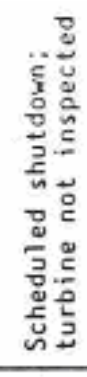 & 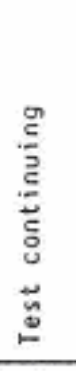 & 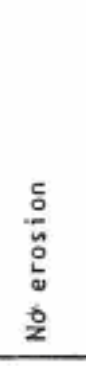 \\
\hline 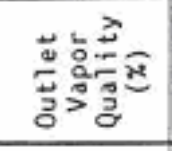 & $\begin{array}{c}\text { के } \\
\text { î̀ } \\
\text { in }\end{array}$ & $\begin{array}{l}c \\
\text { ch } \\
\text { ồ } \\
i \\
\end{array}$ & & q & $\approx$ & 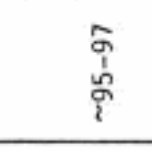 & 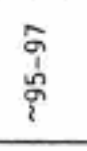 & to & 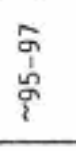 & 商 \\
\hline 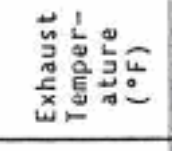 & : & $\stackrel{\circ}{\varrho}$ & & $\stackrel{8}{2}$ & & $\stackrel{9}{9}$ & 异 & 㖂 & $\stackrel{\circ}{9}$ & $\stackrel{ }{\Xi}$ \\
\hline 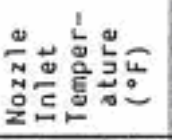 & 怘 & 吕 & & 8 & 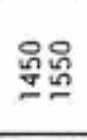 & 宅 & $\stackrel{\text { D. }}{\text { D. }}$ & 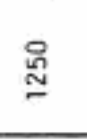 & 品 & 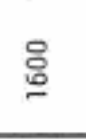 \\
\hline 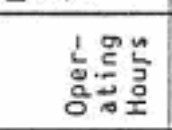 & 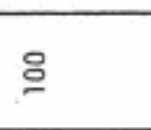 & ঃ & is & $\frac{8}{6}$ & 。్ & $\stackrel{\circ}{\circ}$ & 总 & 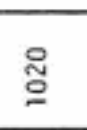 & ఏ్ & $\stackrel{\circ}{\circ}$ \\
\hline 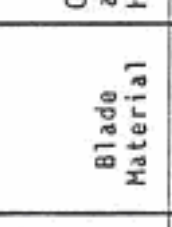 & $\stackrel{I}{I}$ & 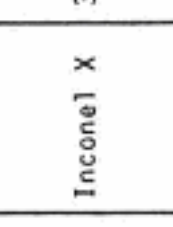 & & 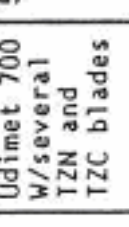 & $\stackrel{I}{I}$ & $\stackrel{\Sigma}{\Sigma}$ & $\stackrel{\Sigma}{\Sigma}$ & $\stackrel{\Sigma}{\Sigma}$ & $\stackrel{\Sigma}{\Sigma}$ & 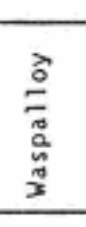 \\
\hline 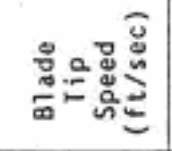 & 品 & 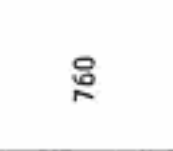 & 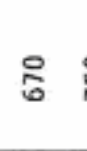 & 品员 & 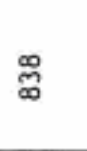 & $\approx$ & $\approx$ & $\approx$ & 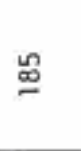 & 员 \\
\hline 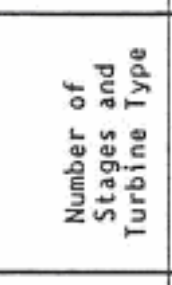 & 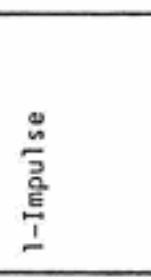 & 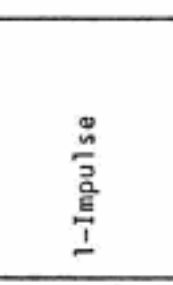 & 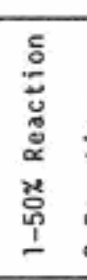 & & 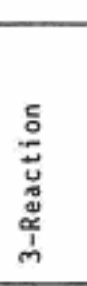 & 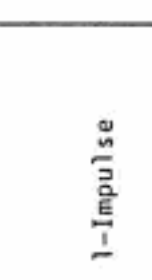 & 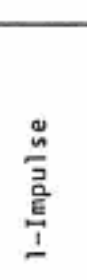 & 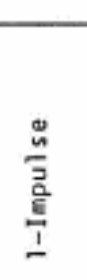 & 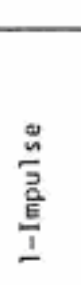 & 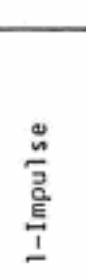 \\
\hline 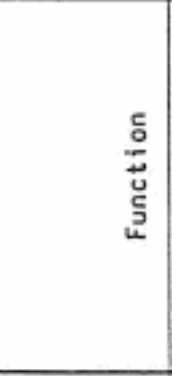 & 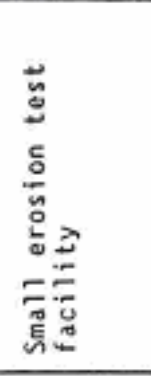 & 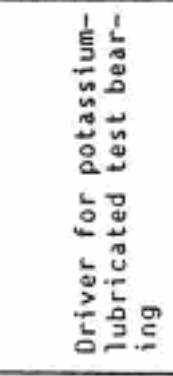 & 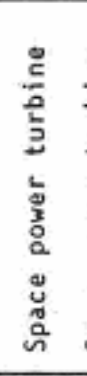 & 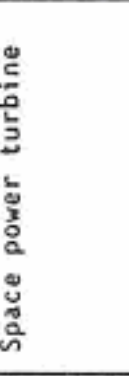 & 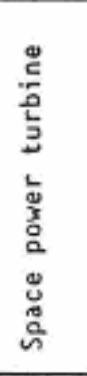 & 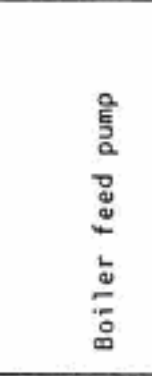 & 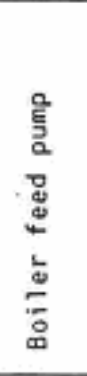 & 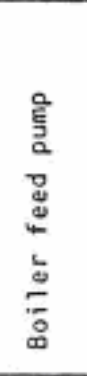 & 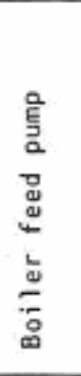 & 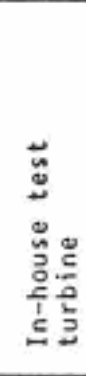 \\
\hline 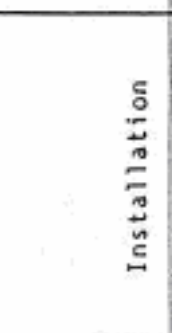 & 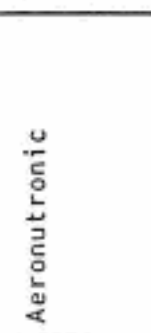 & 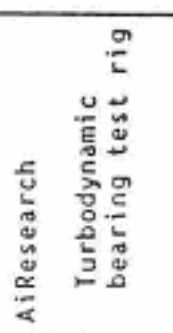 & 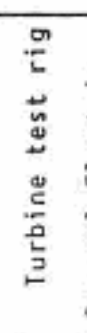 & 这 & 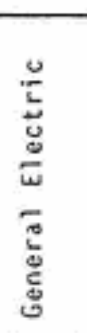 & 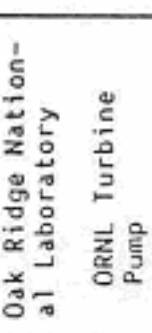 & 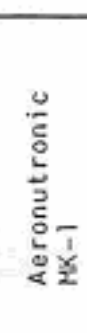 & 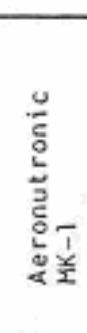 & 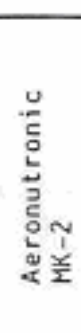 & 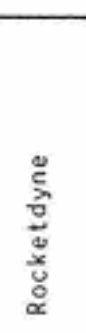 \\
\hline
\end{tabular}


A multi-stage, axial flow turbine is used in this design. The turbine uses nine stages and a tilting pad bearing system lubricated with $750 \mathrm{~K}$ liquid potassium. The turbine produces a shaft power of $127 \mathrm{~kW}$ operating at approximately 55,000 rpm. Turbine tip speed was limited to $260 \mathrm{~m} / \mathrm{s}$ in order to minimize turbine blade erosion due to moisture. At these conditions, turbine efficiency is approximately $74 \%$ overall. Turbine rotor diameter is $8.2 \mathrm{~cm}$, and turbine overall length is $27 \mathrm{~cm}$.

Moisture level in the turbine expansion path is maintained at a reasonably low level by using both external moisture separators and interstage separators. An external separator is utilized at about the middle stage, and interstage separators are used where required to maintain moisture at acceptable levels.

An interstage separator is assumed to remove $25 \%$ of the moisture present in the working fluid at the location of the separator. An associated penalty with this type of separator is the requirement that $0.25 \mathrm{lb}(0.1134 \mathrm{~kg})$ of vapor be removed with each pound $(0.4536 \mathrm{~kg})$ of moisture removed.

An external separator is assumed to remove $90 \%$ of the moisture in the working fluid as it enters the separator. Two performance penalties are associated with this type of separator. First, $0.1 \mathrm{lb}(0.045 \mathrm{~kg})$ of vapor accompanies each pound $(0.4536 \mathrm{~kg})$ of removed moisture. Second, the working fluid undergoes a pressure drop of approximately two velocity heads ( 1.5 psi or 10.3 $\mathrm{kPa}$ is assumed in the model) as it passes through the separator. In addition, there is a weight penalty associated with an external separator as a result of the separator itself and the additional turbine length to accommodate the fluid passages leaving and returning to the turbine flow path.

Each stage of the turbine is assumed to have an aerodynamic efficiency equal to the input value for dry-stage efficiency. As the mass and energy balance analysis progresses, the actual efficiency for each stage is then assumed to be the aerodynamic efficiency degraded by $1 \%$ per percentage point of average moisture in the stage. In addition, a value for turbine exhaust loss, caused by the last stage exit velocity, is specified.

Similar to the detailed design calculations for the turbopump, calculations for the turbine were performed. Turbine design results have been collapsed into performance curves for use in ALKASYS-SRPS.

The performance of small axial flow turbines operating on potassium vapor can be estimated by use of Fig. 4.12. This figure shows that for small axial flow turbines, operating on potassium vapor, the turbine efficiency is a function of turbine size.

Figure 4.12 also shows the available data for turbine efficiency. Figure 4.13 shows that the optimum turbine operating speed is also primarily a function of turbine size. Efficiency and size are the only two parameters required for system optimization studies, since turbine size and efficiency can both be estimated if turbine speed is set. The size and mass of the alternator can then be determined. 


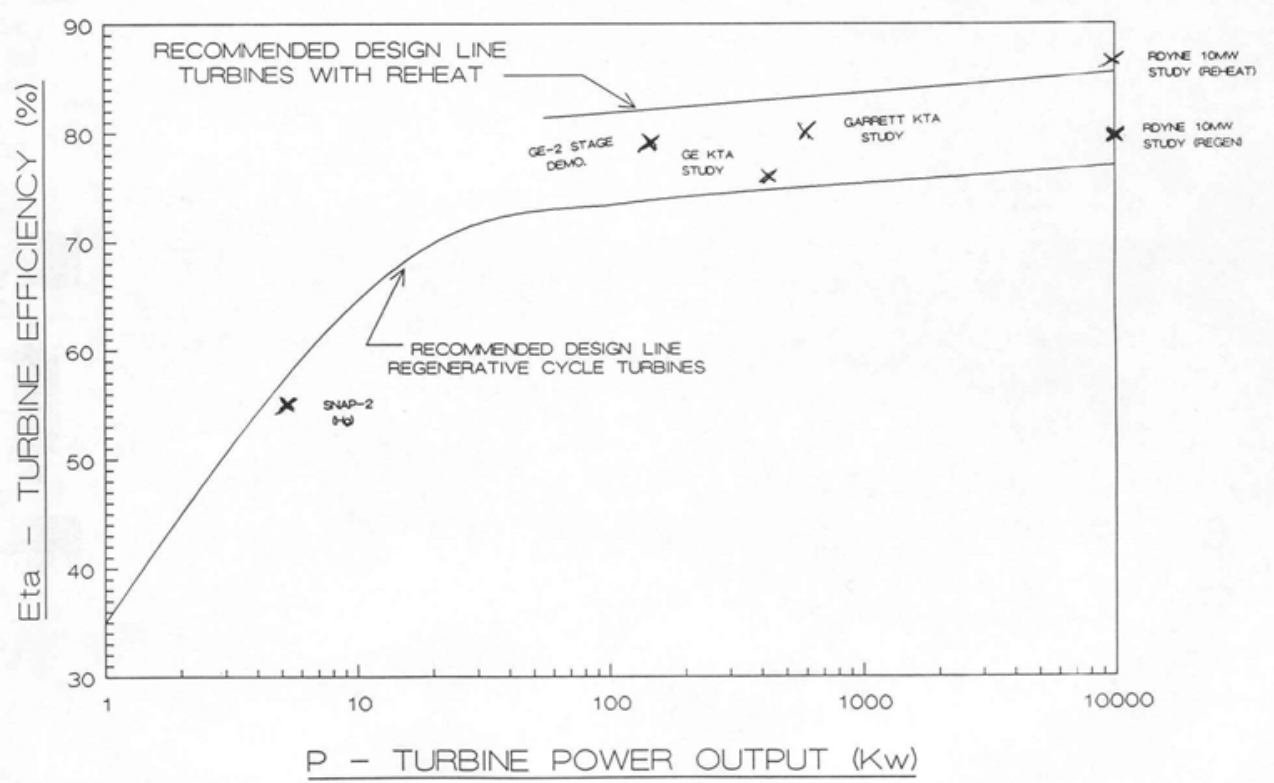

Fig. 4.12. Power turbine efficiency is driven by turbine power output.

Turbine mass was found to be well represented by the simple expression given as

$$
\mathrm{W}=7.0 * \mathrm{~T}^{* *} 0.6
$$

Where

$$
\begin{aligned}
& \mathrm{W}=\text { turbine mass }(\mathrm{lb}) \\
& \mathrm{T}=\text { turbine torque }(\mathrm{ft}-\mathrm{lb})
\end{aligned}
$$

Since

$$
\mathrm{T}=7043.0 * \mathrm{KW} / \mathrm{N}
$$

Where

$$
\begin{aligned}
& \mathrm{KW}=\text { turbine shaft power }(\mathrm{kW}) \\
& \mathrm{N}=\text { turbine } \mathrm{rpm}
\end{aligned}
$$

Then

$$
\mathrm{W}=1424.8 *(\mathrm{KW} / \mathrm{N}) * * 0.6
$$

These relationships do not define a turbine design, but they do provide sufficient information to proceed with system optimization and a design specification for the detailed design of the turbine. 


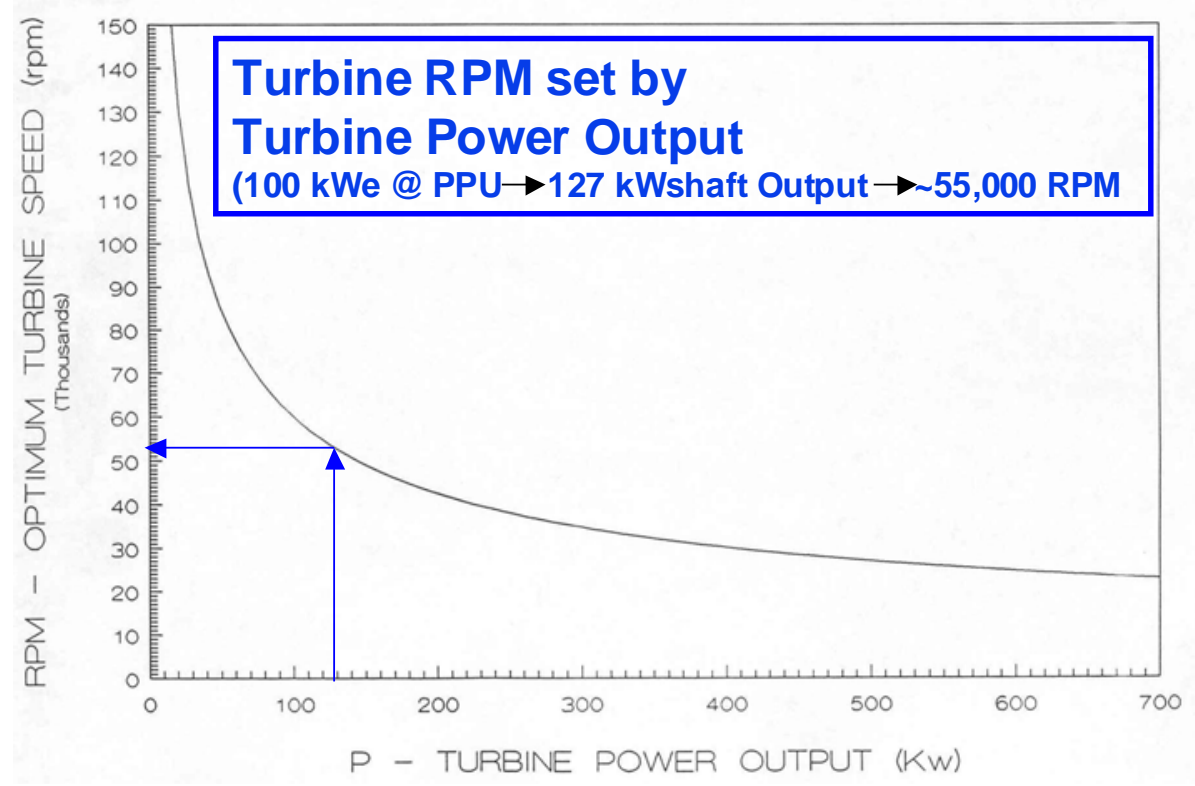

Fig. 4.13. Power turbine optimum speed is driven by shaft output power.

Figure 4.14 shows an approximate relationship between maximum allowable tip speed and number of stages in the turbine. Data collected to date do not support the use of tip speeds higher than $850 \mathrm{ft} / \mathrm{sec}(259 \mathrm{~m} / \mathrm{s})$. Therefore, $850 \mathrm{ft} / \mathrm{sec}(259 \mathrm{~m} / \mathrm{s})$ is recommended as the maximum allowable tip speed.

Figure 4.15 shows the conceptual design of a potassium power turbine designed to deliver a $100 \mathrm{~kW}_{\mathrm{e}}$ system power level in a single unit. The turbine uses nine expansion stages in order to observe the tip speed limit. The unit is very compact and should be easily integrated into the overall power system.

The preliminary material selection for the turbine is TZM alloy because most of the early test data were obtained with this alloy. Other potential alloy candidates for potassium turbines and wheels are $\mathrm{Nb}-1 \% \mathrm{Zr}$ (or CB 103), TZM, T-111, and ASTAR 811C or 1411C. The primary selection criteria would be specific creep strength normalized to the turbine inlet temperature. This parameter usually drives the selection of the turbine blade and disc materials toward the tantalum alloys (T-111 or ASTAR) at temperatures above about $1350 \mathrm{~K}$. 


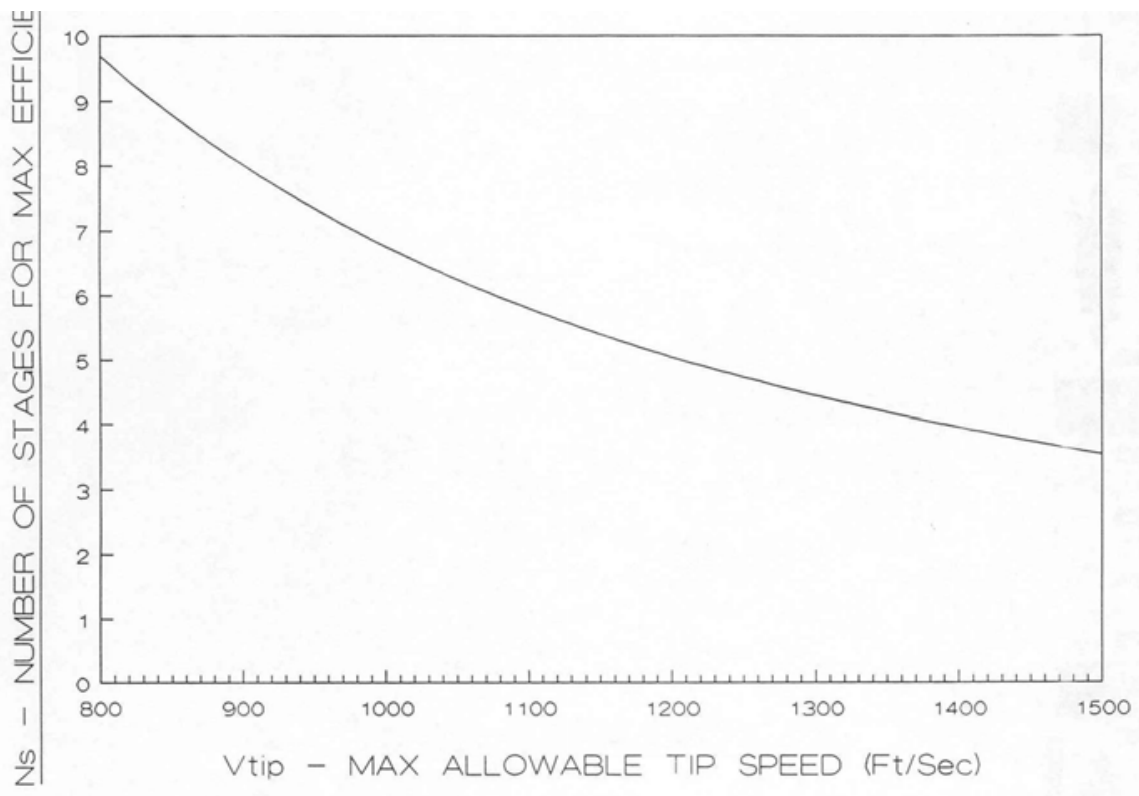

Fig. 4.14. Number of turbine stages is driven by maximum allowable tip speed.

Using molybdenum or tantalum alloys for moving blades and wheels of a turbine operating in liquid potassium systems that are contained in niobium alloys should not pose any mass transfer problems because they would be exposed primarily to potassium vapor and not liquid. (A small amount of liquid droplets would exist in some stages; however, its presence would be sufficiently transitory to preclude solution of the metal alloy elements into the potassium.) If the metal does not have an opportunity to dissolve in potassium, then constituent transport that often occurs in liquid metal systems does not occur.

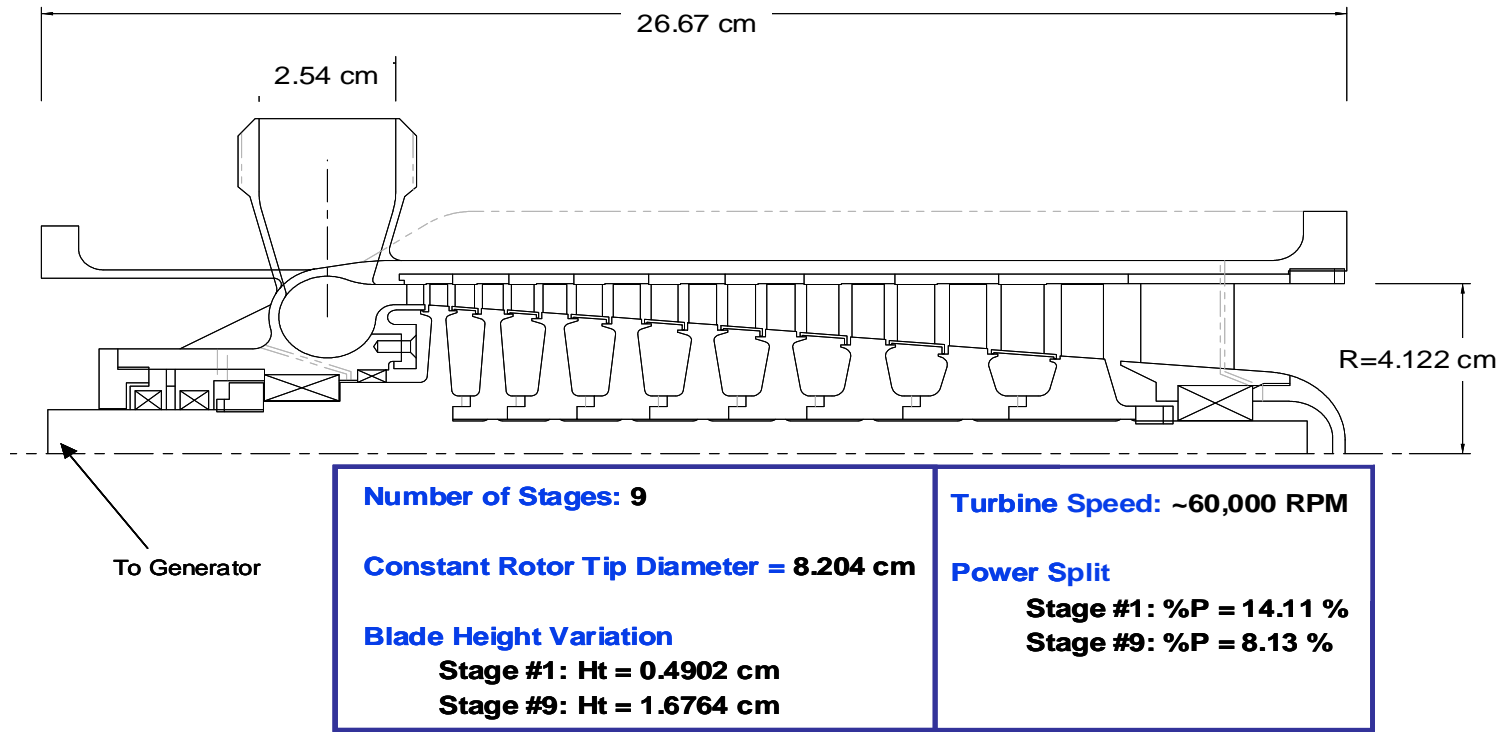

Fig. 4.15. Turbine design concept and characteristics. 


\subsection{ALTERNATOR}

\subsubsection{Configuration Selection}

Several alternator configurations were assessed during the Phase I study, including permanent magnet, Rice/Lundell, and homopolar inductor alternators.

Permanent magnet alternator: A field is generated by high-strength permanent magnets (PMs) with no voltage control. This alternator configuration has a fixed field resulting in fairly constant voltage at operating speed ( $\sim 10 \%$ voltage variation from no load to full load). Voltage regulation must be performed outside the alternator in the PMAD system. The PM alternator is highly efficient, 93 to $96 \%$, because of a short magnetic field path and because the absence of a field coil eliminates resistance losses in field coil windings. A 2000 Vrms L-L, 60,000 rpm PM alternator is considered TRL 6. Figure 4.16 shows the PM alternator construction.

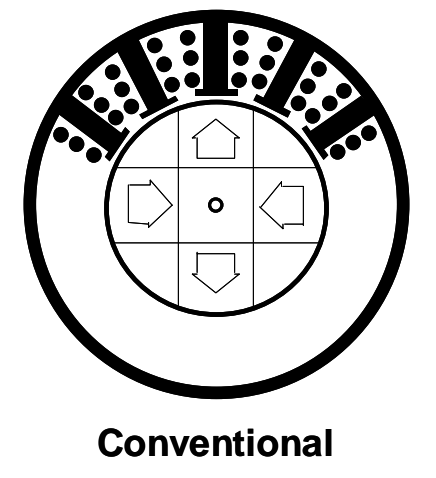

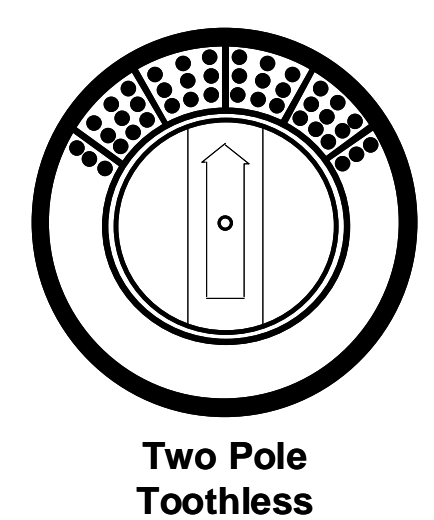

Fig. 4.16. Permanent magnet alternator construction.

Rice/Lundell Alternator: The Rice/Lundell alternator has a three-piece, high-strength brazed rotor construction. Field current is controllable from 0 to rated value, allowing generated voltage to be regulated to a fixed value over a wide speed range. The configuration has good efficiency, 89 to $92 \%$. Longer magnetic field path and field coil resistance losses result in lower efficiency than the PM machine. This alternator configuration is TRL 6 based on extensive testing of Rice/Lundell alternators in Brayton rotating unit, ground test demonstrator, and other test programs. The Rice/Lundell alternator has been commercially replaced by the PM alternator, and no known manufacturers currently exist. Figure 4.17 shows the Rice/Lundell alternator construction. 


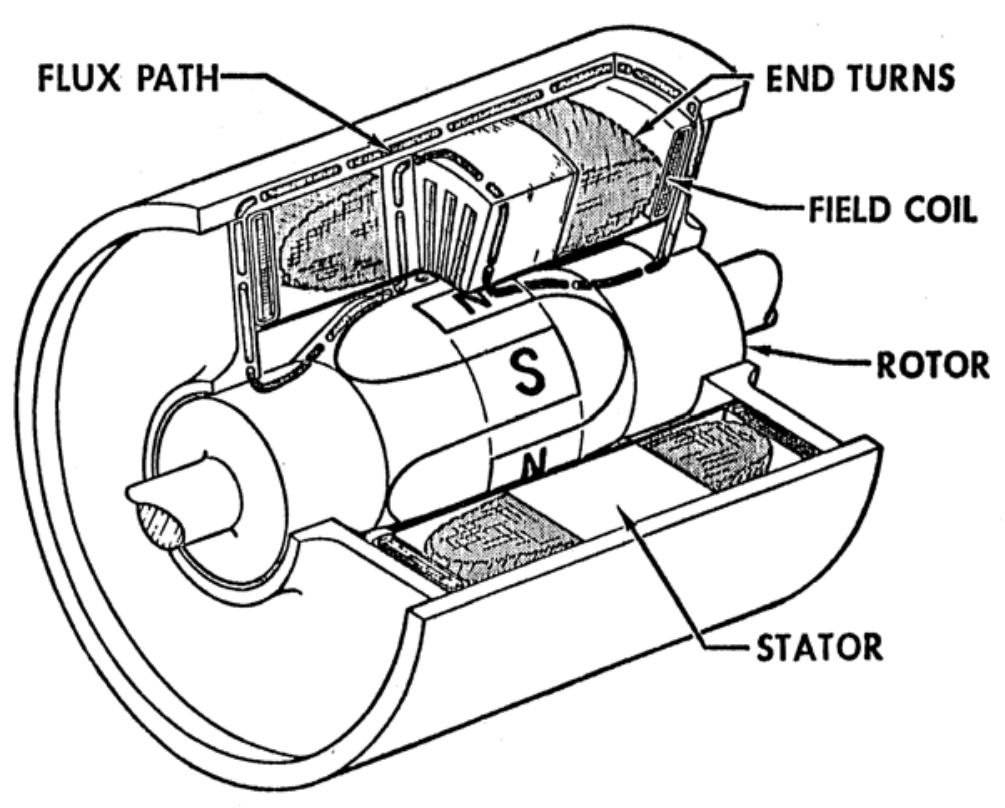

Fig. 4.17. Rice/Lundell alternator construction.

Homopolar inductor alternator: The homopolar inductor alternator uses a solid, forged rotor that is very robust and enables high-speed operation. It was determined to be the best alternator candidate for high-temperature operation $\left(500^{\circ}\right.$ to $\left.600^{\circ} \mathrm{C}\right)$ with liquid metal cooling. General Electric and Garrett developed $450-\mathrm{kW}_{\mathrm{e}}$ liquid-potassium-cooled designs under contract to the National Aeronautics and Space Administration (NASA) in the late 1960s, to early 1970s. Garrett began a 1.75-MWe liquid-lithium-cooled (stator) and potassium cooled (rotor) design for the multimegawatt program in 1985 but discontinued it because of temperature and electrical design problems that drove up its mass. Field current is controllable from 0 to rated value, allowing generated voltage to be regulated to a fixed value over a wide speed range. This configuration has fair efficiency, 86 to $90 \%$. The long magnetic field path and field coil resistance losses result in somewhat lower efficiency compared with other machines. The alternator was assessed to be TRL 5. No history of testing for space applications was noted in the review, but configurations have been operated in similarly demanding environments. The U.S. Army is a main customer. The homopolar inductor alternator is valued for military vehicles because of its ruggedness and ability to perform in adverse environments. The homopolar inductor alternator construction is shown in Section 4.4.3 (Fig. 4.18).

Table 4.3 shows a comparison of the three alternator configurations in terms of operating temperature capability, rotor peripheral speed limits, operating speed, and estimated specific mass for $100-\mathrm{kW}_{\mathrm{e}}$ machines. 
Table 4.3. Alternator configuration comparison indicates the homopolar inductor alternator is the best solution to meet the K-Rankine requirements and operating conditions

\begin{tabular}{|c|c|c|c|}
\hline & Permanent magnet (PM) & Rice/Lundell & Homopolar inductor \\
\hline $\begin{array}{l}\text { Hardware operating } \\
\text { temperature limits }\end{array}$ & $\begin{array}{l}\text { Samarium cobalt PM } \\
\text { limited to } \sim 250^{\circ} \mathrm{C} \\
(942 \mathrm{R})\end{array}$ & $\begin{array}{l}\text { Rotor limited to } \\
\sim 500^{\circ} \mathrm{C}(1392 \mathrm{R})\end{array}$ & $\begin{array}{l}\text { Rotor limited to } \sim 600^{\circ} \mathrm{C} \\
(1572 \mathrm{R})\end{array}$ \\
\hline \multirow[t]{2}{*}{$\begin{array}{l}\text { Insulation operating } \\
\text { temperature limits }\end{array}$} & $\begin{array}{l}\text { Standard class } \mathrm{H} \\
\text { insulations such as } \\
\text { Nomex limited to } 180^{\circ} \mathrm{C} \\
(816 \mathrm{R})\end{array}$ & $\begin{array}{l}\text { Glass-and ceramic- } \\
\text { based insulations such } \\
\text { as beryllium, alumina, } \\
\text { and anadur required at } \\
\text { operating temperatures } \\
\text { exceeding } \sim 400^{\circ} \mathrm{C} \\
(1212 \mathrm{R})\end{array}$ & $\begin{array}{l}\text { Glass-and ceramic-- } \\
\text { based insulations such } \\
\text { as beryllium, alumina, } \\
\text { and anadur required at } \\
\text { operating temperatures } \\
\text { exceeding } \sim 400^{\circ} \mathrm{C} \\
(1212 \mathrm{R})\end{array}$ \\
\hline & $\begin{array}{l}\text { Mica-, fiberglass-, glass-, } \\
\text { and or ceramic--based } \\
\text { insulations allow higher- } \\
\text { temperature operation but } \\
\text { lower maturity and less } \\
\text { life information }\end{array}$ & $\begin{array}{l}\text { Much less mature, } \\
\text { limited life information } \\
\text { and heritage }\end{array}$ & $\begin{array}{l}\text { Much less mature, } \\
\text { limited life information } \\
\text { and heritage }\end{array}$ \\
\hline $\begin{array}{l}\text { Rotor peripheral speed } \\
\text { Limit }\end{array}$ & $\sim 210 \mathrm{~m} / \mathrm{s}$ & $\sim 275 \mathrm{~m} / \mathrm{s}$ & $\sim 350 \mathrm{~m} / \mathrm{s}$ \\
\hline Operating speed limit ${ }^{\mathrm{a}}$ & $40,000 \mathrm{rpm}$ & $40,000 \mathrm{rpm}$ & $60,000 \mathrm{rpm}$ \\
\hline Specific mass ${ }^{\mathrm{a}}$ & 5 to $7 \mathrm{~kW}_{\mathrm{e}} / \mathrm{kg}$ & 3 to $4 \mathrm{~kW}_{\mathrm{e}} / \mathrm{kg}$ & 2 to $3 \mathrm{~kW}_{\mathrm{e}} / \mathrm{kg}$ \\
\hline
\end{tabular}

${ }^{a}$ Alternator speed and specific mass estimated for $100 \mathrm{kWe}$ machines. Operating speed can be increased at lower power levels, with specific mass decreasing.

The homopolar inductor alternator was found to be the best technical solution for the potassium Rankine cycle operating conditions because of its high operating temperature capability, simple rugged rotor design, one-piece forged rotor, and lack of windings. The configuration does show disadvantages, including lower specific power capability and lower technical maturity than the other configurations.

\subsubsection{Alternator Mass and Sizing Algorithms}

The alternator equations used in ALKASYS were revised based on three homopolar inductor alternator designs developed for the Army, one developed for the multimegawatt program by Allied Signal, and two liquid-metal-cooled designs developed under contract to NASA in the early 1960s by General Electric and Allied Signal, respectively.

ALKASYS calculates generator length, generator outer diameter, volume, and mass based on the following equations. New equations and values based on the recent assessment are shown. The original ALKASYS values are indicated in square brackets.

Rotational speed: $\quad \mathrm{v}=(\mathrm{DSL} / 0.356)^{0.5} \quad(\mathrm{~m})$

Design stress level: $\quad$ DSL $=32,000$ psi for steel rotor

Rotor diameter: $\quad \mathrm{D}_{\mathrm{R}}=32 \times(\mathrm{DSL})^{0.5} / \mathrm{rpm} \quad(\mathrm{m})$ 
Stator diameter: $\quad \mathrm{D}_{\mathrm{S}}=42.9 \times(\mathrm{DSL})^{0.5} / \mathrm{rpm} \quad(\mathrm{m})$

These equations are based on reference designs where the average stator diameter was approximately $34 \%$ larger than the rotor diameter.

The stator diameter coefficient was changed from 39.4 to 42.9 based on the designs reviewed that showed the ratio of stator outer diameter to rotor outer diameter in the range of 1.31 to 1.34 , instead of the 1.23 value used in ALKASYS. A value of 1.34 was selected because it matches the lowerpower $\left(95 \mathrm{~kW}_{\mathrm{e}}\right.$ and $\left.520 \mathrm{~kW}_{\mathrm{e}}\right)$ machine data better. These power levels are more within the range of interest of the current potassium Rankine power conversion system program.

Power factor: $\quad$ pf $=0.85$

The power factor is used to convert electric power output (real power) to alternator complex power (measured in $\mathrm{kVA}$ ) that is used to calculate alternator sizing and mass. The electric output power term, "P", is the same term used in the original ALKASYS equations.

$$
\begin{array}{lll}
\text { Generator complex power: } & \mathrm{P}_{\mathrm{CPLX}}=\mathrm{P} / \mathrm{pf} \quad(\mathrm{kVA}) \\
& \mathrm{P}_{\mathrm{CPLX}}=\mathrm{K} \times \mathrm{D}_{\mathrm{S}}{ }^{2} \times \mathrm{L}_{\mathrm{S}} \times \mathrm{rpm} \quad(\mathrm{kVA})
\end{array}
$$

The use of complex power and a power factor of 0.85 results in the alternator being sized for approximately $18 \%$ higher kilo-voltamperes.

Proportionality constant: $\quad \mathrm{K}=0.6$ in ALKASYS $\quad$ (kVA-min/m3-rev)

Based on range of 0.36 to 0.68 from reference designs.

The proportionality constant was changed from 1.0 to 0.6 . The values calculated for the different designs reviewed ranging from 0.36 to 0.68 . 0.6, yielded the best rotor length and machine volume values.

Stator length: $\quad \mathrm{L}_{\mathrm{S}}=\mathrm{P}_{\mathrm{CPLX}} \times \mathrm{rpm} /(\mathrm{K} \times 1840 \times \mathrm{DSL}) \quad(\mathrm{m})$

The changes and corrections above modify the factor used to calculate the stator length from 1552 to 1840 .

Alternator density: $\quad \rho_{\mathrm{S}}=7920 \mathrm{~kg} / \mathrm{m}^{3}$

The alternator average density was changed from 3850 to $7920 \mathrm{~kg} / \mathrm{m}^{3}$. The alternator is mainly composed of magnetic iron and copper that have densities of about 7650 and $8890 \mathrm{~kg} / \mathrm{m}^{3}$, respectively. An overall density 
was calculated from estimated proportions of these materials. Upon review, it was unclear from where the density value of $3850 \mathrm{~kg} / \mathrm{m}^{3}$ used in ALKASYS originated. An alternator is relatively solid, and even though the materials vary, they all have fairly similar densities.

The density of the alternator is based on the material densities and proportions shown in Table 4.4.

Table 4.4. Homopolar inductor alternator density estimation

\begin{tabular}{lcc}
\hline \multicolumn{2}{c}{ Alternator density estimation } \\
Construction material & Density & \% of Unit \\
\hline Density of magnetic iron - M15 (g/cm3) & 7.65 & $64 \%$ \\
Density of nickel - coated copper (g/cm3) & 8.89 & $34 \%$ \\
Density of insulation - alumina (g/cm3) & 4.6 & $2 \%$ \\
Calculated density of machine (g/cm3) & 7.920 & $100 \%$ \\
Allied Signal estimated density (g/cm3) & 3.85 & \\
\hline
\end{tabular}

The following relationships are presently used in the ALKASYS code.

Overhead factor: $\quad \mathrm{OVHDF}=\left(\mathrm{P}_{\mathrm{CPLX}} / 1784\right)^{-0.1 * 1.2}$

An overhead factor was developed to replace the previous density factor used in ALKASYS. The term "overhead factor" was used because this factor is supposed to account for the masses of the alternator elements beyond the machine's electromagnetic mass. It appeared that the previous factor had not included the masses of the field coils and housing.

Experience indicates that the mass of these overhead elements becomes a larger portion of the machine's mass at lower power levels. The overhead mass of these elements was estimated, and an equation to replace the previous fixed factor was developed as shown above.

An addition was applied for shaft extensions, bearings, field coils, housing, etc. An equation was developed to place a proportionally larger mass penalty on lower-powered machines for overhead items. Overhead factor varies from $\sim 1.8$ to $\sim 1.2$ for machines ranging from 30 to 1800 $\mathrm{kVA}$, respectively

Alternator mass: $\quad \mathrm{m}_{\mathrm{ALT}}=\mathrm{OVHDF} \times 7920 \times \pi / 4 \times \mathrm{DS}_{\mathrm{S}}^{2} \times \mathrm{L}_{\mathrm{S}}$

Substituting the equations above for OVHDF, $\mathrm{D}_{\mathrm{S}}$, and $\mathrm{L}_{\mathrm{S}}$, and simplifying yields the following equation for alternator mass as a function of rated power in $\mathrm{kVA}$ and operating speed in rpm.

Alternator mass: $\quad \mathrm{m}_{\mathrm{ALT}}=26300 \times \mathrm{P}_{\mathrm{CPLX}}{ }^{0.9} / \mathrm{rpm}$

Table 4.5 shows a summary of the alternator values for a $100-\mathrm{kW}_{\mathrm{e}}$ system calculated using the algorithms recommended by Rocketdyne based on this assessment. 
Table 4.5. Homopolar Inductor alternator mass calculations

\begin{tabular}{lllll}
\hline \multicolumn{1}{c}{ Term } & \multicolumn{1}{c}{ Units } & \multicolumn{1}{c}{ Calculated values } & \multicolumn{2}{c}{ Additional units } \\
\hline Design stress level & $\mathrm{DSL}(\mathrm{psi})$ & 32000 & 220 & $\mathrm{MPa}$ \\
rpm & $\mathrm{rpm}$ & 60000 & & \\
Rotational speed limit & $\mathrm{v}(\mathrm{m} / \mathrm{s})$ & 299.8 & 9.5 & $\mathrm{~cm}$ \\
Rotor diameter & $\mathrm{D}_{\mathrm{R}}(\mathrm{m})$ & 0.095 & 12.8 & $\mathrm{~cm}$ \\
Stator diameter & $\mathrm{D}_{\mathrm{S}}(\mathrm{m})$ & 0.128 & & \\
Proportionality constant & $\mathrm{K}\left(\mathrm{kW}-\mathrm{min} / \mathrm{m}^{3}\right.$-rev) & 0.6 & & \\
Electric power output & $\mathrm{kWe}$ & 114 & & \\
Power factor & & 0.85 & 22.8 & $\mathrm{~cm}$ \\
Alternator complex power & $\mathrm{P}_{\mathrm{CPLX}}(\mathrm{kVA})$ & 134.1 & & \\
Stator length & $\mathrm{L}_{\mathrm{S}}(\mathrm{m})$ & 0.228 & & \\
Alternator volume & $\mathrm{m}^{3}$ & 0.0029 & & \\
Alternator material density & $\rho_{\mathrm{s}}\left(\mathrm{kg} / \mathrm{m}^{3}\right)$ & 7920 & & \\
Overhead factor & & 1.55 & & \\
Alternator mass & $\mathrm{m}_{\mathrm{ALT}}(\mathrm{kg})$ & 36.0 & & \\
\hline
\end{tabular}

The calculated mass of $36 \mathrm{~kg}$ for a $114-\mathrm{kW}_{\mathrm{e}}$ electric output power system [accounting for efficiency effects to provide $100 \mathrm{~kW}_{\mathrm{e}}$ to the thruster power processing units (PPUs)] is six times higher than the calculated mass based on the original ALKASYS equations. The significant driver in the mass increase is that the use of a corrected proportionality constant, stator diameter factor, and complex power factor result in a stator length 1.7 times longer than calculated using the old equations. The corresponding value for alternator volume is two times as high as the value calculated using the old algorithms. In addition, the updated value for average alternator material density is 2.05 times larger than the original value. The recommended overhead factor is also 1.3 times larger than the original value. The $114-\mathrm{kW}_{\mathrm{e}}$ alternator output power (to provide $100 \mathrm{kWe}$ at PPU) is 1.14 times higher than the original value. The combined product: $(2) \times$ $(2.05) \times(1.3) \times(1.14)=6$ result in the improved alternator mass value being six times higher than the old calculated value.

In summary, the revised equations yield mass values much closer to the masses of the reference designs reviewed and should provide a significant improvement for mass calculations of the alternator subsystem. In comparison with masses of alternators that have previously been built, the values predicted for the lower-power machines are low; but these machines were designed for terrestrial applications, and it is assumed that no significant attempt was made to optimize their masses. The values predicted for the 600- and 733-kVA machines are high; but these machines were designed on paper, and it is quite possible their masses would have grown as the design was developed. When graphical comparisons of the algorithm-calculated masses, volumes, and rotor lengths are compared with the reference design values, the algorithm calculated values tend to fall between the design case extremes and appear to yield fairly good results over the power range of interest.

\subsubsection{Alternator Concept Definition}

As stated, the homopolar inductor alternator was found to be the best technical solution for the potassium Rankine cycle operating conditions. It shows the advantages of high-operatingtemperature capability with the rotor limited to $\sim 600^{\circ} \mathrm{C}(1572 \mathrm{R})$, high operating speed capability 
with a rotor peripheral speed limit of $\sim 350 \mathrm{~m} / \mathrm{s}$, and an operating speed of $\sim 60,000 \mathrm{rpm}$ (for $100-\mathrm{kWe})$. It also provides a simple, rugged rotor design with a one-piece forged rotor and no windings.

Figure 4.18 shows a top-level concept layout of a homopolar inductor alternator sized for $100-\mathrm{kW}_{\mathrm{e}}$ power to thruster PPUs and provides some approximate dimensions.

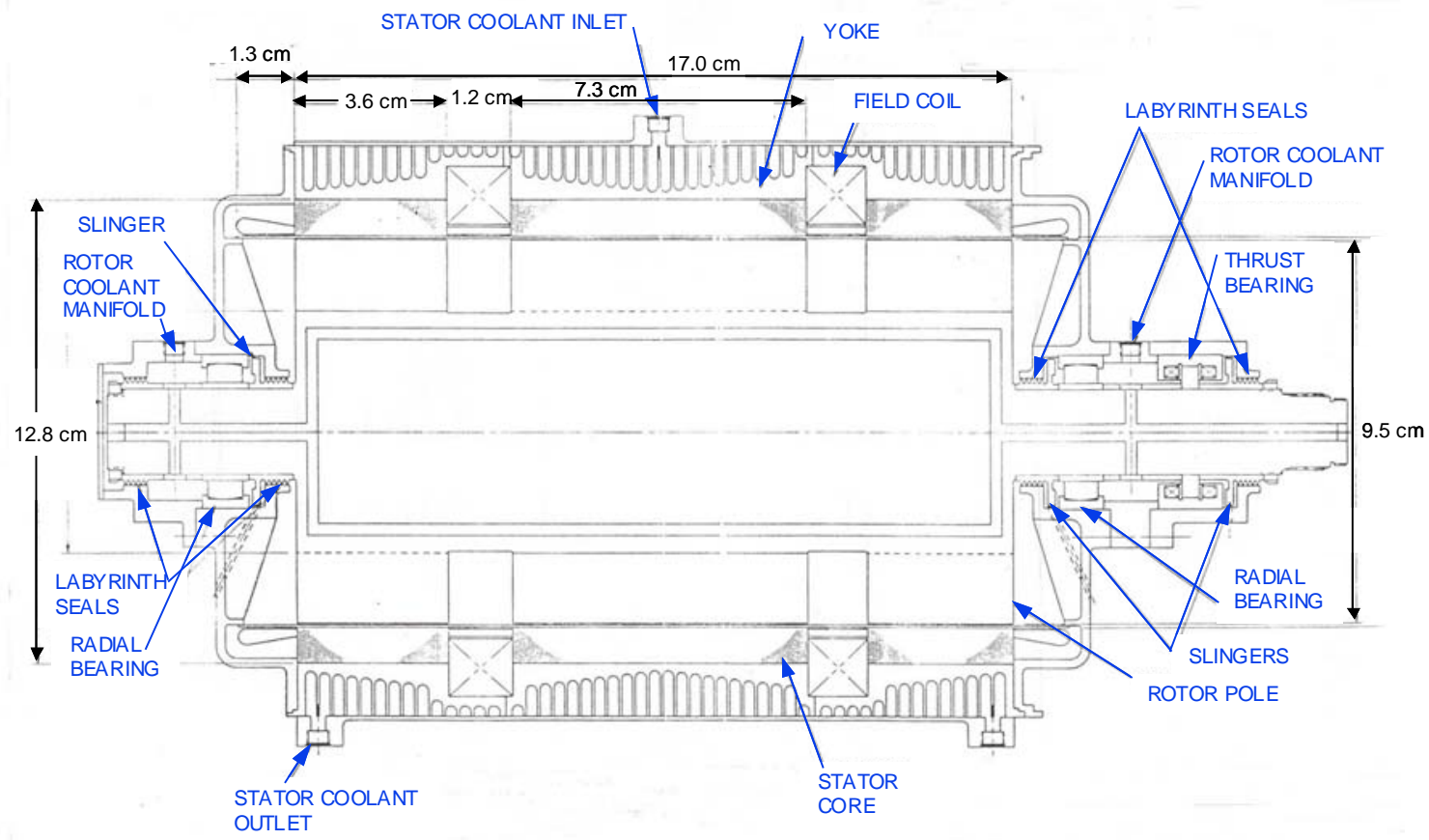

Fig. 4.18. Homopolar inductor alternator concept for $100-\mathrm{kW}_{\mathrm{e}}$ Power to thruster PPUs.

The alternator is coupled directly to the power turbine and is "canned" with the power turbine in a common housing to eliminate external rotating seals. Thermal isolation of the alternator from the turbine is provided by a low-conductivity coupling incorporated in the drive shaft. The alternator is isolated from the potassium in the turbine through a seal between the turbine and alternator. Potassium vapor at $600 \mathrm{~K}$ is used to cool the rotor of the alternator, while $600 \mathrm{~K}$ potassium liquid is used to cool the stator. 


\subsection{POWER MANAGEMENT AND DISTRIBUTION}

The PMAD system conducts the power produced by the potassium Rankine (K-Rankine) turboalternator to the payload area and distributes conditioned power to the thruster PPUs and spacecraft and mission module buses. It also regulates the bus voltage and controls the operating speed of the turboalternator by controlling the amount of generated power that is dissipated to space. Finally, it includes the drives that power and control the operation of the RFMD, auxiliary, and thermoelectric module (TEM) pumps. The TEM pump drive is only employed prior to reactor activation. After the reactor is started, the heat contained in the primary heat transport system coolant is sufficient to enable the embedded thermoelectric elements to supply the power the pump requires for operation.

The K-Rankine power system has two turboalternators, each sized to meet the power requirement of $100 \mathrm{~kW}_{\mathrm{e}}$, but only one unit operates at a time. This feature reduces the complexity of the PMAD system because the paralleling and load sharing control challenges present in a multi-channel system are eliminated with a single unit. But it is the heaviest approach because of the need to carry a second 100\%-rated PMAD channel. The transition from one turboalternator to the other also presents a unique challenge, because of the greater potential for interruption of the main power feed. During nominal operation, the transition shouldn't be difficult to perform, but an emergency turboalternator shutdown may be problematic, depending on the time it takes to activate the other unit. This issue needs to be studied further. Power would continue to be available to the critical loads (control computers, communications, guidance and navigation, etc.) from the auxiliary power bus, but there wouldn't be enough power to continue thrusting or meet the maximum science power and spacecraft power demand of approximately $17 \mathrm{~kW}_{\mathrm{e}}$. This power demand is based on an assumed science demand of $10 \mathrm{~kW}_{\mathrm{e}} ; 5.2 \mathrm{~kW}_{\mathrm{e}}$ combined to the RFMD and auxiliary pumps, and about $2 \mathrm{~kW}_{\mathrm{e}}$ to the spacecraft bus.

The K-Rankine PMAD system design uses de distribution. The voltage on the switchgear bus is approximately $1200 \mathrm{Vdc}$, resulting in an alternator voltage of about $900 \mathrm{Vrms}$ line-to-line (L-L). The rationale behind these selections and the requirements that lead to them are presented in the following sections, plus brief functional descriptions of the PMAD components.

\subsubsection{PMAD Requirements and Assumptions}

The higher-level PMAD requirements were developed from the requirements stated in the NASA Research Announcement (NRA) and related programs. Additional requirements were derived from mission analyses and spacecraft and science instrument power requirements to provide a more complete requirements database for architecture and technology assessments. The requirements are summarized in Table 4.6. 
Table 4.6 Top-Level PMAD Requirements

\begin{tabular}{lc}
\hline \multicolumn{1}{c}{ Parameter } & Requirement \\
\hline Power to electric propulsion system & $100 \mathrm{kWe}$, but scaleable to $250 \mathrm{~kW}_{\mathrm{e}}$ \\
Electric propulsion thruster voltage & 4.5 to $8 \mathrm{kVdc}$ \\
Vehicle launch date & 2015 (CDR est. 2010) \\
Power to mission module & \\
During science phase, no thrusting & $10 \mathrm{~kW}$ \\
During science phase, thrusting & $3 \mathrm{~kW}_{\mathrm{e}}$ \\
Reliability & 1 fault tolerant \\
Radiation at S/C bus & \\
Total integrated dose & $500 \mathrm{krad}^{\mathrm{a}}(\mathrm{Si})$ \\
Displacement damage dose & 2 \\
Radiation design factor & $5 \times 10^{11} \mathrm{~N} / \mathrm{cm}^{2}(1 \mathrm{MeV} \mathrm{Si})$ \\
\hline
\end{tabular}

${ }^{a}$ Separate shielding for the electronics would be required to meet this dose level. Electronics shield mass was not included in the mass estimates since shielding must also be used to protect the science instruments, thruster power processing units, etc.

Many PMAD design requirements and interfaces were undefined, making it necessary to assume values for certain items. These assumptions are only intended to provide a framework to perform the analyses, and alternate values can be incorporated. The following assumptions were used to support the PMAD assessments:

1. The PMAD system contains the elements required to provide vehicle and power system startup power, except motoring the turboalternators, multi-junction cell solar array, lithium-polymer battery, and electronics (included in the auxiliary power subsystem).

2. Autonomous control shall be used to control the dissipation of power generated in excess of load demand, alternator speed regulation, and bus voltage regulation.

3. Spacecraft and mission module bus voltage is $30 \mathrm{Vdc}$.

4. Combined spacecraft $30-\mathrm{V}$ bus load (GN\&C, C\&DH, ACS, etc.) is $1 \mathrm{~kW}_{\mathrm{e}}$.

5. High-power communications is assumed to draw $1 \mathrm{kWe}$ at the main distribution bus voltage.

6. RFMD pump requires $5 \mathrm{~kW}_{\mathrm{e}}, 3$-phase, $300 \mathrm{Vrms} \mathrm{L}-\mathrm{L}, 60-\mathrm{Hz}$ ac power.

7. Auxiliary pump requires $200 \mathrm{~W}_{\mathrm{e}}, 3$-phase, $300 \mathrm{Vrms} \mathrm{L-L}, 60-\mathrm{Hz}$ ac power.

8. The reactor primary heat transport system (PHTS) assumes TEM pumps provide reactor coolant flow. Nominally the heat in the coolant powers the TEM pump, but prior to reactor startup $70 \mathrm{~W}$ must be supplied to operate the pump to prevent the PHTS coolant from freezing.

These assumptions were used to define the PMAD system architecture and to develop a model of the PMAD system. Additional ground rules and assumptions were employed to 
develop the ALKASYS equations, and they are contained in the section covering the ALKASYS equation development.

\subsection{2 dc versus ac PMAD System Considerations}

Two forms of power distribution are available, an ac system that distributes power at the alternator output voltage and frequency and a dc system that uses a rectifier to convert the alternator ac output to dc. A dc system tends to be best if the alternator frequency is relatively low $(<1 \mathrm{kHz})$, while an ac system provides mass and efficiency benefits at higher frequencies $(>5 \mathrm{kHz})$. The homopolar alternator is inherently a high-frequency alternator. A frequency of $6 \mathrm{kHz}$ was assumed for the PMAD studies based on an operating speed of $60 \mathrm{krpm}$ and a 10-pole rotor construction. The ability of the alternator to provide a $6-\mathrm{kHz}$ output frequency needs to be studied as part of a comprehensive alternator design study. Homopolar inductor alternator rotor designs with more than 10 poles have been constructed in the past, but the stator magnetic iron losses may be unacceptably high at $6 \mathrm{kHz}$ or higher frequencies. High-temperature operation limits the number of suitable magnetic iron materials; the result is that there may be significant limitations on how thin the laminations can be made. Machines in this power and frequency range have been constructed, but for low-temperature operation. For example, a lowtemperature, 95-kVA, 39-krpm, 3.2-kHz, 10-pole unit was built for the Army around 1975. Very-high-frequency, 10- to 100-kHz, homopolar inductor machines have also been constructed for metal working applications that employ induction heating; but again these are low-temperature machines.

Even though ac distribution has potential mass advantages, a dc system was selected for this study based on the advantages it has over an ac system when power must be transferred from one unit to the other. Although the transition should be relatively straightforward for dc and ac systems during nominal operation, emergency turboalternator shutdown and activation presents some challenges and needs to be studied further. An overview of the power transfer scenarios for dc and ac systems during nominal and emergency operation is provided to reveal the potential problems and present the rationale for selecting a dc PMAD system.

The output of the alternators is rectified in a dc system, so it isn't necessary for them to operate in synchronism. Therefore, assuming the field controllers hold the alternator field flux densities at the default levels corresponding to full voltage, the output voltage of the unit being accelerated to speed will reach that of the unit already operating. When the two voltages are exactly equal, the two units evenly share the load. The potassium flow to the previously operating turboalternator can then be shut off, causing that unit to gradually slow down. As it slows down, the load is picked up by the new unit, resulting in a smooth power transfer from the first unit to the second. During an emergency that requires an immediate shutdown of the operating turboalternator, the main power feed isn't available while the new unit is being brought up to speed. As noted earlier, the auxiliary bus continues supplying critical loads, and the time to bring the new unit on line should be brief; but there wouldn't be enough power to continue thrusting or supplying the maximum science load. This may be acceptable, because an emergency shutdown would likely only happen once during the mission; but the implications of a power interruption must be considered.

An ac system requires the alternators to operate in synchronism while the load is transferred between units. This is doable - alternators are routinely synchronized in terrestrial applications to enable paralleling — but it does require precise timing. It is again assumed that the flux densities of both units are held at the values corresponding to full voltage. This is required 
so that the units can be loaded by the speed regulator-parasitic load radiator (PLR) to control their speed. If the alternator flux coils aren't energized, the alternators can't produce any power, and there wouldn't be any way of imposing a braking torque to prevent the turboalternators from accelerating out of control. The new unit would again be accelerated up to nominal speed, but its full load output would initially have to be placed on the PLR while it is synchronized with the already operating unit. The speed regulator would synchronize a unit by adding or removing some load to change its operating speed and phase relationship with the other unit. Once the units are synchronized, a switch would be closed to temporarily tie the two units together. This would cause the new unit's speed regulator to quickly remove the portion of the PLR load equal to the now imposed spacecraft load, while the operating unit would initially see half its load removed. This portion of the load would now have to be assumed by the PLR. There would be a power transient when the switch is closed and the PLRs are rebalancing the load, but it shouldn't be excessive if the units are properly synchronized, and it should be quite brief. The time the speed regulator-PLR takes to rebalance the load should be under 20 milliseconds, which wouldn't be long enough to cause any significant change in the speed of the turboalternators. The 20-millisecond response time referenced here has been demonstrated during the testing of Brayton systems.

The biggest problem with transferring the load from one unit to the other again occurs during an emergency shutdown. Because the speed of the failing unit is potentially declining quickly, there wouldn't be any point in trying to synchronize with it to perform an orderly power transfer. Instead, it would probably be best to quickly transfer its load to the PLR to avoid a voltage drop on the main bus that could damage the PPUs and load converters (a brownout). Consequently, the system would be without the main power feed for an even longer time than with a dc system. Potentially this would be acceptable, but the implications of this longer power interruption must be considered. Because of the greater difficulties in performing a power transfer with an ac system, and the potential for a longer main power outage during an emergency situation, a dc PMAD system was selected. This decision should be revisited when the alternator properties are determined, the operational scenarios are better defined, and the implications of a main power feed interruption have been evaluated.

\subsubsection{Distribution Voltage Selection}

The distribution voltage to use for the PMAD system is difficult to select because of several competing effects. High-voltage distribution is advantageous to reduce transmission line conductor mass. But the thickness of the insulation must be increased to keep the design working voltage (DWV) or voltage stress within acceptable limits to meet the mission life. Other challenges arise with high-voltage distribution that must be resolved before a reliable, long-life system can be built. The primary issues are availability of parts and insulation material and corona control. These issues are compounded by the extreme radiation environment, which severely limits the choices of suitable parts and insulation materials. These issues were addressed during the Brayton $\mathrm{NRA}^{16}$, and this analysis was heavily relied on to determine the optimum distribution voltage for the K-Rankine NRA system

The highest distribution voltage widely employed to date on a space platform is the nominal $160 \mathrm{Vdc}$ used on the International Space Station (ISS). To assess the effects of voltage on cable mass, a detailed cable model was developed and the cable mass was calculated for a series of insulation DWVs for a 40-m-long, 6-phase cable designed to conduct $25-\mathrm{kW}_{\mathrm{e}}$. The 25 - 
$\mathrm{kW}_{\mathrm{e}}$ power level roughly matches the channel power level in the Brayton NRA system. The Brayton NRA architecture has five channels, but only four are required to provide full power. Normally the fifth channel doesn't operate. The results of this assessment are shown in Fig. 4.19. Based on the steep increase in cable conductor mass below $500 \mathrm{~V}$, a nuclear electric power (NEP) PMAD system should use a higher voltage to keep the cable mass within acceptable limits.

Cable mass also varies significantly with the insulation DWV. The ISS cables are limited to a maximum DWV of $37 \mathrm{~V} / \mathrm{mil}$, including the required derating factor of 2 . But recent vendor data indicate cable designs are capable of higher DWVs, in the range of 100 to $200 \mathrm{~V} / \mathrm{mil}$ for aerospace applications (with a derating factor of 2.) These DWVs yield a minimum cable mass within the range of 1000 to $2000 \mathrm{Vrms} \mathrm{L}-\mathrm{L}$. The conductor mass increases at voltages below this, while the mass of the cable insulation increases at higher voltages. Based on data indicating a cable could be developed that is capable of withstanding the radiation received during a Jupiter mission, and a required derating factor of 2, a DWV of $150 \mathrm{~V} / \mathrm{mil}$ was employed in subsequent system analyses. An accelerated test is necessary to demonstrate this DWV in a relevant environment over a simulated mission life.

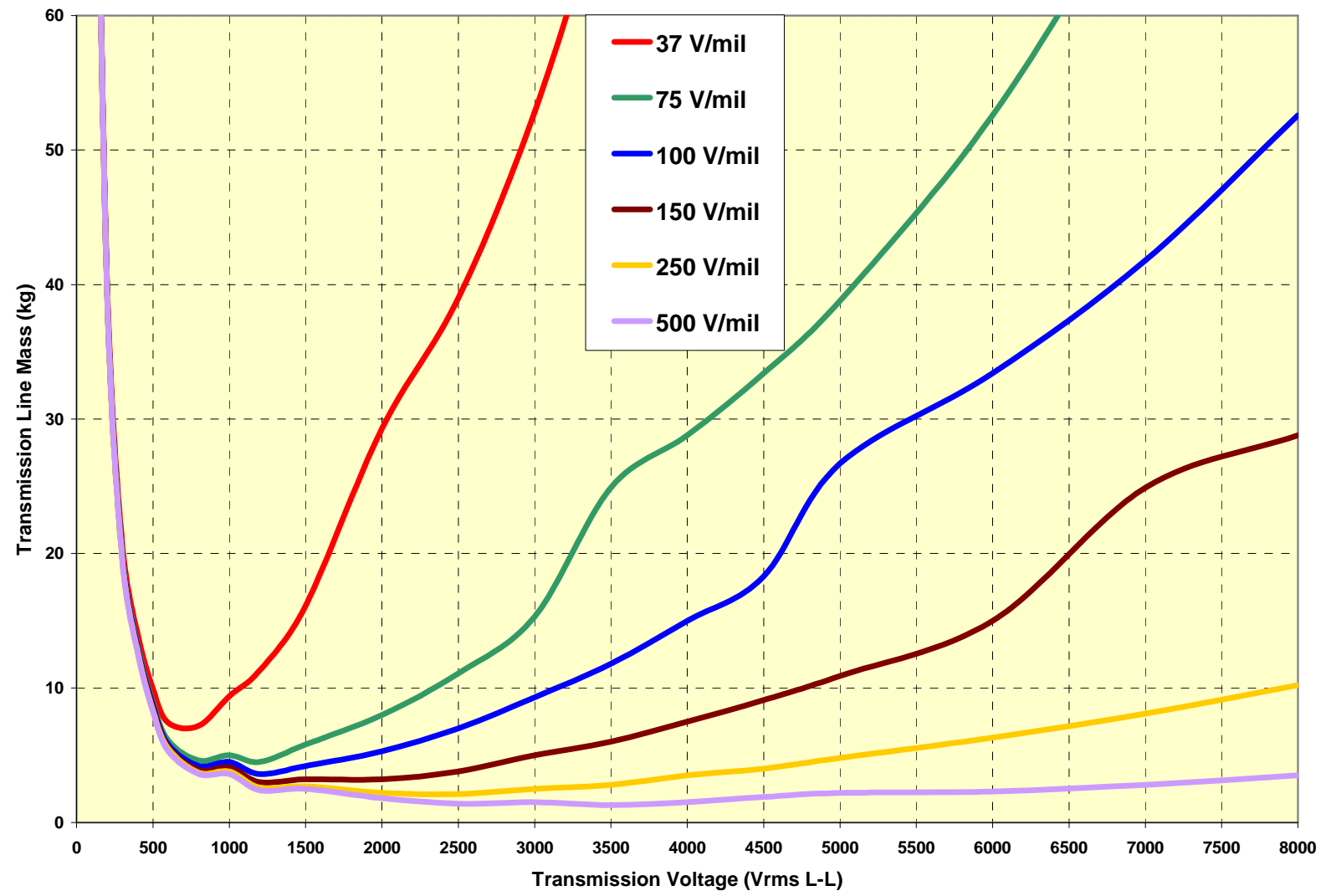

Fig. 4.19. Cable mass versus insulation working voltage.

The cable insulating materials are acted on by corona, displacement damage, ionizing radiation, and charges introduced by high-energy electrons. These phenomena degrade their mechanical and dielectric properties. The combined effects sharply limit the types of insulations that can be employed. Several insulation materials were evaluated for characteristics such as 
mass, radiation tolerance, voltage capability, temperature tolerance, and flexibility during the Brayton NRA study. Based on this assessment, Tefzel and Kapton were selected for further study. Tefzel insulation was used for the ISS cables. Kapton insulation is widely used in components and to a lesser degree for conductor insulation. It is lighter than Tefzel, has a higher radiation tolerance and temperature capability, and is more flexible. But Kapton is susceptible to arc tracking in the presence of moisture. Because moisture wouldn't be present on the K-Rankine vehicle, this weakness shouldn't pose a problem as long as proper care is used in handling the cables during manufacture, assembly, and testing. Consequently, Kapton was selected.

The number of suitable parts is limited by the combination of high radiation and voltage levels. The preferred high-voltage converter switches, silicon (Si) insulated gate bipolar transistors (IGBTs) and metal oxide switch field effect transistors (MOSFETs) utilize oxide semiconductor insulators that break down under radiation. Bipolar junction transistors (BJTs) don't have oxide insulators, and they withstand radiation better. But IGBTs have supplanted BJTs because they have better characteristics for most applications. It is no longer possible to purchase high-voltage, high-power BJTs. After conducting a survey of semiconductor parts manufacturers, it was concluded no Si switches currently being manufactured were suitable for the K-Rankine NRA requirements. But wide bandgap silicon carbide ( $\mathrm{SiC}$ ) switches under development offer an attractive alternative to Si switches. They can withstand 10-100 times the radiation levels, are capable of higher switching speeds and power densities, operate at $300^{\circ} \mathrm{C}$, and are capable of high operating voltages. For these reasons, $\mathrm{SiC}$ power switches were chosen for the K-Rankine PMAD system design.

After optimizing on mass and efficiency, and considering high-voltage, rad-hard parts availability and high-voltage corona effects, a dc PMAD system with a 1200-Vdc bus supplied by a 3-phase Y-connected, 900-Vrms L-L homopolar inductor alternator was selected for the KRankine PMAD system.

\subsubsection{Component Functions and Description}

The reactor basically provides a constant thermal input to the K-Rankine turboalternator, which requires it to operate at a constant power output rather than in a load-following mode. Power generated in excess of load demand is dissipated in a series of parasitic load resistors and radiated to space. This is the function of the PLR, which is basically a bank of resistors bonded to a carbon-carbon plate. The back side of this plate is insulated to reduce the heat flux radiated back to the spacecraft. The shunt regulator maintains a constant load on the alternator and controls its speed by adjusting the PLR load. Speed control is accomplished by monitoring load current and alternator speed. Load current is sensed to allow the PLR load to be quickly adjusted to compensate for changes in thruster or payload power demand. Because speed changes take longer to occur, speed feedback is used as a trim.

Both of the alternators are followed by full wave rectifiers to convert their ac output into dc. If the current system, with one channel operating at a time, is retained, a diode rectifier would be adequate. But if a multi-channel system is adopted to reduce mass, a phase control rectifier would be better to facilitate paralleling. The masses of the two rectifier designs are similar, but the diode rectifier is simpler and thus more reliable. A diode-based fault isolator follows the rectifier. It is included to provide a redundant means of fault isolation between the alternator and switchgear bus. If a rectifier diode should break down and cause an alternator L-L short, the fault isolator would maintain isolation between the switchgear bus and the fault. That alternator 
wouldn't be usable, but it would still be possible to activate the other alternator and connect it to the switchgear bus to provide system power. If the system didn't have the fault isolator and the switchgear bus was shorted, the system wouldn't be usable because any attempt to activate the second alternator and connect it to the switchgear bus would simply short it out.

The switchgear unit consists of a power bus and several fault isolator switches. Normally all the switches would be closed to allow any load, such as a PPU-thruster or converter, to draw power. But if a fault should occur in a PPU, converter, or pump drive, the switchgear fault isolator feeding it would open-isolating the power system from the fault - to allow continued operation. The fault isolators also allow the system to disconnect from a malfunctioning unit.

Redundant dc/dc converters are employed to convert the 1200-Vdc switchgear bus voltage to $30 \mathrm{Vdc}$ for most of the spacecraft loads and the mission module loads. Redundant drives to power and control the operation of the RFMD, auxiliary, and TEM pumps are also included. The RFMD and auxiliary drives nominally provide 3-phase, $300 \mathrm{Vrms}$ L-L power to those pumps. But the drive inverters employ pulse-width-modulation switching so that the pump frequency to be controlled ranges from 0 to $60 \mathrm{~Hz}$. This enables the pump speed to be ramped up from 0 to full speed and allows the pumps to be operated at any speed in between.

\subsubsection{PMAD, Instrumentation and Control, and Auxiliary Power ALKASYS Equations}

The PMAD-related equations used in ALKASYS were revised. Separate mass algorithms were developed for the PMAD subsystem, the instrumentation and control subsystem, and the auxiliary power subsystem.

\subsubsection{Ground Rules and Assumptions}

1. Output electrical power $(\mathrm{P})$ is defined in $\mathrm{kW}_{\mathrm{e}}$ at the input to the thruster PPUs.

2. Power values must be limited to 100 to $300 \mathrm{~kW}_{\mathrm{e}}$ to remain within the applicable range of these equations.

3. The RFMD, auxiliary, and thermoelectric electromagnetic pump power demands are assumed to be $5 \mathrm{~kW}_{\mathrm{e}}, 200 \mathrm{~W}_{\mathrm{e}}$, and $70 \mathrm{~W}_{\mathrm{e}}$, respectively for a $100-\mathrm{kW}_{\mathrm{e}}-$ rated PMAD system.

4. Pump power demands are assumed to scale by the square root of the PMAD system output power level. For example, the RFMD power demand with a $200-\mathrm{kW}_{\mathrm{e}}$ PMAD system power output is $(200 / 100){ }^{0.5} * 5=7.07 \mathrm{~kW}_{\mathrm{e}}$.

5. Equations for PMAD efficiency and alternator output power are also provided.

Equations for the PMAD subsystem were developed for several channel configurations for redundancy considerations.

\subsubsection{Channel Definition}

The channel configuration is identified as $\mathrm{X} / \mathrm{Y}$ where $\mathrm{X}$ is the total number of channels with Y channels required to meet the specified electric output power. For example, a 2/1 channel configuration for $100-\mathrm{kW}_{\mathrm{e}}$ indicates that each of two channels is sized to accommodate $100 \mathrm{~kW}_{\mathrm{e}}$, 
and one of the two is redundant. A $4 / 3$ channel configuration for $100 \mathrm{~kW}_{\mathrm{e}}$ means that each channel would be sized for $33.3 \mathrm{~kW}_{\mathrm{e}}$ with one redundant channel.

\subsubsection{PMAD Subsystem Mass Equations}

The PMAD subsystem mass is a function of the total thruster power at the PPU input. The following equations enable calculations of the PMAD mass based on the desired level of redundancy.
1/1 Channel Configuration
Mass $(\mathrm{kg})=358 \times(\mathrm{P} / 100)^{0.643}+(\mathrm{P} / 185)^{8.9}$
2/1 Channel Configuration
Mass $(\mathrm{kg})=463 \times(\mathrm{P} / 100)^{0.691}+(\mathrm{P} / 160)^{7.68}$
3/2 Channel Configuration
Mass $(\mathrm{kg})=444 \times(\mathrm{P} / 100)^{0.61}+(\mathrm{P} / 185)^{8.85}$
4/3 Channel Configuration
Mass $(\mathrm{kg})=453 \times(\mathrm{P} / 100)^{0.58}+(\mathrm{P} / 185)^{7.75}$
5/4 Channel Configuration
Mass $(\mathrm{kg})=463 \times(\mathrm{P} / 100)^{0.548}+(\mathrm{P} / 160)^{7.03}$
6/5 Channel Configuration
Mass $(\mathrm{kg})=474 \times(\mathrm{P} / 100)^{0.581}+(\mathrm{P} / 185)^{6.55}$

The mass of the core PMAD system for a $100-\mathrm{kW}_{\mathrm{e}}$ vehicle with a $2 / 1$ channel configuration, which is the current baseline, is $463 \mathrm{~kg}$.

\subsubsection{Instrumentation and Control Subsystem Mass Equation}

The instrumentation and control (I\&C) subsystem includes the MUX, cabling, power system controller, sensor, reflector stepper motors, and stepper motor drives. These units are required to control and monitor power system operation. The following equation calculates instrumentation and control subsystem mass as a function of the power input to the PPUs.

Mass $(\mathrm{kg})=129 \times(\mathrm{P} / 100)^{0.26}$

The mass of the instrumentation and control subsystem for a $100-\mathrm{kW}_{\mathrm{e}}$ vehicle is $129 \mathrm{~kg}$.

\subsubsection{Auxiliary Power Subsystem Mass Equations}

The auxiliary power subsystem (APS) includes the solar array, battery, and electronics required for vehicle and power system activation. During launch and ascent, the APS mainly supplies power to the controller monitoring the system. After the spacecraft reaches a nuclear safe trajectory and receives a signal to start the reactor, the APS would supply the power required to operate the reactor control drums or reflectors and to command and monitor the activation of the reactor and the remaining vehicle subsystems until the turboalternator and PMAD system are operating and supplying vehicle power. The following equation was used to estimate APS mass as a function of the power input to the PPUs.

$\operatorname{Mass}(\mathrm{kg})=112 \times(\mathrm{P} / 100)^{0.44}$

The mass of the APS for a $100 \mathrm{~kW}_{\mathrm{e}}$ vehicle is $112 \mathrm{~kg}$.

\subsubsection{PMAD Efficiency and Input Power Equations}

The efficiency of the PMAD subsystem dictates the power output required from the alternator to supply the specified total thruster power (at the PPU input). The efficiency term is 
shown as a function of power. Based on 100-kWe power to the PPUs, the power output required from the alternator is approximately $114 \mathrm{kWe}$.

PMAD efficiency $(\mathrm{PMADEFF})=0.878 \times(\mathrm{P} / 100)^{0.035}$

Alternator output power [PMAD input power] $\left(\mathrm{kW}_{\mathrm{e}}\right)=\mathrm{P} / \mathrm{PMADEFF}$

For the $100-\mathrm{kW}_{\mathrm{e}}$ system, with redundant Rankine cycle PCSs, the PMAD system consists of the following components:

- 2 phase control rectifiers: Individual fine speed control of turboalternator

- 1 shunt regulator: Voltage regulation, speed control, PLR shunt control

- 1 PLR: Excess power dissipation

- 2 fault isolator diodes: Alternator fault isolation

- 1 switchgear unit: Main bus switching and primary feed fault isolation

- 2 startup inverters: Motor turboalternators to self-sustaining speed

- 2 RFMD pump inverters: Drive RFMD pumps

- 2 TEM pump converters: Drive TEM Pump prior to reactor activation

- 230 Vdc converters: Supply 30 Vdc spacecraft and mission module loads

Auxilliary power systems include

- Solar array: Supplies vehicle/reactor startup power and 30-Vdc bus during insolation prior to reactor startup

- Battery: Supplies vehicle/reactor startup power and 30-Vdc bus during eclipse prior to reactor startup

- Electronics: Controls array and battery operation and provides switching and fault isolation, health monitoring, and data bus interface

And instrumentation and control elements include

- 1 power system Controller: Autonomously control and monitor power system

- 8 multiplexers: Multiplex reactor and PC sensor signals to reduce cabling

- 6 stepper motors and controllers: Reflector drive control and operation

- Voltage, current, pressure, position, temperature and flow sensors, and gamma and neutron detectors

The PMAD subsystem mass is approximately $463 \mathrm{~kg}$ and is $91 \%$ efficient. This is a configuration where there are two channels, each of which is capable of providing $100 \mathrm{~kW}_{\mathrm{e}}$ to the thrusters, with one channel being redundant. The instrumentation and control system mass is approximately $129 \mathrm{~kg}$, and the mass of the auxiliary power system is approximately $112 \mathrm{~kg}$.

\subsection{ROTARY FLUID MANAGEMENT DEVICE}

The RFMD is designed to scavenge liquid from the condenser and provide appropriate net positive suction head (NPSH) to the boiler feed pump. The device is also designed to separate 
vapor or non-condensables from the liquid, if required. Under normal operating conditions, it is expected that there would be $100 \%$ liquid exiting the condenser and that the RFMD would operate as a standard pitot pump. If system transients are such that vapor carryunder occurs in the condenser, the RFMD separates the two phases and holds up the vapor until it can be recondensed. Although not expected, if non-condensables form in the potassium working fluid, the RFMD provides a means to accumulate these during operation and prevent them from circulating through the PCS.

RFMD systems have been developed for organic cycles and have been tested both on the ground and in aircraft (KC-135) parabolic flights to examine their performance under lowgravity conditions. ${ }^{17,18,19}$ Results of this testing have shown that these devices can be used to successfully separate liquid and vapor phases and maintain positive interface control, while providing appropriate pressure rise through the device. These systems provide separation control by establishing high radial accelerations within the rotating drum device. In the design for this application, approximately $300 \mathrm{gs}$ are provided for phase separation and control. Most of the pressure rise in these devices is therefore provided by control of the liquid level within the device.

The RFMD consists of a casing that encloses both a rotating drum and an electric motor used to drive the drum. Flow enters the RFMD from the condenser through a welded connection to the RFMD casing. Multiple concentric tubes at the RFMD entrance allow for exit liquid flow (to the boiler feed pump) from the stationary pitot tube, tubing to vent NCG (if necessary), and a spray system for injecting subcooled liquid into the RFMD (from the rotating equipment bearing cooling system). The subcooled liquid spray is used to condense any vapor that may be carried through the condenser and be separated from the bulk liquid flow by the RFMD. Bearing systems include both tilting pad, potassium-lubricated bearings and labyrinth seals used to prevent liquid from entering the cavities formed by the rotating drum and casing and the rotor of the motor and the motor housing. The tilting pad bearings are supplied by the low-temperature $(<750-\mathrm{K})$ bearing cooling system. These systems are similar to those used in the turbo-alternator system described earlier. As with the alternator, the motor includes a rotor cooling circuit to maintain rotor temperatures below $600 \mathrm{~K}$.

The rotating drum diameter is approximately $20 \mathrm{~cm}$, and the length is approximately $40 \mathrm{~cm}$. The stationary pitot tube located just inside the rotating drum is used to supply potassium at $0.08 \mathrm{MPa}$ to the boiler feed pump. The drum is rotated at $1700 \mathrm{rpm}$ by an electric motor that requires $0.1 \mathrm{~kW}$ of electrical power. A motor efficiency of $45 \%$ and a pump efficiency of $32 \%$ were used to estimate power requirements. A sketch of the RFMD is shown in Fig. 4.20. 


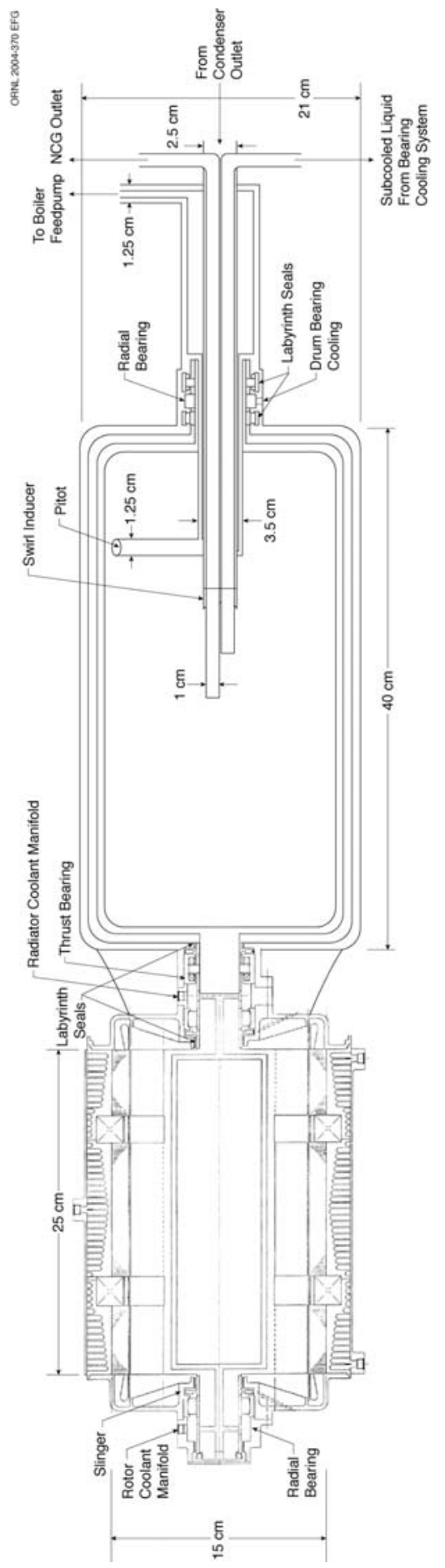

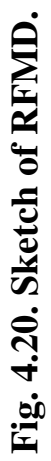


Equations used in the ALKASYS-SRPS code were developed based on the required pressure rise through the device, and the equation for calculating the mass of the RFMD was based on a Boeing/Rocketdyne expression presented in the MNRANK code. ${ }^{20}$ The required potassium mass flow rate and pressure rise are input parameters. Additionally, the RFMD outer radius and liquid thickness are user input. The equations used in ALKASYS-SRPS are

$\mathrm{T} 1=8 \mathrm{~m}^{2} /\left(\rho_{1} \pi^{2} \mathrm{~d}^{4}\right)$

$\mathrm{T} 2=4 \pi^{2}\left(2 \mathrm{r}_{\mathrm{p}}^{2}-\mathrm{r}_{\mathrm{i}}^{2}\right) \rho_{\mathrm{l}} / 2$

$\Omega=\left(144 \Delta \mathrm{P}+\mathrm{T} 1+\Delta \mathrm{P}_{1}\right) / \mathrm{T} 2$

$\mathrm{P}_{\mathrm{kW}}=0.196 \Delta \mathrm{P} \mathrm{m} /\left(\rho_{1} \eta_{\mathrm{RFMD}} \eta_{\mathrm{m}}\right)$

$\mathrm{M}=2208.7 \mathrm{P}_{\mathrm{kW}} / \Delta \mathrm{P}$

Where

$\mathrm{T} 1$ and $\mathrm{T} 2=$ terms defining velocity and static head inside the RMFD

$\mathrm{m}=\quad$ mass flow rate $\left(\mathrm{lb}_{\mathrm{m}} / \mathrm{s}\right)$

$\Delta \mathrm{P}=\quad$ required pressure rise through the RFMD (psf)

$\Omega=\quad$ RFMD rotational velocity (revolutions per second)

$\mathrm{P}_{\mathrm{kW}}=\quad$ RFMD electrical power $(\mathrm{kW})$

$\rho_{1}=\quad$ liquid density $\left(\mathrm{lb}_{\mathrm{m}} / \mathrm{ft}^{3}\right)$

$\mathrm{r}_{\mathrm{p}}=\quad$ radius of the pitot tube $(\mathrm{ft})$

$\mathrm{r}_{\mathrm{i}}=\quad$ radius of the liquid/vapor interface $(\mathrm{ft})$

$\mathrm{M}=\quad$ mass of the RFMD/motor $\left(\mathrm{lb}_{\mathrm{m}}\right)$

Heat rejection system

\subsection{RANKINE CYCLE CONDENSER}

Since only a portion of the heat produced by the nuclear reactor can be converted into useful power, the remaining heat must be rejected from the power cycle through the condenser system and then transmitted for ultimate rejection to space through the radiator system. Thus, the function of the condenser system is to use the radiator to remove heat from the turbine exhaust, producing $100 \%$ liquid that is recycled to the boiler. The primary design approach in Phase I makes use of a rotary fluid management system to move liquid from the condenser to the boiler feed pump (Such an arrangement has been demonstrated in zero-gravity during flights on a NASA KC-135 using an organic liquid).

Because the condenser system interfaces with the (1) turbine system exit stream, (2) the rotary fluid management system inlet stream, and (3) the radiator system, it must concurrently accommodate a wide variety of constraints to ensure system integration and successful operation. In combination with the turbine system, the condenser system must cause the turbine exit stream to be uniformly distributed. Acting with the rotary fluid management system, the condenser system must deliver condensate to the liquid feed pump with sufficient inlet pressure to preclude cavitation. In concert with the radiator system, the condenser system must provide adequate thermal conductance to permit operation at design temperatures.

Of course, the condenser system and its interfaces must meet the same general requirements as other system components, such as stability, fabricability, operation under micro- 
gravity conditions, modulation to partial power loads, and accommodation of thermal stresses and launch loads.

\subsubsection{Issues}

The primary operational issues for the condenser system are heat transfer performance, pressure drop performance, and stability. If heat transfer performance is poor, temperature differences, sizes (and associated weights), and/or cycle inefficiencies increase. High pressure drop can also increase inefficiencies and sizes. Instabilities can lead to maldistribution, unpredictable heat transfer, unpredictable pressure drop performance, and even system failure. As indicated, in two-phase systems, these three issues ultimately interact with one another. However, within limits, some may be (or be made to be) less important in the current design situation.

Incoming vapor condenses and forms liquid on the (relatively) cool condenser wall with vapor flow away from the wall. If there are no forces (gravity or surface tension, for example) substantial enough to move the liquid away from the wall, the thickness of the liquid wall layer increases in the flow direction until, at some point, condensation is complete and liquid fill the entire passage. Thicker layers of liquid on the wall lead to increased resistance to heat being transferred to the wall (lower heat transfer coefficients exist because of the longer conduction path between the vapor and the wall). Therefore, if heat transfer performance were the dominant concern, thinning or removal of the liquid layer from the wall would be desirable. However, for the current design situation, the extremely high thermal conductivity of liquid potassium tends to decrease the importance of liquid film thickness on the condensing surface to heat transfer performance. Of greater potential importance is the interfacial thermal resistance between the condensing surface and the radiator surface.

From the hydrodynamic standpoint, however, it is desirable to maintain the liquid film on the wall. Such a configuration promotes the maintenance of annular flow, a relatively predictable and stable two-phase flow regime. In fact, it may be advisable to implement methods of employing surface tension and dynamic forces to accomplish this end over most of the flow path, even at the price of increased pressure drop.

Based on consideration of these issues, the general strategy employed in the Phase I condenser system design effort was to

(1) embody efficient thermal coupling between the condenser system and the radiator system by means of an integral condenser/heat pipe arrangement,

(2) employ dynamic and surface tension forces to maintain desired vapor and liquid flow through the condenser,

(3) attempt to minimize gravity effects in the 1-g situation to facilitate meaningful ground-based development experiments in Phase II, and

(4) build upon previous related work.

The concepts presented here build upon previous work by Sundstrand (organic shear flow condenser/RFMD), ${ }^{17}$ Netherlands Aerospace Laboratory (high efficiency, low pressure drop two-phase condenser), ${ }^{21}$ ORNL (medium-power reactor experiment), ${ }^{2}$ General Electric Astrospace (low-pressure-drop heat exchanger with integral heat pipe), ${ }^{22}$ and General Electric Missile and Space (thermal hydraulic performance of potassium during condensation inside 
single tubes). ${ }^{23}$ At this point, the most promising condenser/heat rejection system design involves an array of modules, each consisting of a shear flow condenser coupled directly to a heat pipe (see Fig. 4.21). The shear flow condenser module consists of a tapered, finned, helical annulus around a cylindrical heat pipe. This arrangement offers the promise of implementing liquid/vapor interface control by maintaining appropriate vapor velocities throughout the condensing process while providing a high thermal conductance pathway to extended area radiator surfaces.

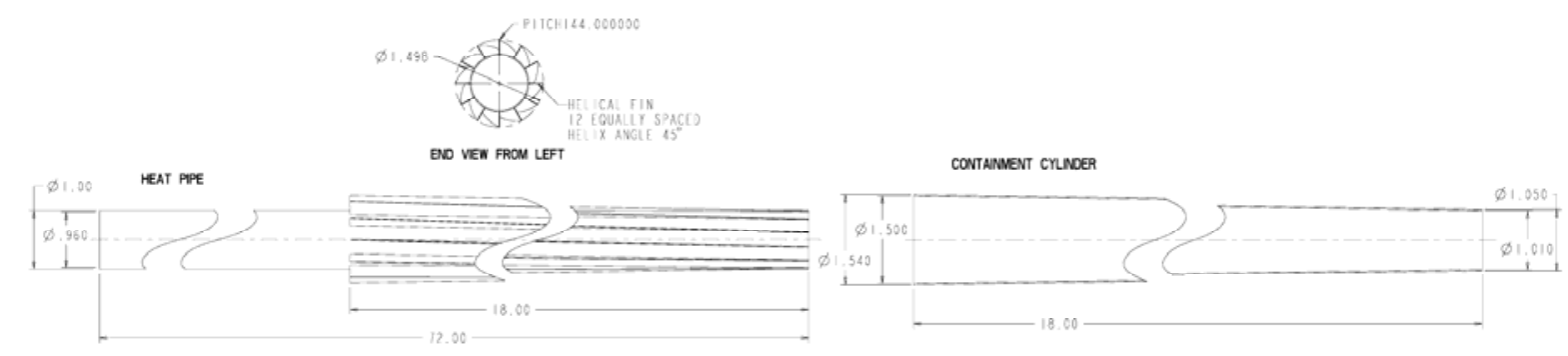

Fig. 4.21. Exploded view of Rankine cycle condenser (dimensions in inches).

Characteristics of a typical module are

Heat pipe inside diameter: 0.960 in. $(2.44 \mathrm{~cm})$

Heat pipe outside diameter/annulus inside diameter: 1.000 in. $(2.54 \mathrm{~cm})$

Inlet annulus outside diameter/shell inside diameter: 1.500 in. $(3.81 \mathrm{~cm})$

Inlet shell outside diameter: 1.540 in. $(3.9 \mathrm{~cm})$

Number of fins: 12

Fin thickness: 0.010 in. $(.025 \mathrm{~cm})$

Helix angle: $45^{\circ}$

Inlet flow area: $0.952 \mathrm{in}^{2}\left(6.14 \mathrm{~cm}^{2}\right)$

Inlet wetted perimeter: 13.610 in. $(34.6 \mathrm{~cm})$

Inlet hydraulic diameter: 0.280 in. $(0.71 \mathrm{~cm})$

Condenser/heat pipe evaporator length: 18.000 in. $(45.72 \mathrm{~cm})$

Heat load: $3.958 \mathrm{~kW}$

Cycle potassium mass flow ( 1 condenser module): $15.56 \mathrm{lb}_{\mathrm{m}} / \mathrm{h}(0.002 \mathrm{~kg} / \mathrm{s})$

Inlet (vapor) volume flow: $56.2 \mathrm{ft}^{3} / \mathrm{min}\left(.0265 \mathrm{~m}^{3} / \mathrm{s}\right)$

Outlet (liquid) volume flow: $0.0439 \mathrm{gal} / \mathrm{min}(0.003 \mathrm{~L} / \mathrm{s})$

Inlet (vapor) flow velocity: $142 \mathrm{ft} / \mathrm{s}(43.3 \mathrm{~m} / \mathrm{s})$

Outlet (liquid) flow velocity: $0.93 \mathrm{ft} / \mathrm{s}(0.28 \mathrm{~m} / \mathrm{s})$

An isometric view of a heat pipe/Rankine cycle condenser is shown in Fig. 4.22. 


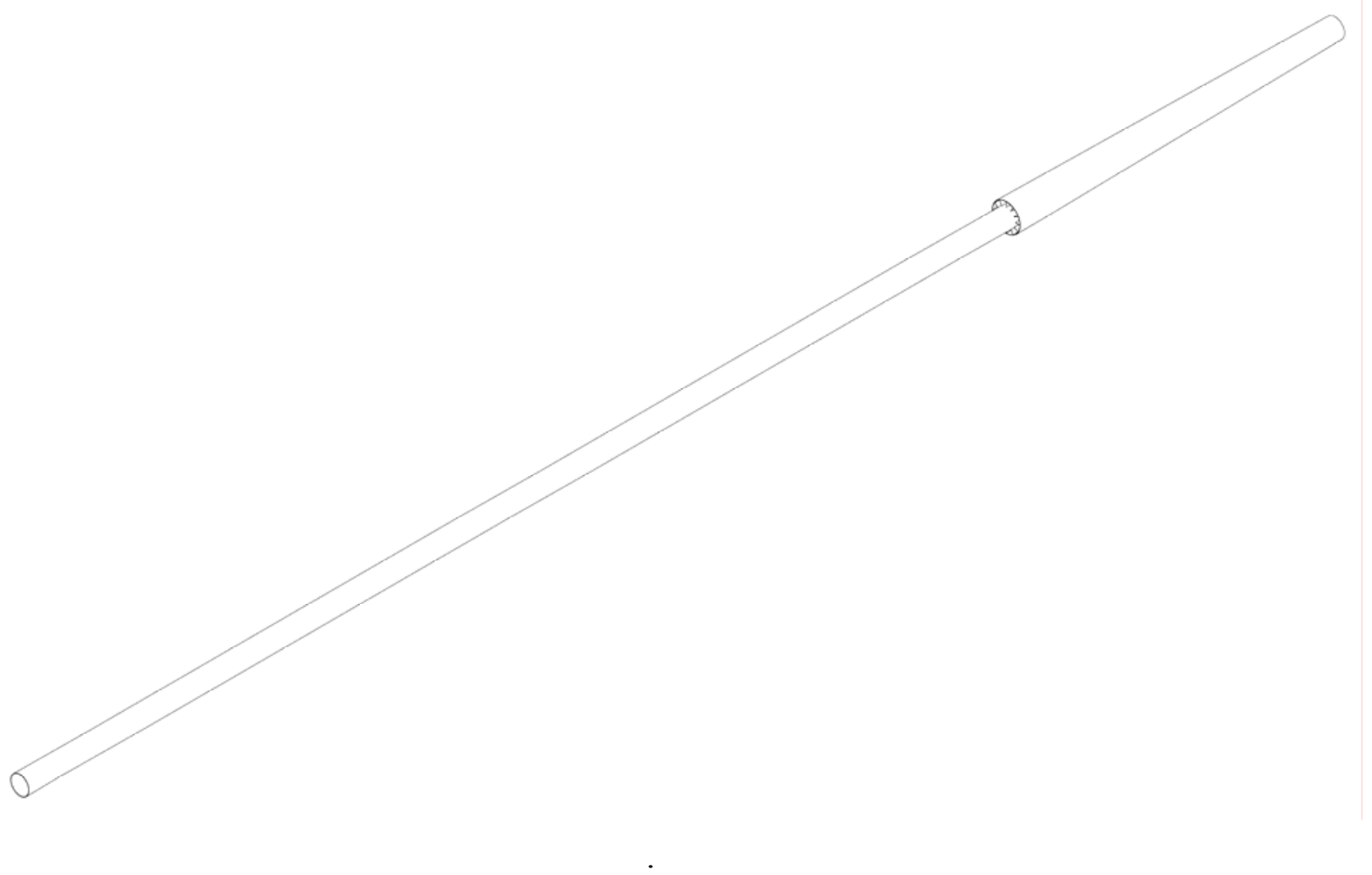

Fig. 4.22. Rankine cycle condenser and heat pipe module

For the $100-\mathrm{kW}_{\mathrm{e}}$ system, 222 separate heat pipes are used [ 2 power conversion units (PCUs)]; therefore, 222 parallel annular condensing channels are used in the design. Each channel rejects approximately $4 \mathrm{~kW}$ of heat from the Rankine cycle. Because potassium has a high thermal conductivity, temperature drop across the liquid film to the heat pipe evaporator surface under these conditions is only about $1^{\circ} \mathrm{C}$. The total flow rate through the condenser is $0.27 \mathrm{~kg} / \mathrm{s}$, and total heat rejected through the condenser is $440 \mathrm{~kW}$.

This design is considered to be modular, so that higher or lower power Rankine cycle design would simply use a fewer or greater number of condenser/heat pipe assemblies to reject the appropriate amount of waste heat.

In Phase I, attempts have been made to arrange the design to minimize the likelihood that gravitational effects would significantly impact those associated with convective or surface tension considerations. The examination of relevant non-dimensional groups has indicated potential surrogate working fluids for scaling experiments. However, it remains to be seen whether the predicted performance (especially hydrodynamic/pressure drop) would be obtained in practice.

\subsection{HEAT PIPE SYSTEM}

All PCSs operate at efficiencies of less than $100 \%$, resulting in the need to reject waste heat to space. Several different heat rejection systems (HRS) potential designs have been identified for rejecting nuclear electric power (NEP) waste heat. Several of them for a Rankine-cyclebased PCS are described herein and the results of their initial analyses presented. The flow diagram of a Rankine PCU, together with the HRS, is presented in Fig. 3.2. The analyses 
presented were performed as part of an initial trade study to recommend a promising HRS for advancement of its TRL for aerospace application of Rankine power conversion.

Several HRS concepts were considered, based on the use of the traditional approaches suitable for such an application. Basically two types of devices were considered. The first is based on the use of heat pipes to transport and spread waste heat over the radiator for rejection to space. This concept includes as a sub-option a mechanically pumped loop as a heat-transporting device. In addition, designs based on loop heat pipe (LHP) technology were evaluated. Several different LHP architectures were evaluated, ranging from traditional configurations using a single evaporator to more advanced LHP configurations using multiple evaporators for heat acquisition.

The HRSs considered for analysis needed to be potentially capable of rejecting the significantly higher heat loads of an NEP system at the higher operating temperatures compared with the heat loads and temperatures typical of today's standard payloads. Feasible HRS designs were identified, analyzed, and compared, especially in terms of thermal performance characteristics, mass, life, envelope, and integration. The HRS current TRL and its potential for advancement were also key considerations in selecting and evaluating the different HRS designs.

\subsubsection{Requirements overview} (Table 4.7). ${ }^{8}$

Before the trade study began, the list of basic requirements (estimated) was generated

Three basic materials for PCU construction were considered for analysis and evaluation: stainless steel, $\mathrm{Nb} 1 \%-\mathrm{Zr}$, and ASTAR 811-C. The temperature range of these materials determined three groups of initial input data (temperature, power, and overall cycle efficiency). All of the preliminary calculations and the modeling of all the concepts considered were performed for each of these three groups of input data.

Because these were very top-level requirements, the system concept and preliminary design were generated in a flexible environment. The thermal power required to be rejected by the system was assumed to be a fixed number throughout the operational temperature range in each material group; that assumption may be somewhat conservative because Rankine cycle efficiency gradually increases with temperature. The effective sink temperature for the radiator was not determined precisely with all the variations during flight; however, it was assumed that if the sink temperature was maintained at the same level for each concept, the design cases would be comparable. For all of the modeling performed during the course of the trade-off program, the sink temperature was assumed to be $90 \mathrm{~K}$. The Rankine PCU condenser operation was enveloped by the maximum vapor inlet temperature (turbine exhaust temperature). The thrust created by the engine during active flight is assumed to be negligible and therefore assumed not to affect the heat rejection system performance. 
Table 4.7. Top-Level HRS requirements

\begin{tabular}{lccc}
\hline \multicolumn{1}{c}{ System Design } & & \\
\multicolumn{1}{c}{ System } & $\begin{array}{c}\text { Stainless } \\
\text { Steel }\end{array}$ & Nb1-Zr & $\begin{array}{c}\text { ASTAR } \\
\mathbf{8 1 1 - C}\end{array}$ \\
\hline Net power output, $\mathrm{kW}(\mathrm{e})$ & 100 & 100 & 100 \\
Net cycle efficiency, \% & 15 & 20 & 22.3 \\
Reactor outlet temperature, K & 1190 & 1350 & 1590 \\
Turbine inlet temperature, $\mathrm{K}$ & 1100 & 1260 & 1500 \\
Turbine inlet pressure, $\mathrm{kPa}$ & 186 & 579 & 1965 \\
Turbine exhaust temperature, $\mathrm{K}$ & 850 & 900 & 1025 \\
Radiator Temperature, K & 806 & 856 & 981 \\
\hline
\end{tabular}

\subsubsection{Trade-off Space}

In order to simplify the trade space and reduce the number of cases compared, some basic assumptions were made (Table 4.8). The length of the heat acquisition device (evaporator of heat pipe or LHP) was fixed, even if it is not an optimal area for heat exchange. Once this length is fixed, systems can be compared on a one-to-one basis, and optimization of the heat acquisition surface can then be made.

It was determined that one of the main parameters for the trade study would be to examine redundancy on both the PCU and HRS levels. Therefore, the study concentrated on four PCU redundancy approaches: one operational PCU and one spare (1+1), two operational PCUs and one spare $(2+1)$, three operational PCUs and one spare $(3+1)$, and four operational PCUs with one spare $(4+1)$. Several HRS redundancy concepts were examined. Two approaches examined were (1) all PCUs connect to a joint radiator via an interface manifold, and (2) each PCU has an independent HRS. It was decided not to overcomplicate the trade space by introducing any new variables; therefore, it is assumed that each PCU is equipped with an independent radiator system. In addition, it was demonstrated that the joint radiator approach has very little advantage over the other options (if any) because of the additional temperature drops through the joint manifold.

It was necessary to have a logical approach to represent the Rankine vapor-to-HRS condenser. This condenser works as a classical two-phase condenser. For the purpose of this trade-off study, it was assumed that condensation of the Rankine vapor occurs on the outer surface of the heat pipe or LHP evaporator, which has a cylindrical shape. In order to enhance the heat transfer, this cylinder can be equipped with fins to increase the condensation area for Rankine vapor and improve liquid inventory control. Condensation was assumed to occur at constant temperature at every point on the path of the condensing vapor. With proper fluid management and distribution between individual condensers, it can be assumed that the entire HRS operates at a constant temperature. It is acknowledged that the condensation film coefficient, as well as the evaporation film coefficient inside the heat pipe (or LHP) evaporator is very dependent on the internal design and fluid properties. Determination of these parameters requires an extensive literature search and, probably, some experimental investigation as well. However, for the purposes of this study, the condensation (as well as evaporation) film coefficient was chosen to be $10,000 \mathrm{Btu} / \mathrm{h} \cdot \mathrm{ft}^{2} \cdot{ }^{\circ} \mathrm{F}\left(5678 * 10^{4} \mathrm{~W} / \mathrm{K} / \mathrm{m}^{2}\right)^{24}$. 
Prior to preliminary selection of the operating temperature range corresponding to the material selection for the HRS, two basic materials were built into the model: below temperatures of $700 \mathrm{~K}$ the system was assumed to use Inconel; above $700 \mathrm{~K}$, TZM was used. A hard switch was built into the model, which made analysis results look somewhat discontinuous at and around the transition temperature of $700 \mathrm{~K}$.

Table 4.8. Main assumptions

\begin{tabular}{ll}
\hline Assumption & Value \\
\hline Length of the heat acquisition section & $0.45 \mathrm{~m}$ \\
Number of redundant PCU sections & $1+1 \ldots 4+1$ \\
Redundancy approach on heat pipes & $10 \%$ extra heat pipes \\
Redundancy approach on radiator & Each PCU is equipped with a radiator \\
Temperature of Inconel to TZM & $700 \mathrm{~K}$ \\
$\quad$ \\
$\quad$ change & $90 \mathrm{~K}$ \\
Sink temperature & None \\
Subcooling & \\
\hline
\end{tabular}

The literature and background information search has shown that the most appropriate working fluids for this application are potassium for the higher temperature range and mercury for the lower temperature range considered. This change occurs because of the fluid saturation pressure and surface tension parameters. All systems considered were modeled with these two working fluids.

\subsubsection{Selection Criteria}

The main selection criterion was system weight; however, this criterion cannot be considered without two other very important parameters: (1) radiator area required to reject the required amount of heat and (2) overall system reliability. In addition, the final HRS selection cannot be performed based only on these selection criteria, because the HRS cannot be completely analyzed and compared as a stand-alone system. The HRS is an integral part of the overall Rankine NEP concept. Overall system optimization has its own "peaks and valleys"; therefore, it was very important to make the output data generated at the HRS modeling level suitable for integration into an overall NEP model. All analytical results were presented in a tabulated format, which was later built into an algorithm for the overall model. These initial output data were generated for the entire temperature range and for the entire trade-off space as well (utilized system and redundancy). After the preliminary directions and trends were established at the NEP level, more detailed analysis (with a different level of optimization) was performed. 


\subsubsection{Heat Rejection Systems}

Before the modeling and optimization phases started, a preliminary selection of the potential candidates for the role of high performance HRS were considered. Some of the most feasible technical solutions were highlighted. Basically, all of the potential candidate systems are based on utilization of one of the modern heat transport technologies (or a combination of both). The first technology is a conventional high-temperature heat pipe, and the second is an LHP. The following two subsections of this report describe physical principles and operation of these devices and highlight their pros and cons.

\subsubsection{Heat Pipe Design and Operation}

George Grover from Los Alamos National Laboratory discovered heat pipe operational principles and invented a device later called a heat pipe. On July 24, 1963, he made the following entry into his laboratory notebook:

Heat transfer via capillary movement of fluids. The "pumping" action of surface tension forces may be sufficient to move liquids from a cold temperature zone to a high temperature zone (with subsequent return in vapor form using the difference in vapor pressure at the two temperatures as the driving force) to be of interest in transferring heat from the hot to the cold zone. Such a closed system, requiring no external pumps, may be of particular interest in space reactors in moving heat from the reactor core to a radiating system. In the absence of gravity, the forces must only be such as to overcome the capillary and the drag of the returning vapor through its channels. $^{26}$

These words are still 100\% valid and the use of heat pipe devices for space-based cooling systems is still growing.

The interest in heat pipes as a capillary-driven heat transfer device is based on their ability to transport thermal energy at high rates and with small temperature gradients and their ability to operate without external resources (in particular, electrical energy).

A heat pipe is essentially a passive heat transfer device with an extremely high effective thermal conductivity. The two-phase heat transfer mechanism results in heat transfer capabilities from one hundred to several thousand times that of conduction through an equivalent piece of copper.

As shown in Fig. 4.23, the heat pipe in its simplest configuration is a closed, evacuated cylindrical vessel with internal walls lined with a capillary structure or wick that is saturated with a working fluid. Since the heat pipe is evacuated and then charged with the working fluid prior to being sealed, the internal pressure is set by the vapor pressure of the fluid.

As heat is input at the evaporator, fluid is vaporized, creating a pressure gradient in the pipe. This pressure gradient forces the vapor to flow along the pipe to a cooler section where it condenses, giving up its latent heat of vaporization. The working fluid is then returned to the evaporator by capillary forces developed in the wick structure.

Heat pipes can be designed to operate over a very broad range of temperatures, from cryogenic $\left(\leq 243^{\circ} \mathrm{C}\right)$ applications utilizing titanium alloy/nitrogen heat pipes, to hightemperature applications $\left(>2000^{\circ} \mathrm{C}\right)$ using tungsten/silver heat pipes. In electronic cooling applications where it is desirable to maintain junction temperatures below $125-150^{\circ} \mathrm{C}$, 
copper/water heat pipes are typically used. Copper/methanol heat pipes are used if the application requires heat pipe operation below $0^{\circ} \mathrm{C}$. Heat pipes used in high-temperature applications use a range of high-boiling-point fluids such as mercury, potassium, sodium, lithium and other liquid metals. Traditional body materials for such heat pipes are Inconel, stainless steel, and titanium (for the lowest-temperature end of the liquid metal heat pipe) and refractory alloys, molybdenum alloys, and niobium alloys for higher-temperature applications.

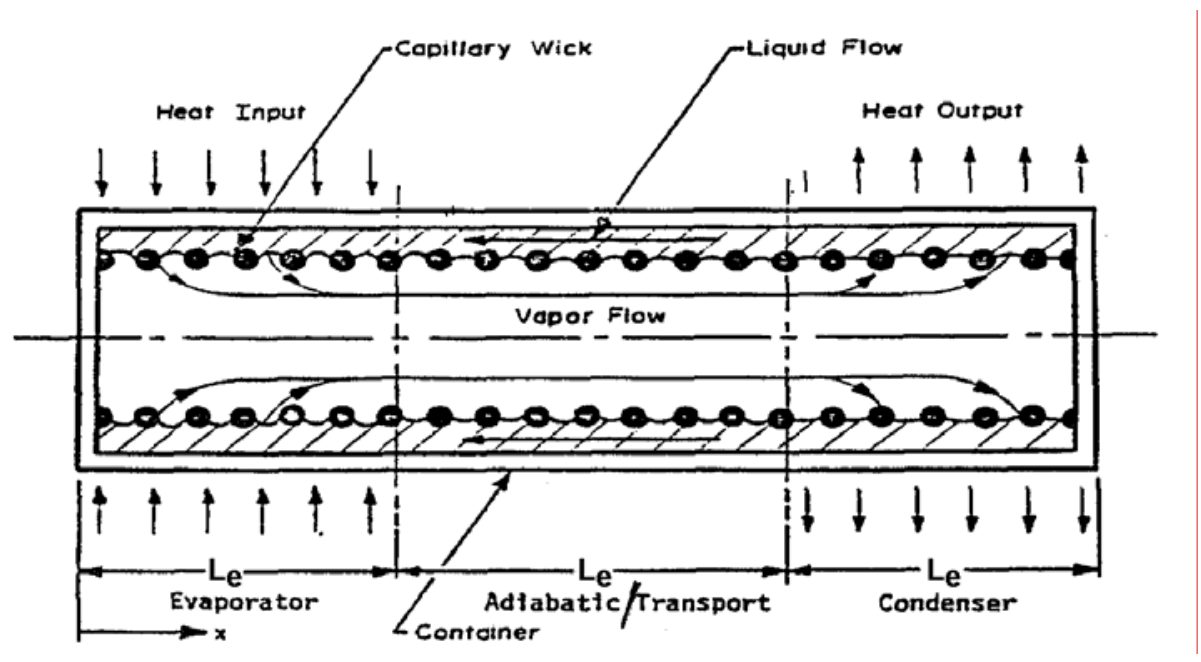

Fig. 4.23. Heat pipe schematic.

There are many factors to consider when designing a heat pipe: compatibility of materials, operating temperature range, diameter, power limitations, thermal resistances, and operating orientation. However, the design issues are reduced to two major considerations. These considerations are the amount of power the heat pipe is capable of carrying and its effective thermal resistance.

The most important heat pipe design consideration is the amount of power the heat pipe is capable of transferring. Heat pipes can be designed to carry a few watts or several kilowatts, depending on the application. Heat pipes can transfer much higher powers for a given temperature gradient than even the best metallic conductors. If it is driven beyond its capacity, however, the effective thermal conductivity of the heat pipe is significantly reduced. Therefore, it is important to ensure that the heat pipe is designed to safely transport the required heat load.

The maximum heat transport capability of the heat pipe is governed by several limiting factors, which must be addressed when designing a heat pipe. There are five primary heat pipe heat transport limitations. These heat transport limits, which are a function of the heat pipe operating temperature, include viscous, sonic, capillary pumping, entrainment or flooding, and boiling. 


\subsubsection{Loop Heat Pipe Design and Operation}

A classical LHP consists of an evaporator and compensation chamber assembly, a condenser, and transport lines. The configuration of each particular LHP is determined by the real application and can vary from unit to unit. The "classical" LHP diagram is presented in Fig. 4.24 .

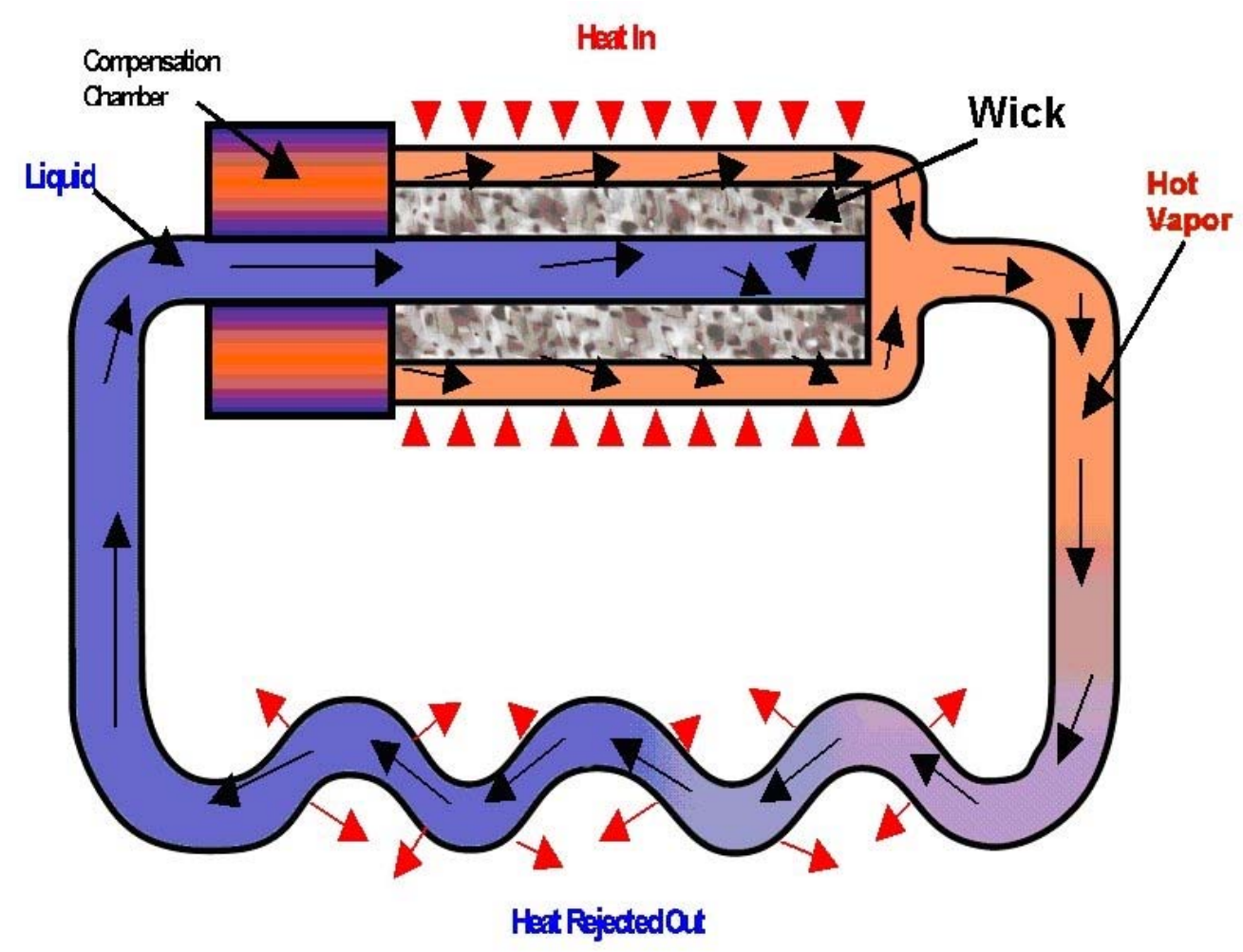

Fig. 4.24. The classical LHP with the direct condensation condenser

Traditionally, the evaporator consists of a cylindrical metallic case with the wick inserted into it. The case is then either attached to, or forms, the heat acquisition surface. There were several successful attempts to create a "flat" evaporator with a plate-like case. However, in most cases, the internal pressure of the LHP system is so high that the pressure containment considerations dominate in the evaporator design, and the walls of the evaporator case are generally too thick if a flat geometry is used. The system of vapor-removing channels is formed at the contact between the body and the wick. The area of contact is considered as the active evaporator area.

The compensation chamber shares liquid with the inside of the primary wick in the evaporator (i.e., the liquid core). This is accomplished either by gravitational forces or via the use of a secondary distribution wick. Vapor and liquid lines enter and exit the evaporator and compensation chamber assembly. The liquid return flows either into or through the compensation chamber with intimate thermal contact with its content. It should be noted that the compensation chamber is a critical component: its design has to be considered very carefully, 
because its sizing affects the performance of the LHP (conductance, maximum power, minimum start up power, etc.).

The condenser of the LHP serves to condense the vapor that was generated in the evaporator and transfer heat to the sink (of any nature: conduction, radiation, or convection). For modern space applications, two types of condensers are usually considered in trade-off studies, direct and indirect. Direct condensation assumes the condenser is designed as a tubing network (parallel or series) attached directly to the radiator face sheet (or to another heat rejecting device). Indirect condensation assumes that the condenser has an additional interface between the surface of condensation and the heat sink, which in most cases is a heat exchanger connected to the evaporator of the heat pipe. Both of these approaches have their advantages and disadvantages, and selection of the correct solution for the particular application is a matter of a detailed tradeoff studies. Transport lines are simply smooth tubing without any capillary structure.

The selection of materials for the LHP components, as well as the working fluid, is the subject of a detailed study during the design phase of each particular LHP. The most studied and reliable combination of the LHP materials includes stainless steel, aluminum, and nickel (using ammonia, as the working fluid); the success of a water-titanium system has also been demonstrated. These combinations have been experimentally proven to be compatible, minimizing non condensable gas (NCG) generation. (NCGs and physical leakage are considered to be the two most important factors that can reduce the lifetime of LHP.) A detailed experimental study ${ }^{25}$ of the LHP with such combinations of materials showed that even the most conservative predictions of the NCG volume generated at the end of life in such an LHP do not cause much distortion in the LHP operational behavior and performance. Alternative materials for LHPs include the following: nickel for the evaporator body, porous titanium as the wick, and propylene as the working fluid. There is only one LHP known which was constructed for hightemperature application (similar to that required here). It has a stainless steel body and was filled with cesium as the working fluid. The knowledge and test information are very limited, as well as the NCG issues at high temperatures. However, high-temperature LHPs would use the same set of materials as conventional heat pipes designed for the same temperature range, and the knowledge about material compatibility in such HP systems is extensive. It should therefore be possible to extend this knowledge to high-temperature LHP material combinations.

In order to simplify consideration of LHP operation, an LHP with a very simple point design is discussed. This design was described as a classical one: a single evaporator, combined with the compensation chamber, serial direct condensation condenser, and semi-flexible transport lines.

It is necessary to describe the design cases of LHP operation before the processes inside the LHP can be considered. Designers of LHPs consider three design cases: hot and cold cases of operation, and maximum non-operating temperature. "Cold case" means zero power applied to the evaporator and condenser while transport lines are exposed to the coldest environmental conditions. The most conservative assumption in this case is that the entire loop (other than most of the compensation chamber) is filled with liquid (in the extreme case, this liquid can even be frozen), including the primary wick and the evaporator's vapor exhaust grooves.

"Hot case" means that the maximum power is applied, and the rest of the loop is exposed to the hottest environmental conditions. The assumed fluid distribution in a hot case is as follows: the vapor exhaust grooves in the primary wick, vapor line, and condenser are filled with 
vapor, while the primary wick, the liquid line, and most of the compensation chamber are filled with liquid.

A related third case is often a driver in LHP design: the maximum exposure temperature under non-operating conditions (storage, transportation, or perhaps some manufacturing process like brazing or soldering) after the loop has been charged with the working fluid. The concern with this case is whether there is enough void in the loop to avoid bursting of the heat pipe due to high hydrostatic pressures.

The hot case is used to size the radiator to allow rejection of heat without overheating the payload and without hard-filling the compensation chamber with warm (low-density) liquid.

Such a condition would lead to condenser blockage.

In the cold case, the designer must worry about the potential freezing of the system and the requirement that some liquid must exist within the compensation chamber despite the high density of the cold fluid. The name "compensation chamber" ("hydroaccumulator" and "reservoir" are frequently used as synonyms) derives from the main purpose of that assembly: to compensate for the thermal expansion of the working fluid at different operating temperatures. In other words, the main idea of the LHP is to have the compensation chamber and the fluid charge sized so as to provide enough liquid in the cold case to keep the evaporator wetted before startup, yet prevent condenser blockage in the hot case.

The typical performance curve (temperature vs. power) of a classic LHP design is presented in Fig. 4.25. As is evident in that plot, the shapes of the hot and cold case curves are identical to each other. Cold and hot cases of operation differ from each other only because of the difference in operating temperature due to different sink conditions. The performance curve of a classic LHP can be considered to consist of two parts: the variable conductance mode (the curved line at lower powers) and the constant conductance mode (the straight line at higher powers).

The curves in Fig. 4.25 show the evaporator case temperature and the saturation vapor temperature as functions of heat input. The operating temperature of this LHP is different from the temperatures covered by this study; however, the shapes of these curves may give an idea of the LHP modes of operation and behavior. This type of curve is typical whenever the sink

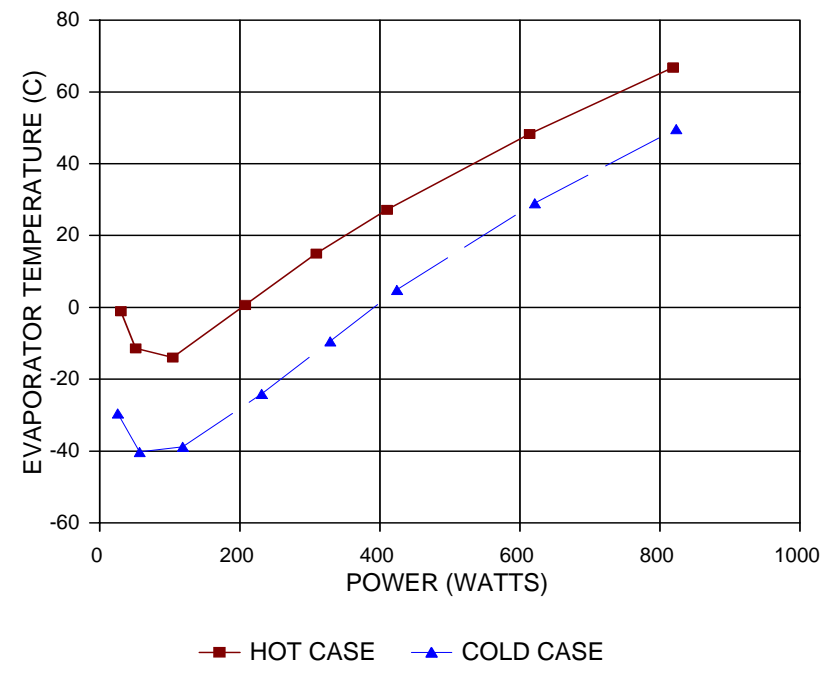

Fig. 4.25. Typical performance curves of an ammonia LHP. 
temperature is lower than the ambient temperature. In this case, the vapor and evaporator temperatures at low powers (up to about $100 \mathrm{~W}$ for this particular loop in this particular environment) drop with increasing power, corresponding to a decrease in the overall resistance, until a minimum is reached. As power continues to increase, the temperature $(\mathrm{T})$ versus heatflow (Q) curve has a positive slope and approaches a straight line; the overall resistance is nearly constant in this regime. The difference between evaporator and vapor temperature is due to the finite evaporator resistance. This difference is zero at low powers and increases linearly with power.

This particular behavior is directly related to the location of the compensation chamber and its coupling to the evaporator. When some power is applied to the evaporator, a capillary pressure difference across the wick develops in order to sustain the pressure drop created by the hydraulic resistance of the transport lines and condenser. This capillary pressure also must sustain the gravity head of the liquid column in the return line (if the evaporator is located higher than the condenser). This pressure difference, which is essentially a driving force of the working fluid in any LHP, creates a corresponding heat leak into the compensation chamber through the walls and the wick structure of the evaporator. This heat leak can eventually increase compensation chamber temperature (and pressure accordingly) to the point where the driving potential (the pressure difference) is not able to move the working fluid through the loop. In a real LHP system, this heat leak is in stable equilibrium with a compensating heat leak via subcooling brought into the compensation chamber from the condenser. This subcooling is generated in the condenser by its partial blockage. While powers applied to the LHP are low, a small flow rate returns very little liquid to the compensation chamber; therefore, the subcooling brought into the compensation chamber is limited by the flow rate and the sink temperatures. In such low-power cases, the compensation chamber temperature is determined by its heat exchange with the evaporator and with the environment. This can be illustrated by the simple equation that describes the basics of the compensation chamber thermal balance:

The required subcooling that needs to be generated in the condenser must be equal to the total heat leaks to the compensation chamber: through the environment $\left(\mathrm{Q}_{\mathrm{CC}}\right)$, through the wick and evaporator structure $\left(\mathrm{Q}_{\text {wick }}\right)$, and through heat applied to the liquid line $\left(\mathrm{Q}_{\text {liq-line }}\right)$ :

$$
\mathrm{Q}_{\text {subcool__ }} \approx \mathrm{Q}_{\mathrm{CC}}+\mathrm{Q}_{\text {wick }}+\mathrm{Q}_{\text {liq-line }}
$$

The generated subcooling brought into the evaporator can be determined using this simple equation, where mdot is a flow rate determined by the applied power and a latent heat of the working fluid, $\Delta \mathrm{T}$ subcool is the temperature difference between the saturation temperature of the loop and the temperature of the liquid exiting the condenser:

$$
\text { mdot } * \mathrm{C}_{\mathrm{p}} * \Delta \mathrm{T}_{\text {subcool }}=\mathrm{Q}_{\text {subcool }}
$$

At low powers, mdot is small and $\Delta \mathrm{T}_{\text {subcool }}$ is limited by the sink temperature, therefore required and actual subcooling can not be equal, and the thermal balance of the compensation chamber is dominated by the parasitic heat leak. They increase the system temperature to the point where $\Delta \mathrm{T}_{\text {subcool }}$ is high enough to satisfy the balance between the required and generated subcooling. 


$$
\text { Hot case }(\mathrm{T} \sin \mathrm{k}=233 \mathrm{~K}) \text { and cold case }(\mathrm{T} \sin \mathrm{k}=153 \mathrm{~K})
$$

At zero flow, there is no capillary pressure difference across the wick and, because saturation conditions exist on both sides of the wick, no temperature gradient exists. Consequently, the only heat input to the compensation chamber is from the environment, and its temperature is equal to the ambient temperature. As heat is applied, some degree of subcooling starts to enter the compensation chamber; as the heat input increases; cooler liquid from the condenser gradually lowers the temperature of the compensation chamber. The saturation temperature follows the downward trend, because the subcooling produced increases while the parasitic heat leaks into the compensation chamber remain approximately unchanged.

Since the sink temperature is constant, the decrease in evaporator temperature is synonymous with increasing heat pipe conductance. As with any heat pipe, the overall conductance of LHP is determined by the evaporator and condenser conductances:

$$
1 / \mathrm{C}_{\text {overall }}=1 / \mathrm{C}_{\text {evap }}+1 / \mathrm{C}_{\text {con }}
$$

The evaporator conductance is normally assumed to be constant; thus the increase in overall conductance with increasing power must be the result of an increasing condenser conductance. Condenser conductance is increased by gradually displacing more liquid from the condenser and exposing more condenser area for two-phase heat exchange. At zero or very small powers, only a short section of the condenser is active; the remainder is filled with liquid, producing as much subcooling as it can in an attempt to compensate parasitic heat leaks into the compensation chamber.

As the power is increased, more and more condenser area becomes active, and the overall conductance of the LHP continues to increase. In this mode of operation, the LHP behaves like a variable conductance heat pipe (VCHP). The range of power over which the VCHP behavior applies, and the exact nature of the accompanying temperature changes, depend on the design of the LHP and the sink and environment temperatures.

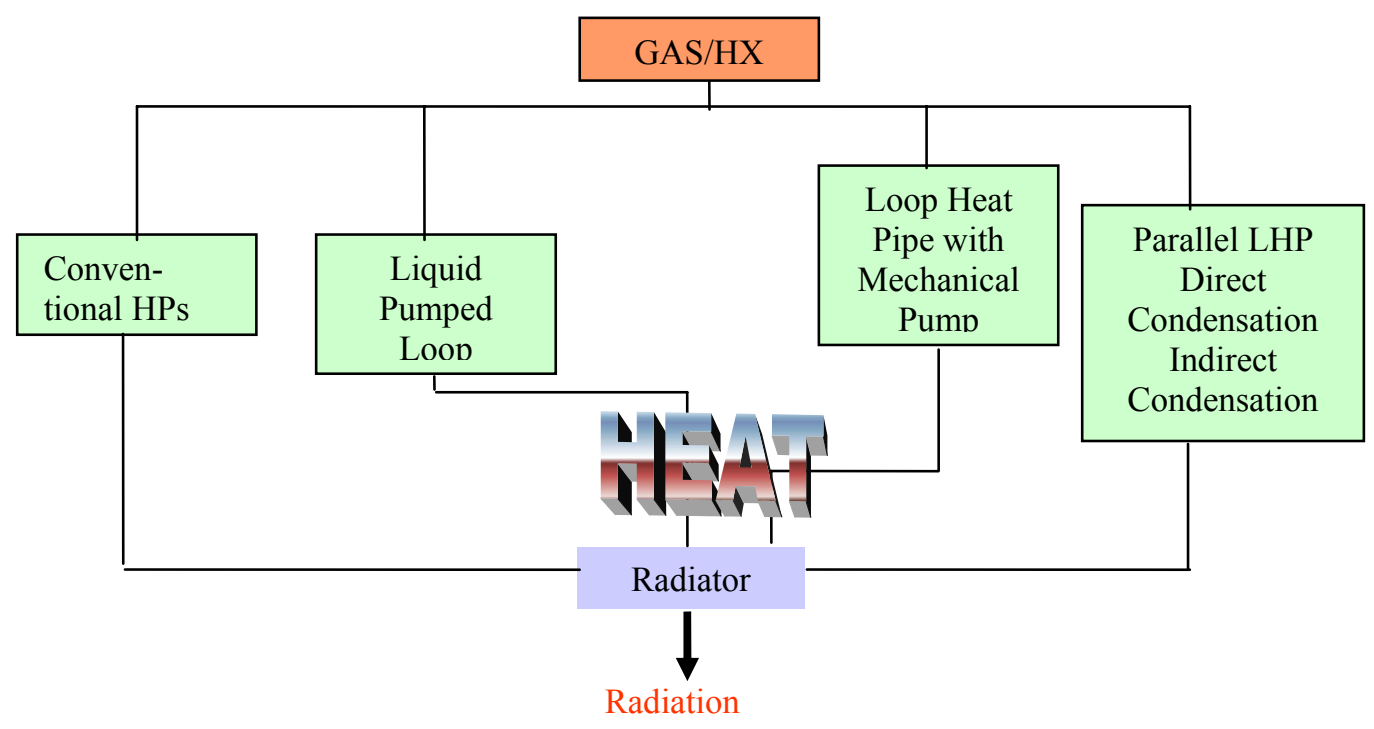

Fig. 4.26. Heat rejection system concept. 
At a certain power, the active portion of the condenser reaches its maximum, reserving some percentage of is length to produce the required subcooling, and a further increase in the condenser conductance is no longer possible. In order to reject additional power, the driving potential between condenser and sink must increase, resulting in increased saturation temperature. From this point on, the LHP behaves like a constant conductance heat pipe: the $\Delta \mathrm{T}$ between the evaporator and condenser increases linearly with power. The physics of LHP operation were well studied in the former Soviet Union-the country of origin for the LHP. One of the most detailed publications, which presents LHP fundamentals, is ref. 21.

\subsubsection{Systems Considered}

Several concepts of the HRS can be applied to reject heat from the Rankine-cycle-based PCU. After a feasibility study and literature search, a diagram (Fig. 4.26) was generated.

Based on the results of the preliminary concept selection, it is feasible to apply one of four HRS concepts. The first concept is based on utilization of conventional heat pipes transporting heat from the Rankine cycle condenser to the radiator (System 1). The second approach assumes utilization of an intermediate, mechanically pumped single-phase fluid loop transporting heat from the PCU's condenser to the heat-pipe-based radiators (System 2). The third approach utilizes the LHP to transport heat from the PCU's condenser manifold to the radiator. There are two sub-versions of this system. One is a direct condensation version, in which the LHP condenser is attached directly to the radiator face sheet and condensation of the working fluid occurs directly on the surface that radiates heat to space (System 3 ). The second sub-version of the third approach is a non-direct condensation LHP, where conventional heat pipe(s) serve to spread heat from the LHP condenser to the radiator (System 4). The fourth approach uses a multiple-evaporator LHP with non-direct surface condensation and a mechanical pump built into the liquid return line (System 5). The pump assists liquid returning to the evaporator and creates additional pressure at the liquid side of the loop; this arrangement eliminates the need for liquid subcooling and eases fluid management and distribution among the parallel evaporators, which are connected to the condenser manifold of the Rankine cycle. The use of this design significantly reduces the need for subcooling and makes the overall system lighter. It is necessary to mention that each LHP requires some degree of subcooling for its operation, and thus a larger radiator area. In some cases (at low temperatures), the increase of the radiator area to meet subcooling requirements can be rather substantial; therefore, the utilization of the miniature pump assisting the liquid flow can be very attractive.

The heat transfer device design (diameter, wick structure, lengths) for each of the considered systems was assumed to be temperature independent (this assumption is only valid for the preliminary design selection) in order to compare systems in an identical environment. After a final selection was made, design optimization was taken to the next level, and the final geometry and performance of the selected system were refined. It was also assumed that the structure of the facesheet and the design of the heat pipes remain identical to the previously modeled system designs.

As was discussed earlier, a preliminary analysis of each system was performed with two different working fluids, potassium and mercury. These working fluids have advantages in different temperature ranges; and, as the final operating temperature was to be determined as a result of the trade-off process, analysis for both working fluids was carried through all of the system designs. 
Each system was also modeled for three different design versions ( $\mathrm{SS}, \mathrm{Nb} 1-\mathrm{Zr}$, and ASTAR 811C). The only difference between designs was the net cycle efficiency, which led to a different heat load (for the fixed electrical power). Even these three design approaches can result in different system operation temperatures. For ease of modeling, they were analyzed over a common temperature range that covers the expected, optimized final heat rejection temperature of the Rankine cycle.

\subsubsection{HRS Based on Conventional Heat Pipes (System 1)}

Architecturally, System 1 is based on the direct heat removal from the Rankine cycle condenser manifold into a set of conventional heat pipes. This design would dictate a fixed radiator. The Rankine cycle condenser manifold would consist of a number of individual condensers connected either in parallel or in series (depending on the Rankine cycle loop pressure drop requirements). These condensers form an outer shell around the heat pipe evaporator, providing condensation on the heat pipe evaporator OD. The condensed heat is transported from the heat pipe evaporator to the radiator. The length of the heat pipe condenser attached to the radiator is determined by the heat pipe's transport capacity and by the ability of the radiator to reject heat (this ability depends on the operating temperature). The schematic of this system is presented in Fig. 4.27.

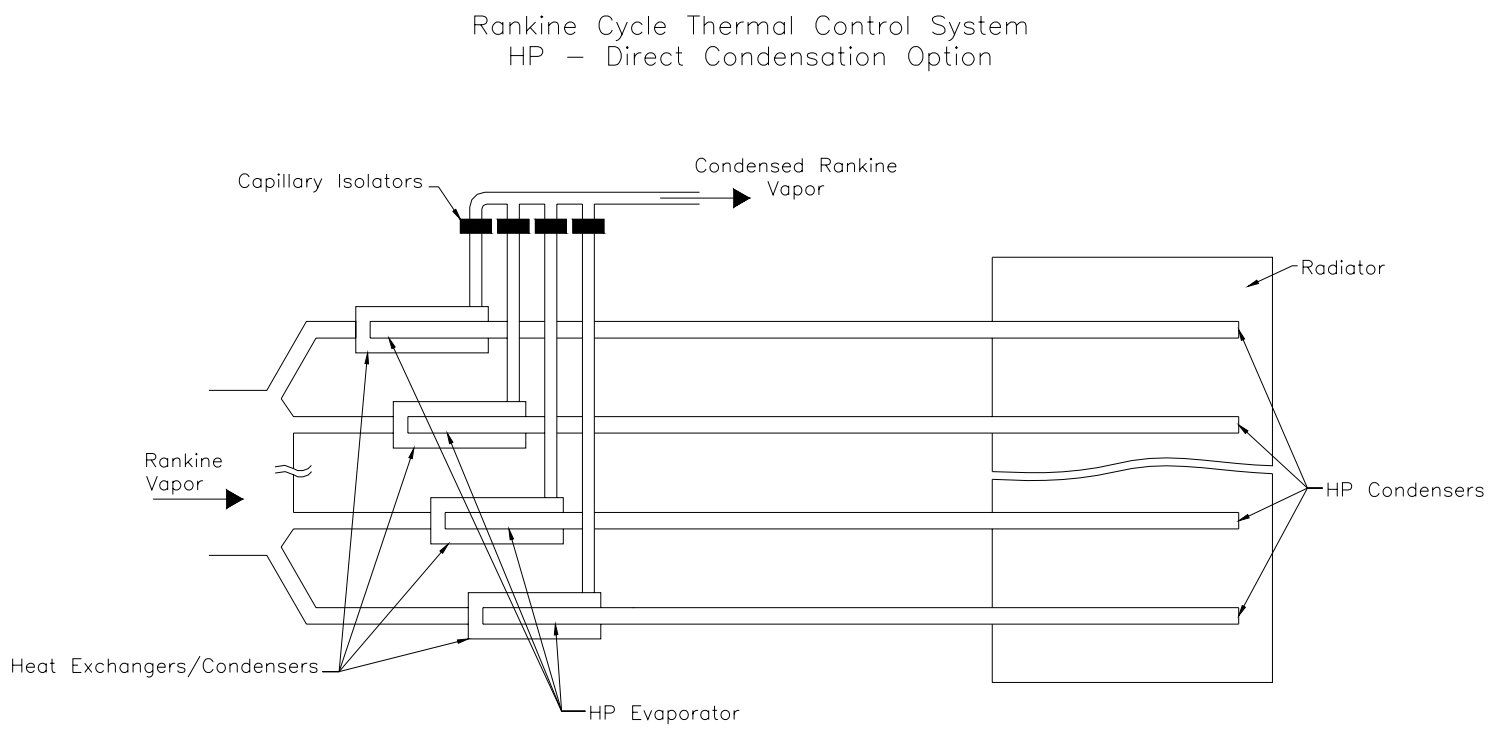

Fig. 4.27. HRS based on conventional heat pipes. System 1 schematic.

As a result of the analysis performed for this system, a number of curves were produced. The operating temperature was chosen as a main variable; curves for the total HRS mass and radiator area were generated. These curves are presented in Figs 4.28 through 4.31. These curves assume a constant total amount of heat rejection $\left(Q_{\text {tot }}\right)$ over the entire turbine exhaust temperature (or Rankine cycle condenser temperature) range. 
Total heat rejection System Mass

System 1 (Heat Pipes) Potassium

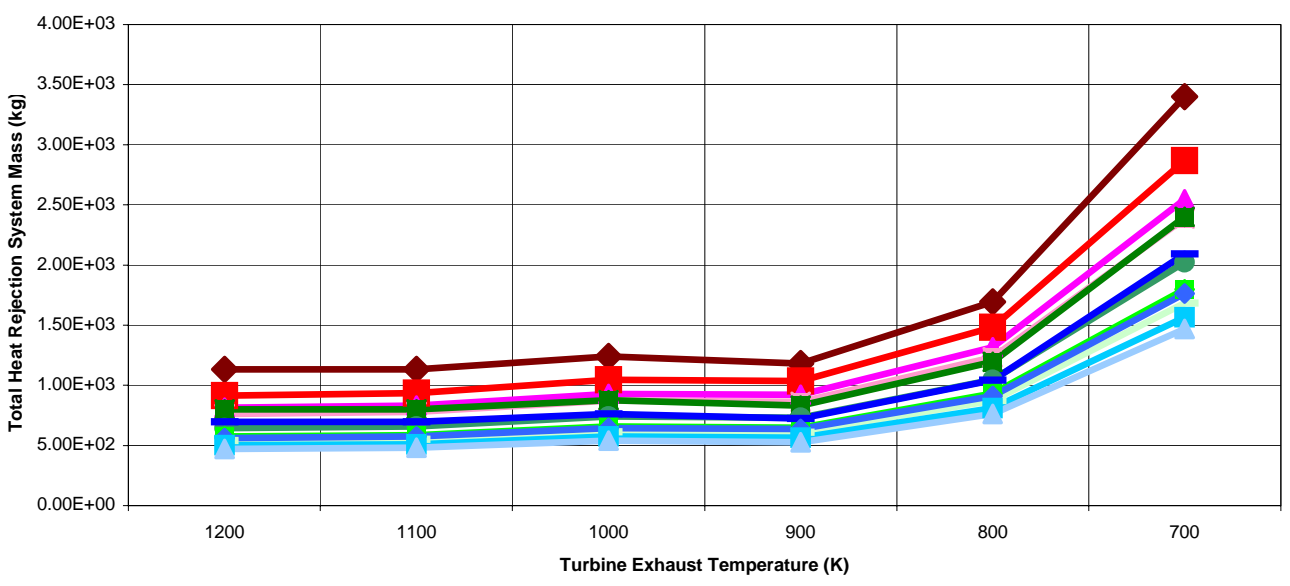

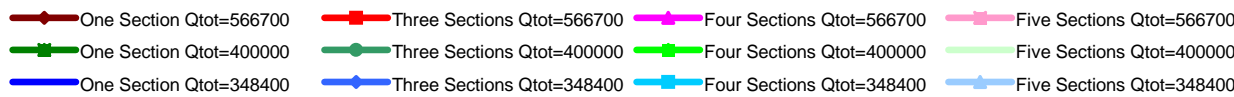

Fig. 4.28. System 1 with potassium total heat rejection system mass.

Single Sided Radiator per Total Area Including Redundancy System 1 (Heat Pipes) Potassium
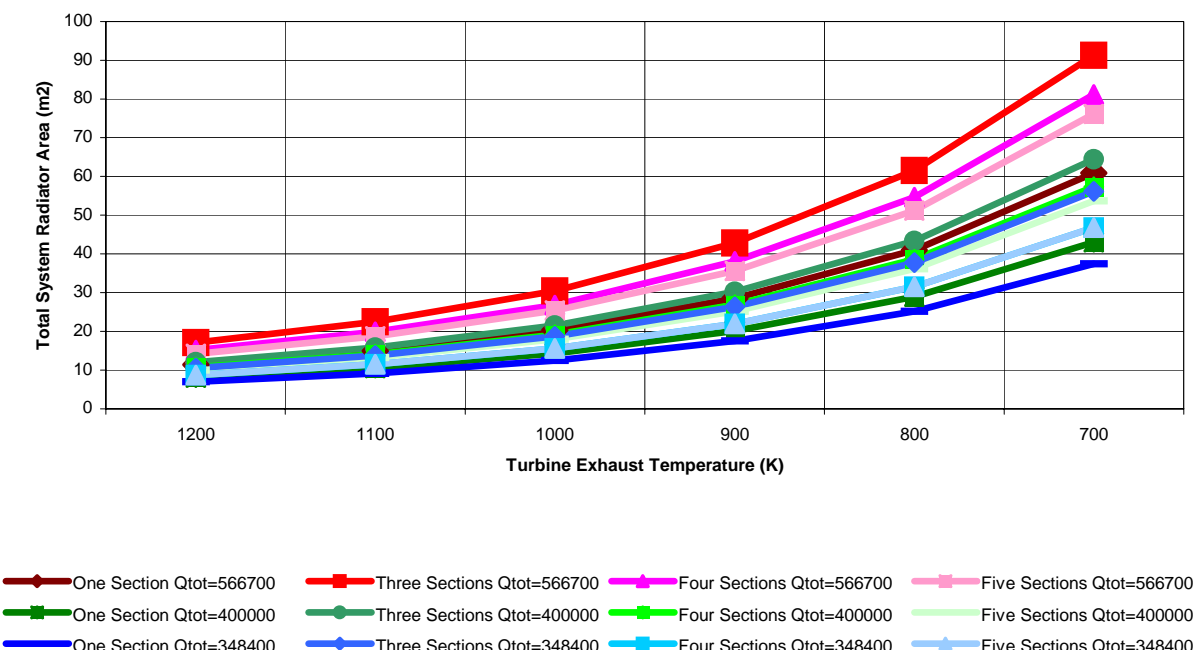

Fig. 4.29. System 1 with potassium total radiator system area. 
Total Heat Rejection System Mass

System 1 (heat Pipes) Mercury

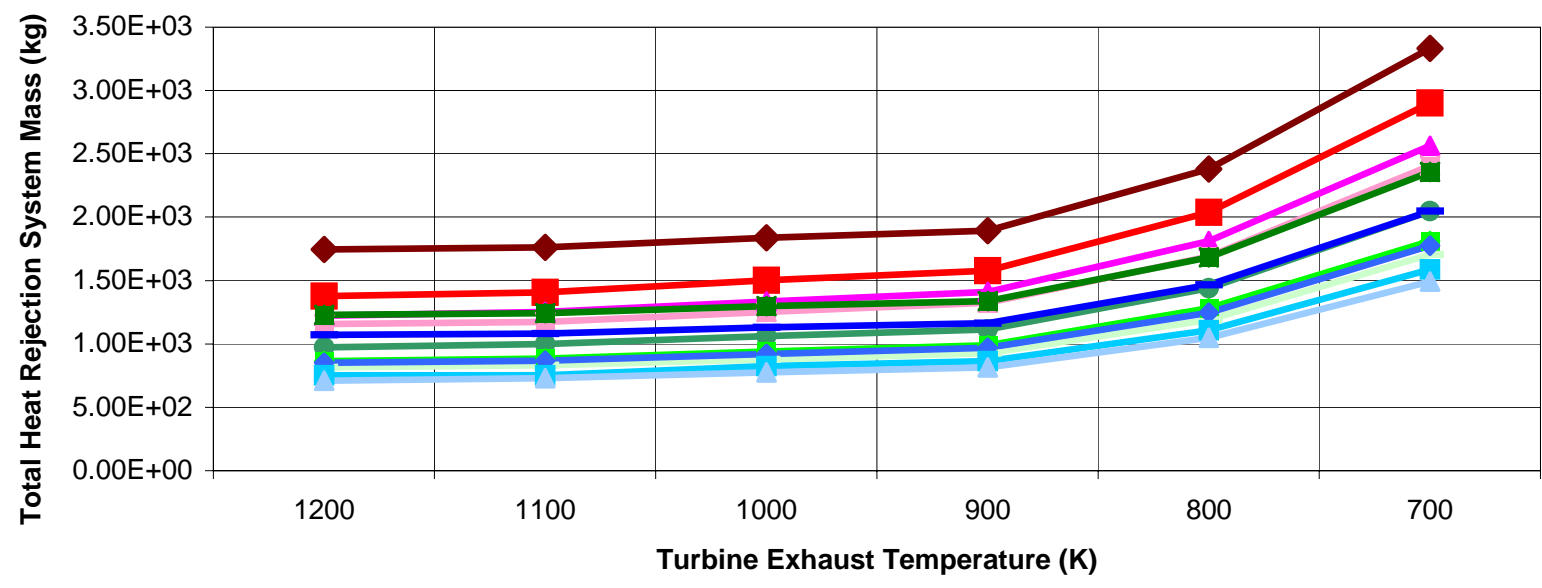

Fig. 4.30. System 1 with mercury total heat rejection system mass.

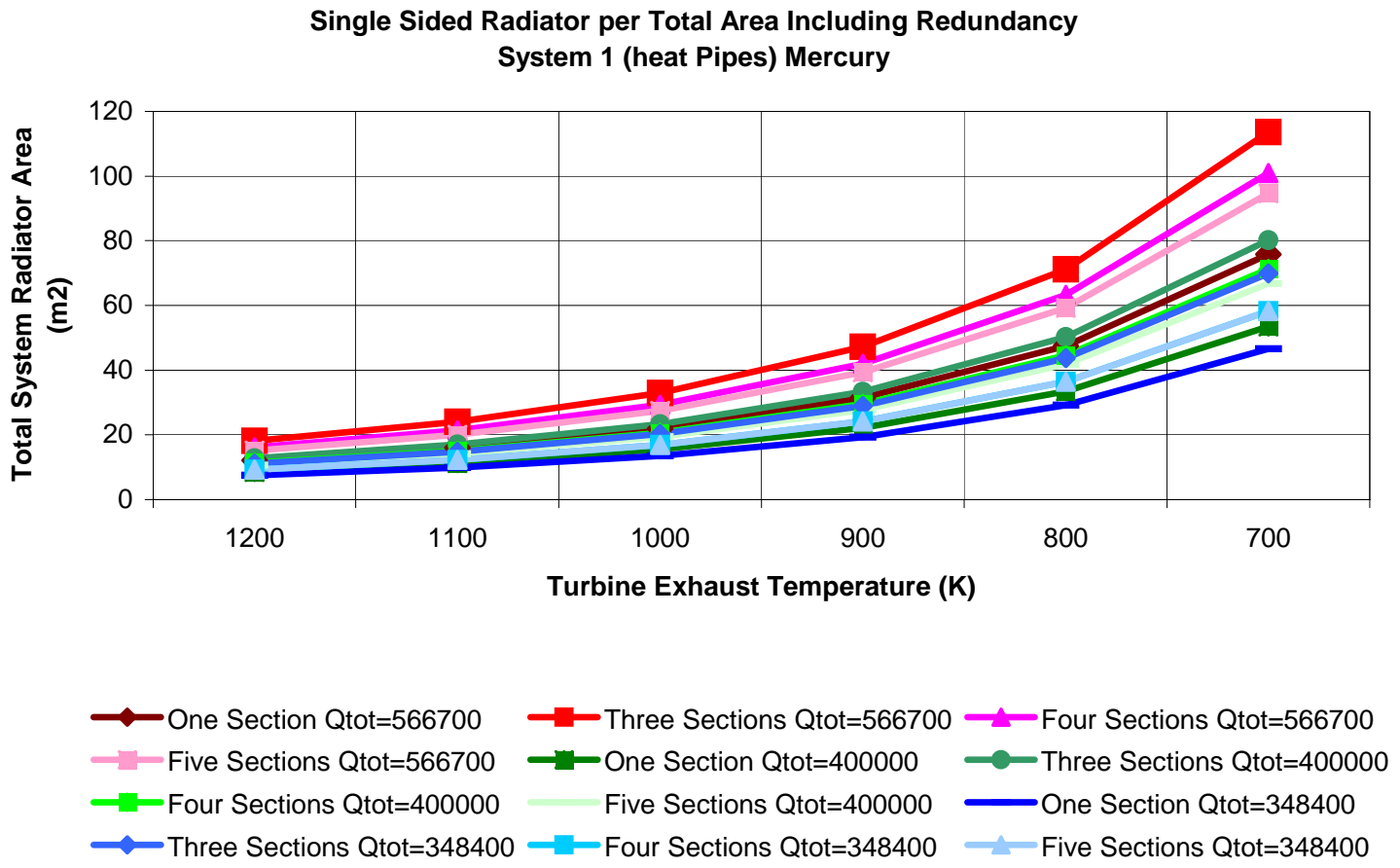

Fig. 4.31. System 1 with mercury total radiator system area. 


\subsubsection{HRS Based on a Single-Phase Loop (System 2)}

The utilization of a mechanically pumped loop is a traditional (from the late 1970s) HRS design for space-based nuclear reactor power systems. In the application to the Rankine cycle, cooling of the mechanically pumped loop would be applied in the following manner: The mechanical pump supports circulation of the coolant, which passes through the heat exchanger connected to the Rankine loop condenser manifold. This heat exchanger absorbs heat from the condenser manifold using the sensible heat of the working fluid. The working fluid is transported into the HRS's condenser area, where heat exchange to conventional heat pipe evaporators occurs. This heat exchanger design uses the sensible heat of the working fluid to vaporize the working fluid of a heat pipe. Heat pipes spread heat over the area of the radiator, from which it is finally rejected to space. The schematic of System 2 is presented in Fig 4.32.

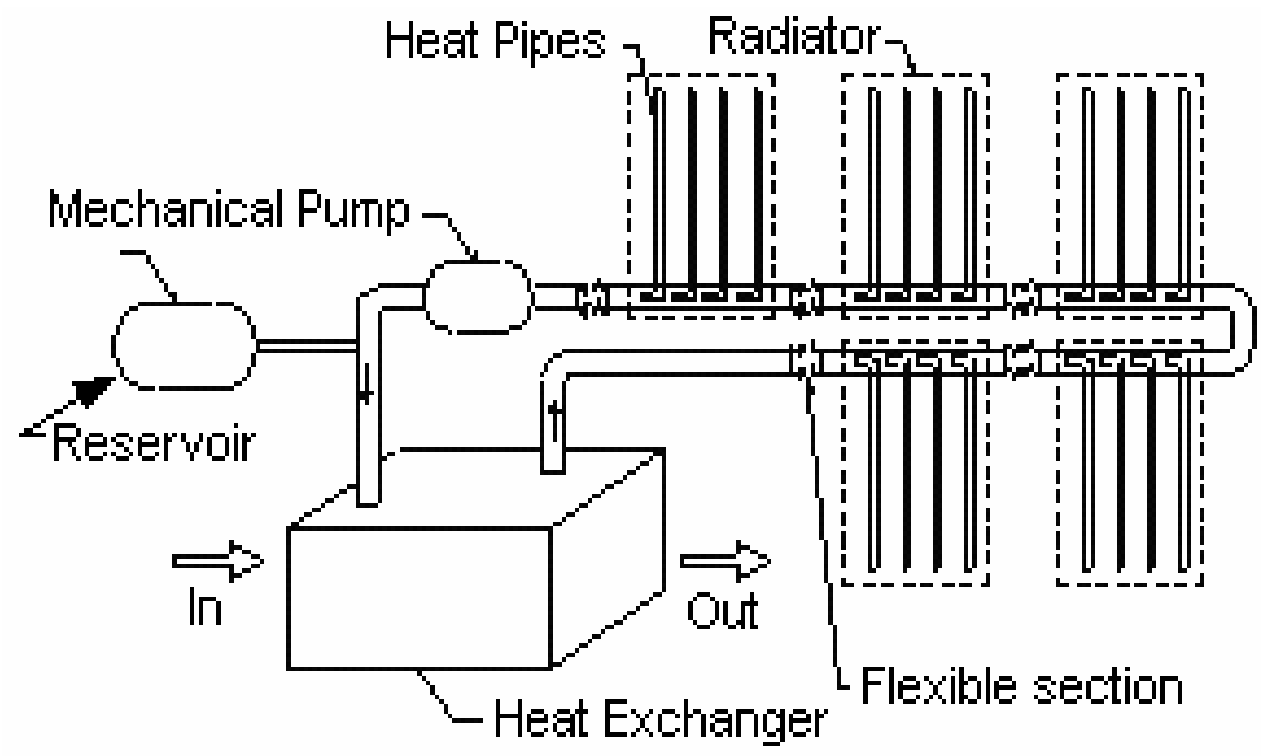

Fig. 4.32. HRS based on mechanically pumped loop (System 2).

Basically this system is very similar to System 1 with an intermediate heat transfer medium and all of the negative implications related to it. Consequences of using a mechanically pumped loop include additional temperature drops at the interfaces, additional temperature drop along the mechanically pumped loop caused by sensible heat transfer, moving parts and an associated reliability decrease, and additional power consumption for operation. These issues make this concept one of the least attractive for future consideration and comparison.

\subsubsection{HRS Based on a Loop Heat Pipe with Direct Condensation (System 3)}

The system design is based on the following concept: The potassium vapor leaving the Rankine cycle turbine enters a number of parallel condensers (the same as in all other system concepts) and is condensing inside. The heat is transferred through the inner wall of the heat exchanger into the LHP evaporator. The LHP transports heat through its small-diameter thinwall transport lines into a freeze-tolerant condenser. The LHP condenser is attached to the radiator, which radiates heat into space. Schematically this HRS is shown in Fig. 4.33. 
Several working fluids were considered for LHP operation: cesium, potassium, and mercury. It was determined that mercury is the most beneficial fluid thermally, based on pumping capabilities and heat transfer performance. Both of the alternative working fluids, cesium and potassium, have much poorer performance. As a result, the thermal control system was designed and sized for mercury. Figures 4.34 and 4.35 contain analysis results for the System 3 approach (total HRS mass and required system area). Because of the very high temperatures, traditional stainless steel cannot be used as a construction material for the thermal control system components because the mechanical strength parameters decrease rapidly at high temperatures. Therefore, there are two options: for temperatures below $700^{\circ} \mathrm{C}$ the use of Inconel alloy was considered; for higher temperatures TZM alloy is preferable. Inconel is slightly lighter and easier to machine. TZM is heavier and more difficult to machine; however, it has much higher thermal conductivity, which is very important for the LHP components. Because heat fluxes on the evaporator and condenser are high, a higher-conductivity material would help to reduce the temperature drop.

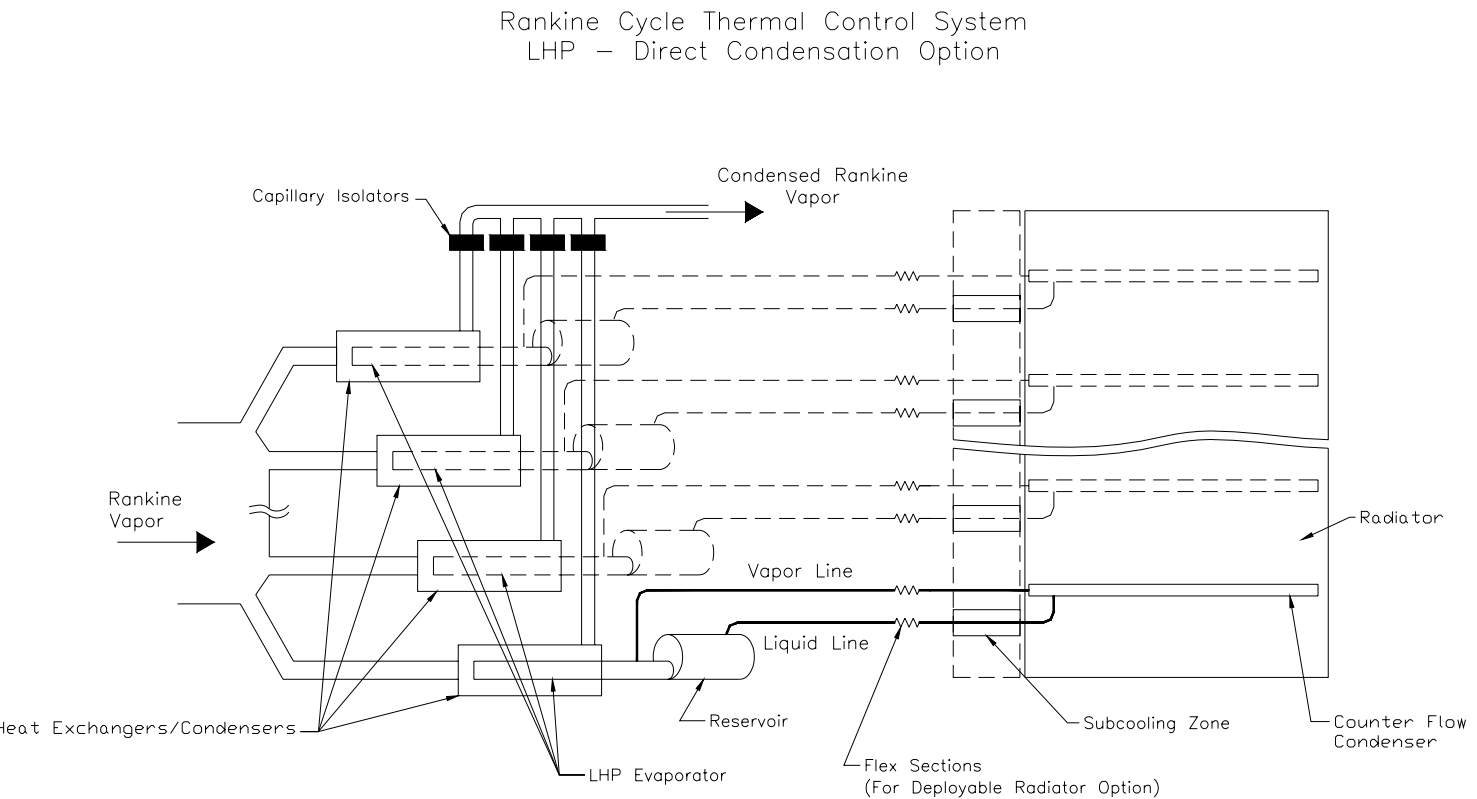

Fig. 4.33. HRS based on loop heat pipe with direct condensation (System 3). 
Heat rejectionSystem Mass Including Redundancy

System 3 HRS based on LHPs

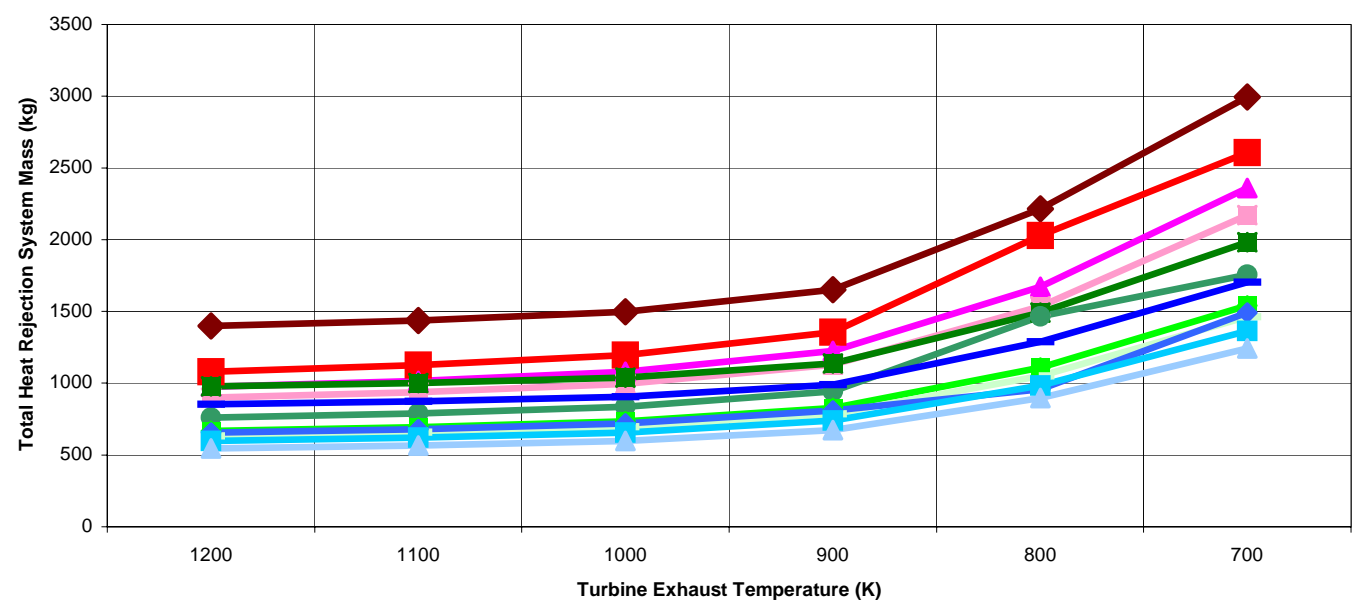

One Section Qtot=566700

$\simeq$ One Section Qtot $=400000$

- Three Sections Qtot=566700 - Four Sections Qtot=566700 $\longrightarrow$ Five Sections Qtot=566700
- Three Sections Qtot=400000 - Four Sections Qtot=400000

One Section Qtot=348400 -Three Sections Qtot=348400 - Four Sections Qtot=348400 - Five Sections Qtot=348400

Fig. 4.34. System 3 with mercury total heat rejection system mass.

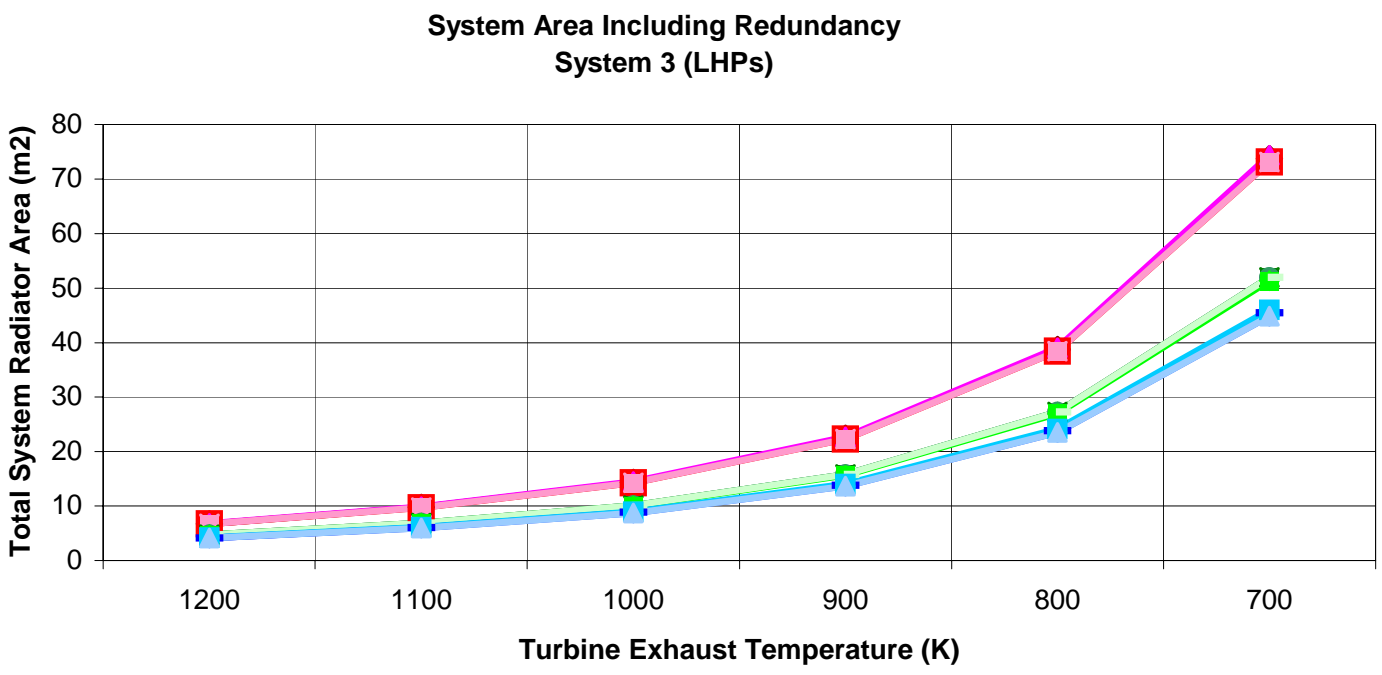

\begin{tabular}{|c|c|c|}
\hline One Section Qtot=56 & $\neg$ Three Sectic & \\
\hline- Five Sections Qtot $=566700$ & Qtot $=400000$ & ons Qtot $=400000$ \\
\hline Four Sections Qtot $=400000$ & Five Sections Qtot=400000 & on Qtot=348400 \\
\hline -T & Otot $=34$ & ons Qtot=348400 \\
\hline
\end{tabular}

Fig. 4.35. System 3 with mercury total radiator system area. 
Due to the extremely large temperature differences between the radiator and the heat sink (on the order of $1000^{\circ} \mathrm{C}$ ), the total area required for heat rejection is not large (several square meters). The lower the operation temperature of the system, the more subcooling is required for proper operation of LHPs; therefore, the final radiator area is somewhat larger than determined by simple radiation equations.

\subsubsection{HRS Based on a Loop Heat Pipe with Indirect Condensation (System 4)}

Basically this system is very similar to System 3, except for the use of an indirect LHP condenser. "Indirect" means that condensation of the LHP's working fluid occurs in the LHP condenser, which is directly coupled to the radiator surface. In this case, a LHP is used to remove energy from the Rankine cycle condenser, and conventional heat pipes are used to spread the energy over the radiator panel surface. The condenser of the LHP is connected with the evaporator of the conventional heat pipes. The concept schematic of such a condenser-radiator approach is presented in Fig. 4.36. In some cases, the tolerance of such system for micrometeoroid damage can significantly improve the reliability of the overall HRS; therefore, the System 4 concept was considered.

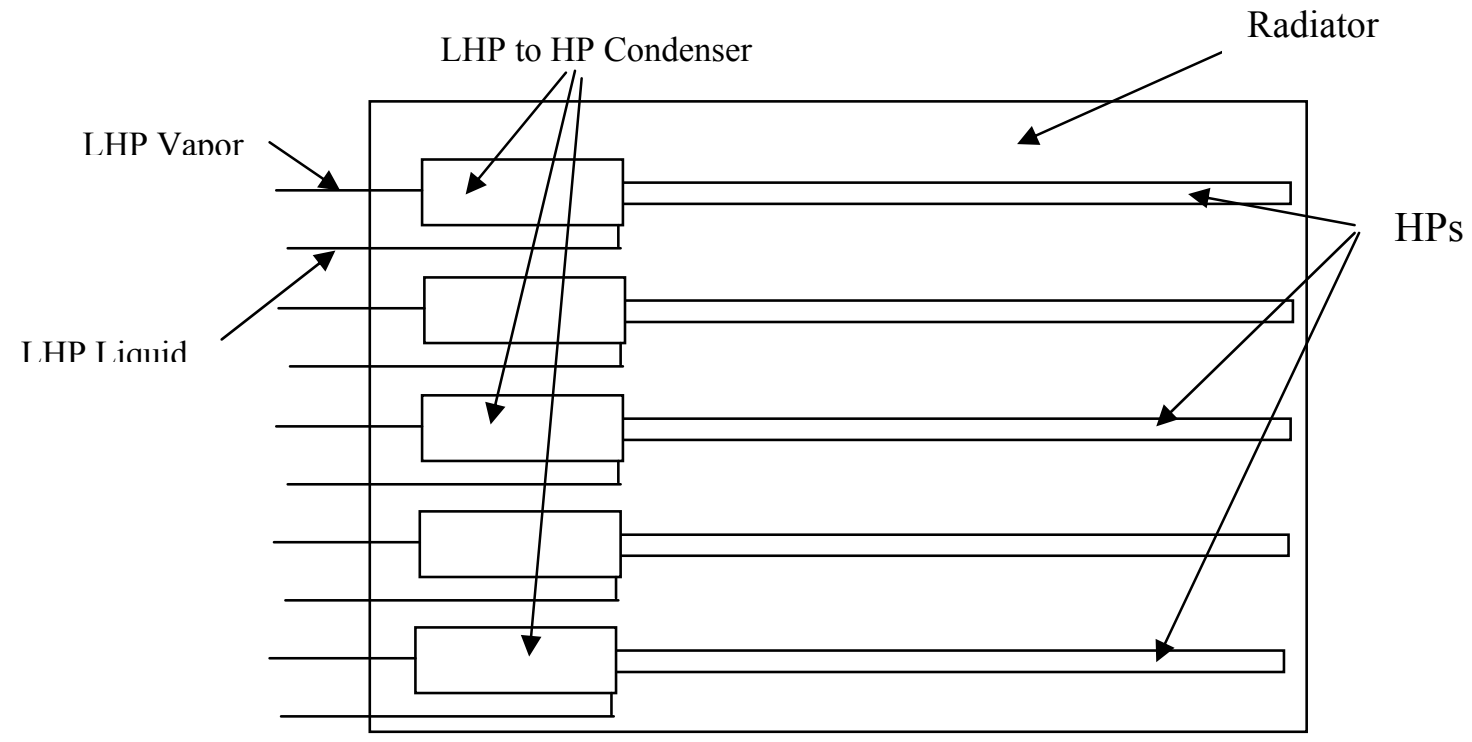

Fig. 4.36. HRS radiator based on loop heat pipe with indirect condensation (System 4).

\subsubsection{HRS Based on a Multiple Evaporator LHP with a Mechanical Pump (System 5)}

System 5 is basically an implementation of the multiple-evaporator, multiple-condenser LHP concept in the System 4 concept. All individual single-evaporator single-condenser LHPs are combined into several groups with 10-15 LHP in each. All LHPs in one group have joint internal spaces and just two transport lines. This group can be considered as a single LHP with 


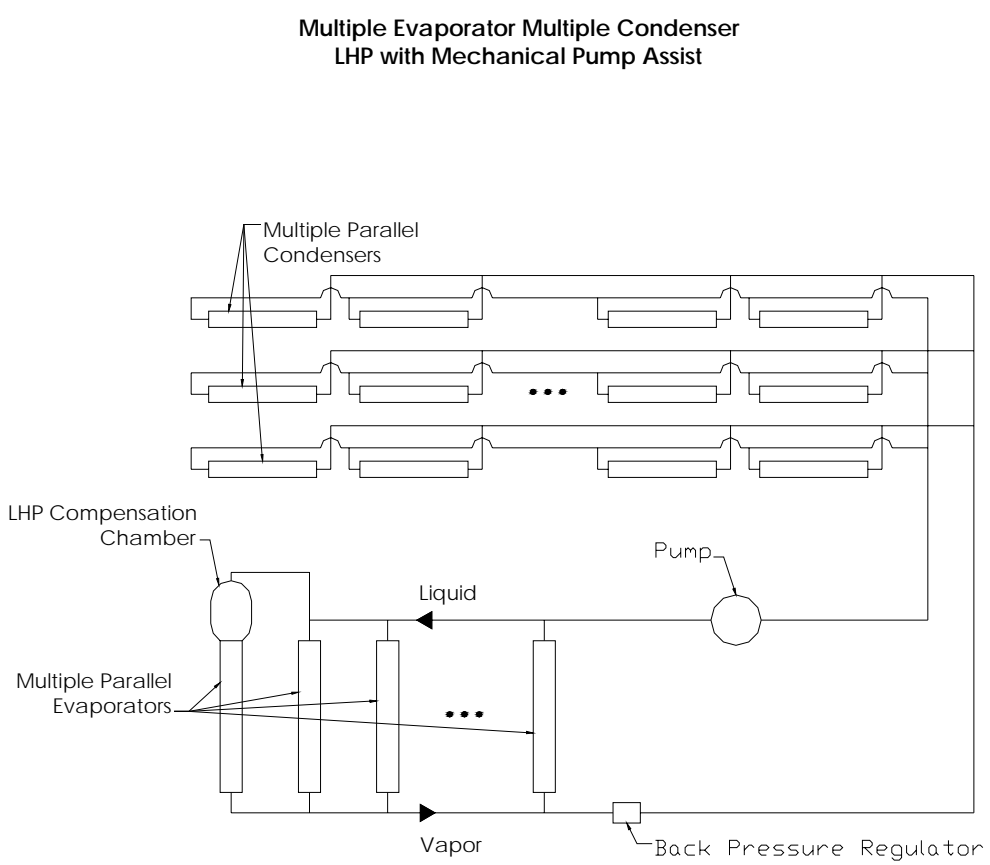

Fig. 4.37. HRS radiator based on multiple-evaporator, multiple condenser loop heat pipe with indirect condensation (System 5).

multiple heat acquisition and heat rejection devices. Schematically, the LHP with multiple evaporators and condensers is shown in Fig. 4.37. Operation at the lower end of the temperature range may require the LHP to generate some degree of subcooling. The amount of subcooling required by the LHP depends on the primary wick properties and on the pressure drop through the LHP. The greater the pressure drop, the larger the corresponding temperature difference through the evaporator; as a result, the heat leak through the wick is large, and a significant amount of subcooling is required for compensation. In a classic LHP concept, some portion of the condenser is dedicated to subcooling. If the demand for subcooling in the LHP is large enough, the condenser/radiator area can be significant, and significant mass and envelope penalties can result. An additional mechanical pump, built into the liquid line, can be very beneficial. This pump, which can be very small, is supposed to generate some additional pressure to compensate viscous pressure losses in the loop. As a result, the temperature difference across the evaporator is reduced (or even disappears), which affects the need for subcooling. The use of the small mechanical pump can also resolve the flow management issues related to power sharing and proper feeding of multiple evaporators in a multiple evaporator loop. This concept looks very attractive for complicated high-power HRS systems such as Rankine cycle; the lower the temperature, the more advantageous it looks. Unfortunately the TRL of this system is about 2 ; therefore, it can be a potential future improvement, but it was dropped from consideration for the NEP Rankine application. 


\subsubsection{Pros and Cons}

Table 4.9 contains a summary of pros and cons of the systems considered. This information was useful during the selection process. There is one concern, which is addressed for each of the listed systems: potassium and mercury are very hazardous materials that must be handled with extreme care, and special techniques and special facilities must be used for processing.

Table 4.9. Summary of pros and cons

\begin{tabular}{|c|c|c|}
\hline & Pros & Cons \\
\hline HPs (System 1) & $\begin{array}{l}\text { Simplicity achieved by using just one type } \\
\text { of device. } \\
\text { Heat pipe technology in general is well } \\
\text { established. } \\
\text { Fixed radiator section has minimum } \\
\text { possible area for heat rejection. } \\
\text { Heat pipe design used in the system mass } \\
\text { and area estimation is the most } \\
\text { conservative and can be significantly } \\
\text { improved. } \\
\text { Highest degree of freeze-tolerance; no } \\
\text { power required for thawing. } \\
\text { Not a subject for the freeze-thaw concerns. } \\
\text { Some degree of mechanical flexibility can } \\
\text { be implemented into design (15 to } 20 \\
\text { degrees), which may allow an increase in } \\
\text { operational area and utilize some additional } \\
\text { area inside the cone (if necessary). }\end{array}$ & $\begin{array}{l}\text { Wick structure has to be proven for } \\
\text { operation at liquid metal } \\
\text { temperatures; however, it is well } \\
\text { established for lower-temperature } \\
\text { applications. }\end{array}$ \\
\hline $\begin{array}{l}\text { Intermediate } \\
\text { Mechanical Loop } \\
\text { (System 2) }\end{array}$ & $\begin{array}{l}\text { Significant heritage. } \\
\text { High degree of survivability because of } \\
\text { heat pipes used. } \\
\text { Transport length is not an issue, } \\
\text { determined by the pump. }\end{array}$ & $\begin{array}{l}\text { Single-phase heat exchangers on } \\
\text { both ends of the loop assume } \\
\text { significant temperature drop and } \\
\text { lower (and variable) radiator } \\
\text { temperatures as a result. } \\
\text { Reliability of the pump is an issue. } \\
\text { Liquid metal pump has to be } \\
\text { qualified. } \\
100 \% \text { redundancy on the transport } \\
\text { loop (for each PCU) is required. }\end{array}$ \\
\hline
\end{tabular}


Table 4.9. Summary of pros and cons (cont'd)

\begin{tabular}{|c|c|c|}
\hline & Pros & Cons \\
\hline $\begin{array}{l}\text { Parallel LHP } \\
\text { with direct } \\
\text { condensation } \\
\text { (System 3) }\end{array}$ & $\begin{array}{l}\text { One of the lightest } \\
\text { versions with one of the } \\
\text { highest radiator operating } \\
\text { temperature. } \\
\text { One of the simplest } \\
\text { versions. } \\
\text { Extensive heritage for } \\
\text { lower temperature } \\
\text { applications and lower } \\
\text { powers. } \\
\text { Ease of performance } \\
\text { verification at the } \\
\text { component level. } \\
\text { High degree of freeze } \\
\text { tolerance, low power } \\
\text { consumption for thawing. } \\
\text { (primarily transport lines) }\end{array}$ & $\begin{array}{l}\text { Noticeable amount of "waste" radiator area } \\
\text { required for generating necessary subcooling } \\
\text { (at lower temperatures). } \\
\text { Entire length of the sub cooler needs to be } \\
\text { heated for system restart from frozen } \\
\text { conditions. } \\
\text { Noticeable weight increase due to increase of } \\
\text { internal volumes and amounts of charged } \\
\text { fluid. } \\
\text { Heavier implementation of redundancy } \\
\text { requirements (single penetration causes the } \\
\text { whole LHP to stop operating). } \\
\text { Wick material needs to be developed and } \\
\text { qualified. } \\
\text { Mercury is toxic. }\end{array}$ \\
\hline $\begin{array}{c}\text { Parallel LHP } \\
\text { with indirect } \\
\text { condensation } \\
\text { (System 4) }\end{array}$ & $\begin{array}{l}\text { This concept has smaller } \\
\text { volume, therefore less } \\
\text { fluid and related weight. } \\
\text { Ease of performance } \\
\text { verification-each } \\
\text { component can be tested } \\
\text { separately prior to } \\
\text { integration. } \\
\text { High degree of freeze } \\
\text { tolerance, low power } \\
\text { consumption for thawing } \\
\text { [primarily transport lines] } \\
\text { (reliable, well-established } \\
\text { freeze-tolerant features). } \\
\text { One of the most } \\
\text { developed versions (for } \\
\text { lower powers and } \\
\text { temperature range). }\end{array}$ & $\begin{array}{l}\text { Noticeable amount of "waste" radiator area } \\
\text { required for generating needed subcooling (at } \\
\text { lower temperatures). } \\
\text { The presence of an additional interface LHP- } \\
\text { heat pipe adds extra temperature drop, which } \\
\text { makes the radiator colder and bigger/ heavier. } \\
\text { This system would be more expensive because } \\
\text { of added heat pipes. Does not add any } \\
\text { micrometeoroid protection improvements, } \\
\text { because of the single heat pipe used as a sink } \\
\text { for the LHP condenser (LHP cannot transport } \\
\text { enough power to support radiation from the } \\
\text { radiator, where several heat pipes can be } \\
\text { routed). }\end{array}$ \\
\hline
\end{tabular}


Table 4.9. Summary of pros and cons (cont'd).

\begin{tabular}{|c|c|c|}
\hline & Pros & Cons \\
\hline $\begin{array}{l}\text { Multiple } \\
\text { evaporator } \\
\text { LHP with } \\
\text { mechanical } \\
\text { pump } \\
\text { (System 5) }\end{array}$ & $\begin{array}{l}\text { This concept has smaller volume than } \\
\text { the equivalent amount of LHP/heat } \\
\text { pipe combinations per System } 4 \text {. } \\
\text { There are just two transport lines per } \\
\text { LHP, which means fewer routing } \\
\text { problems and fewer problems with } \\
\text { thawing these lines. High degree of } \\
\text { freeze tolerance, low power required } \\
\text { for thawing (primarily transport } \\
\text { lines). No need to generate } \\
\text { subcooling by "waste" radiator area. }\end{array}$ & $\begin{array}{l}\text { Mechanical pump makes this system } \\
\text { less reliable. Need to provide } \\
\text { redundancy on the mechanical } \\
\text { pumps. The presence of an additional } \\
\text { interface LHP-heat pipe adds extra } \\
\text { temperature drop. This system would } \\
\text { be more expensive. The LHP/heat } \\
\text { pipe becomes a very complicated } \\
\text { branched system. This system was } \\
\text { never demonstrated in full. Reliable } \\
\text { mechanical pump needs to be located } \\
\text { and qualified. Fluid management } \\
\text { concept needs to be verified. }\end{array}$ \\
\hline
\end{tabular}

\subsubsection{Systems Rejected from Consideration}

Based on detailed consideration of the pros and cons listed in Table 4.9, it was decided that just two systems can compete for use in the final Rankine cycle NEP HRS concept design. System 5 with a multiple-evaporator, multiple-condenser, mechanical pump-assisted LHP was dropped from further consideration because of its complexity and low TRL.

- The overall TRL is too low (TRL 2).

- Mechanical pump assist for the multiple-evaporator LHPs is developed in theory but has never been demonstrated.

- Miniature mechanical pumps are not available.

- The depth of development required does not match expectations.

The System 2 option (mechanically pumped loop) was dropped because of its large mass, complexity, freeze-thaw concerns, and low reliability.

- Every joint between the loop and a heat pipe significantly increases temperature drop (condenser area becomes unmanageable for the single-sided approach).

- Flexible inserts to implement the deployable radiator concept are not available and are expected to cause a significant reduction of heat pipe performance.

- Rotateable flexible joints can be used as an alternative for flexible sections in heat pipes; however, the performance degradation would be even more significant.

- A mechanically pumped loop requires implementation of multiple pumps for redundancy, which caused a significant mass increase.

- Since the condenser temperature must vary, operation of the single-phase loop would be affected and the required area would increase even more. 
System 4 was also dropped because it does not add any attractive features (compared with System 3) and has only a negative impact on overall system mass because of the additional interfaces required. This option definitely has a higher overall cost due to the additional components used.

These considerations have left only System 1 and System 3 for the overall NEP Rankine cycle HRS trade-off.

\subsubsection{Design Selection}

After system-level modeling and optimization, System 1 was selected to perform more detailed optimization. System 1 offers lower mass and radiator area, providing the best combination of mass and area for all of the HRS options evaluated, with the highest simplicity and reliability rating. Freeze-thaw considerations were also another important factor, making System 1 attractive.

In addition, $\mathrm{Nb}-1 \% \mathrm{Zr}$ was recommended as the main material for all components in order to avoid joining dissimilar materials. Major components include the Rankine loop condenser manifold, the heat pipes, and the radiator facesheet. Potassium was recommended as the working fluid. The system performance was modeled for these materials, and the result of this analysis was included in the ALKASYS-SRPS code. A chart of HRS mass vs. operating temperature is presented in Fig. 4.38, and system area vs. operating temperature curves are presented in Fig. 4.39. These curves demonstrate that the main parameters of the selected design are dependent on heat transport length as well as the operating temperature. Proper packaging of the heat pipes in the HRS radiator would minimize the heat pipe transport zone and the associated radiator sections. The design of the heat pipes used in this modeling exercise was identical for each operating temperature; therefore, it appears that at low temperatures it becomes sonic limit restricted. This implies that detailed optimization of each component should be conducted after the general decision about concept selection. Table 4.10 presents the comparison of two heat pipe design approaches at $700 \mathrm{~K}$ : sonic limited (the same design used for all of the previous considerations) and transport limited (the heat pipe was re-designed to have the transport limitations prevail over sonic limitations).

Overall Rankine cycle system-level modeling has determined that an optimal system would operate at $865 \mathrm{~K}$ at the entrance into the Rankine cycle condenser manifold. The redundancy approach recommended for future consideration is a $1+1$ formula with $100 \%$ redundancy on the PCU and HRS level, which means that each PCU would utilize its own HRS equipped with a separate radiator. It is necessary to note that all previous analysis for the $1+1$ option was performed for two PCUs sharing the same radiator facesheet; this approach was changed for the final design optimization. 
Total HRS Mass Including Redundancy

HRS based on HPs with Potassium (at $400 \mathrm{kWt}$ and variable transport length)

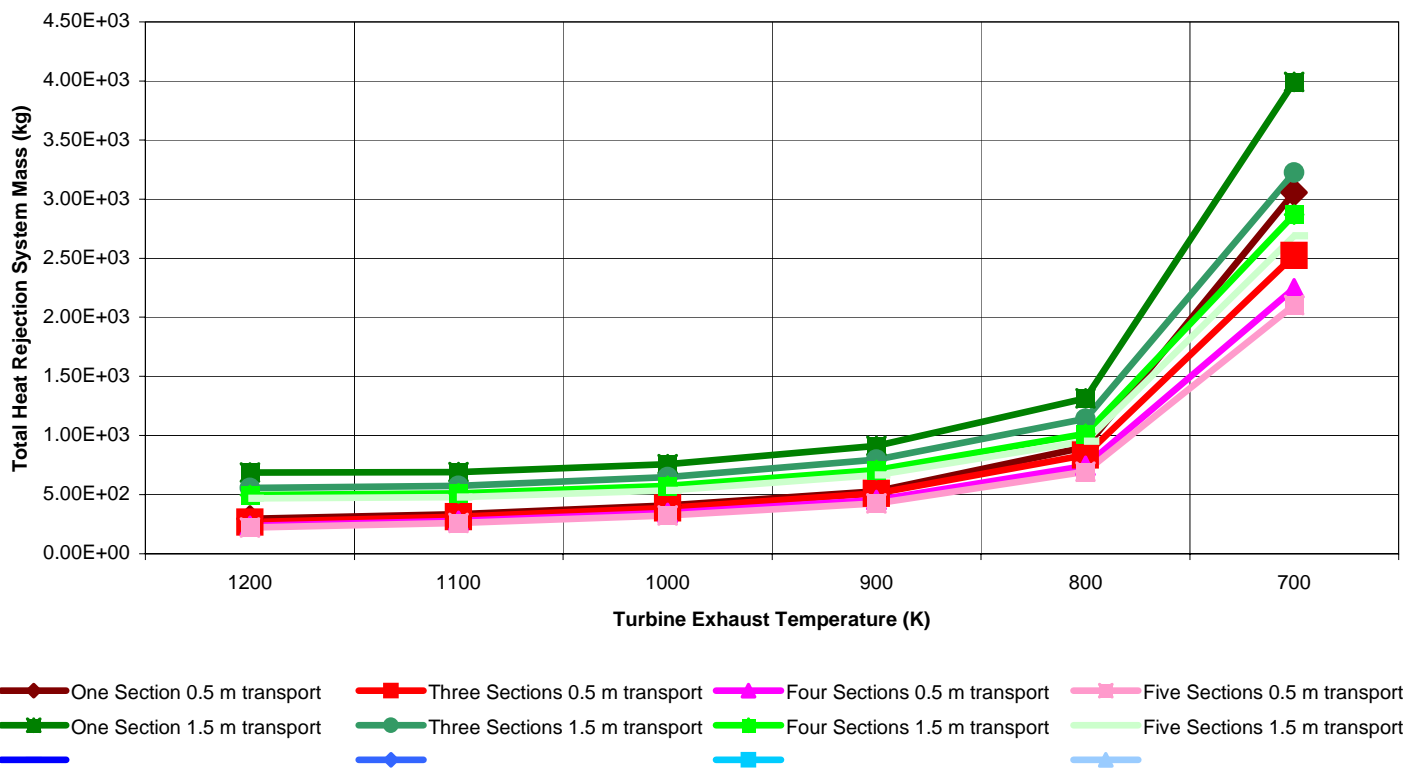

Fig. 4.38. System 1 with potassium and Nb-1\%Zr. Total heat rejection system mass.

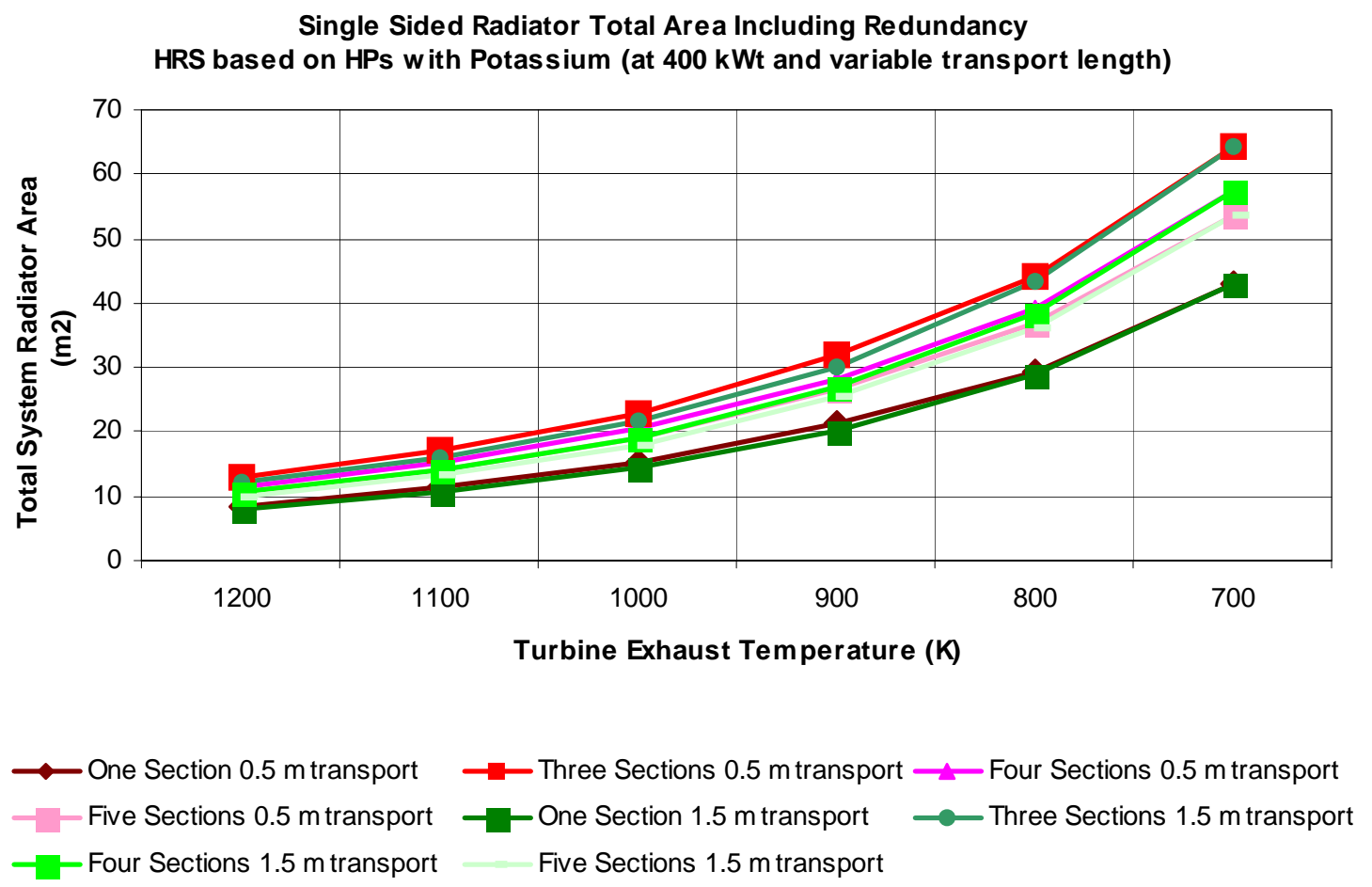

Fig. 4.39. System 1 with potassium and Nb-1\%Zr. Total system area. 
Table 4.10. Sonic and transport limit heat pipe comparison

\begin{tabular}{|c|c|c|}
\hline & Sonic limited $0.5 \mathrm{~m}$ & Transport limited $0.5 \mathrm{~m}$ \\
\hline Temperature (K) & 700 & 700 \\
\hline Number of heat pipes & 3808 & 514 \\
\hline Heat pipe ID (cm) & 2.0 & 6.45 \\
\hline Power one heat pipe (W) & 231 & 1712 \\
\hline Sonic limit (W) & $2.88 \mathrm{E}+02$ & $2.21 \mathrm{E}+03$ \\
\hline Heat pipe length $(m)$ & 1.592 & 2.837 \\
\hline heat pipe total weight $(\mathrm{kg})$ & $2.75 \mathrm{E}+03$ & $1.74 \mathrm{E}+03$ \\
\hline Radiator area $\left(m^{\wedge} 2\right)$ & 42.961 & 48.905 \\
\hline Mass of the radiator $(\mathrm{kg})^{\mathrm{a}}$ & 308.441 & 351.114 \\
\hline $\begin{array}{l}\text { Total heat rejection system } \\
\text { mass }(\mathrm{kg})\end{array}$ & $3.05 E+03$ & $2.09 \mathrm{E}+03$ \\
\hline Specific weight $\left(\mathrm{kg} / \mathrm{kW}_{\mathrm{t}}\right)$ & 7.635 & 5.222 \\
\hline
\end{tabular}

This combination of parameters makes the System 1 option a superior solution. This design is used as a baseline for further study and development testing of key features in the Phase II program.

After the system selection was made, a more detailed analysis was performed to investigate the trends and potential gains from varying one or several design parameters of the HRS. The whole optimization process for the selected system can be reduced to a compromise between how much power the heat pipe can extract from the Rankine cycle condenser manifold and how much power can be rejected from the heat pipe condenser with the associated radiator facesheet attached to it. It is assumed that the transport length is fixed at $0.5 \mathrm{~m}$. This value can be updated when a detailed system layout is generated, including all system restrictions on routing and connections.

Optimization of heat pipe transport and condenser radiation capabilities was performed by varying two main parameters of the system: heat pipe ID and the width of the fin associated with the heat pipe condenser. The internal structure of the heat pipe in each optimization case was chosen to avoid conflict between the transport and sonic limitations. It was assumed that transport limitations would be approximately $80 \%$ of sonic limits (rule of thumb for the heat pipe industry). Based on this assumption, the ratio between the heat pipe ID and the wick structure OD was selected (see Table 4.11). The main idea of system optimization was that the heat pipe cannot transport more heat than its radiator can reject, and visa versa. The condenser length was optimized to satisfy this assumption for each combination of the heat pipe ID and fin width.

Based on the review of the optimization results, the combination of a 1-in.-ID $(2.54 \mathrm{~cm})$ heat pipe associated with a 1-in.-wide $(2.54 \mathrm{~cm}$ ) fin on the condenser (on each side of the condenser) looks attractive. These results can only be considered as preliminary, and some detailed heat pipe modeling, together with updates of the system analysis, may be required during Phase II of the project. It is not expected that results would vary by more than $10 \%$. 
The following three charts (Figs. 4.40, 4.41, and 4.42) and Table 4.11 summarize the optimization process and provide the look-up field for the NEP Rankine PCU optimization.

Table 4.11. Some heat pipe optimization results

\begin{tabular}{ccccc}
\hline ID HP (in) & Fin (in) & Q HP (W) & HP/wick ratio & L cond $(\mathrm{m})$ \\
\hline 1.5 & 1.5 & 7882 & 1.5 & 3.35 \\
1.25 & 1.5 & 5712 & 1.6 & 2.59 \\
1 & 1.5 & 4071 & 1.55 & 1.98 \\
0.75 & 1.5 & 2389 & 1.65 & 1.24 \\
1.5 & 1 & 7457 & 1.5 & 3.4 \\
1.25 & 1 & 5500 & 1.6 & 2.7 \\
1 & 1 & 3958 & 1.55 & 2.13 \\
0.75 & 1 & 2285 & 1.65 & 1.35 \\
1.5 & 0.5 & 6777 & 1.5 & 3.9 \\
1.25 & 0.5 & 4960 & 1.6 & 3.15 \\
1 & 0.5 & 3441 & 1.55 & 2.44 \\
0.75 & 0.5 & 2062 & 1.65 & 1.65 \\
\hline
\end{tabular}

Number of heat pipes Utilized in the HRS (1+1) One Section

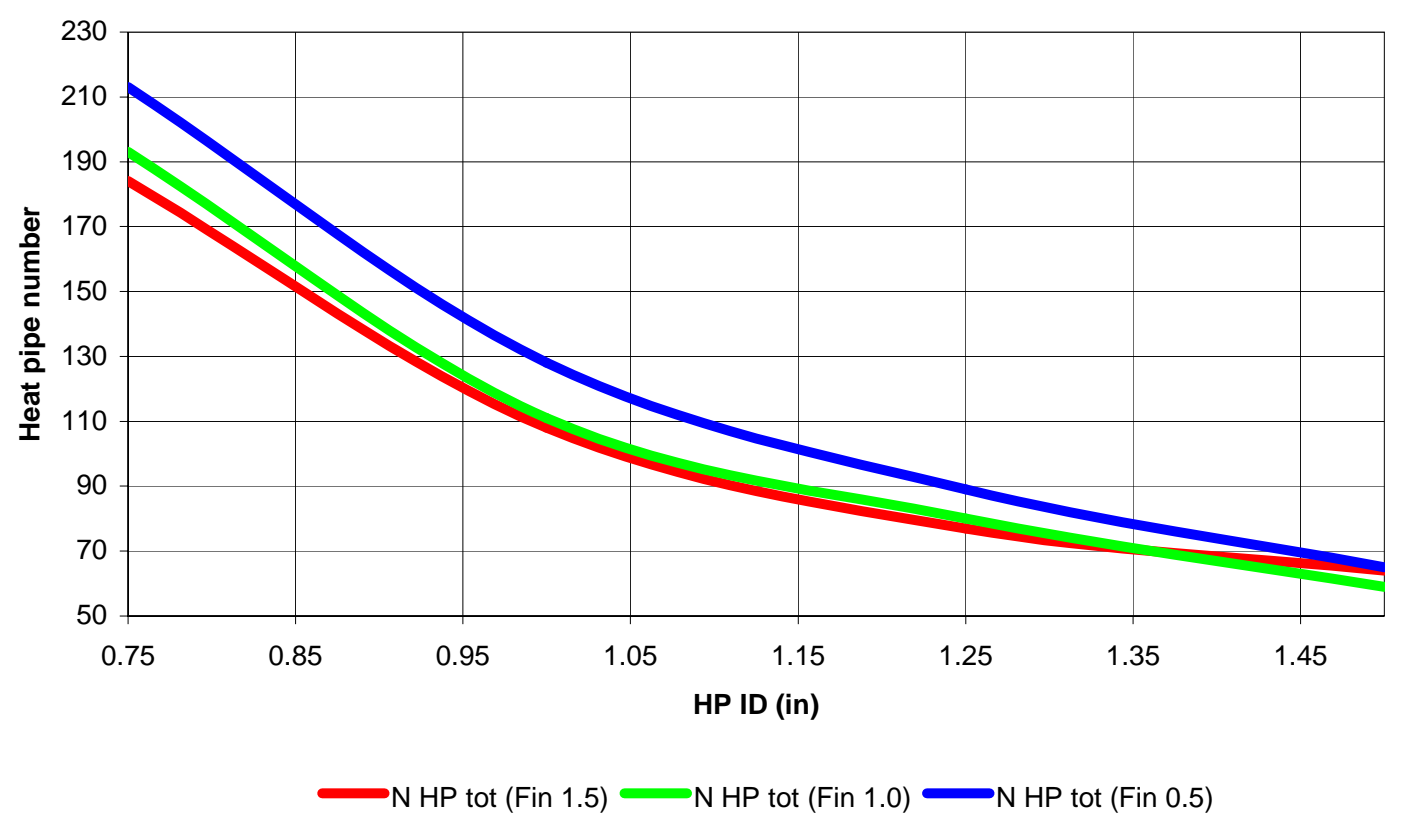

Fig. 4.40. System 1 (optimization). Number of heat pipes required (one PCU). 
Total Mass of HRS (1+1)

One section

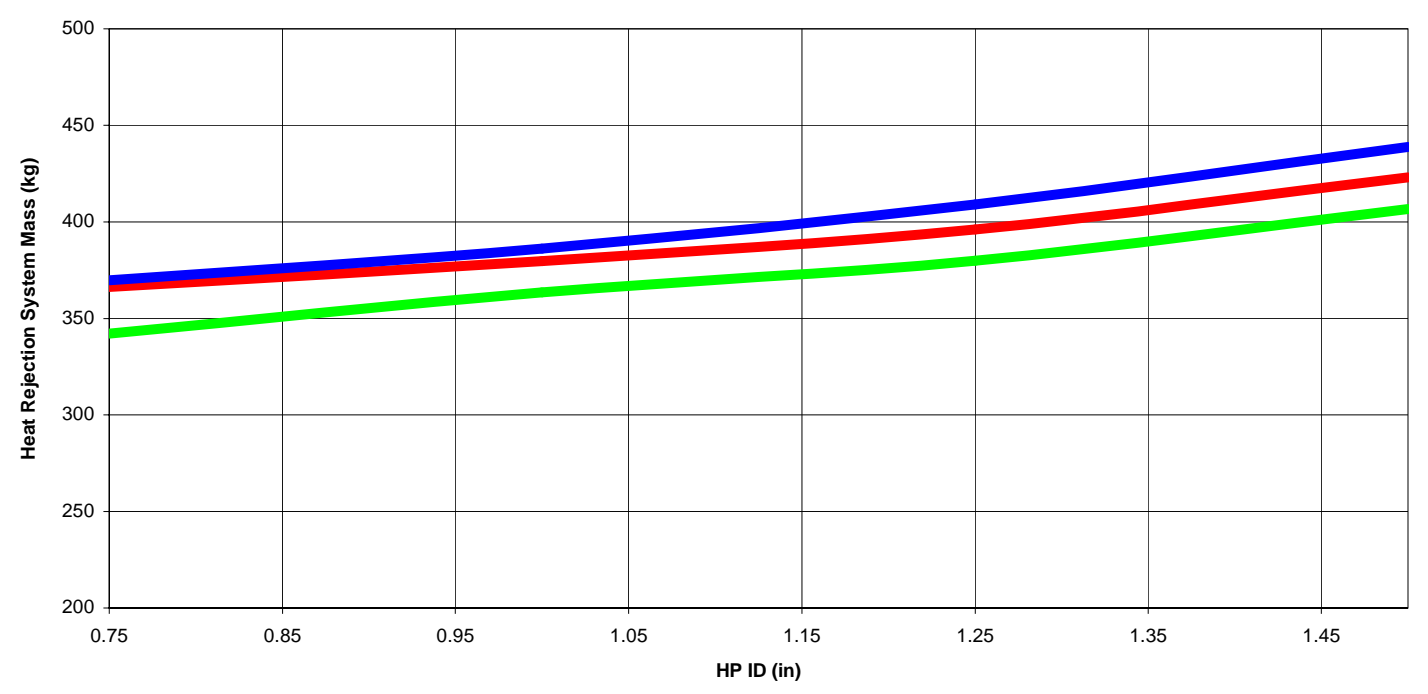

$\longrightarrow$ M syst (kg) (Fin 1.5) M syst (kg) (Fin 1.0) $\longrightarrow$ syst (kg) (Fin 0.5)

Fig. 4.41. System 1 (optimization). Total mass of HRS (one PCU).

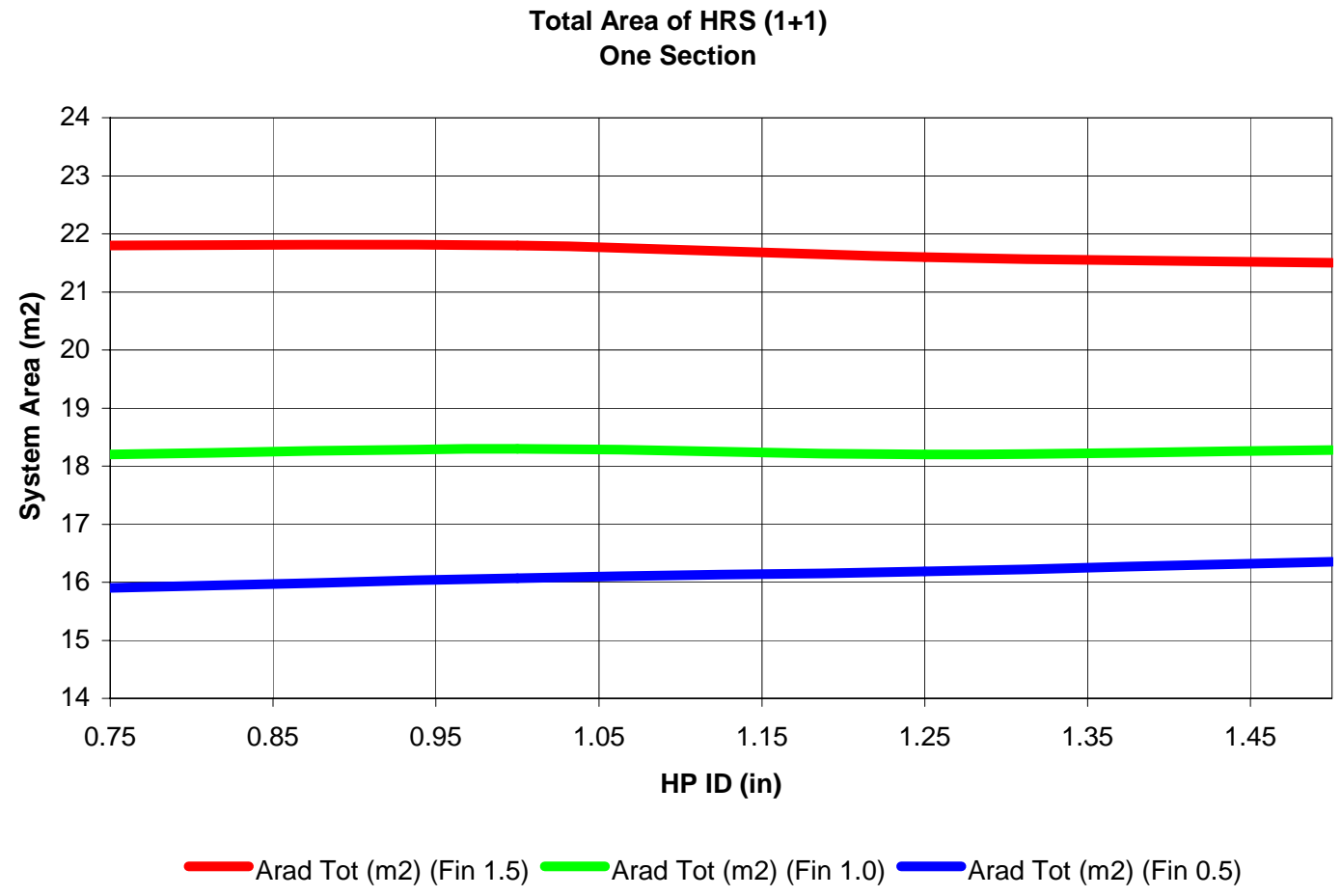

Fig. 4.42. System 1 (optimization). Total area of HRS (one PCU). 


\subsubsection{Packaging}

In order to determine overall system geometry, it was assumed that a maximum diameter of $4.5 \mathrm{~m}$ was available in a heavy lift vehicle. In addition, it was assumed that the reactor shield had a $26^{\circ}$ cone angle. Since two independent radiators were needed for the design, it was decided that one HRS would have a conical shape with the cone angle of $26^{\circ}$ and a diameter at the bottom of $4.5 \mathrm{~m}$. The second HRS would have a radiator shaped as a cylinder with 4.5-m OD. Figure 4.43 illustrates the proposed packaging approach. The optimization case described in the previous section (1-in. [2.54 cm] heat pipe ID and 1-in. [2.54 cm] fin) was selected to demonstrate the packaging approach.
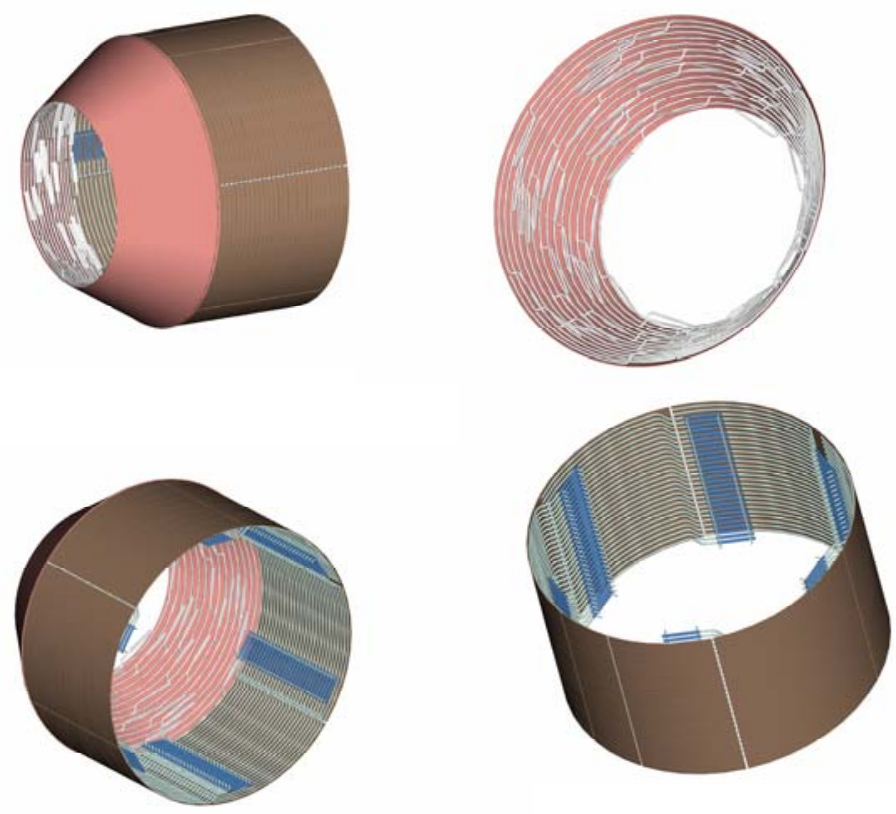

Fig. 4.43. Nuclear electric power HRS suggested packaging approach.

The conical HRS consists of a number of heat pipes with a 3-in.-wide $(7.62 \mathrm{~cm})$ section of radiator facesheet attached to the entire heat pipe condenser length. The beginning of the next heat pipe condenser is touching the end of the previous facesheet, forming an uninterrupted band spiraling up from the bottom of the cone to the top edge of the cone. This approach allows maximum utilization of the cone's surface and would be related only to minor difficulties in routing the PCU condenser manifold to cover each heat pipe evaporator. The cylindrical packaging approach for the second PCU is also shown in Figs. 4.43 and 4.44. Condensers with face sheets attached are organized in cylindrical sections; each of these sections contains 6 heat pipes. Cylindrical packaging provides a very easy and straightforward method for Rankine cycle condenser manifold routing. 

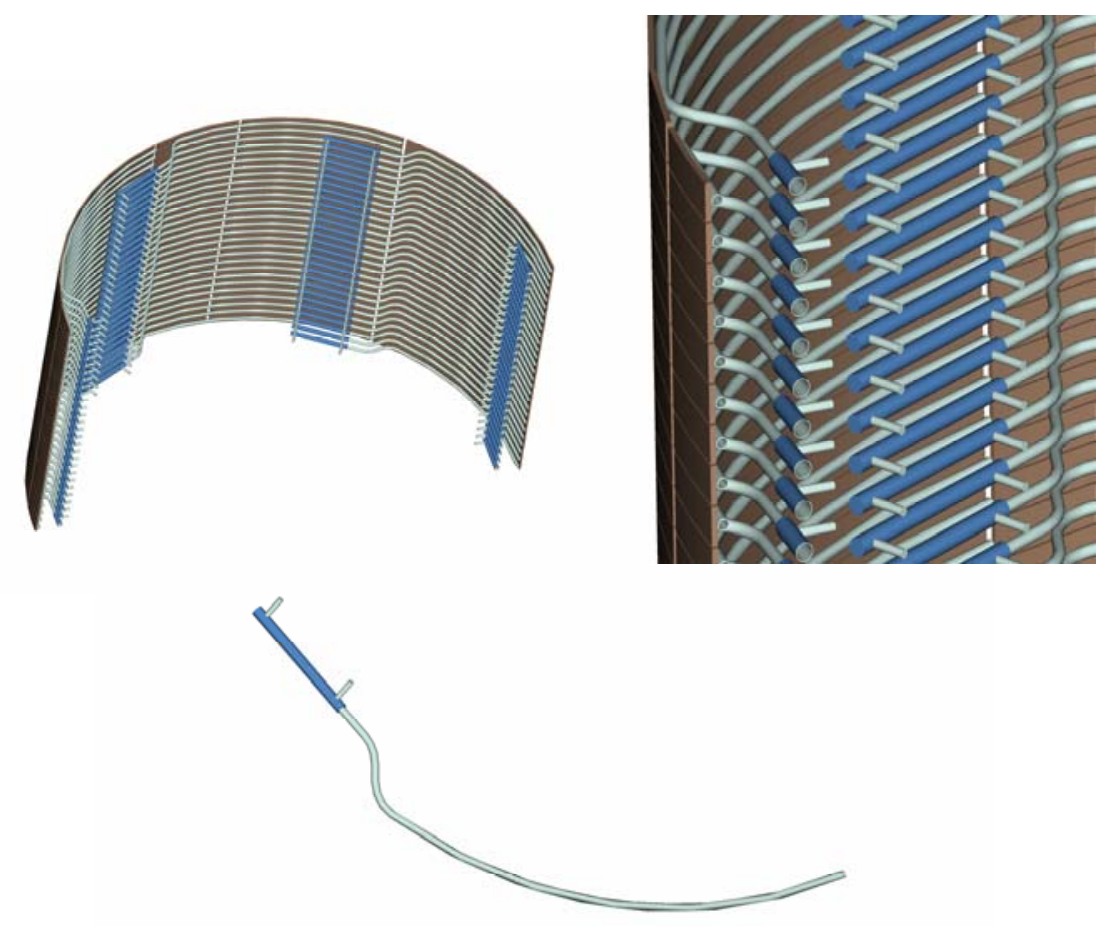

Fig. 4.44. Nuclear electric power HRS suggested shape of heat pipes and condenser manifold routing.

This packaging approach looks very attractive for future system testing. In order to obtain proper performance measurements during heat pipe testing, the heat pipe would need to be tested in the horizontal (or close to horizontal) position. The proposed packaging approach allows testing of the entire system with the heat pipes horizontal.

\subsubsection{Main Components}

This section presents highlights of some critical HRS components and their parts.

\subsubsection{Heat Pipe}

The heat pipe design concept proposed in the present study is well established and proven for lower temperatures and has been used in several flight applications. The main feature of the heat pipe design is the fibrous wick. The cross-section schematic is presented in Fig. 4.45. The heat pipe is constructed from $0.020-\mathrm{in} .(0.05-\mathrm{cm}) \mathrm{Nb}-1 \% \mathrm{Zr}$ tube and endcaps welded to the ends to seal the envelope. 


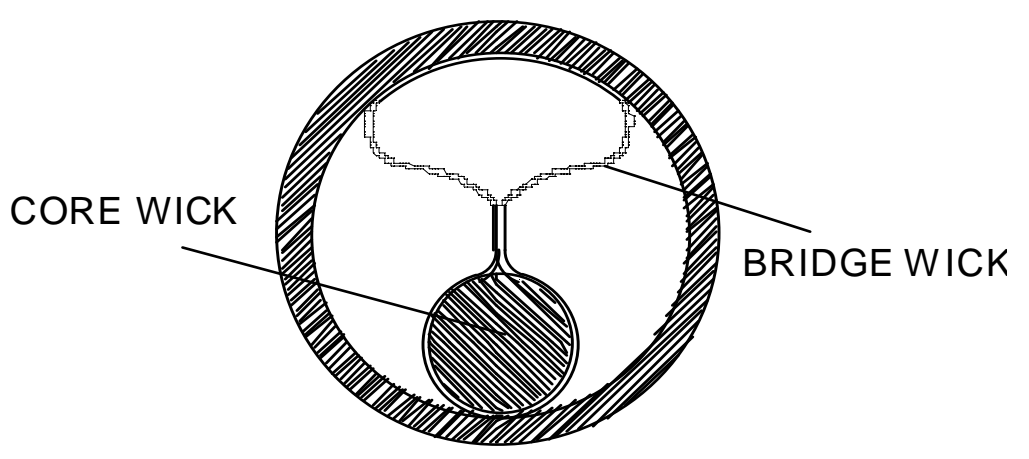

Fig. 4.45. Fibrous wick for the heat pipe design. Cross section.

There are still several open questions that need to be addressed for the high-temperature, long heat pipes:

- Compatibility of materials (envelope, wick) with the working fluid

- Compatibility of the capillary structure design with the design of the rest of the pipe

- Performance of the capillary structure for long heat pipes

- Manufacturing technique and approaches for fabrication of a long (up to $4 \mathrm{~m}$ ) heat pipe

- Thermal cycling tolerance

- Long life and compatibility with space radiation

\subsubsection{Radiator}

Heat rejection is provided by radiators, which would be constructed from a 0.040 -in. thick $(10.16 \mathrm{~cm}) \mathrm{Nb}-1 \% \mathrm{Zr}$ facesheet. The shape of the radiator would be either a cone or a cylinder, depending on the PCU that it serves.

\subsubsection{Rankine Cycle Loop Condenser/ heat pipe Interface}

The Rankine cycle condenser would be constructed as an annulus around the evaporator with some flow turbulizers and mixing devices to enhance the heat exchange and to provide uniform condensation of Rankine vapor over the evaporator surface (see Fig. 4.21). The lowertemperature version of this device has already been developed and was proven to work well.

More than 100 Rankine cycle condensers of this design would be required to reject the entire amount of heat. These condensers are plumbed in parallel so that the pressure drop through the overall heat exchanger is minimal. All of the trade-off calculations discussed in this section were based on an 18-in.-long $(45.72 \mathrm{~cm})$ heat pipe evaporator (Rankine condenser). This length would be updated after the film coefficients for condensation of potassium on the finned surface are finalized.

The pressure drop through the condenser manifold is somewhat unknown; therefore, it is premature to design the connection between the individual condensers. They can be connected in parallel or in series. Parallel connection would minimize pressure drop through the Rankine loop, 
but series connection would simplify routing of the condenser-to condenser connections. A final version of the condenser manifold design probably would be a combination of parallel and series connections.

\subsubsection{Flow Distributors}

Flow distributors, along with capillary isolators, are one option that may be used to prevent vapor penetration beyond the Rankine cycle condenser into the liquid manifold. This kind of device is widely used to manage flow in parallel condenser systems. The main part of the flow distributor is a capillary isolator, which is actually a piece of a porous structure. This structure, while wet, creates a capillary force preventing vapor bubble penetration from the condensate line (exit from the actual condenser) into the liquid manifold that collects liquid from multiple condensers. The liquid permeability of a capillary isolator is very low; therefore, it does not add any significant pressure drop into the overall Rankine cycle system.

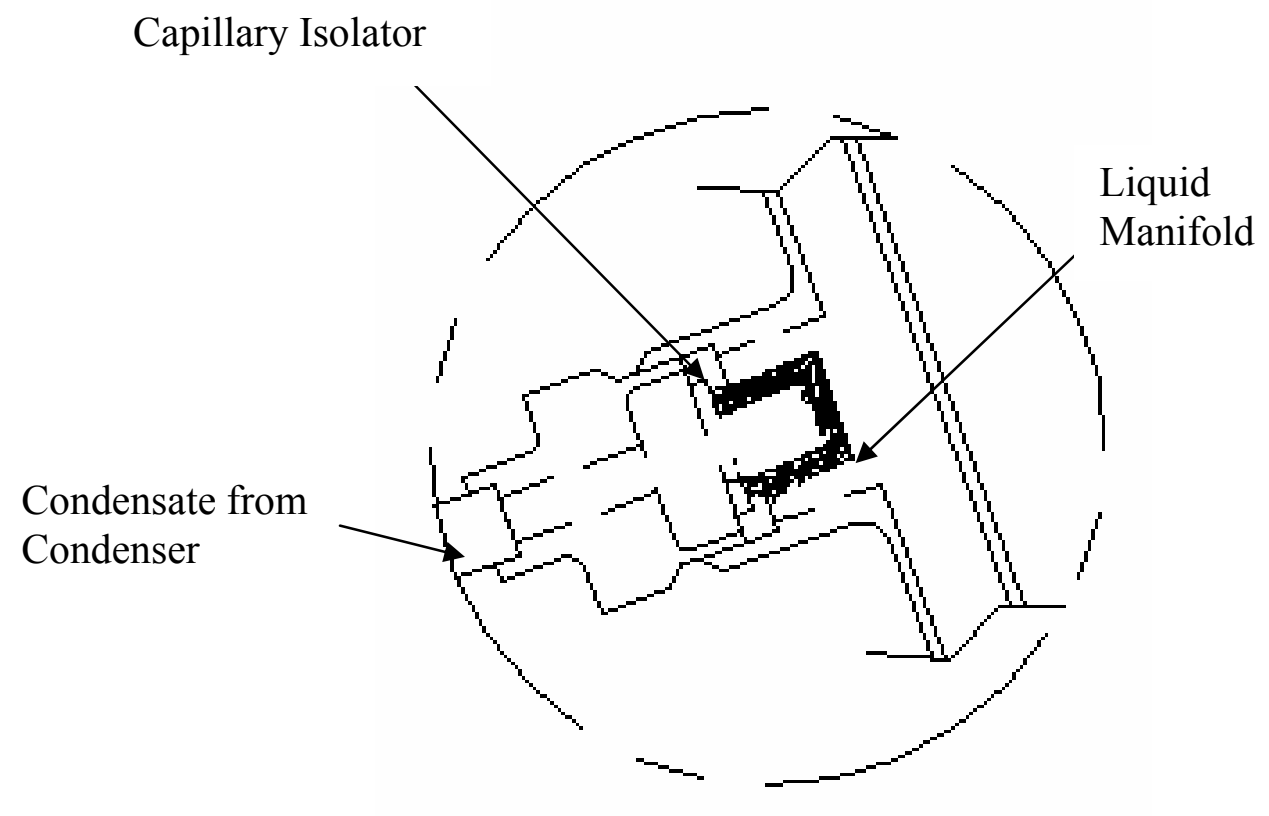

Fig. 4.46. Flow distributor.

A sample isolator design is presented in Fig. 4.46. In this design, the flow distributor is made from a 20-micron stainless steel wick structure that creates a capillary barrier preventing superheated vapor from exiting the condenser. In addition, it assumes that condensation in multiple condensers is uniform. The hydraulic resistance of this isolator for liquid is just $2.5 \%$ of the overall external loop hydraulic resistance.

The specific design of the flow distributor for the Rankine HRS depends mostly on the pressure drop between the most- and least-stressed condensers. It also depends on the allowable pressure drop provided by the Rankine cycle boiler feed pump.

The proposed approach provides a reliable and simple means to manage the uneven flow of condensate between the condensers of the Rankine cycle loop. However, the effectiveness of this device in an actual loop would depend on how much NCG would be produced in the loop 
during the operating life time and the solubility of these NCGs in the working fluid. If the bubble of the NCG blocks the flow distributor, the flow of the condensate may stop and the condenser would betemporarily excluded from the overall heat transfer. To avoid such a situation, the flow area of the isolator would be maximized so that the probability of the NCG bubble with a size large enough to block the entire surface of the isolator is minimized.

\subsubsection{Freeze-tolerant Features}

It is well known that heat pipe behavior during start from the frozen state can be unpredictable; and most likely, without any special measures, the heat pipe would not start at all. The issue with freezing of the heat pipe and restarting from frozen conditions is very important for high-temperature applications with liquid metal heat pipes, because their working fluid is in a solid state at room temperatures and below. The main reason the heat pipe does not re-start after being frozen is that during the freezing process, the evaporator is the warmest spot on a heat pipe; and while the condenser temperatures are already below freezing, the evaporator is still producing vapor. After being condensed in the condenser, the working fluid freezes and builds up in the condenser and cannot be returned to the evaporator. As a result, the evaporator is starved and then dries out. During thawing, heat is applied to the evaporator, but there is no fluid in the wick structure to be vaporized and initiate thawing of the rest of the heat pipe. One of the best measures to guarantee reliable restart is gas loading of the heat pipe (with some amount of NCG). There are other known ways to provide some degree of freeze tolerance, such as organized thawing, thaw-assisting heaters, and others; however, all of them are related to some heating and preconditioning of a heat pipe prior to startup. The method of loading the heat pipe with some amount of NCG is the most reliable and worry-free method to guarantee heat pipe start from frozen conditions.

Loading a heat pipe with some amount of NCG provides reliable blockage of the heat pipe's vapor space at temperatures close to freezing. Therefore, the vaporized working fluid can be condensed only in the vicinity of the evaporator without penetrating the cold condenser zone. The lower the temperature, the more blockage of the condenser is provided by the NCG load. When the temperature is approaching the freezing point, the entire heat pipe is blocked with NCG. Vapor cannot leave the evaporator area and freezes there.

The simplicity and reliability of this method has a minor drawback at the normal, hightemperature operating point. In the high-temperature environment, the NCG load is compressed by the internal pressure and is collected in a "blind end" of the condenser, blocking it. The percentage of condenser blockage is very small, however, just a few percent, depending on the temperature difference between the operating and freezing temperatures and on the internal design of the heat pipe.

\subsection{SYSTEM DESIGN}

The flow paths through one loop are shown schematically in Fig. 4.47. Each 115-kW PCS (from alternator to PMAD) comprises four separate loops: (1) startup loop, (2) main potassium loop, (3) bearing cooling loop, and (4) alternator and PMAD cooling loop. 


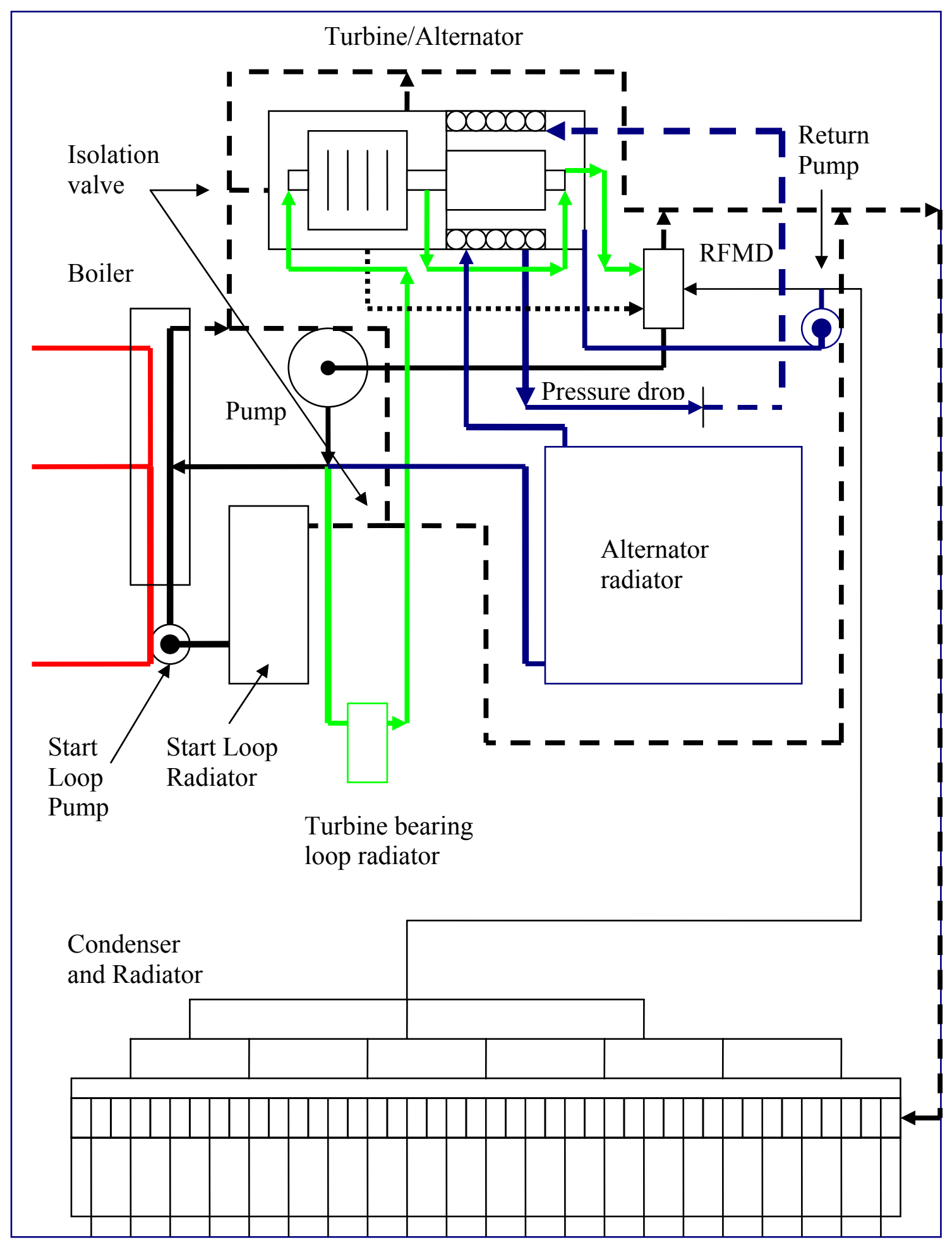

Fig. 4.47. Flow schematic of the 115-kW(e) Rankine system (from alternator to PMAD). Dashed lines are primarily vapor. Lithium flow is red. The bearing cooling and alternator cooling loop is green, and the alternator rotor cooling loop is in blue. 
The major components of the system are as follows:

\author{
Boiler \\ Vapor control valve \\ Turbine bypass loop \\ Turbine \\ Alternator \\ Condenser \\ Main radiator \\ Liquid return lines \\ RFMD \\ Main pump \\ Startup pump \\ Startup radiator \\ Startup loop shutoff valve \\ Alternator cooling loop radiator \\ Alternator cooling loop pressure drop device \\ Rotor cooling loop return pump.
}

All components are duplicated for each PCS with the exception of the boiler, which is common to both units.

\title{
4.9.1 Power Conversion Layout
}

The PCS components, including the radiators, are arranged behind the shield to protect them from a direct line of sight to the reactor. There are no other restrictions on system layout other than that it must fit within the available payload volume of the launch vehicle. The approximate payload volume of a Delta 4 heavy lift vehicle has been assumed for the layout presented here. A rendering of a possible layout of the PCS components (excluding the radiators) is shown in Fig. 4.48.

Consideration does have to be given to the orientation of rotating components that could possibly impact attitude control of the vehicle. For this effort, however, we are considering only the location and connection of the components. The turbine and alternators are shown rotating perpendicular to the main vehicle axis and in opposite directions in Fig. 4.48.

All system components are $\mathrm{Nb}-1 \% \mathrm{Zr}$, and the system joints are welded or brazed. The layout would be strongly driven by the ability to gain the required access to joining surfaces to perform the brazing and welding and, just as importantly, inspect the results. Each component has a minimum of two connection points, and most have more. A summary of the possible connections is listed in Appendix C. 


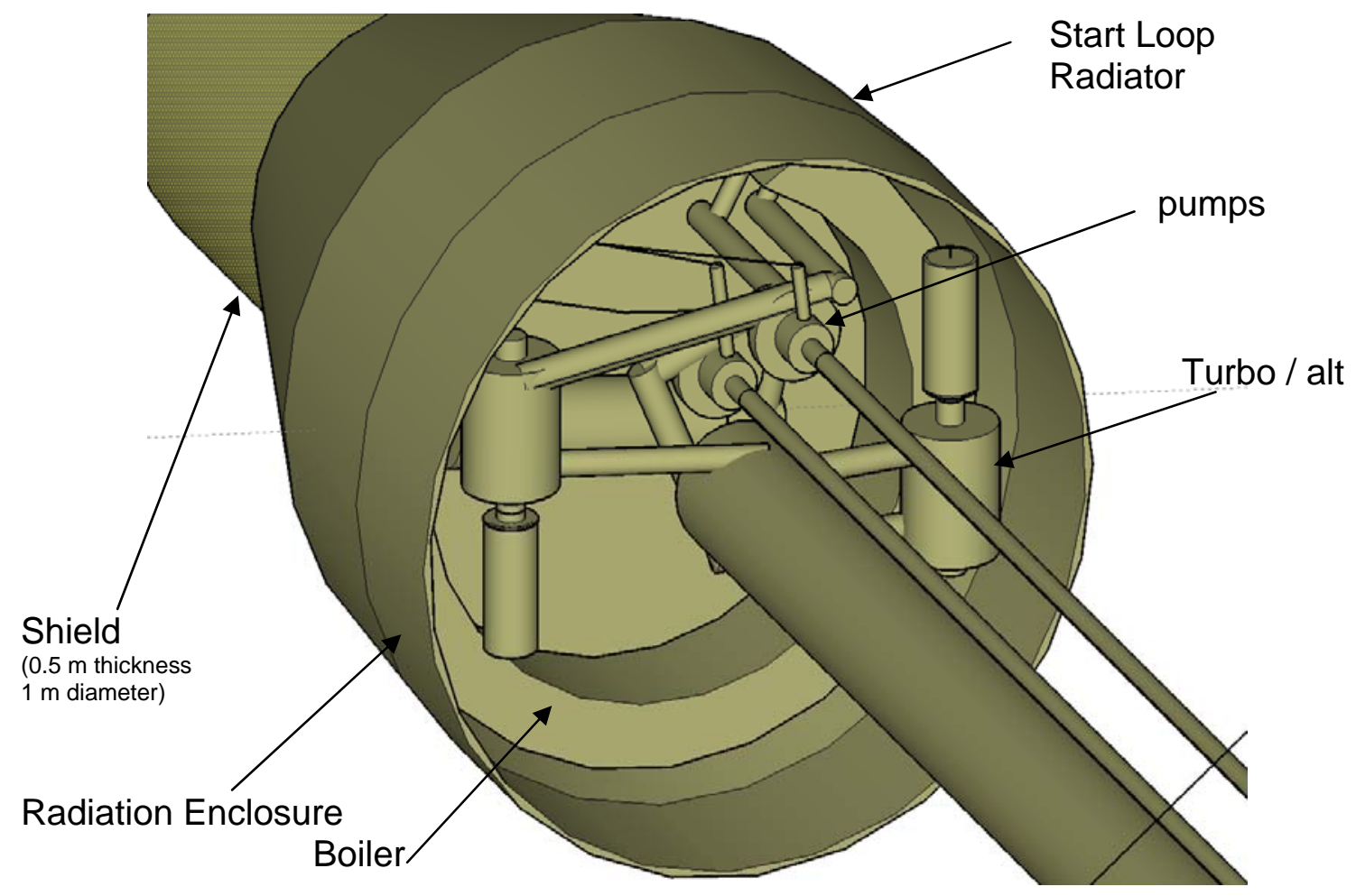

Fig. 4.48. Rendering of the arrangement of the $115 \mathrm{~kW}(\mathrm{e})$ rankine system components. The boiler is positioned against the rear of the shield.

For this study, the diameter of the back of the shield was assumed to be $1 \mathrm{~m}$. This value would change when more realistic reactor and shield designs are considered; however, they are not the primary focus of this effort. The boiler was designed to curve along the outer perimeter of the back of the shield. Therefore, the diameter of the shield determines the length available for the boiler.

For this system, two separate groups of 12 tubes were required in the boiler to supply the required amount of vapor within the available length. Fig. 4.48 shows that adequate room exists at each end of the boiler to accommodate the required lithium and potassium piping connections.

The reactor coolant ALIP pump is located against the back of the shield within the bend of the boiler as is shown in Fig. 4.49. 


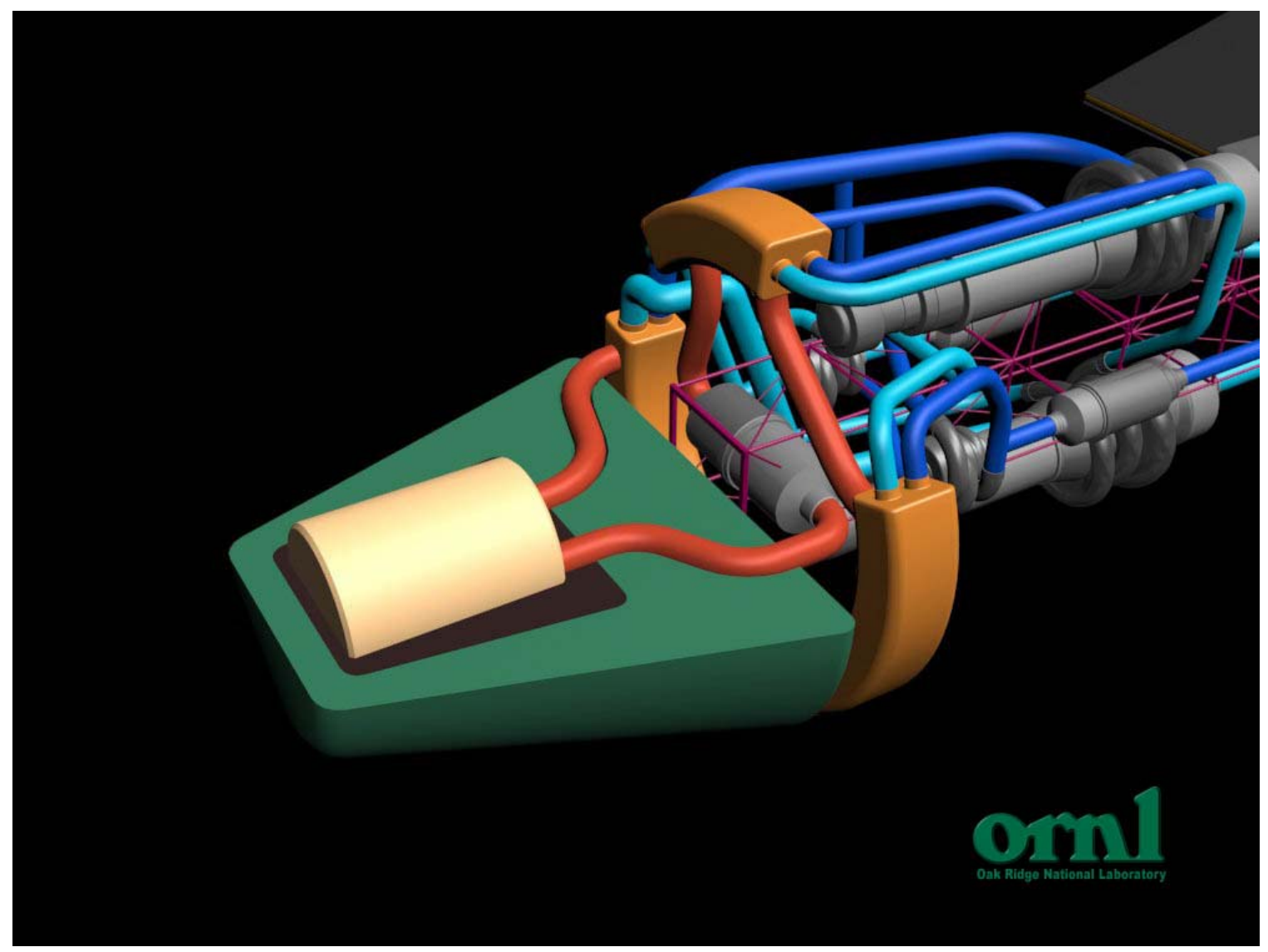

Fig. 4.49. Rendering of a potential layout (not optimal) of a reactor within a shield connected to two power conversion units.

Curved piping (red) through shield (green) transports lithium to the boiler and from the reactor coolant pump (gray). Separate potassium inventories circulate through the boiler and to the turbines (light and dark blue piping).

The turbines and alternators developed for the $115-\mathrm{kW}_{\mathrm{e}}$ power system are relatively small. The combined overall length of the turbine is approximately $60 \mathrm{~cm}$. The overall outer dimension of the turbine housing is an estimated $10 \mathrm{~cm}$, and the alternator OD is approximately $13.6 \mathrm{~cm}$. Two turbine-alternator combinations can fit within the ID of the boiler; however, they would be displaced axially because of the location of the reactor coolant pump.

\subsubsection{Radiator Layout}

The largest components of the system are the main radiators. Approximately $27 \mathrm{~m}^{2}$ of surface area is required for the main radiators to reject the waste heat from the system to space for each of the two units. An additional $3 \mathrm{~m}^{2}$ is required for low-temperature radiators. Two 
options for the radiator design are single-sided conical radiators or flat radiators that reject heat from both sides.

The heat pipe diameter and evaporator length set the fundamental dimensions of the condenser. The heat pipe transport length (the distance from the evaporator section to the condensation section) can vary; but as it increases, performance decreases. As a result, more heat pipes are required to carry the waste heat. The better designs minimize heat pipe transport lengths and therefore the number of heat pipes.

The heat pipe diameter is estimated to be $1.9 \mathrm{~cm}$ for this system. The heat pipe diameter is the basic minimum component thickness for the condenser and radiator. The condenser surrounds each heat pipe with a tapered annular region that is approximately $2.5 \mathrm{~cm}$ in diameter at the entrance and approximately $2.0 \mathrm{~cm}$ in diameter at the exit where liquid is extracted.

The heat pipes condense the potassium working fluid over an evaporation section (evaporator section of the heat pipe) of approximately $45 \mathrm{~cm}$. The heat pipe evaporator length dictates the length of the tapered channel around the heat pipe, and that dimension plus the inlet and outlet manifolds determine the width of the condenser.

A flat panel radiator requires a condenser with a minimum characteristic length equal to the evaporator section of the heat pipe, which is approximately $45 \mathrm{~cm}$. With the addition of an entrance manifold, the characteristic minimum dimension of the condenser is estimated to be 50 $\mathrm{cm}$. The minimum-configuration-width two-panel layout would be one in which the two condensers overlap along the central axis of the vehicle. If a 4.5-m-diameter launch vehicle payload were available, then approximately $4 \mathrm{~m}$, or $2 \mathrm{~m}$ per radiator, would be available for the heat rejection surface. The required length of the two-panel flat radiator layout would therefore be approximately $6 \mathrm{~m}$, and fits within the available payload lengths of the launch vehicle.

The radiator must also fit within the shielded volume and is tapered toward the shield. A system layout with two flat-panel radiators is shown in Fig. 4.50. It is possible for such an arrangement to work with the $115-\mathrm{kW}_{\mathrm{e}}$ systems (from the alternator to the PMAD) and fit within the volume of available launch vehicles if the radiator is shared between both redundant PCUs.

The overall length of the radiators can be reduced, and redundant radiators (one radiator for each PCU) can be accommodated by using single-sided conical and cylindrical radiators, as opposed to flat-panel radiators. For a conical radiator, the characteristic length would be the required area $\left(27 \mathrm{~m}^{2}\right)$ divided by the available circumference (approximately $13.5 \mathrm{~m}$ ), which is approximately $3.5 \mathrm{~m}$. The characteristic length of two axially displaced conical and cylindrical radiators saves an estimated $2.5 \mathrm{~m}$ of length and accommodates redundant radiator systems. A layout showing a concial and a cylindrical radiator is shown in Fig. 4.51. The radiators are formed from six smaller condenser and radiator panels. 


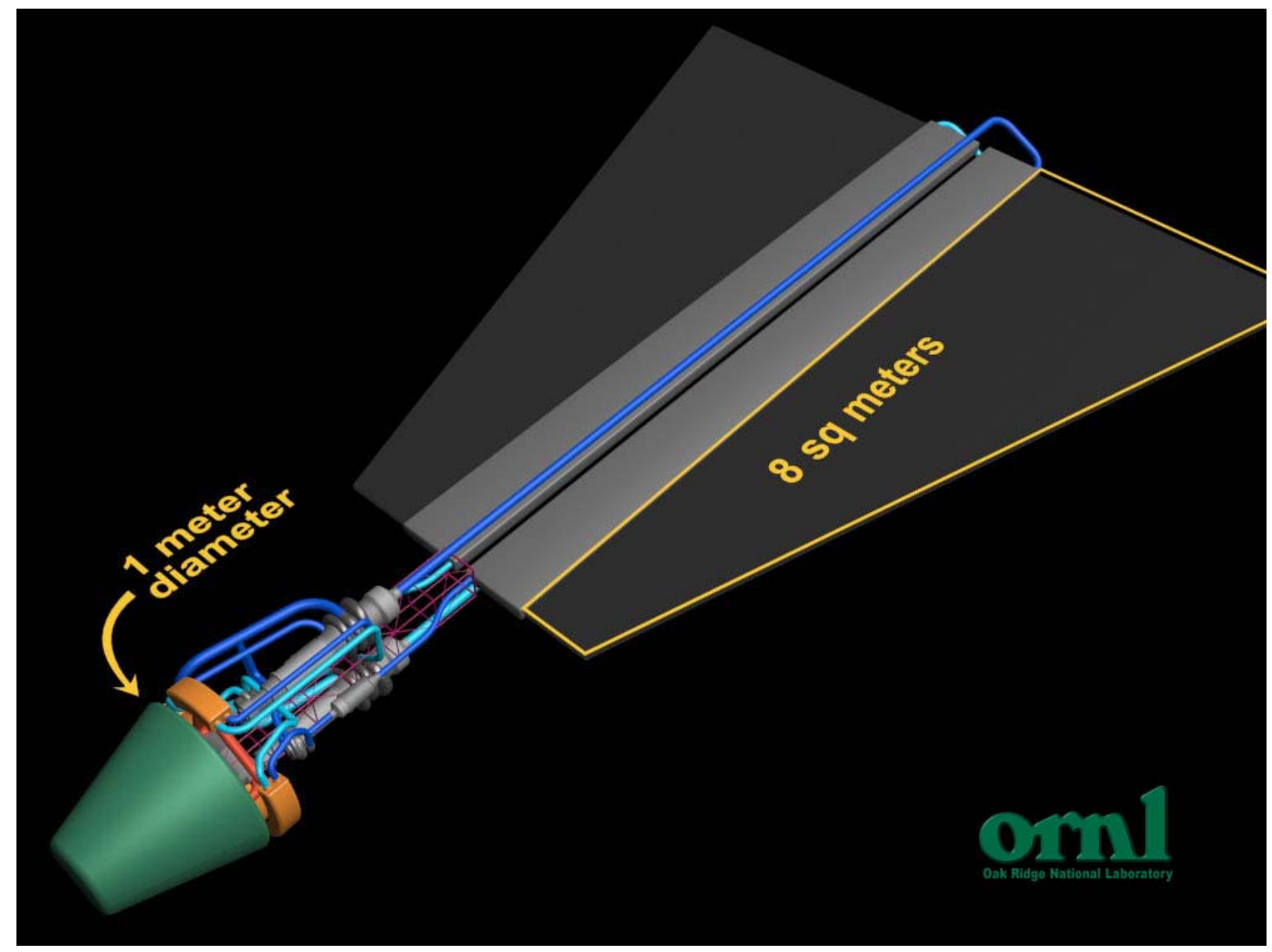

Fig. 4.50. Rendering of a system layout for two 115-kWe systems (from the alternator to the PMAD) positioned behind a shield with a diameter of $\mathbf{1} \mathbf{~ m}$. The total radiator surface area represented is $32 \mathrm{~m}^{2}$, which is more than required for a radiator shared by both PCUs. 


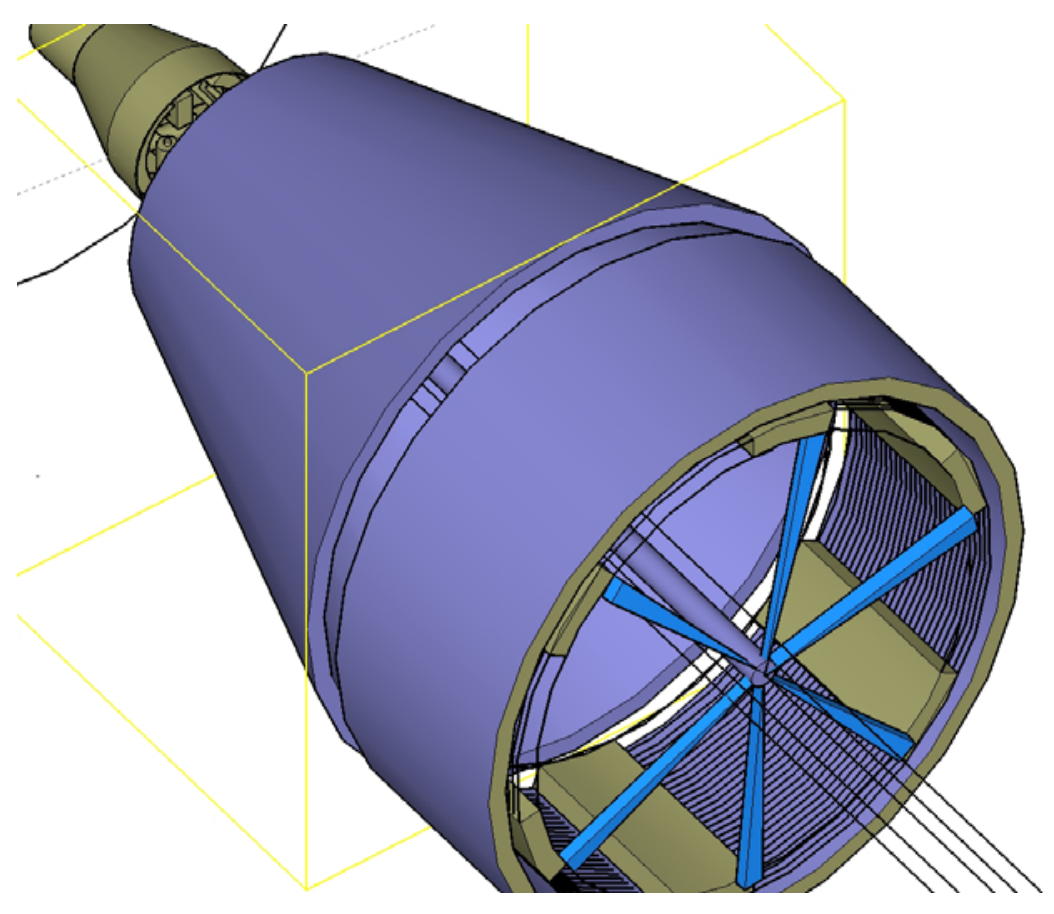

Fig. 4.51. Possible layout of the 115-kWe system (from the alternator to the PMAD) using a conical and a cylindrical radiator. Each radiator consists of six radiator panels. The cylindrical radiator contains a total of 168 heat pipes in six separate condenser and radiator combinations.

The PCSs require additional radiators for the start loop and the auxiliary component coolant loops. The radiators must be positioned so that they do not share a view factor with the main radiators. For a flat radiator layout, the auxiliary radiators would have to be in the same plane as the main radiator. For a cylindrical radiator layout, the auxiliary radiators would have to have the same radius of curvature. The reduced length of the conical and cylindrical radiator layout makes it easier to accommodate the auxiliary radiators and allows them to be positioned closer to the component they are cooling. Also, conical and cylindrical radiators are inherently more structurally supportive than flat-panel radiators. For these reasons, conical and cylindrical radiators have been chosen as the baseline for the system.

Additional thought has to be given to how the radiators are connected to the two PCSs. If the conical radiator is used for one PCS and the cylindrical radiator for the other, the two systems start and operate differently; the system using the cylindrical radiator would presumably be the more difficult to start. If one PCS unit were attached exclusively to the conical radiator, then that unit might be easier to warm and therefore start, simply because it is closer. The unit connected to the cylindrical radiator would have more volume to warm before it could start and the closer conical radiator might interfere with the restart, making the cylindrical radiator potentially more difficult to restart. 


\subsubsection{Thermal Expansion and System Stresses}

All of the power system components are interconnected, and many of the components are massive. The components must be supported to withstand launch loads, but they must be flexible enough to expand and contract with changing temperature.

As an example, the boiler tubes would expand and tend to spread the boiler radially. The boiler is connected to (1) the piping to the reactor primary coolant pump, (2) the reactor vessel, (3) two turbines and (4) two pumps. All of these components would have to move with boiler expansion, or unmanageable stresses could occur.

The system requires dozens of joints excluding the penetration of the heat pipes through the condenser walls, and hundreds of joints if they are considered. Refractory alloys such as $\mathrm{Nb}-$ $1 \% \mathrm{Zr}$ can be welded or brazed only in vacuum enclosures or under high-purity cover gases. A significant amount of additional design work is needed to develop a design that can be fabricated by welding and brazing and be reasonably packaged for launch.

Welding of $\mathrm{Nb}-1 \% \mathrm{Zr}$ can be accomplished with automated or manual gas tungsten arc welding under a high-purity argon gas cover in a glove box. Electron beam welding is an excellent joining technique for $\mathrm{Nb}-1 \% \mathrm{Zr}$, and laser welding can also perform satisfactorily; however these techniques must be performed in a vacuum. Welding surface dimensions ranging from 0.050 to $0.040 \mathrm{in}$. ( 0.127 to $0.102 \mathrm{~cm})$ are preferable for welding $\mathrm{Nb}-1 \% \mathrm{Zr}$ because experience has shown that these dimensions produce more consistent welds than do thicknesses at or below 0.030 in. $(0.076 \mathrm{~cm})$

Brazing is possible; however, for $\mathrm{Nb}-1 \% \mathrm{Zr}$; a vacuum furnace with a $2000^{\circ} \mathrm{C}$ capability would be required, and care must be taken to avoid approaching the $2689 \mathrm{~K}$ niobium melting temperature. Filler agents with silver or copper cannot be used. Titanium-based filler agents have been developed and have acceptable structural properties at temperatures up to approximately $1000 \mathrm{~K}$ and possibly as high as $1100 \mathrm{~K}$.

\subsubsection{Design Issues Driven by Shutdown and Restart}

The system must be able to start in deep space from a cold startup. This requirement implies that the system either would follow a shutdown process that puts the system into a configuration from which it can restart, or would be designed to return inherently to such a condition as it cools down. The preference is for the system to return inherently to a restart condition.

At a minimum, the system must carry enough energy to operate communication equipment (and other critical spacecraft subsystems), reactor instrumentation, and reactivity control structures independent of reactor power. Possible auxiliary sources of electrical power are chemical systems, batteries, and radioisotope thermoelectric generators (RTGs). Of the available power sources, the RTG has the greatest probability of predictably providing electrical power for decades. Therefore, it is assumed that deep-space restart would use an RTG. The nextgeneration multi-mission RTGs currently under development are projected to produce $120 \mathrm{~W}_{\mathrm{e}}$ (at beginning of life) with a total mass of $43 \mathrm{~kg}$, and it is assumed that such a system is available for use in this design. 
The RTG would power electronic equipment through a thermoelectric converter system to allow communication with Earth and to allow control of the reactor at low power. As the reactor power level is increased, lithium is melted throughout the primary loop and flow is eventually induced by a TEM pump. Heat from the flowing lithium warms the potassium in the boilers. Once the boiler temperature is above the melting temperature of potassium, PCS startup can be initiated.

Flow through the main potassium loop cannot occur until a flow path from the boiler exit to the boiler entrance is established that is above the melting temperature of the potassium. From a cold restart, it is difficult to carry enough auxiliary energy to heat a large flow path to these conditions. It is possible to continually maintain a portion of the loop above the potassium melting temperature with a multi-mission RTG, and it may be able to produce enough electrical energy to turn the main pump at partial load during the startup process. For now it is assumed that the multi-mission RTG powers startup equipment and heats a portion of the loop. It is assumed that the main pump would have to be started without the benefit of electric power.

The restart strategy assumed for this design effort is to minimize the requirements for onboard stored energy (other than that in the reactor fuel), a task accomplished by first heating and initiating flow through a smaller start loop within each PCS. The start loop eventually produces enough power to turn the main potassium pump. Vapor production in excess of that required to turn the main pump would be used first to heat the remainder of the main potassium loop by flowing it through a turbine bypass loop and then to turn the turbine under low or noload conditions. The alternator begins to generate electricity as flow through the turbine is gradually increased.

The conditions required to initiate flow in the start loop are the same as those for the main loop. A path above the melting temperature of the working fluid must be established from and back to the boiler, and a means of pumping the system must be provided. Conduction from the boiler and heat pipe tracing from the RTG heats the start loop, and a small TEM pump moves liquid potassium through the start loop.

The start loop requires a small radiator. It would also have to be isolated from the remainder of the PCS during startup to prevent vapor produced in the boiler from condensing out in the condenser manifolds. The isolation must occur between the boiler exit and the turbine inlet. An isolation valve directs vapor only to the start loop until the loop produces enough power to turn the main potassium pump.

The isolation valve gradually allows vapor to be directed to the main potassium loop as vapor production rates increase. Excess vapor production would initially be used to heat the turbine and a portion of the condenser. (The potassium vapor heats the main pump before it begins to turn, and this increases the temperature at the exit of the condenser).

With the main pump turning, the excess vapor can be directed through the turbine and into the condenser. At a sufficient vapor flow rate, the turbine begins to rotate under a no-load condition. Eventually, the alternator produces enough electrical power to operate the reactor coolant pump and allows operation at increasingly higher reactor power levels. 


\subsubsection{Shutdown}

The system could shut down as a result of a problem with the reactor or with the PCS. The primary heat removal systems for the reactor are the PCSs. If the system were operating on a single PCS and failed, the reactor would be left without an energy removal path; unacceptable temperature transients would likely occur. This leads to the conclusion that it is probably best to have both PCSs operational during normal operation so that a failure in one PCS would allow the other to continue to remove energy from the reactor even as power was being reduced. Although, this is not the baseline operational configuration, shutdown considerations necessitate revisiting this issue in future evaluations.

Assuming the reactor has operated a significant period of time before shutdown, it would produce an estimated $50 \mathrm{~kW}$ of decay heat that must be removed immediately after shutdown. Based on estimates of decay heating rates of terrestrial fast reactors, approximately $1 \%$ of the normal reactor power would be produced within the core for as much as 24 hours after initial reactor shutdown. It is presumed that the system would be designed to dissipate this level of energy production without active control. Therefore, the power levels and durations requiring active thermal control range from $50 \mathrm{~kW}_{\mathrm{t}}$ at the time of shutdown to approximately $5 \mathrm{~kW}_{\mathrm{t}}$ tens of hours later.

The PCS would have to coast down with the reactor. The lithium and potassium must continue to flow through the boiler until the decay heat has decreased to inherently safe levels. As the shutdown process approaches its eventual steady state shutdown configuration, adequate volumes of potassium must remain within the boiler and the start loop. If not, the system cannot be restarted.

Potassium liquid would tend to collect in the places that cool first, and the remaining volume would become evacuated. The radiators continue to reject heat as the system shuts down and cool first. Because the start loop is inherently thermally coupled to the boiler, it would cool with the boiler much later in the cooling process. The inherent tendency of the system would be to collect liquid in the condensers while evacuating the boiler during a cool down. The main pump must turn to compensate for this tendency.

To ensure that the start loop has enough potassium inventory to restart, it is isolated in the filled condition from the main potassium loop during normal operation. The potassium in the loop is liquid during normal operation and remains confined to the loop until the loop is required for restart. A similar strategy would be used to isolate potassium in the boiler; however, the isolation can occur only after potassium flow is no longer required for heat removal.

\subsubsection{Restart}

At startup the system components are in thermal equilibrium with the ultimate heat rejection temperature, which is position dependent. If the restart were to occur early in the mission near a 1-AU solar distance, the heat rejection temperature could be as high as $200 \mathrm{~K}$; but if it were to occur in deep space, it could be as low as $4 \mathrm{~K}$. The restart must work thermally under either condition.

The restart process is a series of phases that are essentially steady state. The distinctive characteristics of each phase are the amount of energy being added to the boiler and the flow 
configuration of the PCS isolation valves. At startup the flow of heat through the boiler is zero, and at full power it is approximately $450 \mathrm{~kW}_{\mathrm{e}}$. Each level of heat input into the boiler must correspond to a defined operational state of the system, and the operational states must have some overlap to allow for transition from one state to the next. The thermal links from the boiler to the other components warm them, and the radiators attempt to cool them. These links must be designed so that the heat flow allows thaw progression to occur properly. It must not permit a component to become too hot before other essential components become operational to cool them, or allow a component to remain too cold to preclude operation.

Some additional constraints for the startup phases are as follows:

1) The potassium in the startup loop must be melted and the start loop radiator must be above the potassium freezing temperature before the start loop flow begins.

2) The condenser temperature must be above the freezing point of potassium before vapor flow is directed into the condenser.

3) The turbine temperature must be above the potassium freezing point before the bearing loop flow begins.

4) The bearing loop must be operational before vapor flow is introduced into the turbine.

A startup sequence may follow the basic steps outlined as follows.

Phase $1 \quad$ Cold shutdown

RTG operating communication hardware

RTG heating critical areas

Phase $2 \quad$ Low power critical

Low-power instrumentation is energized

Reflector drive mechanisms is unlocked

Power reflector drive motors are energized

Reflector operation is confirmed

Reflectors are actuated to bring reactor to zero power criticality

Sufficient power is established to test reactor instrumentation

Phase 3 Power increases

Lithium melts

Lithium is pumped through primary side by TEM pump

Phase 4 Turbine inlet valve and bypass valve is closed

Start loop isolation valve opens

Conductive heating of main pump and start loop radiator begins 
Phase $5 \quad$ Start loop temperature exceeds working fluid melting temperature Flow occurs through start loop powered by TEM pump

Phase 6 Vapor production occurs in boiler and flows through driving side of turbine driven pump

Condensation occurs in the start loop radiator

Temperatures increase as freeze thaw line propagates to the turbine, RFMD, and condenser

Phase $7 \quad$ Main pump begins to turn

Flow begins from condenser through RFMD into boiler

Flow to turbine bearings begins

Turbine bypass valve is opened

Turbine and condenser warm

Phase $8 \quad$ Vapor production increases and turbine temperature increases

Flow diverter valve directs flow through the turbine

Turbine begins to spin

Electrical power available for reactor pump

Once the turbine is up to temperature and the vapor production rate is adequate, vapor flow can be directed through the turbine and begin to spin it up. The vapor flow rate from the start loop through the turbine must be capable of producing enough motive power to turn the alternator enough to operate the reactor pump. Once the reactor pump is operating, the system is essentially on line. 


\section{5. $250 \mathrm{~kW}_{\mathrm{e}}$ GROWTH STUDY}

\subsection{INTRODUCTION}

The objective of the growth study was to evaluate the effect of an increase in power level from the $100-\mathrm{kW}_{\mathrm{e}}$ baseline design to $250 \mathrm{~kW}_{\mathrm{e}}$ to determine if significant changes in system or component design are required.

\subsection{PARAMETRIC DESIGN EVALUATION AND DESIGN SUMMARY}

As with the $100-\mathrm{kW}_{\mathrm{e}}$ analysis, a study was conducted to evaluate the performance of the $250-\mathrm{kW}_{\mathrm{e}}$ system using feed heaters and reheaters in the cycle. The analysis examined the impact of using three feed heaters, and one reheater, both separately and in combination, on the system efficiency and overall system mass. The results of these calculations are shown in Table 5.1.

Table 5.1 Effect of feed and reheat on 250-kWe system efficiency and mass

\begin{tabular}{ccccc}
\hline $\begin{array}{c}\text { No. of Feed } \\
\text { heaters }\end{array}$ & $\begin{array}{c}\text { Reheat temperature } \\
(\mathrm{K})\end{array}$ & $\begin{array}{c}\text { Cycle efficiency } \\
(\%)\end{array}$ & Relative mass & $\Delta$ mass (kg) \\
\hline 0 & 0 & 23.4 & 1.0 & 0 \\
3 & 0 & 24.6 & 0.97 & -200 \\
0 & 160 & 29.0 & 0.87 & -820 \\
3 & 160 & 31.9 & 0.83 & -1070 \\
\hline
\end{tabular}

A base case shown in Table 5.1 is for a reactor outlet temperature of $1350 \mathrm{~K}$. Masses and efficiencies shown are for the minimum mass point of the design. For the base case with no feed heaters and reheaters, a cycle efficiency of $23.4 \%$ is calculated, with a system mass of $6087 \mathrm{~kg}$. For the case that uses three feed heaters and no reheat, efficiency is improved to $24.6 \%$ and system mass decreases approximately $200 \mathrm{~kg}$ over the base case. The reheat temperature given in the table is the temperature increase of the vapor stream exiting the low-pressure turbine through the reheater. In the reheat cases, it was assumed that the turbine mass increases $80 \%$ above that of a turbine without reheat. This is due to the added complexity that is required to extract the vapor stream from the high-pressure turbine stages and then reintroduce it in the low-pressure turbine stages. Additionally, the reheater was assumed to be $50 \%$ of the boiler weight in these calculations. Feed heater masses were calculated explicitly. Offsetting these mass increases are decreases in the mass of both the radiator and reactor/shield system because of an increase in cycle efficiency. A mass savings of $1070 \mathrm{~kg}$ is predicted using both feed heat and reheat. However, it was decided to eliminate these components from the baseline design for two reasons. (1) Elimination of feed heaters and reheaters simplifies the overall system. Since components are still very small at this power level, the development of very small and efficient feed heaters and reheaters may be difficult. (2) The $250-\mathrm{kW}_{\mathrm{e}}$ system is small enough in volume to be launched in a heavy lift vehicle, but is still well under the mass lift capability for those systems. However, it is recognized that $1070 \mathrm{~kg}$ is a significant amount of launch weight, and additional trades and 
considerations may make feed heat and reheat cycles worth pursuing even at these low power levels. The system schematic, therefore, looks the same as that of the $100-\mathrm{kW}_{\mathrm{e}}$ system shown in Fig. 3.4.

Parametric calculations were performed using PCS radiator temperature as a variable to determine minimum system mass. The results of this calculation are shown in Fig. 5.1. The figure shows overall system mass on the $\mathrm{Y}$ axis and radiator temperature on the $\mathrm{X}$ axis. As radiator temperatures increase, cycle efficiencies decrease for the same reactor outlet temperature. However, as radiator temperatures increase, the heat rejection capability per unit area of radiator also increases. These two competing effects cause a minimum in the mass vs. rejection temperature curves. For the $250-\mathrm{kW}_{\mathrm{e}}$ system being studied, a minimum system mass was found at a radiator temperature of $875 \mathrm{~K}$.

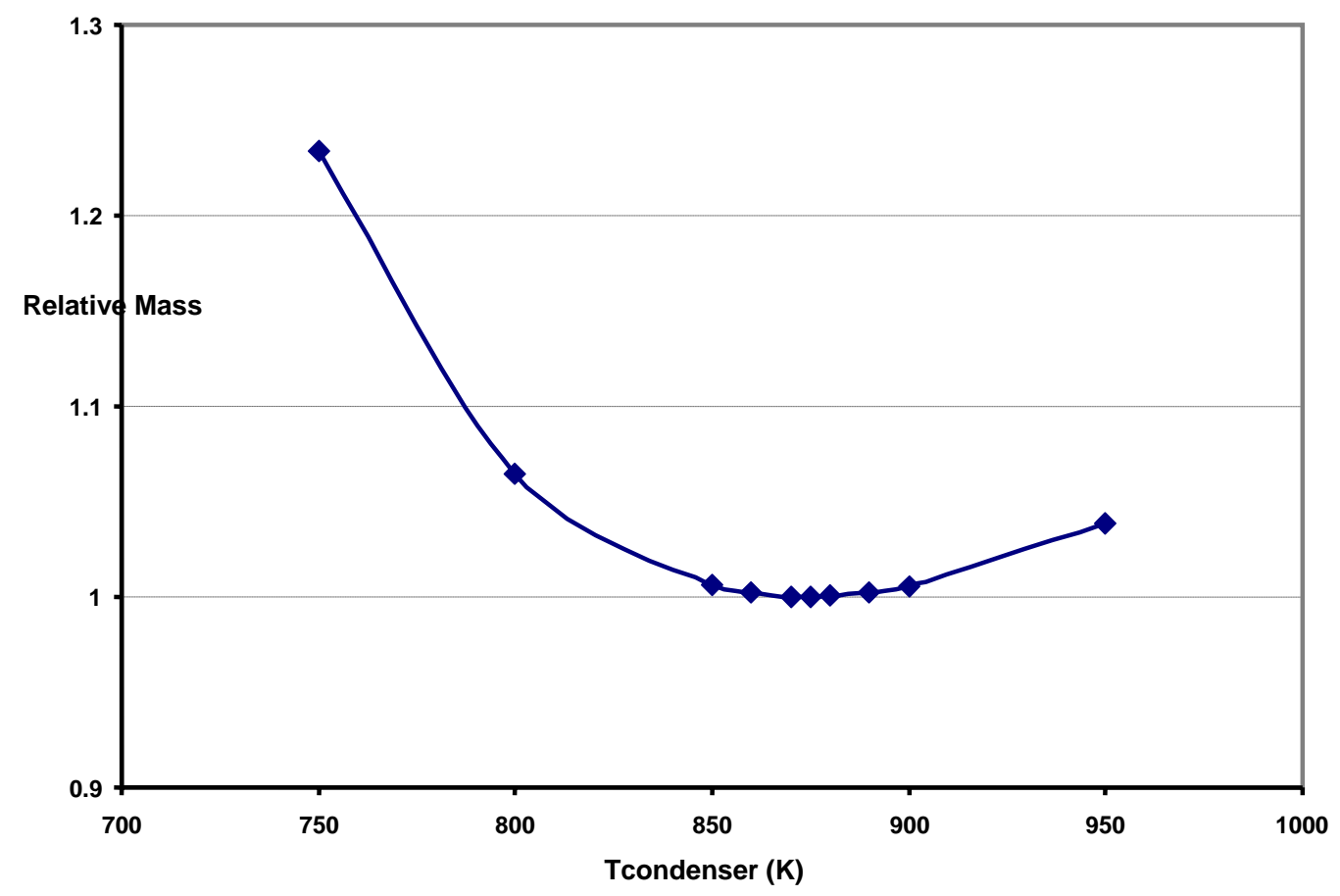

Fig. 5.1. Minimum mass results for the 250-kWe system.

An overall system mass of $6277 \mathrm{~kg}$ is predicted for the $250-\mathrm{kW}_{\mathrm{e}}$ system that corresponds to an $\alpha$ value of $25.1 \mathrm{~kg} / \mathrm{kW}_{\mathrm{e}}$. The major system mass breakdown is presented in Table 5.2. As noted in Table 5.2, the major mass components are the reactor and shield, the heat pipes and radiator, and the PMAD, comprising $30 \%, 39 \%$, and $20 \%$ of the overall system mass respectively. A radiator of $86 \mathrm{~m}^{2}$ is needed to reject the waste heat from the dynamic PCSs shared by the two redundant units. Sharing the radiator surface allows the $250-\mathrm{kW}_{\mathrm{e}}$ (at the PPUs) system to be launched in a heavy lift vehicle. A detailed mass breakdown and piping dimensions are presented in Appendix D. 
Table 5.2. Major component mass and radiator area

\begin{tabular}{lcc}
\hline Component & Mass $(\mathrm{kg})$ & \% of Total mass \\
\hline Reactor & 470 & 7.5 \\
Shield & 1400 & 22.3 \\
Boiler & 42 & 0.7 \\
Turbo-alternator & 380 & 6.1 \\
HP+radiator & 2060 & 32.8 \\
Low-temp. radiators & 400 & 6.3 \\
Power conditioning & 1235 & 19.7 \\
Remainder of PCS & 290 & 4.6 \\
Total & 6277 & 100.0 \\
\hline
\end{tabular}

\begin{tabular}{lc}
\hline & Area (m2) \\
\hline PCS radiator & 66 \\
Low-temp. radiators & 20 \\
\hline
\end{tabular}

PCS state points are shown in Fig. 5.2 with the corresponding pressure and thermodynamic values shown in Table 5.3.

Table 5.3. State points for $250-\mathbf{k W e}$ system

\begin{tabular}{clllllll}
\hline Number & Description & Temp (R) & Temp (K) & $\begin{array}{l}\text { Pressure } \\
\text { (psi) }\end{array}$ & $\begin{array}{l}\text { Pressure } \\
\text { (MPa) }\end{array}$ & $\begin{array}{l}\text { Mass flow } \\
\text { rate } \\
\text { (lbm/s) }\end{array}$ & $\begin{array}{l}\text { Mass flow } \\
\text { rate (Kg/s) }\end{array}$ \\
\hline & & & & & & & \\
1 & Boiler outlet & 2358 & 1310 & 112.183 & $0.771 \mathrm{E}-00$ & 1.31 & $5.947 \mathrm{E}-01$ \\
2 & Turbine inlet & 2358 & 1310 & 112.183 & $0.771 \mathrm{E}-00$ & 1.28 & $5.857 \mathrm{E}-01$ \\
3 & Turbine outlet & 1575 & 875 & 2.689 & $1.854 \mathrm{E}-02$ & 1.103 & $5.008 \mathrm{E}-01$ \\
4 & Condenser inlet & 1575 & 875 & 2.689 & $1.854 \mathrm{E}-02$ & 1.31 & $5.947 \mathrm{E}-01$ \\
5 & Condenser outlet & 1565 & 869.4 & 2.689 & $1.854 \mathrm{E}-02$ & 1.31 & $5.947 \mathrm{E}-01$ \\
5 & RFMD inlet & 1565 & 869.4 & 2.689 & $1.854 \mathrm{E}-02$ & 1.31 & $5.947 \mathrm{E}-01$ \\
6 & RFMD outlet & 1565 & 869.4 & 12.689 & $8.749 \mathrm{E}-02$ & 1.31 & $5.947 \mathrm{E}-01$ \\
6 & Boiler pump inlet & 1565 & 869.4 & 12.689 & $8.749 \mathrm{E}-02$ & 1.31 & $5.947 \mathrm{E}-01$ \\
7 & Boiler pump exit & 1565 & 869.4 & 140.34 & $9.64 \mathrm{E}-01$ & 1.31 & $5.947 \mathrm{E}-01$ \\
8 & Stage 4 extraction & & & & & 0.156 & $7.082 \mathrm{E}-02$ \\
9 & Stage 6 extraction & & & & & 0.031 & $1.407 \mathrm{E}-02$ \\
10 & Boiler inlet & 1565 & 869.4 & 140.34 & $9.646 \mathrm{E}-01$ & 1.31 & $5.947 \mathrm{E}-01$ \\
11 & Pump turbine inlet & 2358 & 1310 & 112.183 & $7.710 \mathrm{E}-01$ & 0.03 & $1.360 \mathrm{E}-02$ \\
12 & Pump turbine outlet & 2008 & 1115.6 & 30.638 & $2.112 \mathrm{E}-01$ & 0.03 & $1.360 \mathrm{E}-02$ \\
\hline
\end{tabular}


The cycle operates between a high temperature of $1310 \mathrm{~K}$ and low temperature at the condenser of $875 \mathrm{~K}$ with corresponding pressures of $771 \mathrm{kPa}$ and $18.5 \mathrm{kPa}$. A 69-kPa pressure rise is provided by the RFMD in order to meet the NPSH requirement of the centrifugal boiler feed pump. The boiler pump provides an $870-\mathrm{kPa}$ pressure rise, while the pressure drop through the boiler is $194 \mathrm{kPa}$. The pressure drop across the turbine is $754 \mathrm{kPa}$. Two moisture extractions from the nine-stage turbine are performed, one after stage 4 that uses an external separator and one after stage 6 that uses an interstage separator in order to maintain moisture content within the turbine below $90 \%$. The extraction streams, along with the pump turbine exhaust stream, are routed to the inlet of the condenser. Overall system efficiency is $23.4 \%$.

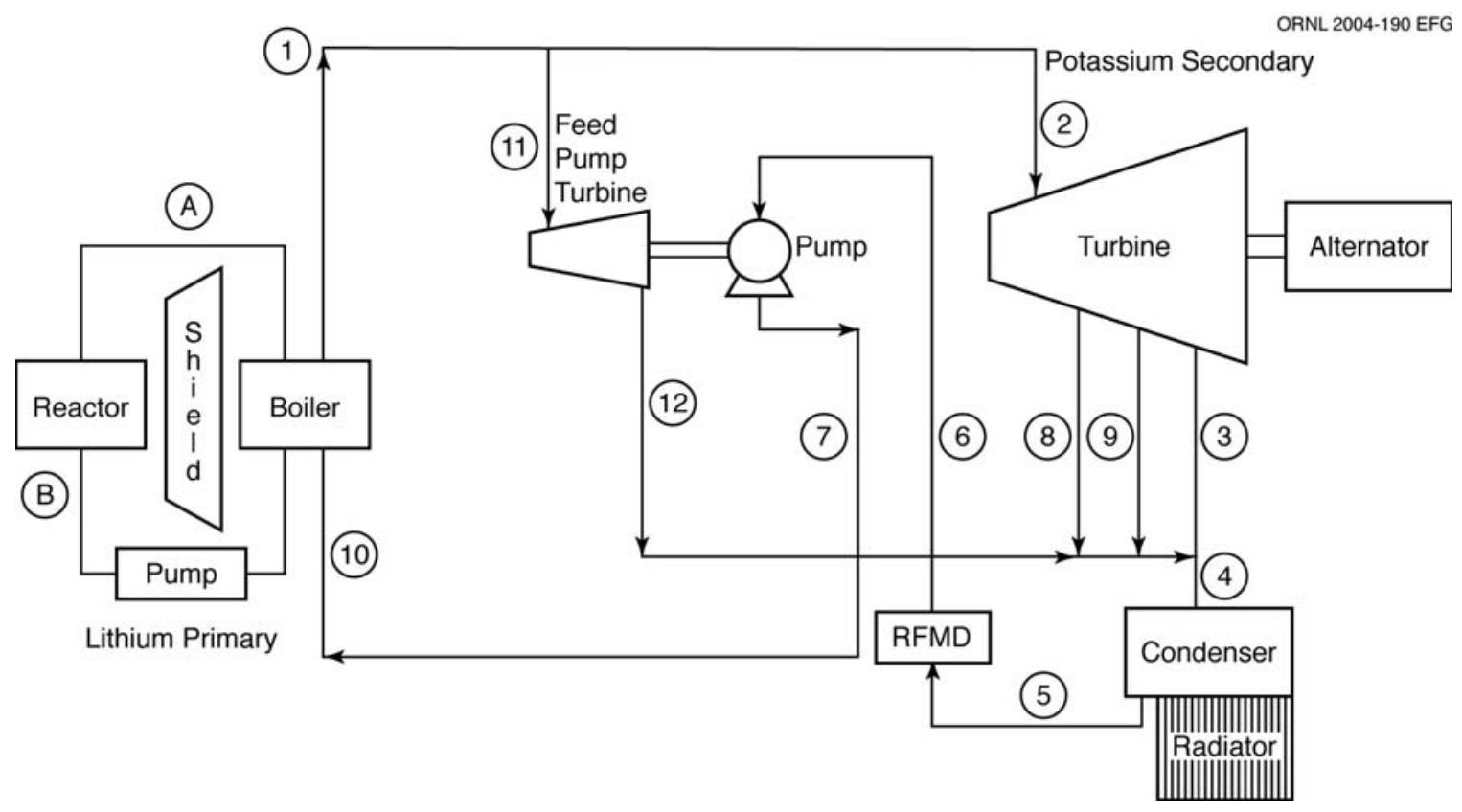

Fig. 5.2. State points for the $250-\mathrm{kW}_{\mathrm{e}}$ system.

\subsection{COMPONENT DESIGNS}

\subsubsection{Boiler}

The boiler is a once-through shell-and-tube design with single-phase liquid lithium flowing through the shell side of the boiler and potassium flowing on the tube side. The potassium is vaporized to approximately $100 \%$ quality. In the present design, which uses two independent dynamic PCSs, a sufficient number of boiler tubes are incorporated for both systems (ie., double the number of tubes that would be used for a single unit). The two PCSs are separated by using two nozzles each in the boiler inlet and outlet heads, one for each unit. The heads are separated in two sections that partition the tube sheet as well. In this way, the two PCSs remain independent. Baffles on the shell side of the boiler ensure sufficient mixing to provide heat to either unit.

Twisted tapes internal to the boiler tubes are incorporated to provide sufficient swirl flow in the boiling potassium to de-entrain any liquid flow in the vapor stream, preventing liquid carryover in the boiler exit vapor. Typical boiler geometry and operating conditions are shown in 
Table 5.4. The boiler has a circular cross section with the tubes arranged in a hexagonal pitch and is shaped in a circular arc from inlet to outlet in order to fit behind the reactor shield.

Table 5.4. Boiler design data

\begin{tabular}{lr}
\hline Number of tubes & 61 \\
Tube diameter $(\mathrm{cm})$ & 1 \\
Tube length $(\mathrm{cm})$ & 250 \\
Tube pitch $(\mathrm{cm})$ & 1.74 \\
Tube wall thickness $(\mathrm{cm})$ & 0.08 \\
Twisted tape pitch & 2 \\
Boiler diameter $(\mathrm{cm})$ & 17.5 \\
Boiler wall thickness $(\mathrm{cm})$ & 0.12 \\
Number of inlet nozzles & 2 \\
Inlet nozzle diameter $(\mathrm{cm})$ & 2 \\
Number of outlet nozzles & 2 \\
Outlet nozzle diameter $(\mathrm{cm})$ & 4.4 \\
Potassium flow rate $(\mathrm{kg} / \mathrm{s}-1$ unit) & 0.6 \\
Lithium flow rate $(\mathrm{kg} / \mathrm{s})$ & 3.4 \\
\hline
\end{tabular}

\subsubsection{Turbine}

A multi-stage, axial flow turbine is used in this design. The turbine uses nine stages and a tilting pad bearing system lubricated with $750 \mathrm{~K}$ liquid potassium. The turbine produces a shaft power of $318 \mathrm{~kW}$ operating at approximately 34,000 rpm. Turbine tip speed was limited to $260 \mathrm{~m} / \mathrm{s}$ in order to minimize turbine blade erosion due to moisture. At these conditions, turbine efficiency is approximately $74 \%$ overall. Turbine rotor diameter is $15 \mathrm{~cm}$, and turbine overall length is $50 \mathrm{~cm}$.

The moisture level in the turbine expansion path is maintained at a reasonably low level by using both external moisture separators and interstage separators. An external separator is utilized at about the middle stage, and interstage separators are used where required to maintain moisture at acceptable levels.

An interstage separator is assumed to remove $25 \%$ of the moisture present in the working fluid at the location of the separator. An associated penalty with this type of separator is the requirement for the removal of $0.25 \mathrm{lb}(0.1134 \mathrm{~kg})$ of vapor with each pound $(0.4536 \mathrm{~kg})$ of moisture removed.

An external separator is assumed to remove $90 \%$ of the moisture in the working fluid that enters the separator. Two performance penalties are associated with this type of separator. First, $0.1 \mathrm{lb}(0.045 \mathrm{~kg})$ of vapor accompanies each pound $(0.4536 \mathrm{~kg})$ of removed moisture. Second, the working fluid undergoes a pressure drop of approximately two velocity heads (1.5 psi or 10.3 $\mathrm{kPa}$ is assumed in the model) as it passes through the separator. In addition, there is a weight penalty associated with an external separator as a result of the separator itself and the additional turbine length to accommodate the fluid passages leaving and returning to the turbine flow path. 
Each stage of the turbine is assumed to have an aerodynamic efficiency equal to the input value for dry-stage efficiency. As the mass and energy balance analysis progresses, the actual efficiency for each stage is then assumed to be the aerodynamic efficiency degraded by $1 \%$ per percentage point of average moisture in the stage. In addition, a value for turbine exhaust loss, caused by the last-stage exit velocity, is specified.

\subsubsection{Alternator}

The alternator, a homopolar inductor design, operates at a temperature of $600 \mathrm{~K}$. The alternator is coupled directly to the power turbine, and is "canned" with the power turbine in a common housing to eliminate external rotating seals. Thermal isolation of the alternator from the turbine is provided by a low-conductivity coupling incorporated in the drive shaft. The alternator is isolated from the potassium in the turbine through a seal between the turbine and alternator. Potassium vapor at $600 \mathrm{~K}$ is used to cool the rotor of the alternator, while $600 \mathrm{~K}$ Potassium liquid is used to cool the stator.

The alternator stator is approximately $23 \mathrm{~cm}$ in diameter and $32 \mathrm{~cm}$ in length. The rotor is $17 \mathrm{~cm}$ in diameter and operates at $34,000 \mathrm{rpm}$. Alternator mass is estimated to be $140 \mathrm{~kg}$.

\subsubsection{Condenser}

The condenser takes the exhaust from the turbine and the streams from the moisture separators and boiler feed pump turbine and then interfaces with the heat pipe radiator system to re-condense the potassium vapor back to a liquid while rejecting the cycle waste heat. The condenser consists of a number of parallel condensing surfaces. The condensing surface is the outer diameter of the heat pipe evaporator and is approximately $2 \mathrm{~cm}$ in diameter and $46 \mathrm{~cm}$ long. Vapor travels parallel to the evaporator centerline through an annular condensing channel. The annular condensing channel is formed by surrounding the heat pipe evaporator by a circular (in cross section) outer shroud that tapers along the length of the evaporator. Concentricity is maintained using 12 ribs between the shroud and the heat pipe evaporator outside diameter. The shroud diameter tapers from $3.9 \mathrm{~cm}$ ID to $2.6 \mathrm{~cm}$ ID from the vapor inlet to the condensate outlet. This taper is used to maintain shear flow control of the liquid film as the vapor condenses along the length of the heat pipe evaporator. The schematic is the same as for the $100-\mathrm{kWe}$ system and is shown in Fig. 4.21. A vapor header is used to connect the inlet of each of the annular condensing segments, and a condensate header is used to connect the outlets. For the $250-\mathrm{kW}_{\mathrm{e}}$ system, 242 separate heat pipes are used; therefore, 242 parallel annular condensing channels are used in the design. Each channel rejects approximately $4 \mathrm{~kW}$ of heat from the Rankine cycle. The inlet vapor velocity is approximately $43 \mathrm{~m} / \mathrm{s}$, and the channel outlet liquid velocity is $0.28 \mathrm{~m} / \mathrm{s}$. Because potassium has a high thermal conductivity, temperature drop across the liquid film to the heat pipe evaporator surface under these conditions is only about $1^{\circ} \mathrm{C}$. The total flow rate through the condenser is $0.6 \mathrm{~kg} / \mathrm{s}$, and total heat rejected through the condenser is $960 \mathrm{~kW}$. 


\subsubsection{Rotary Fluid Management Device}

The RFMD is designed to scavenge liquid from the condenser and provide appropriate NPSH to the boiler feed pump. The device is also designed to separate vapor or noncondensables from the liquid, if required. Under normal operating conditions, it is expected that there would be $100 \%$ liquid exiting the condenser and that the RFMD operates as a standard pitot pump. If system transients are such that vapor carryunder occurs in the condenser, the RFMD separates the two phases and holds up the vapor until it can be re-condensed. If noncondensables form in the potassium working fluid (not an expected occurrence), the RFMD provides a means to accumulate these during operation and prevent them from circulating through the PCS.

The RFMD consists of a casing that encloses both a rotating drum and an electric motor used to drive the drum. Isolation of the electric motor from the RFMD is accomplished through the use of a seal system that separates the potassium liquid in the RFMD from the potassium vapor between the motor stator and rotor used to cool the rotor. This system is similar to that used in the turbo-alternator system described earlier. The rotating drum diameter is approximately $30 \mathrm{~cm}$ and the length is approximately $40 \mathrm{~cm}$. A stationary pitot tube located just inside the rotating drum is used to supply potassium at $0.08 \mathrm{MPa}$ to the boiler feed pump. The drum is rotated at $1100 \mathrm{rpm}$ by an electric motor that requires $0.45 \mathrm{~kW}$ of electrical power. A motor efficiency of $45 \%$ and a pump efficiency of $32 \%$ were used to estimate power requirements. A $750 \mathrm{~K}$ liquid potassium lubricated bearing system is used to support the rotating drum.

\subsubsection{Turbo-pump}

The turbo-pump consists of a single-stage, partial admission turbine coupled to a singlestage centrifugal pump. The two components are enclosed in a common, canned housing, eliminating any external rotating seals. The turbine rotor diameter is approximately $16 \mathrm{~cm}$ and the pump impeller diameter is approximately $4 \mathrm{~cm}$ for the $250-\mathrm{kW}_{\mathrm{e}}$ unit. Expected pump efficiency is $47 \%$ and turbine efficiency is $13 \%$ for this system. The turbo-pump operates at approximately $15,000 \mathrm{rpm}$.

The turbine is supplied with $0.0136 \mathrm{~kg} / \mathrm{s}$ of potassium vapor directly from the boiler exit at $1310 \mathrm{~K}$ and $0.77 \mathrm{MPa}$ pressure. The potassium is expanded through the turbine to a pressure of $0.21 \mathrm{MPa}$. Boiler pump flow is $1.31 \mathrm{~kg} / \mathrm{s}$, and the pump provides a pressure rise of $0.88 \mathrm{MPa}$.

\subsubsection{PMAD, Instrumentation and Control, and Auxiliary Power Systems}

The PMAD system consists of the following components:

- 2 phase-control rectifiers: Individual fine speed control of turboalternator

- 1 shunt regulator: Voltage regulation, speed control, parasitic load radiator shunt control

- 1 parasitic load radiator: Excess power dissipation

- 2 fault isolator diodes: Alternator fault isolation

- 1 Switchgear Unit: Main bus switching and primary feed fault isolation 
- 2 Start up-inverters: Motor turboalternators to self-sustaining speed

- 2 RFMD pump inverters: Drive RFMD pumps

- 2 TEM pump converters: Drive TEM pump prior to reactor activation

- 2 30-Vdc converters: Supply 30-Vdc spacecraft and mission module loads

Auxiliary power systems include

- solar array: Supplies vehicle/reactor startup power and 30-Vdc bus during insolation prior to reactor startup

- Battery: Supplies vehicle/reactor startup power and 30-Vdc bus during eclipse prior to reactor startup

- Electronics: Controls array and battery operation and provides switching and fault isolation, health monitoring, and data bus interface

Instrumentation and control elements include

- 1 power system controller: Autonomously control and monitor power system

- 8 multiplexers: Multiplex reactor and PC sensor signals to reduce cabling

- 6 stepper motors and controllers: Reflector drive control and operation

- Voltage, current, pressure, position, temperature, and flow sensors and gamma and neutron detectors

The PMAD subsystem mass is approximately $900 \mathrm{~kg}$ and is $91 \%$ efficient. This is a configuration where there are two channels, each of which is capable of providing $250 \mathrm{~kW}_{\mathrm{e}}$ to the thrusters, with one channel being redundant. The instrumentation and control system mass is approximately $164 \mathrm{~kg}$, and the mass of the auxiliary power system is approximately $168 \mathrm{~kg}$.

\subsubsection{Heat Rejection System}

The HRS consists of an array of potassium heat pipes whose evaporators interface with the condenser of the Rankine power conversion cycle. A total of 242 heat pipes are required for each PCU to reject $960 \mathrm{~kW}$ of waste heat. The heat pipes are $2 \mathrm{~cm}$ in diameter, and have a $46-\mathrm{cm}-1 \mathrm{ong}$ evaporator region operating at $865 \mathrm{~K}$ (a $10 \mathrm{~K}$ temperature drop between the Rankine cycle condenser and the heat pipe evaporating temperature is assumed). The heat pipe condensers are approximately $1 \mathrm{~m}$ in length. A $0.5-\mathrm{m}$ inactive transport length connects the evaporator to the condenser and allows some flexibility in location of the radiators. Two totally independent heat pipe systems are provided, one for each PCU. Each heat pipe weighs about $1 \mathrm{~kg}$ and is capable of transporting approximately $4 \mathrm{~kW}$. A single-sided radiator design is used to reject heat to space. The heat pipes are integrated into the radiator through a support structure designed to minimize the thermal resistance between the radiator face sheet and heat pipe condenser. As with the PCS, the heat pipe and radiator are constructed using $\mathrm{Nb}-1 \% \mathrm{Zr}$ in order to eliminate the requirement to join dissimilar materials. The total radiator surface area is $66 \mathrm{~m}^{2}$, shared by both units. 


\subsubsection{System Design}

The $250-\mathrm{kW}_{\mathrm{e}}$ system design uses a single fast-spectrum reactor fueled with highly enriched uranium in the form of uranium nitride. A total of 1098 fuel pins, $0.738 \mathrm{~cm}$ in diameter and $61.44 \mathrm{~cm}$ long are arranged on a 0.782 square pitch. The present design uses $172 \mathrm{kgs}$ of uranium with a fuel burn-up limit of $4 \%$. Thirteen control drums located outside the reactor pressure vessel and a single fixed control assembly at the center of the core are used for reactivity control. A 10-year full-power lifetime was used in the design. The reactor shadow shield is constructed of layered tungsten and lithium hydride to control gamma and neutron fluence at the payload. The tungsten layer is $6.38 \mathrm{~cm}$ thick and the lithium hydride is $45.83 \mathrm{~cm}$ thick, limiting gamma dose levels at the payload to $10^{6}$ rads and neutron dose to $10^{13} \mathrm{n} / \mathrm{cm}^{2}$ at a distance of $15 \mathrm{~m}$ from the reactor. The shield tapers in diameter from $50 \mathrm{~cm}$ at the core to $112 \mathrm{~cm}$ facing the payload. The reactor is cooled by single-phase lithium circulated by two redundant electromagnetic pumps.

The arc shaped boiler, located behind the shield, feeds potassium vapor to both redundant power conversion system loops. A single $66 \mathrm{~m}^{2}$ radiator surface area is used to support both power conversion units. Each unit has its own set of heat pipes with the condensers from each unit sharing a common radiator. This configuration allows the $250 \mathrm{~kW}_{\mathrm{e}}$ system to be launched within a single heavy lift cargo volume.

The bearing lubricant supply and alternator cooling system are fed by a side stream of potassium from the boiler pump outlet. Separate low temperature radiators are used to cool the liquid potassium to $750 \mathrm{~K}$ for the bearings (potassium heat pipes) and to $600 \mathrm{~K}$ for the alternator (mercury heat pipes). The subcooled potassium return flow is routed back to the RFMD and is used as a means of condensing vapor that might accumulate in the RFMD. The electro-magnetic pumps used to circulate the lithium reactor coolant are also cooled by a $750 \mathrm{~K}$ radiator system. The PMAD system must be cooled to $400 \mathrm{~K}$. A separate water heat pipe system, attached to a cold plate is used for this purpose.

A separate start-up system is used to provide both initial start-up and re-start capabilities. Thaw of the system, when the potassium is frozen, is accomplished by a combination of trace heating using heat pipes, and having the PCS units enclosed, using radiative heating to initially warm the system to the melting point. The design uses a thermoelectric driven electro-magnetic pump to begin initial potassium circulation through a loop made up of the boiler and the turbopump turbine flow path. A three way valve located at the inlet to the power turbine blocks initial flow through the power turbine and forces all flow through the turbo-pump turbine and start-up loop. Reactor power is increased, and the heat from the primary system is used to drive the thermoelectric start-up pump that circulates potassium flow through the boiler and the start-up circuit. The start-up loop is used until sufficient vapor is generated to heat up the power turbine and begin potassium circulation through the entire PCS using the turbo-pump unit. Because the heat pipes in the heat rejection system are freeze tolerant, they also remain inactive until the Rankine cycle condenser temperature is sufficiently high to activate operation of the heat pipes. Thus, only a small amount of energy is rejected by the main radiator during the start-up process. Once sufficient vapor is generated to begin to roll the power turbine, the start-up loop shuts down, and the PCS system becomes operational. 
PAGE INTENTIONALLY LEFT BLANK 


\section{MICROGRAVITY ISSUES AND EXPERIMENT SCALING}

\subsection{MICROGRAVITY PHENOMENOLOGY AS IT APPLIES TO THE RANKINE CYCLE}

Most major components in the Rankine cycle operate in the two-phase region. Control of the vapor and liquid location in each component and an understanding of the heat transfer processes throughout the cycle are necessary to ensure proper operation and high system reliability. A key element in proving the feasibility of using the Rankine cycle in space is demonstrating two-phase interface control in these components. Additionally, boiling characteristics often set design limitations on both the single-phase and the two-phase coolant loops-for example, the CHF limit for some types of transient occurrences in the nuclear reactor system.

Earth-based two-phase systems normally rely on gravitational forces in various components to orient the liquid/vapor interfaces. Operation of two-phase systems in the lowgravity environment of space requires that other forces such as surface tension or centrifugal forces be used for liquid/vapor control. Additionally, boiling system behavior may be radically different under some low-gravity conditions, because buoyancy forces are not available to separate the vapor and liquid components.

Up to this time, the study of interface control techniques and boiling behavior under lowgravity conditions, for the most part, has been limited to the short time scales available in drop towers (low-g $<5 \mathrm{~s}$ ) and aircraft Keplerian trajectories (low-g $<30 \mathrm{~s}$ ). These time scales are not sufficient, under many circumstances, to allow the systems to come to steady state. Alternatively, longer-term, low-gravity, two-phase experimentation would ensure that steady state conditions would be obtained and that two-phase flow and heat transfer data would be gathered under realistic low-gravity conditions.

Discussion follows on specific phenomenology occurring in the Rankine cycle that could be impacted by low-gravity conditions. Phenomenology is described on a component-bycomponent basis.

\subsubsection{Boiler}

In the indirect system, single-phase liquid lithium flows through the shell side of the boiler; and potassium, flowing on the tube side of the boiler, is vaporized to approximately $100 \%$ quality. In the boiler, because the lithium enters at a constant temperature, there is no real danger of damaging the boiler tubes, and knowledge of the CHF or dryout limit is not as critical as it is in the direct boiling reactor core. However, understanding the dryout phenomena is important to determine at what quality level the boiler tubes become dry; that information is needed to design the dryer and superheat region of the boiler. Effective design of the dryer/superheater region requires understanding of droplet entrainment and deposition and the behavior of flows operating in thermal non-equilibrium.

Additionally, understanding parallel channel boiling instability limits is important to ensure that the boiler operates as desired. As noted previously, turbine quality must remain above approximately $90 \%$ in order to minimize turbine blade erosion. Quantifying carryover within the boiler is necessary in order to ensure high exit quality. As for the direct boiling reactor core discussed earlier, stable boiling initiation must be ensured to prevent undesirable transients in the 
boiler. Operative phenomena that need to be understood and controlled in the boiler, therefore, include boiling initiation, liquid entrainment and deposition, liquid bridging, and liquid film dryout under forced convection conditions.

Boiler designs generally incorporate design features that force liquid to remain on the tube walls to prolong dryout, including twisted tapes and macroscopic modification of tube surfaces, among others. Characterization of the performance of actual engineering geometries is needed to demonstrate the performance of these designs.

\subsubsection{Rotating Equipment}

It is generally expected that rotating equipment (e.g., turbine, pump) would operate under conditions where the absence of gravity would have negligible effect on performance. Overall turbine efficiency, confirmation of separator stages, and turbine reliability would be evaluated through a ground test program.

\subsubsection{Condenser}

Exhaust from the turbine mixed with feed heater flows can enter the condenser at quality levels as low as approximately $60 \%$. The design of the condenser must ensure that the working fluid is fully condensed so that no vapor is carried into the boiler feed pump. In terrestrial applications, separation of liquid from vapor is usually accomplished using gravitational forces. In space, dynamic, centrifugal, and surface tension forces must be relied upon to eliminate vapor carryover from the condenser. Similarly, the design must move the condensed liquid through the condenser and to the pump suction. Shear flow condensers are most commonly proposed for space application and are designed to maintain sufficient vapor velocity to move the liquid to the condenser outlet.

Although the high thermal conductivity of potassium tends to decrease the importance of liquid film thickness on the condensing surface, condenser design generally attempts to minimize liquid film thicknesses to decrease the temperature drop between the condensate and the condensing surface. Efficient methods of maintaining liquid/vapor interface control in the condenser are needed to ensure reliable condenser operation. The condensation process itself, however, should not be gravity dependent unless NCGs are present. Since these systems would be designed to eliminate or minimize non-condensables, it should be possible to investigate the condensation process itself through ground testing. The basic phenomena that are pertinent to condenser operation include entrainment and deposition, shear flow control of liquid films, and condensation heat transfer. In addition, characterization of actual design geometries is needed to verify condenser performance.

\subsubsection{Feed Heaters and Reheaters}

Issues associated with the design of feed heaters and reheaters are almost identical with those of boilers and condensers, and operative phenomena should be the same as those discussed in the appropriate sections above.

Phenomenology that would add to our understanding of Rankine cycle designs include

1. Bubble formation and departure during the forced convection boiling process 
2. Liquid entrainment and deposition processes

3. CHF and parallel channel flow stability limits under forced convection conditions

4. Liquid carryover characteristics during boiling

5. Shear flow behavior of liquid films

For the Rankine cycle, components operate under forced convection conditions, and the most critical aspect of designing components is to know the point (such as the minimum flow rate) where gravitational effects begin to cause the phenomena to differ from those that would occur under more highly convective conditions. A primary design objective would be to ensure that components operated well above these limits. In order to characterize off-normal operations of the Rankine cycle system, where gravitational effects are important, additional quantitative description of the operative phenomena is necessary.

Initial microgravity experimentation is proposed using surrogate fluids in order to minimize the experimental costs. In order to begin that experimental development, a scaling exercise from potassium to surrogate fluid systems was initiated.

\subsection{EXPERIMENT SCALING ANALYSIS}

\subsubsection{Identification Of Normalized Parameters}

In order to scale experimental test results to prototypical operating conditions, it is necessary to design the experiment using normalized parameters. Each dimensionless group represents a ratio of fluid properties, forces, heat transfer parameters, etc. If the appropriate normalized parameters have the same values for both the experimental and prototype conditions, the systems are said to exhibit dynamic similarity. The normalized parameters necessary for dynamic similarity of a thermal/hydraulic experiment involving two-phase flow with heat transfer have been relatively well established by many years of engineering practice and can be grouped into several categories.

\subsubsection{Fluid Property Ratios}

The primary fluid property ratios of interest are:

- Prandtl number, $\operatorname{Pr}=v / \alpha$ (ratio of momentum diffusivity to thermal diffusivity)

- Density ratio, $\rho_{\mathrm{v}} / \rho_{\mathrm{f}}$

- Viscosity ratio, $\mu_{\mathrm{v}} / \mu_{\mathrm{f}}$

- Specific heat ratio, $\mathrm{c}_{\mathrm{p}, \mathrm{v}} / \mathrm{c}_{\mathrm{p}, \mathrm{f}}$

\subsubsection{Hydrodynamic Flow Parameters}

The main hydrodynamic scaling parameters governing the flow are

- Reynolds number, $\operatorname{Re}=\rho \mathrm{VD} / \mu$ (ratio of inertia forces to viscous forces)

- Peclet number, $\mathrm{Pe}=\mathrm{RePr}$

- Weber number, $\mathrm{We}=\rho \mathrm{V}^{2} \mathrm{D} / \sigma$ (ratio of inertia forces to surface tension forces)

- Mach number, $\mathrm{M}=\mathrm{V} / \mathrm{V}_{\text {sonic }}$ (ratio of average flow velocity to sonic velocity)

- Froude number, $\mathrm{Fr}=\mathrm{V} /(\mathrm{gD})^{1 / 2}$ (ratio of inertia forces to gravity forces) 
- Bond number, $B n=g\left(\rho_{1}-\rho_{v}\right) D^{2} / \sigma$ (ratio of gravity force to surface tension force)

- Gravity/viscous force ratio $=\rho_{1} g\left(\rho_{1}-\rho_{v}\right) D^{3} / \mu^{2}$

\subsubsection{Heat Transfer Parameters}

Major heat transfer scaling parameters in two-phase flow are:

- Jakob number, $\mathrm{Ja}=\mathrm{c}_{\mathrm{p}, \mathrm{f}}\left(\mathrm{T}-\mathrm{T}_{\mathrm{sat}}\right) / \mathrm{h}_{\mathrm{fg}}$ (ratio of sensible heat to latent heat effects)

- Boiling number, $\mathrm{Bo}=\mathrm{q} " /\left(\rho \mathrm{Vh}_{\mathrm{fg}}\right)$ (ratio of heat transfer to vapor formation rate)

- Quality, $X=\mathrm{m}_{\mathrm{vap}} / \mathrm{m}_{\text {tot }}$

- Nusselt number, $\mathrm{Nu}=\mathrm{hD} / \mathrm{k}_{\mathrm{f}}$ (normalized heat transfer coefficient)

\subsubsection{Centrifugal Flow Parameters}

Normalized groups related to centrifugal flow effects include:

- Flow coefficient $=\mathrm{Q} /\left(\omega \mathrm{D}^{3}\right)$

- Rotational Reynolds number, $\operatorname{Re}_{\mathrm{rot}}=\rho \omega \mathrm{D}^{2} / \mu$

- Centrifugal pressure ratio $=\rho \omega^{2} \mathrm{R}^{2} /(2 \mathrm{P})$

Not all these parameters can be matched simultaneously in a scaled experiment, and a degree of engineering judgment is required to obtain the best similarity possible. Fluid property ratios are especially difficult to match because of the limited choice of experimental fluids. However, it is sometimes possible to compensate for these problems by adjustments to the scaled geometry or heat flux. Matching the flow hydrodynamics is particularly critical for studies involving centrifugal flow in a microgravity environment. Some of the scaling parameters also are not relevant under certain conditions. For example, those parameters involving the gravitational acceleration, $g$, tend to go to either zero or infinity under microgravity assumptions.

\subsubsection{Scaling from an Actual Potassium Boiler Design}

A schematic layout of the potassium boiler design from the 1960s used as a basis for scaling the new space Rankine cycle experiment is shown in Fig. 6.1. Fig. 6.2 is a close-up of the test section boiling channel with its helical insert. ${ }^{4}$ 


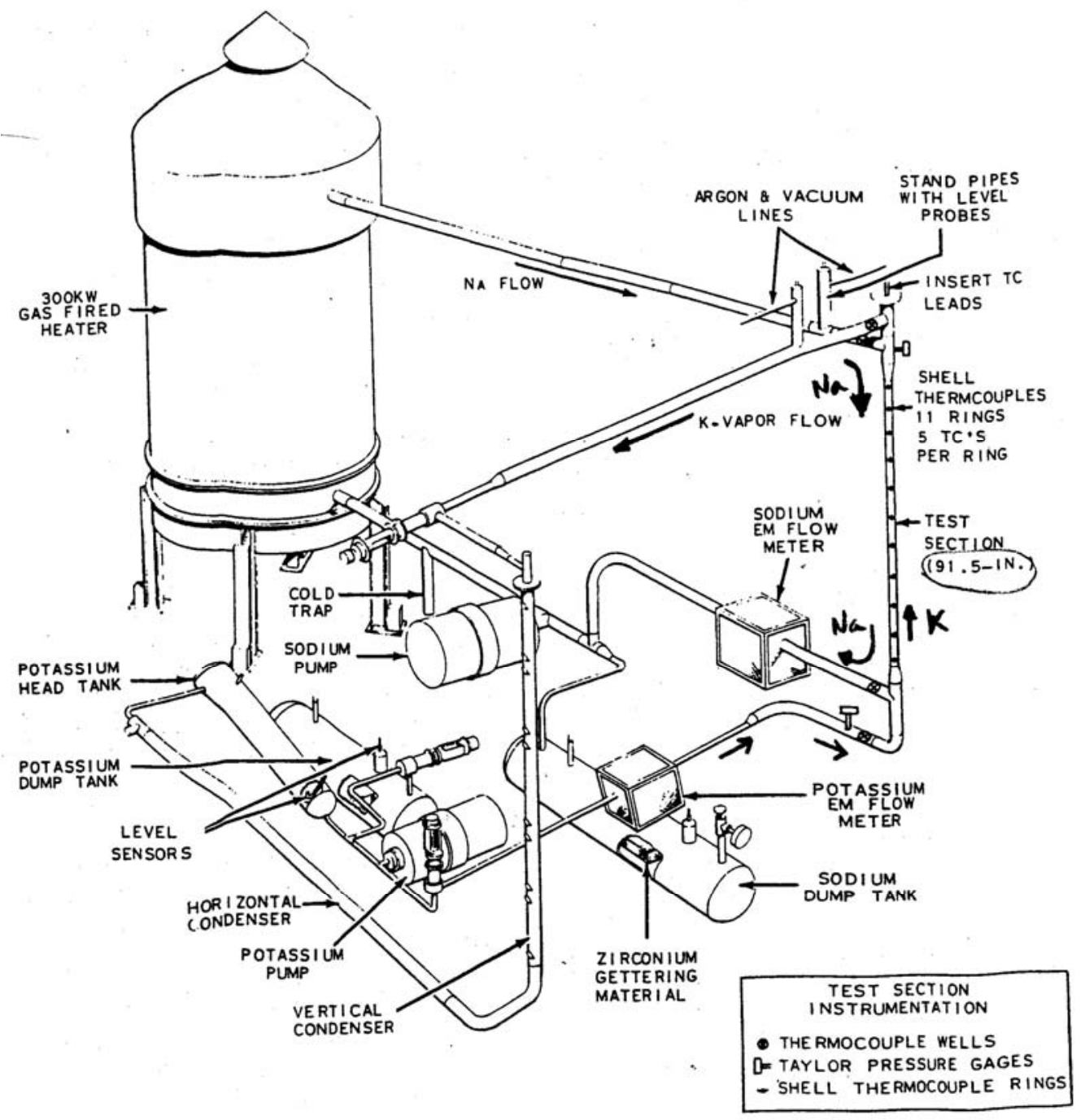

Fig. 6.1. Schematic of the potassium boiler design chosen for scaling purposes. Source: ref. 4

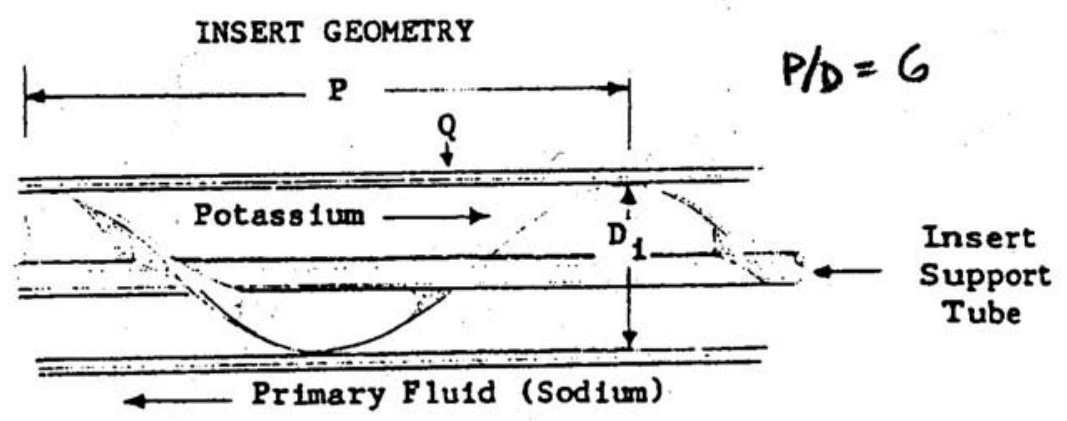

Fig. 6.2. Channel helical insert used in the original potassium boiler design. Source: ref. 4 
A plot of temperature and pressure conditions along the experimental channel for a particular run on October 12, 1964, is presented in Fig. 6.3, indicating the presence of superheated potassium vapor at the channel outlet.

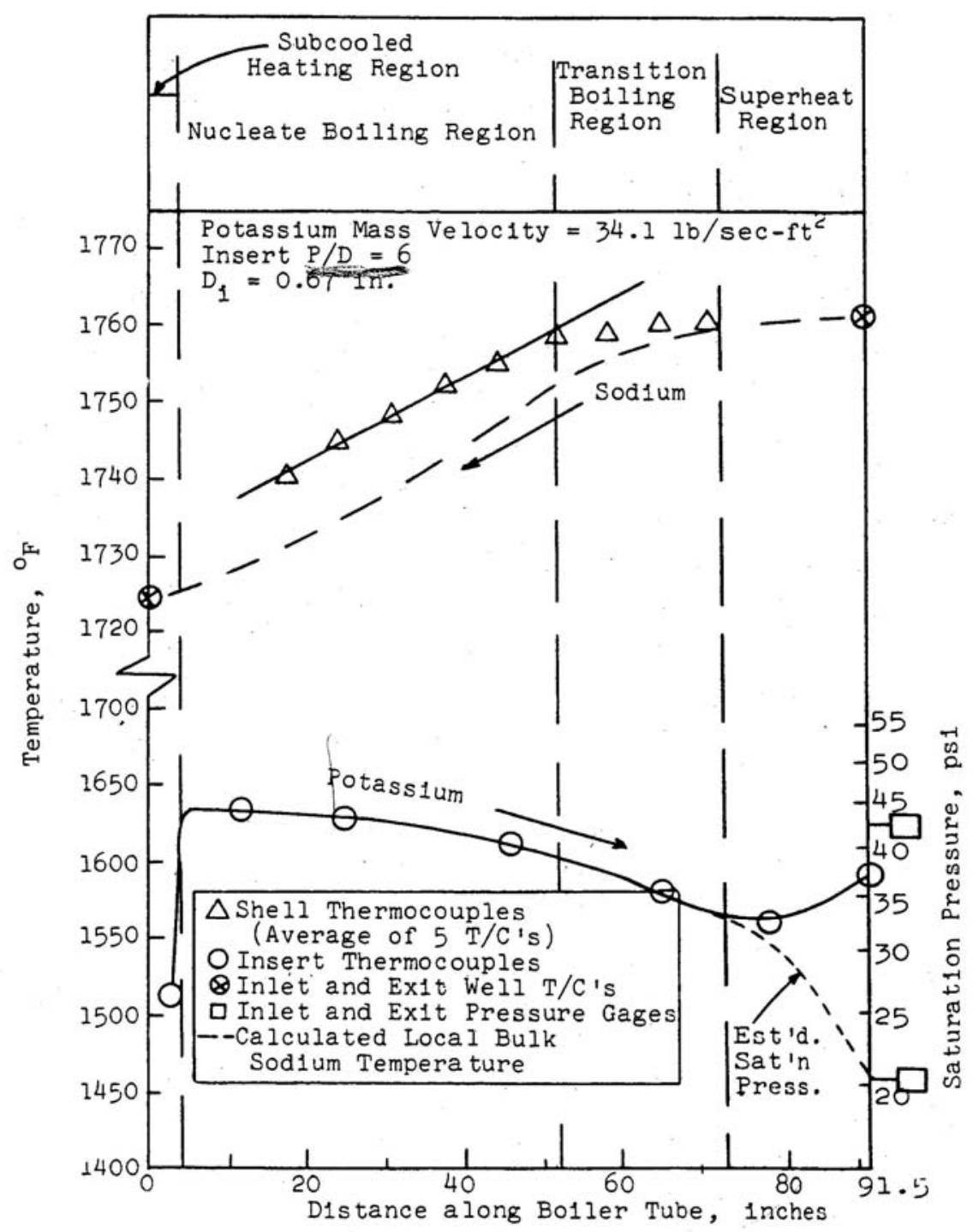

Fig. 6.3. Temperature profile from potassium boiler experiment on Oct. 12, 1964. Source: ref. 4

The specific experimental conditions chosen for scaling purposes were taken from an experimental run that clearly resulted in superheated potassium vapor. These experimental conditions were as follows:

Flow rate $=0.038 \mathrm{~kg} / \mathrm{s}$

$\mathrm{T}_{\mathrm{i}}=1044.9 \mathrm{~K}$ (subcooled liquid)

$\mathrm{T}_{\mathrm{o}}=1139.9 \mathrm{~K}$ (superheated vapor)

$\mathrm{P} / \mathrm{D}=6$ (helical channel insert has a pitch of 6) 


$$
\begin{aligned}
& \mathrm{D}=1.70 \mathrm{~cm} \\
& \mathrm{~L}=2.32 \mathrm{~m} \\
& \mathrm{~V}_{\mathrm{o}}=243.8 \mathrm{~m} / \mathrm{s} \text { (channel outlet flow velocity) }
\end{aligned}
$$

The corresponding values for the most critical normalized scaling parameters under these flow conditions are

$$
\begin{aligned}
& \mathrm{Ma}_{\mathrm{o}}=0.44 \text { (outlet Mach number) } \\
& \mathrm{Ja}_{\mathrm{i}}=-0.1617 \text { (inlet Jakob number) } \\
& \mathrm{Ja}_{\mathrm{o}}=0.0496 \text { (outlet Jakob number) } \\
& \mathrm{Re}_{\mathrm{o}}=96,277 \text { (outlet Reynolds number) } \\
& \mathrm{Re}_{\mathrm{rot}}=100,821 \text { (rotational Reynolds number) }
\end{aligned}
$$

Since the sonic velocity is a material property of the fluid chosen for the experiment, fixing the outlet Mach number also determines the exit flow velocity. The specified Jakob numbers indicate the degree of subcooling or superheat at the channel inlet and outlet, respectively. Hence $J a_{i}$ and $J a_{o}$ determine the temperature and pressure conditions for inlet and outlet. Matching the exit Reynolds number then gives the necessary channel diameter. Once the inlet and outlet pressures as well as the channel diameter are known, the length of the scaled channel can be determined from the pressure drop. Channel mass flow is then calculated from the diameter and average velocity, while the power requirements are obtained using the mass flow rate and enthalpy change between inlet and outlet. Finally, the rotational Reynolds number, $R e_{\text {rot }}$, is used to find the channel helix pitch, $P / D$, for similar swirl-flow effects.

\subsubsection{Initial Scaling Results for Three Fluids}

The procedure just described was followed to obtain the design parameters for a scaled potassium boiler using each of three stimulant test fluids.

\subsubsection{Water}

A scaled experimental system using water would have the following design parameters:

$$
\begin{aligned}
& \mathrm{L}=2.65 \mathrm{~m} \\
& \mathrm{D}=1.75 \mathrm{~cm} \\
& \text { Flow rate }=0.0179 \mathrm{~kg} / \mathrm{s} \\
& \text { Power }=42.97 \mathrm{~kW} \\
& \mathrm{P} / \mathrm{D}=6 \\
& \mathrm{~T}_{\mathrm{i}}=20^{\circ} \mathrm{C} \text { (subcooled liquid) } \\
& \mathrm{T}_{\mathrm{o}}=141.5^{\circ} \mathrm{C} \text { (superheated vapor) } \\
& \mathrm{V}_{\mathrm{o}}=222 \mathrm{~m} / \mathrm{s}
\end{aligned}
$$

The scaling match obtained between a water system and the potassium system is excellent, with all the piping sizes and flow velocities quite comparable. However, the system power requirement of $42.97 \mathrm{~kW}$ is probably too high for a water system to be practical in the available microgravity environments. 


\subsubsection{Freon-12}

Freon-12 was examined as a possible candidate fluid. Initial scaling evaluations led to the following scaled diameter and velocity:

$$
\begin{aligned}
& \mathrm{D}=0.5 \mathrm{~mm} \\
& \mathrm{~V}_{\mathrm{o}}=66.3 \mathrm{~m} / \mathrm{s}
\end{aligned}
$$

The channel diameter is unacceptably small using Freon-12 because of the high R-12 vapor density. The outlet velocity is also too low (which would largely invalidate scaling of the centrifugal flow effects for phase separation) because of the low sonic velocity in R-12 vapor. Both these problems result from the high molecular weight of the experimental fluid (about $120.91 \mathrm{~kg} / \mathrm{kmol}$ for R-12), which is a general characteristic of all freons.

\subsubsection{Acetone $\left(\mathrm{C}_{3} \mathrm{H}_{6} \mathrm{O}\right)$}

A scaled experimental system using acetone would have the following design parameters:

$$
\begin{aligned}
& \mathrm{L}=1.42 \mathrm{~m} \\
& \mathrm{D}=3.6 \mathrm{~mm} \\
& \text { Flow rate }=2.56 \mathrm{~g} / \mathrm{s} \\
& \text { Power }=1.36 \mathrm{~kW} \\
& \mathrm{P} / \mathrm{D}=3 \\
& \mathrm{~T}_{\mathrm{i}}=27^{\circ} \mathrm{C} \text { (subcooled liquid) } \\
& \mathrm{T}_{\mathrm{o}}=73.9^{\circ} \mathrm{C} \text { (superheated vapor) } \\
& \mathrm{V}_{\mathrm{o}}=112.7 \mathrm{~m} / \mathrm{s}
\end{aligned}
$$

The system using acetone as the simulant fluid was the closest scaling match with moderate power input requirements that was found during the initial scoping study for a potassium boiler experiment. 


\section{TECHNOLOGY DEVELOPMENT PLAN FOR ACHIEVING A TECHNOLOGY READINESS LEVEL OF 6 FOR THE RANKINE CYCLE}

\subsection{PRESENT DEVELOPMENT STATUS}

A TRL of 6 is defined as

"System/subsystem model or prototype demonstration in a relevant environment (ground or space)."

A review of the systems and components comprising a potassium Rankine cycle was conducted to determine their effective readiness level. Table 7.1 describes the estimated readiness levels of critical components and describes some of the logic associated with the assignment. As noted in the table, there are no components presently at a TRL level of 6 . There has been no component testing in microgravity environments with potassium as the working fluid. Those components that are impacted by microgravity environments, even though they may be commonly used in space, were given a lower TRL level. However, components are sufficiently developed that there is confidence that the Rankine cycle can be effectively developed for space application. The component development levels reflected in Table 7.1 were also used to help shape the technology development plan that is described in this section.

\subsection{DEVELOPMENT CONSIDERATIONS AND DEVELOPMENT PROGRAM}

Discussion of the technology development requirements and development program is arranged by individual component.

\subsubsection{Structural Materials}

The goal of this effort is to re-establish the engineering feasibility of $\mathrm{Nb}-1 \% \mathrm{Zr}$ for space reactor structural applications

Key issues to be addressed include (1) comparison of elevated creep strength and other mechanical properties of current heats of $\mathrm{Nb}-1 \% \mathrm{Zr}$ with results obtained in the $\mathrm{SP}-100$ program, (2) the establishment of welding techniques that maintain oxygen and nitrogen levels below 200 ppm in the weldment, and (3) the performance of mechanical tests on irradiated $\mathrm{Nb}-1 \% \mathrm{Zr}$ (current commercial heats) and weldments in order to establish an appropriate design window.

\subsubsection{Development Program}

In order to accomplish these goals, the tasks listed in Table 7.2 are recommended. 


\section{Table 7.1. Present Rankine power conversion technology readiness levels}

\begin{tabular}{|c|c|c|}
\hline $\begin{array}{l}\text { Component/ } \\
\text { demonstrated performance }\end{array}$ & TRL & Justification \\
\hline $\begin{array}{l}\text { Boiler and reheater/ } \\
\qquad 1447 \mathrm{~K} ; 2750 \mathrm{~h} ; 0.1 \mathrm{MW}(\mathrm{t})\end{array}$ & 4 & $\begin{array}{l}\text { The 7500-h test loop with ASTAR } 811 \mathrm{C} \text { samples showed no } \\
\text { corrosion or carbon depletion. Feasibility of a lithium-heated } \\
\text { boiler for vaporizing potassium was demonstrated in ORNL } \\
\text { and NASA experiments, which operated at temperatures of } \\
1450 \mathrm{~K} \text {. }\end{array}$ \\
\hline $\begin{array}{l}\text { Boiler feed turbopump/ } \\
810 \mathrm{~K} ; 5000 \mathrm{~h} ; 0.08 \mathrm{~kg} / \mathrm{s}\end{array}$ & 4 & $\begin{array}{l}\text { Potassium turbopump has been tested at } 1100 \text { to } 1150 \mathrm{~K} \text { for } \\
2500 \mathrm{~h} \text {. ASTAR } 811 \mathrm{C} \text { and } \mathrm{Nb}-1 \mathrm{Zr} \text { are commercially available. }\end{array}$ \\
\hline $\begin{array}{l}\text { Rotary fluid management } \\
\text { device (RFMD)/ } \\
320 \mathrm{~K} ; 12000 \mathrm{~h} ; 12 \mathrm{~kg} / \mathrm{s}\end{array}$ & 4 & $\begin{array}{l}\text { Small-scale RFMDs tested on Space Station Freedom Program } \\
\text { and Boost Surveillance and Tracking Satellite Program used } \\
\text { organic working fluid. The KC-135 zero-gravity tests have } \\
\text { been successful. }\end{array}$ \\
\hline $\begin{array}{l}\text { Turbine, bearings, and seals/ } \\
1100 \mathrm{~K} ; 12000 \mathrm{~h} ; 12 \mathrm{~kg} / \mathrm{s}\end{array}$ & 4 & $\begin{array}{l}\text { Potassium turbine (final stages) tests have been successfully } \\
\text { performed, showing acceptable erosion of blades. Water tests } \\
\text { show that removal of moisture collected on final stator may be } \\
\text { required. Tests have demonstrated methods to remove } \\
\text { moisture. Erosion was not a problem in tests. ASTAR 1511C } \\
\text { material for the high-temperature applications was produced in } \\
\text { small quantities in the 1970s. ASTAR } 811 \mathrm{C} \text { is commercially } \\
\text { available. Tilting-pad bearings are in common use and have a } \\
\text { large base. Short-term tests of potassium bearings in proper } \\
\text { temperature range have been successful. }\end{array}$ \\
\hline $\begin{array}{l}\text { Alternator/ } \\
493 \mathrm{~K} ; 5 \text { years; } 4.0 \mathrm{MW}(\mathrm{e}) \\
16860 \mathrm{rpm}\end{array}$ & 5 & $\begin{array}{l}\text { Lower temperature, wound-field } 3 \text {, synchronous type design has } \\
\text { long application history. Materials of construction are readily } \\
\text { available and well-characterized. }\end{array}$ \\
\hline $\begin{array}{l}\text { Condenser/ } \\
1050 \mathrm{~K} ; 5000 \mathrm{~h} ; 0.005 \mathrm{~kg} / \mathrm{s}\end{array}$ & 4 & $\begin{array}{l}\text { Design methods for shear flow condenser have been validated } \\
\text { on organic Rankine cycle program. The KC-135 tests have } \\
\text { verified performance in zero-gravity. Operation with } \\
\text { potassium must be verified in development program. }\end{array}$ \\
\hline System behavior & 4 & $\begin{array}{l}\text { Full system testing has been performed during both the MPRE } \\
\text { and SNAP programs (less power turbines and alternators). } \\
\text { Micro-gravity operation is also addressed in the development } \\
\text { program. }\end{array}$ \\
\hline System startup & 3 & $\begin{array}{l}\text { Startup sequences for ground-based systems are well developed, } \\
\text { and sequences for space-based operation have been proposed. } \\
\text { Some design work for freeze/thaw has been performed under } \\
\text { the SP-100 program. }\end{array}$ \\
\hline Alkali liquid metal heat pipes & 5 & $\begin{array}{l}\text { Alkali metal heat pipes have been ground tested and proven to } \\
\text { operate as expected. Heat pipes are presently used in a wide } \\
\text { variety of space systems, proving microgravity operation. } \\
\text { Remaining issues for potassium heat pipes include freeze/thaw } \\
\text { behavior, partial load operation, proving operability of } \\
\text { advanced wick structures, and long-term operation } \\
\text { characteristics. }\end{array}$ \\
\hline
\end{tabular}


Table 7.2. Major tasks in the development of $\mathrm{Nb}-1 \% \mathrm{Zr}$ for space application

\begin{tabular}{ll}
\hline Task & Milestones and deliverables \\
\hline 1 & $\begin{array}{l}\text { Complete measurements and data evaluation of tensile and } \\
\text { thermal creep properties of } \mathrm{Nb}-1 \% \mathrm{Zr}\end{array}$ \\
2 & $\begin{array}{l}\text { Demonstrate prototypic Nb-1\%Zr welding techniques that } \\
\text { limit } \mathrm{O}, \mathrm{N} \text { pickup }\end{array}$ \\
3 & $\begin{array}{l}\text { Complete mechanical property tests on irradiated } \mathrm{Nb}-1 \% \mathrm{Zr} \\
\text { Complete assessment of performance impacts of dissimilar } \\
\text { materials (if any) and O,C,N impurity transport from hot to } \\
\text { cold regions of coolant loop } \\
\text { Complete material corrosion tests for potassium / Nb-1\% } \mathrm{Zr} \\
\text { systems }\end{array}$ \\
\hline
\end{tabular}

\subsection{Task Descriptions}

Task 1: Since the mechanical properties of refractory alloys such as $\mathrm{Nb}-1 \% \mathrm{Zr}$ are dependent on the concentration of impurities, confirmatory tests are recommended to be performed on representative current commercial heats of $\mathrm{Nb}-1 \% \mathrm{Zr}$. Tensile and thermal creep tests are recommended to be performed and compared with previous data generated in the SP100 and other programs. In addition, fracture toughness data is recommended to be obtained for current heats of Nb-1\%Zr. During Year 1, representative heats would be procured (sheet and tubing geometries), tensile tests and much of the fracture toughness testing would be completed, and thermal creep tests in lithium would be initiated.

Task 2: Previous work in the SP-100 program determined that Nb-1\%Zr weldments exhibited high corrosion rates (elevated temperature exposures) when the oxygen or nitrogen levels in the weldment exceeded $200 \mathrm{ppm}$. Welding techniques are recommended to be reestablished that enable low oxygen and nitrogen levels to be maintained in welded $\mathrm{Nb}-1 \% \mathrm{Zr}$. Mechanical properties of the welded specimens would also be measured (tensile, fracture toughness).

Task 3: Very few mechanical properties data are available for neutron-irradiated Nb$1 \% \mathrm{Zr}$. Since the irradiation behavior is expected to depend on fabrication details (impurity content and heat treatment conditions), some neutron irradiation tests (preferably using $\mathrm{Li}$ bonded irradiation capsules) to lifetime neutron fluences are recommended to verify the mechanical performance of $\mathrm{Nb}-1 \% \mathrm{Zr}$, including prototypical welds. The irradiation experiments should preferably be performed with the specimens in contact with liquid lithium.

Task 4: Perform assessment of the impact on $\mathrm{Nb}-1 \% \mathrm{Zr}$ performance of dissimilar materials (e.g., turbine wheel materials), and O,C,N impurity transport from hot to cold regions of the coolant loop. A previous SP-100 assessment concluded that conventional Nb- $1 \% \mathrm{Zr}$ could not be used with the higher-performance PWC-11 (Nb-1\%Zr-0.1C) alloy because of transport of carbon from the PWC-11 alloy by the coolant (with resulting decrease in strength). The activities would focus on reviewing previous compatibility assessments from the SP-100 program and others. The proposed R\&D assumes limited experimental studies would need to be completed.

Task 5: Perform material compatibility/corrosion testing of potassium and refractory metals. Substantial corrosion testing was conducted in the SP-100 program for the SP-100 liquid 
metal coolant/structural material system. Additional testing is recommended to confirm the corrosion behavior of the potassium/ $\mathrm{Nb}-1 \% \mathrm{Zr}$ system. This task would consist of (1) evaluation of the corrosion behavior database for potassium/ $\mathrm{Nb}-1 \% \mathrm{Zr}$ systems, (2) identification of outstanding data requirements and required tests, (3) the design and construction of an appropriate corrosion test loop similar to those developed by ORNL and GE in the SP-100 program, and (4) execution of the specified suite of tests and reduction and analysis of the test data.

\subsubsection{Boiler}

The boiler development program has both a ground test element and a microgravity test element. Microgravity testing is discussed in that section.

\subsubsection{Requirements}

The boiler is required to take subcooled liquid potassium, stably accept heat from the primary system, and supply dry potassium vapor to the turbine. Specifics of the boiler design depend on system optimization. The present boiler is a once-through design. These designs have three boiler sections: an economizer section to heat the subcooled liquid to the saturation temperature, a boiling section to produce vapor, and a superheat section to ensure the vapor is dry. The baseline design uses twisted tapes in the boiling region to force stable boiling initiation and to eliminate or minimize liquid carryover into the turbine feed line.

\subsubsection{Design Issues}

Although a significant amount of boiler testing has been performed in ground-based experiments (see Section 4.1), additional experimentation and development is needed to achieve a TRL level of 6 .

Some regions of the boiler (potassium liquid entrance, wet front) may have large temperature gradients that can potentially cause large stresses in the boiler material. At the entrance, cold potassium from the boiler feed pump is entering the tubes. At this point in the boiler, hot lithium from the primary side is used to heat and boil the potassium. Temperature gradients across the tube wall must be evaluated to ensure that stress levels in the boiler tubes do not cause tube failure. The wet front is defined as the point where the potassium liquid film eventually dries out. The location of the wet front moves over a small axial range during operation. The movement of this wet front can cause stresses in both the tubes and the welded joints in the boiler. Fatigue of these joints can be limiting if stress levels are high enough and time scales are long enough. Because design mission lifetimes are expected to be 10 to 15 years, the fatigue limits in the boiler must be evaluated. Resolution of these issues would require a combination of analysis and experimentation. Stress analysis of the boiler would be necessary to determine the overall stress levels associated with these temperature gradients and, testing would be required to confirm the calculated results. Additionally, long term testing at operating conditions would be needed to evaluate the fatigue limits due to wet front movement.

Static instability within once-through boilers can cause boiler tube dryout under certain conditions if the boiler is improperly designed. Evaluation of static (or Leidenig) instability limits is required to ensure that the design is not limited by these instabilities. A second type of condition that can occur in liquid metal boilers (or boiling systems that use very good wetting 
liquids) is explosive boiling initiation caused by high wall superheats before the boiling process is initiated. Because wetting liquids (such as potassium) cause nucleation sites on a material surface to become filled with liquid, a significant amount of wall superheat is required before vapor can form. Once vapor is formed, since the liquid near the wall is also superheated, a very rapid vaporization of the superheated liquid occurs that can cause large pressure and flow transients in the boiler. Engineering features such as re-entrant cavities and boiling rings are commonly used to prevent this behavior; however, studies would be required to confirm that these engineering features work as expected. A comprehensive study of the potential boiler instability problems under different conditions needs to be performed, and the solutions for any potential problems need to be found.

In the present design, twisted tapes are used in the boiler tubes to induce swirl in the flow and force potassium liquid to remain on the tube inner surface as long as possible. These devices are used to ensure that only saturated or superheated vapor exits the boiler tubes and enters the turbine inlet. However, there are a variety of potential insert designs, some that have significantly less pressure drop through the boiler associated with them. Different inserts should be evaluated to select the most efficient. Pressure drops, heat transfer coefficients, and vapor and superheat efficiency would be tested for different kinds of inserts and different configurations.

\subsubsection{Development Program}

Continued design of the boiler would be performed in multiple stages: conceptual, final, engineering, and prototype. These design stages would support an experimental program after completion of the engineering design. A combination of ground and space testing would be necessary to complete boiler development. Ground testing should consist of both surrogate fluid and potassium experiments.

A very large amount of information is available on boiling for surrogate fluids. As noted in Section 6.2, water appears to be a good simulant for potassium, and a very large amount of boiling data for water is available. Thus, testing using a surrogate fluid should be aimed at those features that require a significant amount of configuration changes, and it should be performed as a prelude to potassium testing. Areas that may be amenable to surrogate fluid testing include initial screening of candidate inserts, flow patterning in boiler inlet and outlet plena, and evaluation of additional separation devices (if needed).

As noted in Section 4.1, a significant amount of data is already available on potassium boiling. However, no potassium loop testing programs have existed for over 20 years. The overall technology for potassium (and alkali metal) testing would be re-established in order to develop the Rankine cycle. This includes developing new test loop facilities that include cleanup, handling, and storage facilities while meeting present safety and environmental requirements. These facilities should be used to perform potassium testing for multiple components in order to reduce costs. The previous testing should be used as a starting point for developing exact boiler configurations. Long-term testing is recommended to establish duration limits, examine fatigue limits in the boiler, and study materials compatibility issues.

The proposed boiler testing program starts with an engineering design for short-term testing and utilizes features that allow boiler design changes to be easily implemented and evaluated in the experiment. These might consist of multiple test configurations, ranging from single-tube experiments to full-scale boiler testing. The engineering test unit would be designed for shortterm testing in order to evaluate multiple design options. The prototype system would be 
designed for long- term testing once a design is finalized. A flight design unit would be tested in preparation for an actual flight.

\subsubsection{Turboalternator and turbopump}

\subsubsection{Development Requirements}

Turbo-equipment designs contain many common elements such as bearings, seals, and dynamic couplings, as well as turbines, alternators and pumps. The bearings, seals, and dynamic couplings can be categorized as small components; and much of their development can be accommodated by low flow rates of working fluid and small amounts of electrical power in a small component test facility. The large components, on the other hand, would require substantial flows of potassium and would generate relatively high levels of power. Their testing can logically be accomplished in a large component test facility.

\subsection{Main power turbine requirements}

A discussion of the functional requirements of the axial turbine is fundamental to developing the requirements for the small components and for the alternator and the turbopump. The power turbine in a potassium Rankine cycle system is required to generate net mechanical power, which is equal to the electrical output of the alternator plus the losses incurred in the alternator and in the turbine mechanical components. The key design considerations that drive the mechanical arrangement of the turbine are to minimize large thermal gradients, rotor axial thrust, the possibility of liquid influx into the turbine blading, and any hot gas influx into the bearings, and to avoid active rubbing of rotor seals. The objective of any development program must therefore be to demonstrate that the selected design can meet the constraints imposed by these design conditions for the number of years required by the mission specified for the particular power system.

For an axial turbine, the thermal gradient resulting from the passing of the hot potassium vapor through a number of expansions can be accommodated by matching the thermal expansions that occur in the rotor shaft to the thermal expansions that occur in the turbine case. This is usually accomplished through materials selection that results in adjusting the coefficients of thermal expansion between the shaft and the turbine case. The overall expansion then must either (1) be resisted by the turbine mountings, resulting in loads on the turbine housing, (2) allow the assembly to flex, or (3) grow freely by use of bellows type mounts or by only mounting the turbine at one end (for example to a firewall structure as is common in light aircraft engine mounting).

Rotor axial thrust is accommodated by the use of a thrust bearing. For potassium turbines, the thrust bearing design is usually of the pivoting pad type, lubricated by potassium. For turbines that use reheat, usually the larger machines, the flow from the boiler may be directed toward the center of the turbine and expanded off into one direction; the flow is then exited from the turbine, reheated, directed back to the center of the turbine, and subsequently expanded in the other direction. The counterflow of the expanding vapor can substantially reduce axial thrust loads.

Liquid influx into the turbine expansion cavities must be limited in order to avoid or reduce turbine erosion. In order to avoid the necessity of having high-pressure vapor or liquid fluid 
sources (i.e., as required for hydrostatic bearings), the bearings for potassium turbine designs are generally hydrodynamic bearings (i.e., they generate their own fluid film and pressure on which the rotating member is supported). It is essential, however, that the bearing cavity pressure be maintained at a sufficiently high level to prevent hot vapor from entering the cavity and causing excessive heating. Accordingly, the pressure in the cavity would need to be maintained at a value higher than the local vapor expansion temperature. In general, a non-rubbing but close- clearance labyrinth seal may be used to separate the bearing cavity from the vapor chambers to minimize bearing fluid leakage into the turbine and to preclude hot gas from entering into the bearing cavity.

\subsection{Alternator requirements}

The alternator is required to generate net electrical power that is equal to the required system delivery power plus the losses incurred in delivering this power to the system bus. The key design considerations that drive the mechanical arrangement of the alternator are operating temperature, the desirability of eliminating wear-out modes that could limit life and reliability, and the necessity of providing for stable high-speed operation.

The homopolar inductor alternator is a high-speed machine particularly well suited for generating a high-frequency output. The rotor is a solid, one-piece construction with lobes on each end that form north and south poles. The stator windings resemble ordinary multiphase alternator windings except that they are only embedded in stator iron near their north and south ends. Two stator sections are required because one stator section utilizes only north pole flux and the other section just south pole flux. These north and south stator sections are aligned with the north and south poles on the rotor. A stationary toroidal field coil is located outside the stator windings between the stator core sections. Direct current is forced through this coil to generate the magnetic flux that flows through the stator and rotor. Flux flows from the field coil into the south stator section, across the gap into the rotor (containing potassium vapor), and back across the gap into the north stator section and then returns to the field coils through the frame. When the shaft is rotated, the reluctance of the flux path varies and causes the flux to alternate from essentially zero to full positive at the north stator pole, and zero to full negative at the south pole. This pulsating flux at the north and south poles generates the positive and negative portions of the output voltage waveform.

The unidirectional flux flow in a homopolar machine causes the stator poles to be sequentially excited. A positive voltage is generated in the north pole, followed by a negatively generated voltage in the south pole. Because the stator iron in each pole is conducting flux only half of the time, only half of the stator conductors are producing a voltage at any instant. Therefore, the magnetic iron is being used only to half of its capacity, and nearly twice as much is needed to generate a full voltage cycle. The amount of iron required to conduct flux between the poles is also increased because the field coil increases the separation distance. The increased separation between the stator poles also increases the length of the stator windings. The additional magnetic iron and copper increases the weight and size of the machine. Also, the longer magnetic path and windings increase the magnetic iron and resistance losses. The result is a machine that is heavier and less efficient than other generator candidates.

The solid, one-piece construction of the homopolar inductor rotor allows extremely highspeed operation. Furthermore, because the rotor does not have windings, it is not prone to the speed-limiting failure mechanisms associated with wound rotors. Previous homopolar inductor 
rotor designs have shown that they are typically capable of peripheral speeds over $1250 \mathrm{ft} / \mathrm{s}$. The main concern is that the long stator inherent in a homopolar inductor machine necessitates an equally long rotor, and this may cause some rotor deflection at high speeds. Even so, it should still be possible to design the rotor to operate at speeds well above those in the other candidate machines. This is probably the greatest advantage of homopolar inductor machines, and it makes it possible to obtain a relatively lightweight machine even though the design approach results in a larger, heavier machine.

A preliminary evaluation of possible alternator types and configurations indicates that the homopolar induction alternator was the best suited for the operating conditions and constraints of the potassium Rankine system. This is due primarily to its being the available configuration with the highest operating temperature possibilities. If a reliable method of cooling the alternator rotor can be devised within the potassium Rankine system, then other configurations that offer higher power density may be more suitable.

\subsection{Boiler feed turbopump requirements}

The function of the boiler feed turbopump is to receive liquid potassium from the condenser RFMD and raise its pressure to the level needed to operate the main power turbine plus the pressure drop through the potassium loop and its components (particularly the potassium boiler). Since the pump also provides the fluid for the power turbine and alternator bearings, it is important that the pump be capable of accelerating quickly during system start-up. This requires the rotor to have a low polar moment of inertia and minimal mechanical drag torque during system start and transition to full power.

A preliminary design that meets the general requirements for the boiler feed turbopump consists of an axial flow inducer followed by a shrouded centrifugal impeller. After the impeller, the liquid potassium is collected in a vaneless diffuser and delivered to the boiler. The inducer is included to provide a large suction performance margin and cavitation-free operation. It would be designed to attain long life through selection of a favorable flow coefficient with a low tip speed, using the technology developed at Rocketdyne for long-life water jet pumps and sodium pumps. The shrouded impeller ensures repeatable performance, independent of rotor axial position, and the capability of minimizing residual rotor axial thrust. A single-stage partial admission turbine would supply the power to drive the pump. Turbine flow would be tapped off from the working fluid supplied to the main drive turbine and therefore would have the same basic inlet conditions. The partial admission feature improves efficiency at the low turbine flow rate. Using the same flow stream for both turbines causes the flow in the pump turbine to be below the saturation pressure, but not sufficiently to achieve condensation in the rotor. The expansion into the two-phase dome region is limited to prevent equilibrium from occurring until the vapor is downstream of the rotor in the discharge system. This arrangement, coupled with a low rotor tip speed, would ensure that no erosion damage would occur in the turbine as a result of condensing droplets.

The rotor is supported radially by tilting pad hydrodynamic bearings lubricated by liquid potassium. Rotor axial thrust is absorbed by opposing tilting pad bearings acting on a single disc. The selection rationale for the turbopump bearings and seals would follow the same approach as used for the main power turbine. The entire bearing cavity is maintained at a pressure about 10 psia higher than that of the turbine cavity and impeller hub rear cavity pressure to preclude entry of hot vapor or liquid from the turbine and pump cavities into the bearing cavity. 


\subsection{Bearing Requirements}

Organic-fluid-cooled bearings are not desirable for this application because of the complex sealing requirement they would create to isolate the organic fluid from the main process fluid, potassium. The feasibility of potassium-lubricated bearings has been demonstrated at Rocketdyne and elsewhere. Therefore, the use of potassium as the bearing fluid is simpler and should result in a more reliable system.

The three bearing types that could be considered for this application include rolling element, hydrostatic, and tilting pad bearings. The rolling element bearings can be eliminated from consideration because potassium does not have sufficient viscosity and lubricity to attain the life requirements.

In the hydrostatic concept, pressurized fluid is supplied to stationary recesses located circumferentially in a stationary housing that sustains the rotating member on a fluid film. In a hydrodynamic bearing, the fluid film is generated within the bearing itself by viscous pumping of the fluid into a wedge formed by the rotating and stationary surfaces of the bearing. Based on the results of prior programs, both hydrostatic and hydrodynamic concepts would be acceptable in conjunction with potassium as the bearing fluid. The tilting pad hydrodynamic bearing has the advantage that it requires a lower flow rate than the hydrostatic type to generate the necessary stiffness and damping. Furthermore, the tilting pad bearings can be assembled with a larger radial clearance than the fixed-diameter hydrostatic bearings. This is because the pads actually establish their own clearance by tilting into operating position, and this clearance is always smaller than the pivot assembly clearance. The three degrees of freedom of the pads to self-align provides a greater tolerance to misalignment and differential thermal growth. For these reasons, Rocketdyne believes that the tilting pad hydrodynamic bearing is the most promising bearing concept for liquid potassium applications.

\subsection{Seal requirements}

The use of liquid potassium bearings greatly simplifies the dynamic sealing requirements. The outboard side of the antidrive end of the turbine does not require a seal in any case, so liquid potassium would be allowed to flood the end of the rotor. A low-clearance but noncontacting labyrinth seal is included between the bearing cavity and the last turbine stage to minimize bearing fluid leakage into the stage.

On the drive end of the turbine, provision must be made to keep bearing liquid out of the coupling cavity to prevent excessive fluid pumping loads and possible cavitation damage on the coupling components. The simplest and most reliable means of accomplishing this is to employ a vaned slinger that reduces the pressure at the hub on the vaned side to the vapor pressure of the fluid. The important factor is not that the pressure level is reduced in the coupling cavity, but the fact that the fluid is changed to the vapor phase. The pumping loads are thereby reduced and the potential for cavitation damage may be eliminated.

The vaned slinger concept presents the best approach to providing an environment for the coupling that should allow it to achieve the required life. By virtue of not having either rubbing interfaces or fatigue-prone components, the slinger should be highly reliable and should not be life- limited. Its effectiveness has been demonstrated in other turbopump applications. 


\subsection{Coupling Requirements}

A flexible disc coupling located between the turbine and the alternator and contained in a cylindrical housing is required. The flexible coupling serves two purposes:

1. It provides for minor misalignment between the turbine and the alternator.

2. It helps to limit the heat transfer along the axial length of the turbine and alternator shafts.

From the turbine designer's point of view, the fewest problems for the turbine/generator set result from mounting both units in a rigid frame such as that on a commercial turbine-generator set. However, in this case, the mounting and arrangement can be left to the system designer since both assemblies are relatively short and can be easily adapted to mounting on only one end. A firewall with the turbine extending to the right and the alternator to the left could be used, for example. Taken together, the turbine and alternator represent a long, slender rotating member that would be difficult to align and balance. The occurrence of natural vibration frequencies and oscillating modes would be difficult to control on such an assembly. Using separate shafts for the turbine and alternator enables each unit to be tuned for much higher natural frequencies. Also, the use of two shafts presents the opportunity to reduce heat losses from the turbine to the alternator by conduction down the length of the shaft. Since the alternator rotor presents a difficult cooling problem, reduction of turbine axial heat conduction is a worthwhile goal.

\subsubsection{Development Program Objectives}

In light of these design constraints, the objective of the development program that is outlined below is to demonstrate by testing of prototypical hardware elements and complete assemblies that the design constraints can be met for durations compatible with mission requirements and in an actual or simulated space environment. Potassium Rankine power turbines are currently considered to have a TRL of 4 (component and/or breadboard validation in a laboratory environment). The objective of the development program outlined below is to bring the turbine technology to a TRL of nearly 6 [system/subsystem model or prototype demonstration in a relevant environment (ground or space)]. The TRL for the turbine is quoted as "nearly TRL-6" since TRL-6 implies that the turbine would be tested as part of a system, not just as a component. The turbine development program outlined goes well beyond TRL 5, in that a turbine ready to participate in a flight demonstration or early mission application would be delivered.

The turbopump is currently considered to be at TRL-4. This rating is primarily due to extensive experience in the design and operation of rocket engine turbopumps and sodium pumps. The remarks applicable to the turbine may be applied to the turbopump as well.

The alternator design is considered to be at TRL 5. The alternator design is an extension of known technology to fit the potassium Rankine cycle requirements and constraints. The major development item is seen to be developing a method to provide adequate cooling for the alternator rotor. Previous efforts in this area have resulted in excessive alternator masses if the rotor could not be adequately cooled. 
Bearings, seals, and couplings are each considered to be at about TRL-4, primarily because specific designs for use on the current project are not yet available. The design principles related to these items are well understood; however, the specific configurations that would be used for this application need to be demonstrated in an appropriate environment.

\subsubsection{Development program}

Successful demonstration of the development of the vapor turbine, alternator, and turbopump is dependent on the development of appropriate bearings and seals for use in conjunction with the rotating machinery. Early designs would rely on legacy data accumulated during the 1960s. These data would be verified and updated, and more modern designs accommodated by the development of appropriate bearings and seals. This development can be conducted in parallel with the development of the rotating elements and in a separate facility. The seal, bearing, and coupling developments would start in parallel with the initiation of the turbine development effort; and their results would be incorporated in the engineering development unit and in the prototype designs of the rotating equipment The basic development strategy to be followed in developing the rotating equipment would be to conduct a 1-year detailed design study; fabricate and place on test an engineering or development unit; design the prototype unit, which would incorporate all of the "lessons learned" from the engineering unit and from the bearing and seal testing; and conduct long-duration testing of an appropriate number of flight-type prototype units. More than one flight-type prototype unit may be required to accommodate periodic teardown inspections of the hardware.

\subsection{Development issues}

Current optimization studies indicate a desire to operate the potassium power turbine at temperatures of up to $1310 \mathrm{~K}$. These temperature levels would likely require the use of refractory materials for construction of the turbine. Refractory materials are suitable for this application because of their compatibility with both liquid metals and high temperatures. They do impose additional constraints on the development cycle because of their sensitivity to oxygen. Table 4.1 indicates that there has been significant, although limited, operating experience with turbines using potassium, particularly with TZM alloy. The producibility of applicable refractory metals has been verified, and analysis shows that alloys such as ASTAR 811-C and TZM may meet the structural requirements.

Starting with this technology base, attaining reliable operation for an extended time at an inlet temperature of $1300 \mathrm{~K}$ represents a significant advance in technology. The major technology issues to be addressed at high operating temperature include material selection, turbine blade erosion/corrosion, bearing life, and the operation of a flexible coupling between the turbine and the alternator. Material selection would be addressed during the design stage of the turbine development program, and programs to verify properties such as creep and specific tensile strength would be required.

A major technology issue associated with Rankine cycle turbines is erosion of the turbine blades by moisture droplets in the final stages. Corrosion can also take place, but only if the potassium contains oxygen. The basis for concern about erosion in the final turbine stages is the well-known possibility of erosion of blading in central station steam power plants if excessive moisture is present, and the results from the NASA-sponsored three-stage potassium turbine test, 
(Table 1-2). In this test, the turbine inlet moisture content was $1 \%$ for the first stage and $8.9 \%$ at the inlet of the last or third stage (outlet moisture was 13\%). After a 5000-h test run, a small amount of erosive damage was experienced on the third-stage rotor blades. As a followup to this observation, NASA sponsored further testing to evaluate methods of removing condensate as it forms in the turbine. These tests were performed in conjunction with the three-stage potassium turbine test and confirmed results from the steam turbine industry showing that the turbine blading may be adequately protected from erosion by using vortex separators and/or rotor condensate removal methods.

The phenomena that cause moving blade damage in a turbine have been studied in an operating steam turbine. In these tests, it was shown that most of the blade erosion is the result of only $0.1 \%$ of the moisture present. Most of the moisture present in the turbine was in the form of water drops less than 50 microns in diameter entrained in the main vapor stream, and these drops did not contribute significantly to blade erosion. Erosion damage to the moving blades was caused by liquid being shed into the low-velocity wake at the outlet edge of the fixed stator blade. The source of the water was the deposition of drops from the steam, principally on the concave surface of the fixed blades. The secondary flow conditions at the outer end of the fixed blades next to the casing concentrate water near the outer ends, causing the most severe damage to the moving blades. Photographs showed rivulets of water slowly running along the stator vanes and then being shed into the path of the moving blades where the sheets of water were broken. The average diameter of the water drops impacting the blade was 450 microns when the turbine was run at full flow. When the turbine was run at $40 \%$ flow, the quantity of water on the vanes was three times more than at full power. This agrees with the extra damage found to be sustained by blading run at partial loads.

There are several means of dealing with the problem of turbine erosion. Based on these observations, trailing edge slots in the stator vanes could be used to remove the most damaging liquid before it could impact the moving blades. Since only about $0.1 \%$ of the moisture present is present on the stator blades, only a small liquid flow needs to be removed through the slots and returned to the condenser. Tests showed that a significant amount of the liquid collected on the stator could be removed with the trailing edge slot. This could be improved by placing small hole patterns to collect liquid upstream of the trailing edge along known liquid flow paths.

Rotor condensate removal devices have been used for many years with steam turbines. Drops (representing 40 to $80 \%$ of the moisture present) of liquid impinging on the rotor blades tend to be centrifuged to the outer wall of the turbine where they can be caught in casing removal devices. Tests on steam turbines have shown that effectiveness values of $95 \%$ can be achieved with this type of device. All of the moisture separating devices mentioned can be applied without significantly impacting overall turbine efficiency. The most significant observation from the potassium turbine testing is that blade erosion can be minimized by operating the turbine with blade tip speeds not exceeding $260 \mathrm{~m} / \mathrm{s}(850 \mathrm{ft} / \mathrm{s})$, and with vapor quality of at least $90 \%$.

Corrosion has not been a significant problem for TZM turbine blades that operate in clean (i.e., oxygen-free) environments, as indicated by the data in Table 1.2. The expected erosion/corrosion resistance of tantalum alloys (ASTAR and T-111) material compared with TZM may be roughly estimated by comparing the hardness of the respective materials. Hardness is the most significant alloy property that correlates with erosion resistance. Room temperature hardness of TZM is 310 (DPH) versus 250 for both T-111 and ASTAR 811-C. Operating temperature hardness values are not available, but it is likely that at operating temperatures, 
tantalum alloy hardness should be at least equal to that of TZM; therefore, both alloys should exhibit good corrosion resistance.

Design of the alternator should be an extension of known technology to fit the potassium Rankine requirements and constraints. Since alternators of the homopolar induction type have been built in similar ratings, scaling to the probable output requirements is not a concern. The major question remaining is how to cool the rotor of the alternator. This requires some development effort since the magnetic properties of the possible materials of construction are strong functions of temperature, and attempts to design for operation at high temperature have generally not been successful.

The capability of the turbopump to operate over the mission life at the inlet temperatures called for is a technology issue, which is discussed in detail in the main power turbine section. The issue is not as significant in the case of the turbopump because the rotor tip speed and attendant stresses can be further reduced to obtain additional margin. The technology required for success in the design of the main power turbine is directly applicable to establishing the technology base for the turbopump. Design of the pump portion of the turbopump uses welldeveloped technology that has been applied to the design of water pumps and of sodium pumps that operate under similar conditions.

A second technology issue relative to the rotating machinery is the capability of attaining the required lifetimes with bearings operated with potassium lubricant. There is a substantial empirical database with 1600 hours of accumulated time at Rocketdyne, 4500 hours at ORNL, and over 3000 hours at Honeywell (AiResearch), but essentially all testing was performed on bearing test rigs without the impact of thermal soakback or gradients. The capability of tilting pad bearings (the most likely candidates for this application) under more realistic conditions needs to be verified.

Seal technology requirements are significantly reduced by the use of potassiumlubricated components for the rotating machinery. The vaned slinger concept appears to present a workable approach to reducing potassium infiltration outside of the various bearing cavities. Potassium infiltration levels should be low enough to permit the use of internal venting of components. The use of a bore seal between the turbine and the alternator might be a good method of limiting heat transfer from the turbine to the alternator. Good results, in terms of life and sealing effectiveness, were found using $\mathrm{Al}_{2} \mathrm{O}_{3}$ as a contact medium over a wide range of temperatures in a potassium environment. This work was conducted by Battelle in the mid 1960s.

The shaft of the turbine and the shaft of the alternator are required to be coupled together by a device that provides for shaft misalignment and possibly limits the heat loss from the turbine shaft to the alternator shaft. This leads to the third technology issue in the turboalternator area, the flexible disc coupling between the turbine and the alternator. The severity of the environment would be attenuated by the presence of seals on either side of the coupling. However, since both the turbine and the alternator designs are likely to use liquid potassium for bearing lubricant, there could exist a region of low-density potassium vapor in the coupling. The long-term effects of the potassium environment on conventional coupling materials are not known. A promising alternative to the use of stainless steel couplings, with their potential longterm constituent transfer problems, is the use of refractory metals for the coupling components. The approach would have to be validated by operating the proposed concept under replicated environment, speed, and stress conditions. 


\subsection{Program implementation to achieve "nearly TRL-6}

TRL-6 is defined as subsystem model or prototype demonstration in a relevant environment (ground or space). Reaching this level of technical readiness implies that the technology has been tested as part of a prototypical system or subsystem and is ready to be demonstrated in space. In the case of potassium-driven Rankine cycle power-generating machinery, a prototypical machine could be tested for both performance and life by testing without failure for an extended length of time in a vacuum chamber. For purposes of this study, we define "nearly TRL 6" as the delivery to the customer of a machine that is ready to be ground tested as part of the overall system development unit or be flown in space as part of an early flight demonstration. The difference between TRL-5 and "nearly TRL-6" is that the prototype machine is tested to demonstrate both performance and life through extended- duration testing. In addition to life testing, a flight qualification program is added with the objective of giving assurance that the prototype rotating machinery design is flight ready.

The time required for life testing would ideally be greater than the time required for an expected mission. Unfortunately, some of the missions contemplated for deep space exploration are expected to extend up to 20 years. Manned missions, on the other hand, are assumed to not exceed 3 years, at least for the foreseeable future. Commercial gas turbines present a development model that may fit many of the constraints associated with the development of potassium Rankine rotating machinery. Typical commercial practice is to conduct 3 years of continuous operation without evidence of failure or impending failure before releasing a new component or system to market with full factory warranties. Commercial development testing usually consists of placing three identical units under test and then conducting complete, detailed teardown inspections at 8000, 16,000 and 25,000 hours of operation. If an impending failure is detected, testing on all units is halted, the problem is resolved, and the cycle is restarted. An extra year is therefore usually allocated for completion of the final development tests. Since testing of potassium Rankine rotating machinery for periods of time similar to anticipated mission durations would generally not be practical, it is recommended that a derivative of the "commercial" development schedule be adopted to demonstrate TRL-6.

A complete development program for potassium Rankine rotating machinery is seen to consist of the following elements:

1. Turbine, Alternator and Turbopump design

a. Conceptual design review (CoDR)

b. Preliminary design review (PDR)

c. Critical final design review (CrDR)

d. Incorporation of results of engineering unit and component tests

e. Facility preparation

f. Facility checkout

g. Sub-component development program

i. Bearing design and development testing

ii. Seals design and development testing

iii. Coupling design and development testing

h. Fabrication experiments (breadboard level)

i. Engineering model fabrication and testing

j. Prototype fabrication 


\section{k. Prototype testing \\ 1. Flight design/fab/test}

The time scales associated with these activities are shown in Section 7.3, Schedule. The development effort associated with raising the potassium Rankine technology to "nearly TRL-6" is seen to consume approximately 9 years of relatively intensive effort. The time associated with the development of the turbine could be reduced by about 2 years with a more aggressive development approach. The more aggressive approach would reflect an increased risk of failure and be considerably more expensive, since it is likely to require several restarts of initially misdirected efforts. To implement the more aggressive approach, engineering model design and fabrication is started 1 year earlier, and prototype fabrication and prototype testing are started 2 years earlier. The risk that arises in this approach results from the fact that fabrication of the prototype starts before any testing is done on the engineering unit, and only minimal testing would have been done on the bearings and seals.

The overall program is divided into four major technical areas: small components, main power turbine, alternator, and turbopump. Each area contains eight or nine major subtasks. The first subtask consists of a component design phase consisting of three major design reviews, conceptual (CoDR), preliminary (PDR), and critical (CrDR). A 6-month period of conceptual design is seen to be required to produce layout drawings and supporting calculations for the component at a selected power level. It is anticipated that three or four competing designs would result from this activity. At the CoDR, one primary design would be selected and used as the basis of proceeding to the PDR. This design would be supported by a detailed layout of the component and detailed drawings of the major subcomponents. These drawings would be supported by detailed models of the thermal and stress behavior of the materials selected. PDR is anticipated to occur 1 year after program start. Following PDR, it is estimated that it would require about 1 year to complete the final design drawings and supporting analysis for the prototype component. One additional year is allowed for the incorporation of the results of testing the engineering unit and the testing of the sub-components.

The second subtask consists of a facility preparation task. A brief survey of possible test sites and previously existing test facilities indicated that no current facilities exist for the testing of potassium components. For the present project, it would appear to be most economical to build two test facilities, one for small components, such as bearings, seals and couplings, and one for large components where the turbine, alternator, and turbopump could be tested simultaneously. The small-component test facility could be permitted and built as an adjunct to an existing test facility, since the inventories of potassium would be small. Of necessity, the large-component test facility would be of entirely new construction and fabrication and would probably be required to locate in a remote area. A critical data item that must be defined before the initiation of the development of the large-component test facility is the size and/or power level of the components that need to be under test at any given time. Once the power level is established, the design of the test facility could be completed in about 3 to 6 months.

Construction of the actual facility could be accomplished in about 15 months. An additional 6 months is allocated for facility activation and checkout.

The small-component development effort is proposed to support main turbine, alternator, and coupling development. This effort contains elements similar to the task of developing the major components, but because of the small size of the components, it should be possible to accomplish these tasks on a much-accelerated schedule. The emphasis in this subprogram would 
be getting competing designs into test rather than performing formal design reviews. It is anticipated that small- component development would occur in the first 5 years of the overall development program.

Fabrication experiments are required to support the component design and fabrication efforts. These would be started at the same time conceptual design is started and would initially consist of the collection and verification of materials properties data. As details of the design become available, fabrication experiments to verify the "fabricability" of semi-prototypical components would be conducted. In the case of the main power turbine, these parts mainly involve the turbine wheel, turbine case, and bearing and seal components. It is anticipated that these experiments would be conducted over about 2.5 years, beginning with the CoDR.

A key task in the development program is the development and test of an engineering model of the prototype components. Each component would be tested to provide early proof of key features of the prototype machine. Initial tests of the various components would be conducted with independent power and fluid inputs. As the initial tests prove successful, the components would be integrated into a single continuous facility in preparation for testing as a combined unit. Emphasis is on developing prototypical performance and the demonstration of key design features such as wheels, shafts, manifolds, bearing configurations, bearing lubrication, and seal configurations. The objective of the engineering test program is to accumulate key data early enough in the program to allow "lessons learned" from the engineering model to be applied directly to the prototype design. Design and fabrication of the engineering model would be initiated at PDR and allow for approximately 1 year of data to be accumulated by the time prototype fabrication is initiated. Testing would continue until the prototype units are ready for test.

Prototype fabrication is scheduled to start after the completion of the fabrication experiments and the accumulation of about 1 year's worth of test data on the engineering unit. It is anticipated that fabrication of the prototype would require approximately 1 year, provided that long-lead procurements are started in the previous year. As noted in the next paragraph, it is expected that four prototype units would be fabricated, three of which would be put on test simultaneously and one held in reserve as a spare. Prototype testing would be conducted in a common facility with each component simulating its function in the final system. The design and layout of the facility are discussed below.

It is recommended that prototype testing follow the commercial gas turbine development model. This requires that three identical units be placed on test and operated for 8,000, 16,000, and 25,000 hours respectively. At the end of 8,000 hours, one unit would be stopped and a complete and thorough teardown inspection would be made of the turbine. Both nondestructive and destructive assessments of the equipment would be made. The objective of the inspection is to determine if significant wear-out modes or early signs of material fatigue are present. After 16,000 hours, a second turbine would be inspected in the same manner. If either of these inspections indicates a wear or fatigue mode of failure, then the testing would be stopped, the problem remedied, and the test restarted. Testing could be completed in 3 years; however, 4 years are allocated to allow for possible development problems in the testing of the prototype.

The development program is completed with the flight design, fabrication, and qualification of a turbine unit or units that would be used on an actual space mission. It is anticipated that this activity would be activated at about the time the 8,000-hour inspection is conducted on the prototype units and would deliver units for qualification testing at about the 
time the prototype testing is complete. Completion of the qualification testing would formally complete the rotating component development program.

\subsection{Test article fabrication}

Based on the development program outlined, the test article fabrication required for this effort consists of:

- The fabrication of specimens for materials properties determinations,

- The fabrication of various rotating machine components of candidate materials,

- The fabrication of engineering unit rotating components,

- The fabrication of four prototype rotating component sets.

It is anticipated that the potassium-Rankine rotating components that would be most desirable for use in space power applications would be fabricated largely from refractory metals because of the high operating temperatures anticipated. Materials properties for candidate materials require experimental verification; therefore, a significant effort to manufacture suitable test samples is anticipated. The design and configuration of these samples are well standardized, and the major effort involved would be obtaining the materials and subsequently forming them into the required geometries. In the case of the alternator, the materials strength and magnetic properties are well known and only a relatively limited number of metallurgical samples would be required to verify these properties. Materials for bearings and seals were identified during the 1960s efforts. Their properties and "fabricability" would require re-demonstration, since the original tests were of relatively short duration.

Fabrication experiments that consist of forming the various candidate materials into the required components such as blades, wheels, housings, shafts, bearings, seals, and alternator parts would be conducted with appropriate candidate materials. The objective of these experiments is to demonstrate the machineability, formability (e.g., forging or casting), and/or weldability as required for the material selected for the application. The secondary objective is to demonstrate the feasibility of using original geometries for the various applications.

An engineering unit would be fabricated that incorporates all of the features of the prototype units that is possible to incorporate at the time. The engineering unit would be tested to demonstrate performance but would not be required to demonstrate extended life. Therefore, compromises in the use of more available alloys or heavier-than-prototypical components may be allowed. Special interest would be paid to tracking potential life-limiting failures such as bearing wear, seal leakage, coupling wear, blade erosion, disk cracking, reduced magnetic properties of as-fabricated alternator parts, and pump cavitation erosion.

Four prototype units would be fabricated. These units would be designed to be space qualifiable in that they would incorporate all of the features of a flight unit. Materials and component dimensions and layout would be identical to those of a flight unit. Three of the four units would be placed on test simultaneously, and the fourth unit would be held in reserve as a spare.

\subsubsection{Development risk and its mitigation}


The basic potassium-Rankine power turbine technology was established in the 1960s and resulted in relatively long-term tests of critical turbine sub-assemblies. The development of such a turbine is therefore seen to be a matter of recovering this technology and then proceeding with the long-term testing required to space-qualify the machinery. The major technical risk that arises with this technology is the application of refractory materials in the fabrication of many of the critical parts in the turbine. Since the end of the previous potassium-Rankine effort, the supply of refractory metals has slowed considerably, and their manufacture has become more stringently controlled. Consequently, the properties of some of the materials in popular use before may not be the same as they were in the 1960s because modern manufacturing processes eliminate more of the contaminants and trace elements that once existed in many of the refractory alloys. This problem can be alleviated by encouraging early production of the more likely candidate alloys and then performing extensive property determination experiments with them.

A second area of risk arises from the fact that a potassium test facility would be considered a hazardous facility, which may make it difficult to obtain building and operating permits from the cognizant government agencies. This risk can be alleviated by selecting a relatively remote site. Early interaction with, and education of the local population and officials would help to reduce this risk.

\subsubsection{Conclusions and Recommendations}

Based on the information developed in this study, the simultaneous development of the main power turbine, the alternator, and the turbopump for a $100-\mathrm{kW}_{\mathrm{e}}$ potassium-Rankine system is expected to require approximately 9 years to complete. Developing the major rotating components together would result in a considerable cost savings since the major facility equipment items are grouped together and the long-duration testing could be conducted on the components simultaneously. In order to facilitate the development of the potassium-Rankine technology, it is recommended that the facility design tasks be started as soon as possible. Other tasks that would have a high priority are the conceptual design tasks, especially the conceptual design of an alternator with an internally cooled rotor.

\subsubsection{PMAD Development}

This report presents a technology development plan for a PMAD System suitable for use with a potassium Rankine power conversion system with the objective of advancing PMAD Technology to TRL 6 by 2013.In the assumed architecture, the PMAD system conducts power from the potassium Rankine turboalternator to the electric propulsion system and mission module and spacecraft loads. It also regulates bus voltage and turboalternator speed by radiating excess power to space. The auxiliary power subsystem provides power for startup of the power system and feeds the auxiliary power bus to ensure critical loads remain powered if main power is temporarily lost.

The development requirements of the PMAD system are driven by the need to survive the environment and reduce mass. The mission determines the radiation levels, with a Jovian mission having the highest total integrated and displacement damage dose values. This drives the need for devices that are more rad-hard to reduce shielding mass. Increasing the operating temperature of the electronics is another method for reducing mass because it reduces the size of 
the electronics radiator. If more high-temperature, rad-hard parts are developed and they can be grouped in a manner that allows a large portion of PMAD component losses to be rejected at higher temperatures and a smaller spot shield volume, the mass of the power system can be reduced. This premise guides basic PMAD electronics technology development.

A higher PMAD distribution voltage reduces transmission line conductor mass. But the thickness of the insulation must be increased to keep the DWV or voltage stress within acceptable limits to meet the mission life. Analyses indicate the optimum distribution voltage is in the range of $900 \mathrm{Vrms} \mathrm{L}-\mathrm{L}$ (1200 Vdc after rectification). Electronics challenges are present at this distribution voltage. The main issues are parts and insulation material availability and corona control. These issues are compounded by the extreme radiation environment, which severely limits the suitable parts and insulation materials. PMAD technologies that enable higher-voltage operation must be developed to achieve the assumed system design.

\subsubsection{Requirements}

The potassium-Rankine NASA Research Announcement requires the power system to be designed for $100 \mathrm{~kW}_{\mathrm{e}}$ (to the thrusters) with the capability to scale to $250 \mathrm{~kW}_{\mathrm{e}}$. These power levels drive the need for higher distribution voltages ( $>1000$ volts) to minimize transmission line mass. The radiation levels the PMAD elements would experience are extremely high, especially in the Jovian environment. The assumed total integrated radiation and displacement damage doses are projected to be about $500 \mathrm{Krad}(\mathrm{Si})$ and $5 \times 10^{11} \mathrm{~N} / \mathrm{cm}^{2}(1 \mathrm{MeV}$ equivalent) at the payload dose plane ( $25 \mathrm{~m}$ from the reactor) with shielding equivalent to $24 \mathrm{~mm}$ of aluminum. These radiation doses are beyond the capabilities of many silicon ( $\mathrm{Si}$ ) parts. The alternatives include increasing the shielding thickness, at the cost of substantial mass, or developing parts that are more rad-hard.

The design of the PMAD system is composed of devices and materials that vary widely in radiation survivability, operating temperature and voltage capability, and technology maturity. Electronics parts can be grouped based on radiation tolerance and temperature capability. Parts that can survive 10 Mrads are adequately shielded by the payload bay enclosure. In the assumed radiation environment, parts rated at 1 Mrad require approximately $13 \mathrm{~mm}$ of aluminum shielding, while the parts limited to $200 \mathrm{Krad}$ require about $54 \mathrm{~mm}$ of aluminum shielding. Most Si parts require a baseplate temperature in the range of 25 to $50^{\circ} \mathrm{C}$ to operate for 20 years, but wide bandgap materials may operate at $300^{\circ} \mathrm{C}$ and provide a 20 -year mission life. Wide band gap devices are at a low TRL, though, with many devices currently at TRL 3.

A wide band gap material under development, $\mathrm{SiC}$, looks promising for power devices; and initial radiation tests show it can withstand 10 Mrad. Currently, 1200-V SiC diodes are commercially available. Some 1-Mrad Si parts are also commercially available, and NASA's development of certain key devices and application specific integrated circuits (ASICs) could further reduce the 1-Mrad spot shield volume. Si logic devices are the most sensitive to radiation. The X-2000 technology development program improved the radiation hardness of many logic devices, but key PMAD control system elements such as processors, memory chips, and gate arrays are generally limited to 200 to $300 \mathrm{Krad}$ and would need to be placed behind a thick spot shield.

The development of SiC power devices and supporting circuit element such as drivers, capacitors, insulations, and circuit boards would allow a large portion of PMAD component losses to be rejected at $250^{\circ} \mathrm{C}$. Although the Si logic devices have a much lower temperature 
capability, the losses in these elements constitute a smaller portion of component losses. This leads to two temperature ranges and thus two radiator designs being established for the $\mathrm{Si}$ and $\mathrm{SiC}$ devices. The higher-temperature radiator would reject the bulk of the SiC electronics power loss at $250^{\circ} \mathrm{C}$, while a lower-temperature $\left(50^{\circ} \mathrm{C}\right)$ radiator would be required to reject the Si logic element losses.

Specialized component requirements could also drive technology needs. A multiplexer near the reactor is desirable to reduce the number of power system sensor signal lines. This would reduce harness mass and ease deployment issues. A converter near the TEM pump also reduces transmission line mass due to the power requirements of the TEM pump. Its low operating voltage and high current requirements result in a fairly large conductor size that would add around $30 \mathrm{~kg}$ to the power system mass if it had to be run the length of a 15-meter boom.

\subsection{Wide bandgap devices}

Wide bandgap materials offer the promise of high operating voltages $(>10 \mathrm{kV})$, are inherently rad-hard (100 Mrad and $\left.10^{18} \mathrm{~N} / \mathrm{cm}^{2}\right)$, and promise operating at temperatures exceeding $300^{\circ} \mathrm{C}$. These capabilities are well suited for high-power, high-radiation applications, such as an NEP vehicle PMAD system. SiC is a wide bandgap material that is especially promising for high-power switches because it has a high thermal conductivity (Table 7.3). This enables higher power density, which translates into smaller, lighter switches and heat sinks. One of the key challenges in realizing SiC's potential, though, is to develop a high-temperature package design that allows reliable operation at high temperatures and radiation levels.

Table 7.3. Candidate semiconductor material properties

\begin{tabular}{lccc}
\hline \multicolumn{1}{c}{ Material properties } & Si & GaAs & 4H-SiC \\
\hline Energy gap $(\mathrm{eV})$ & 1.1 & 1.4 & 3.2 \\
Breakdown field $(\mathrm{kV} / \mathrm{cm})$ & 300 & 400 & $(1-5) \times 10^{3}$ \\
Peak velocity $\left(10^{7} \mathrm{~V} / \mathrm{cm}\right)$ & 0.8 & 2.0 & 2.0 \\
${\text { Mobility }\left(\mathrm{cm}^{2} / \mathrm{Vs}\right)^{\mathrm{a}}}^{\text {Thermal conductivity }(\mathrm{W} / \mathrm{cm}-\mathrm{K})}$ & $\sim 1000$ & $\sim 5000$ & $\sim 200$ \\
Dielectric constant & 1.5 & 0.5 & 5 \\
Johnson FM & 11.9 & 12.8 & 9.7 \\
\hline
\end{tabular}

${ }^{\mathrm{a}}$ Mobility values at $10^{17} \mathrm{~cm}^{-3}$ electron concentration.

The potassium-Rankine PMAD system could take advantage of SiC's high temperature and voltage capabilities. Specifically, SiC could be used for bipolar junction transistors (BJTs) for the shunt regulator and dc/dc converter switches, diodes and gate turn-off (GTO) thyristors for the switchgear unit fault isolators, and silicon control rectifiers (SCRs) in the phase-control rectifiers. Silicon insulated gate bipolar transistors (IGBTs) are generally used in high-voltage, high-power terrestrial switching applications. But IGBTs are quite sensitive to radiation, and Si BJTs aren't rated for these voltages. This makes the development of high-voltage $(\sim 3 \mathrm{kV}) \mathrm{SiC}$ BJTs critical. The power handling requirements of the shunt switches require an improvement in the gain of the BJTs to reduce drive power needs, and a reduction in collector-emitter voltage drop to minimize conduction losses. It is important to reduce diode voltage drops in devices such as the fault isolators, but it is not clear whether a high-voltage schottky or PIN diode should be 
developed to achieve this objective. The choice depends on the operating voltage and characteristics of the two diode types, and it must be studied further. The first GTO thyristors are just becoming available and SCRs haven't been fabricated yet, so these devices are rated TRL 3 .

\subsection{Silicon devices}

Silicon devices are at a much higher level of development than $\mathrm{SiC}$ devices and would likely continue to be required for many functions. SiC technology should be suitable for discreet devices within a few years at the present rate of development. But it needs to mature a great deal before it is able to replace the integrated circuits (ICs) used to control complex switch operations and communicate with sensors and a data bus. For the foreseeable future, Si ICs would likely continue to provide these functions. Consequently, it is important to make critical Si ICs more rad-hard to allow better integration of the two technologies, particularly for the drive circuits that need to be adjacent to the $\mathrm{SiC}$ power switches. The end result would be a reduction in the amount of shielding required.

Silicon device fabrication techniques have improved, enabling the construction of a limited number of 1-Mrad rated parts. For example, 1-Mrad metal oxide semiconductor field effect transistors (MOSFETs) that are well suited to high-speed, lower-voltage switching applications are commercially available. The silicon on insulator (SOI) technology also allows highertemperature operation. It enables certain parts to achieve a 20 -year life at 75 to $100^{\circ} \mathrm{C}$ operating temperatures, but this technology is limited to logic devices because of the difficulties the insulator material and construction present in removing waste heat.

The government recognized the need for more 1 Mrad-rated parts and initiated multiple development efforts. Silicon junction diodes have been tested at a gamma dose of up to $10 \mathrm{Mrad}$ with no significant change in their characteristics observed, indicating they are suitable for 1Mrad operation. These diodes are rated for 1200-V, though, and 3-kV-rated diodes would need to be tested for the potassium-Rankine PMAD system.

NASA has also initiated a program to develop five key 1-Mrad hard ASICs. These ASICs would fill critical needs for controlling basic switch operations such as current limiting and pulse- width modulation, providing analog and digital communication interfaces, and locally implementing commands. The development of these ASICs is scheduled to conclude in October 2005. This would support potassium-Rankine development and has been factored into the PMAD technology development plan.

\subsection{Cables, Connectors, and Electronics Parts}

External cables and connectors, especially those located near the reactor, would be exposed to very high radiation levels. High voltage distribution reduces the mass of transmission line conductors, but it requires the development of higher-voltage insulations. Insulation mass increases as the voltage level rises, but this mass impact may be reduced if the dielectric strength can be improved to allow a higher insulation DWV. The ISS has the highest distribution voltage used to date on a space platform, nominally $160 \mathrm{Vdc}$. It has a DWV of $1450 \mathrm{~V} / \mathrm{mm}$. But this voltage level and DWV are well below the level that would be required on an NEP vehicle to obtain a minimum mass system.

PMAD architecture voltage analyses indicate the minimum mass of a dc NEP system would occur with a distribution voltage near $1200 \mathrm{Vdc}$. This dc voltage is obtained when an 
alternator- generated 3-phase 900 Vrms L-L ac voltage is rectified. The main cables running from the output of the alternators to the payload area drive the PMAD cable requirements. They are the longest cables, and they must carry all the power produced by the potassium-Rankine turboalternator to the payload. This makes them the heaviest cables on the vehicle. They also run from a very high radiation environment near the reactor and must pass across the face of the main radiator. The combined voltage, radiation, and temperature requirements of these cables envelope the PMAD cable requirements. Consequently, if a suitable insulation can be developed for the main cables, it can likely be used for most of the remaining PMAD cables. This doesn't include the specialized cables that are routed to reactor instruments and effectors, or the cables that run from the PPUs to the thrusters, because these are outside the PMAD system. They reside within the reactor module and electric propulsion system, respectively.

The following requirements were generated for the main PMAD cables and connectors and were also applied to the other PMAD cables and connectors to minimize the need for multiple insulation development efforts:

$\begin{array}{ll}\text { Radiation: } & 10^{8} \mathrm{Rad}(\mathrm{Si}) \text { and } 10^{14} \mathrm{~N} / \mathrm{cm}^{2}(1 \mathrm{MeV} \text { equivalent }) \\ \text { Temperature: } & 300^{\circ} \mathrm{C} \\ \text { Life: } & 20 \text { years }\end{array}$

In addition to the ionizing radiation and displacement damage doses specified, the cable and connector insulating materials are acted on by corona and charges introduced by high-energy electrons. These phenomena degrade the mechanical and dielectric properties of the insulation and limit the types of insulations that can be used.

The magnetic and conductor materials utilized in transformers and inductors are very radhard. The insulation is more sensitive, but 100-Mrad hard insulations are available; and the payload bay enclosure limits the radiation dose to $5 \mathrm{Mrad}$, including the radiation design factor of 2. This assessment indicated the transformer and inductor TRL was sufficient and no funding was allocated for their development.

Certain capacitor types, especially ceramic capacitors, are also very rad-hard (10 Mrad). But the dielectric strength of ceramic capacitors changes with temperature, causing the capacitance to decline by as much as $75 \%$ as the temperature is increased from 25 to $300^{\circ} \mathrm{C}$. Improved dielectric materials are required that are rad-hard and maintain their properties at the $300^{\circ} \mathrm{C}$ temperatures proposed for wide bandgap devices.

The proposed fault isolator switch design in the switchgear unit requires a high-voltage, high-current relay. The relays developed for the ISS main bus switching unit are the highestpower units and are rated for $200 \mathrm{Vdc}$ and $225 \mathrm{~A}$. The units that would be required to isolate the feeds to the PPUs would have to be rated for about $1700 \mathrm{Vdc}$ and $50 \mathrm{~A}$. Vacuum relays rated for this voltage are commercially available, but their current ratings aren't sufficient. The proposed development effort would qualify a vacuum relay for $1 \mathrm{Mrad}$ and for the worst-case voltage and current stresses encountered during nominal operation and fault interruption.

Finally, circuit boards, including solders and adhesives, are recommended to be developed to withstand the radiation doses and temperatures experienced by these devices. Coatings are needed to dissipate electrostatic charges caused by high-energy particles. Corona-resistant insulations are required, as well as processes to eliminate the causes of corona. Hightemperature, compact device package designs are also required to allow dense electronics packaging that minimize component volume and mounting area needs. 


\subsubsection{Development Program}

\subsection{Objectives}

The objective of the potassium-Rankine PMAD development program is to advance the TRL of the PMAD system to TRL 6 by 2013 to allow launch of a potassium-Rankine power system after 2015. TRL 6 is defined as "System/subsystem model or prototype demonstration in a relevant environment (Ground or Space)." In the context of this PMAD development program, that is considered successful qualification of the complete PMAD system in a spacecraft test bed. The systems that interface with the PMAD system are assumed to have comparable design fidelity, or suitable simulators should be used.

\subsection{Ground rules and assumptions}

The ground rules and assumptions on which this development program and the associated schedule are based on:

1. The objective is to develop the PMAD subsystem to TRL 6 by 2013.

2. A standard breadboard, engineering model, qualification, flight program is assumed for this development effort. The PMAD subsystem is considered to be at TRL 6 when it has been qualified as a subsystem in the spacecraft qualification test bed with comparably developed (TRL 6) interfacing subsystems (e.g., power conversion, electric propulsion, C\&DH, GN\&C).

3. The effort of providing a complete PMAD subsystem for spacecraft qualification testing and the engineering required to develop PMAD subsystem test plans, integrate PMAD components into the spacecraft test bed, conduct PMAD subsystem tests such as command and response and fault testing, and conduct post-test analysis and documentation is included; but this exercise does not include providing interfacing subsystem components, incorporating them into the test bed, and conducting integrated spacecraft system tests. The PMAD subsystem is just one of the subsystems that would be incorporated into the spacecraft test bed, and the designing and fabricating the interfacing subsystems are assumed to be the responsibility of the groups developing those subsystems.

4. The development of the firmware embedded in PMAD component firmware controllers (those required to control and monitor component operation and enable communication with spacecraft data buses and sensors) is included, but this exercise does not include command and data handling subsystem development such as the power system computers/controllers, external multiplexers and sensors, and control software.

5. The basic PMAD development includes a wide bandgap wafer effort to define device requirements and tests to assess compliance with those requirements at the device and basic circuit level. This testing would include device characterization, functional performance testing within a circuit such as a power supply, radiation testing and accelerated aging testing to determine device activation levels to support component life and reliability prediction models. 
6. Project engineering and direct management are assumed, but program management, system engineering, operations, schedule development, quality assurance, data management, and CDRL submittal are not. It is assumed a product engineer would be assigned to each of the major PMAD components, and that person would be responsible for technical coordination and reporting on the status of that component.

7. The government is funding a program to develop 1-Mrad hard Si devices and ASICs that is scheduled to conclude at the end of 2007. The timing of this program would support the proposed potassium Rankine PMAD subsystem development effort, and it is assumed the following devices and ASICs are available: (1) Si junction rectifier (100V/20A), (2) MOSFET (switch drivers 50V/5A), (3) switch control ASIC (SCAH and SCAL), (4) analog interface ASIC, (5) digital interface ASIC (6) low volt pulse width modulator ASIC, and (7) power actuation and switching module. It is assumed these devices require further testing at the device and circuit level to allow full understanding of their characteristics and maximization of their performance within component designs.

\subsection{Current State of the Art}

Most PMAD components are considered to be at TRL 4, "Component or breadboard validation in a laboratory environment." Substantial development is required to qualify the PMAD system for the power and voltage levels produced by the potassium-Rankine power system and for the environment presented by a reactor-powered NEP vehicle on a Jovian mission. Basic device technologies have been developed, but fabrication techniques and processes must be developed for the potassium-Rankine PMAD system because the distribution voltage level is over five times higher than that of any power system distribution voltage used before. New materials also need to be developed, because the radiation doses are roughly ten times higher than the doses received previously by comparable devices and parts.

The potassium-Rankine PMAD architecture is based on $2-100 \%$ rated power channels, requiring the shunt regulator, PLR, and phase control rectifiers to be designed for the full capability of the power system. This is about $115 \mathrm{~kW}_{\mathrm{e}}$ based on $100 \mathrm{~kW}_{\mathrm{e}}$ to the thruster PPUs, 5 $\mathrm{kW}_{\mathrm{e}}$ to the spacecraft and mission module loads, and slightly over $5 \mathrm{~kW}_{\mathrm{e}}$ to the power conversion and cooling system pumps. The proposed transmission voltage from the alternator to the payload bay is $900 \mathrm{Vrms} \mathrm{L}-\mathrm{L}$, which results in a voltage of about $1200 \mathrm{Vdc}$ on the switchgear bus after rectification. Power distribution components developed for the ISS have the highest power and voltage ratings of space-based power systems. The maximum primary distribution bus nominal voltage and current levels are $170 \mathrm{Vdc}$ and $215 \mathrm{amps}$ at the input to the dc switching unit. Higher-voltage power has been fed short distances, such as the 2000-Vdc power supplied about 5 meters to an ion thruster.

The electronics are assumed to receive total integrated radiation and displacement damage doses of about $500 \mathrm{Krad}(\mathrm{Si})$ and $5 \times 10^{11} \mathrm{~N} / \mathrm{cm}^{2}(1 \mathrm{MeV}$ equivalent) at the payload dose plane ( $25 \mathrm{~m}$ from the reactor) with shielding equivalent to $24 \mathrm{~mm}$ of aluminum. The radiation dose can be somewhat tailored to the device with spot shielding. Processors, memory chips, and gate arrays are limited to 200 to $300 \mathrm{Krad}$ and would need to be placed behind a spot shield, roughly $50 \mathrm{~mm}$ thick. The complexity of these devices makes it very difficult to build them from a more rad-hard material such as SiC. Some of the Si diodes, MOSFET drivers, and a few ASICs are able to withstand $1 \mathrm{Mrad}$, but NASA is developing more devices and ASICs. Parts rated at 1 
Mrad require approximately $13 \mathrm{~mm}$ of aluminum shielding. Early government radiation tests indicate wide bandgap materials should be able to survive a 10-Mrad dose, which would eliminate the need for shielding beyond that provided by the payload bay enclosure.

The highest-voltage-rated Si switches are IGBTs and SCRs. They are produced with the required power and voltage ratings. But IGBTs and SCRs are both sensitive to radiation and limited to radiation doses on the order of $200 \mathrm{Krad}$. Silicon BJTs are more rad-hard, but they are not commercially produced for these voltages. MOSFETs are fairly rad-hard, and 1-Mrad devices are commercially available; but their voltage ratings limit them to $500-\mathrm{V}$ systems, and it would be difficult and costly to develop a device with the 3000-V rating required for the potassium-Rankine PMAD system. Silicon carbide BJTs, GTOs, and SCRs would appear to be the only viable alternative short of the very heavy shielding that would be required for Si IGBTs and SCRs.

Most Si parts need to have a baseplate temperature in the range of 25 to $50^{\circ} \mathrm{C}$ to operate for 20 years, but early projections indicate wide bandgap materials are able to operate at $300^{\circ} \mathrm{C}$ for 20 years. Wide bandgap devices are at a low TRL, though, with many devices currently at TRL 3. The Silicon-on-insulation technology may allow certain logic devices to operate for 20 years with a baseplate temperature of 75 to $100^{\circ} \mathrm{C}$, but this technology isn't suitable for power devices because of the difficulties encountered in extracting internally generated waste heat.

The main PMAD cables and connectors that envelop the requirements of the cables must survive $10^{8} \mathrm{rad}(\mathrm{Si})$ and $10^{14} \mathrm{~N} / \mathrm{cm}^{2}\left(1 \mathrm{MeV}\right.$ equivalent) at a temperature of $300^{\circ} \mathrm{C}$. A select number of insulations are rated for $10^{8} \mathrm{rad}(\mathrm{Si})$, but the insulations with the best properties, high dielectric strength, corona resistance, and flexibility aren't able to operate for 20 years at $300^{\circ} \mathrm{C}$. Presently, these insulations can operate at roughly $200^{\circ} \mathrm{C}$ for 20 years, but they should be able to meet the potassium-Rankine requirements if development is funded. The $300^{\circ} \mathrm{C}$ cable temperature is an early estimate. A problem in assessing the technology readiness of the cables and connectors is determining the specific environment, particularly the temperature, in which they must operate. Based on present information, the cables and connectors were also considered to be at TRL-4, "Component or breadboard validation in a laboratory environment."

\subsection{Development plan and schedule}

A standard PMAD development program is proposed with the fidelity of the PMAD components progressing from breadboard to EM, to Qual, and the test effort from circuit tests to breadboard functional tests, to component functional and environmental tests, to functional and environmental testing of the complete PMAD system with the interfacing systems in a spacecraft test bed. A technology development program must precede the component testing to develop the basic materials, devices, and parts, such as wide bandgap and 1-Mrad Si semiconductors, cable and connector insulations, relays, capacitors, and circuit boards. The PMAD system is considered to have reached TRL 6, when the integrated spacecraft qualification testing is completed. A schedule of the proposed technology and component development activities is shown in Section 7.3.

\subsubsection{Phase separation system}

\subsubsection{Requirements}


The phase separation/NPSH system is located at the condenser exit. It is required to scavenge the condenser and supply sufficient flow to the boiler feed pump at the required NPSH. It must also maintain appropriate vapor liquid interface control at the condenser exit if required. This system must be capable of restarting from the frozen condition, and must be able to operate at partial load to accommodate reduced system power levels. Several different options are available to meet these requirements. Active systems such as the RFMD create high acceleration levels (hundreds of gs) centrifugally to ensure effective liquid and vapor separation. In addition, because of the high acceleration fields, they can effectively maintain the liquid and vapor interface, providing a stable vapor core that could be either condensed (if the vapor is the working fluid) or vented if the vapor is an NCG. Additionally, the design is such that it can also provide the required NPSH to the boiler feed pump by incorporating a pitot style pump in the design. The negative aspect of such a device is that it is an additional piece of rotating equipment and therefore requires rotating bearings and seals and a means of effecting rotation (such as an electric motor).

Other designs that use centripetal acceleration to separate the liquid and vapor are more static, generating a vortex by injecting high-velocity liquid (or a two-phase mixture) tangentially in a cylindrical housing similar to a conventional cyclone separator. These designs do not require rotating equipment and afford positive separation. However, they do require sufficient pressure drop through the device to maintain a vortex; therefore, some level of subcooling is probably necessary in order for them to work effectively. They also require additional systems to provide the necessary NPSH for the boiler feed pump. As noted below, one method of accomplishing this is to use a jet pump in the system design.

System concepts are also available that use capillary forces to both effect liquid and vapor separation and maintain balanced flows between multiple condenser systems. Capillary isolators rely on surface tension forces to prevent vapor from crossing the capillary boundary. These devices would be placed in the condensate flow lines. As long as the capillaries remain wet with working fluid, surface tension forces prevent any vapor from going through the capillary. These devices essentially trap working fluid vapor in the liquid lines until it is condensed by the subcooled liquid flowing in the lines. These devices also trap NCGs similarly. However, unless venting is provided, the non-condensables could build up in these devices, eventually drying out part of the capillary structure and allowing vapor to pass through the system. The system must therefore be designed to allow collection of all of the NCGs throughout the system lifetime. These devices also require some subcooling to be effective. Radiators/condenser systems must therefore have a subcooling section in order for the capillary isolators to function properly. The required degree of subcooling is a topic that must be studied. These devices can separate vapor and liquid; however, some additional devices must be incorporated in the design to provide sufficient NPSH to the boiler feed pump. Traditionally, jet pumps have been used. Jet pumps are very commonly used in terrestrial applications where large flows are desired but only a low pressure rise is required. These devices have been extensively tested in potassium for earlier space nuclear programs such as the MPRE ${ }^{2}$ program; therefore, there is a significant amount of information on jet pump performance in both single- and two-phase potassium flows.

Additional examination of these devices is necessary before a final design solution is possible. 


\subsubsection{Development Program}

The development program consists of a system evaluation phase, four design phases, and two testing phases. An initial evaluation of the various systems noted earlier would be performed to determine the best candidate design. This effort involves evaluating the performance of each candidate design, assessing the various positive and negatives of each design, and downselecting a final concept.

\subsubsection{Phase Separation System Design}

Once a selection has been made, a conceptual design of the phase separation system would be developed. During this phase, various concepts for sub-components would be evaluated. If the system is an RFMD design, it is expected that bearing and seal development would be synergistic with development of those used in the other cycle rotating equipment. If other designs are selected, scales and operating parameters of the devices would be examined; flow rates and pressure drops established; and additional design details developed.

Final design would include detailing specifics of the component, arriving at specific component specifications, and developing enough supporting analysis that cost estimates can be made and an engineering prototype design can be initiated.

The engineering model design process would be used to develop a full-scale engineering mockup designed to do component development. This design would incorporate features that allow engineering changes to be made simply to investigate multiple design options experimentally.

A prototype would be designed based on results from testing of the engineering model. The prototype would be a design capable of long-term testing and flight qualification.

\subsubsection{Phase Separation System Testing}

It is expected that initial testing of this equipment would be performed using a fluid other than potassium to allow easy observation of system performance. These tests would establish a baseline for potassium system testing to follow.

Testing of the engineering model would be used to examine various design options. This test program would consist of short-term tests in potassium to determine component and subcomponent performance. Frequent examination of sub-components would be used to evaluate the potential long-term performance and establish a final system design.

Prototype testing would be used to examine the long-term operation of the phase separation/NPSH system design. This testing examines issues such as long-term durability and compatibility. If the design uses active rotating equipment, the testing program would likely follow the process discussed in Section 7.2.3. If a more static system design is selected, longterm testing is also required to bring this system to a TRL level of 6.

\subsubsection{Rankine cycle condenser}

Similar to the boiler development program, the condenser development program has both a ground test element and a micro-gravity test element. Micro-gravity testing is discussed in that section. 


\subsubsection{Requirements}

The condenser is required to take relatively high-quality potassium vapor from the turbine exhaust, reject heat to the radiator, and stably condense the vapor to a subcooled liquid at the condenser exit. It must interface with the radiator system and reject heat to it.

\subsubsection{Design Issues}

Although a significant amount of condenser testing has been performed in ground-based experiments, additional experimentation and development is needed to achieve a TRL level of 6.

The condenser accepts turbine exhaust, which can contain up to $10 \%$ moisture. In addition, it must accommodate two-phase mixtures from the boiler pump turbine as well as the power turbine moisture separation system. Moisture content entering the condenser can be up to $30 \%$. The design of the condenser system is actually a series of individual condensers connected in parallel by a manifold system. This system must operate stably under micro-gravity conditions. The manifold design must be capable of feeding each individual condenser with equal mass flows of the vapor and liquid mixtures in order to have all condensers and heat pipes operating similarly.

Each condenser must also operate so that no vapor carry under occurs. In terrestrial applications, this is usually accomplished using gravitational forces. In space, dynamic, centrifugal, and/or surface tension forces must be relied upon to eliminate vapor carryover from the condenser. Similarly, the design must move the condensed liquid through the condenser and to the pump suction. Shear flow condensers are most commonly proposed for space application and are designed to maintain sufficient vapor velocity to move the liquid to the condenser outlet.

Although the high thermal conductivity of potassium tends to decrease the importance of liquid film thickness on the condensing surface, condenser design generally attempts to minimize liquid film thicknesses to decrease the temperature drop between the condensate and the condensing surface. Efficient methods of maintaining liquid/vapor interface control in the condenser are needed to ensure reliable condenser operation. The condensation process itself, however, should not be gravity dependent unless NCGs are present. Since these systems would be designed to eliminate or minimize non-condensables, the condensation process itself should be able to be investigated through ground testing. The basic phenomena that are pertinent to condenser operation include entrainment and deposition, shear flow control of liquid films, and condensation heat transfer. In addition, characterization of actual design geometries is needed to verify condenser performance.

\subsubsection{Development program}

Continued design of the condenser would be performed in multiple stages: conceptual, final, engineering, and prototype. These design stages support the experimental program after completion of the engineering design.

A combination of ground and space testing would be necessary to complete condenser development. Ground testing should consist of both surrogate fluid and potassium experiments.

Like the boiler program, the condenser testing program starts with an engineering design for short-term testing utilizing features that allow condenser design changes to be easily 
implemented in the experiment and evaluated. It might consist of multiple test configurations, ranging from single condenser experiments to full-scale condenser testing. The engineering test unit is designed for short term-testing in order to evaluate multiple design options. The prototype system is designed for long-term testing once a design is finalized. A flight design unit would be tested in preparation for actual flight.

Specific design issues that must be addressed are the inlet and outlet manifold designs.

Surrogate fluid experiments can be used to investigate various manifold and component designs (such as capillary isolators) in order to determine their characteristics. Surrogate fluid testing would allow visual observation of liquid and vapor flows and the effect of various design features on those flows in a format that allows rapid experimental changes.

Potassium testing would allow confirmation of the design and evaluation of long-term operation of the condenser system.

\subsubsection{Potassium heat pipes}

The Rankine cycle heat rejection system architecture is very simple and based on utilization of just a few components; therefore, the main emphasis of the development activity is the development, improvement, demonstration, and manufacturability of these components. Some system issues need to be addressed during this phase, most of them related to the reliable and stable operation of the parallel Rankine cycle loop condenser. The parallel condenser is linked to system performance of the overall Rankine cycle.

Simultaneously with component development for high-temperature applications, surrogate fluid testing would be used to verify component design and system operation. The complete list of proposed tasks with priorities assigned is presented in Table 7.4.

\subsubsection{Development tasks}

The ultimate goal of the proposed effort is to demonstrate manufacturability, performance (including heat pipe operation as a part of the parallel condenser manifold simulator), and lifetime of the high-performance, high-temperature potassium heat pipe with a $\mathrm{Nb}-1 \% \mathrm{Zr}$ envelope. The entire effort is divided into several tasks, with a number of subtasks, as listed in Table 7.4.

\subsection{Wick structure}

Several options for the wick structure design look attractive; however, the structure with the exact match with the program requirements has yet to be identified. Several potential suppliers for these structures would be consulted to develop the wick structure with the maximum performance and best compatibility parameters. As was mentioned earlier, the fibrous wick was chosen as the main concept for the heat pipe wick structure. It should provide attractive performance; however, if none of the suppliers can provide the desired wick structure, the wick structures traditionally used for potassium heat pipes would be optimized. 


\section{Table 7.4. Heat pipe tasks}

\begin{tabular}{|c|c|}
\hline Task No. & Name \\
\hline I & $\begin{array}{l}\text { Wick structure, study of available options, and } \\
\text { selection of top three choices }\end{array}$ \\
\hline II & $\begin{array}{l}\text { Material compatibility of the heat pipe material (body, } \\
\text { wick, end-caps, welding) and working fluid }\end{array}$ \\
\hline III,a & $\begin{array}{l}\text { Design of the heat pipe with Rankine condenser and } \\
\text { facesheet (design for potassium and check design } \\
\text { performance for water) }\end{array}$ \\
\hline III,b & Design condenser \\
\hline III,c & Design flow distributor \\
\hline IV,a & $\begin{array}{l}\text { Fabricate } 2 \text { heat pipes, one with condenser and one } \\
\text { without }\end{array}$ \\
\hline IV,b & Fabricate 4 flow distributors \\
\hline $\mathrm{V}, \mathrm{a}$ & Charge and test one heat pipe with potassium \\
\hline $\mathrm{V}, \mathrm{b}$ & Charge and test second heat pipe with surrogate fluid \\
\hline VI & Fabricate 2 more heat pipes with condensers \\
\hline VII,a & $\begin{array}{l}\text { Assemble } 3 \text { heat pipes into a condenser manifold test } \\
\text { article }\end{array}$ \\
\hline VII,b & Charge all three heat pipes with surrogate fluid \\
\hline VII,c & Test condenser manifold for flow distribution \\
\hline VIII,a & Charge all three heat pipes with potassium \\
\hline VIII,b & $\begin{array}{l}\text { Test condenser manifold for flow distribution with } \\
\text { potassium }\end{array}$ \\
\hline IX,a & $\begin{array}{l}\text { Inject some NCG amount into potassium heat pipe } 1 \\
\text { for freeze thaw verification }\end{array}$ \\
\hline IX,b & Perform freeze thaw test (at least 5 cycles) \\
\hline $\mathrm{X}$ & Perform long-term testing \\
\hline
\end{tabular}

All of the issues related to the design of the wick structure would be addressed, not only the transporting wick itself but also the fluid distributing structure on the evaporator and condenser surfaces.

As a result of this task, at least three candidates for the wick structure would be identified and samples obtained from the suppliers. Tradeoff and material compatibility studies would be used to select the best structure for future activities.

\subsection{Material compatibility studies}

One of the main issues with heat pipes is material compatibility, which affects the lifetime of the heat pipe as a result of NCG generation, internal pitting corrosion, and physical properties degradation that can result in heat pipe failure.

The objective is for all of the material issues to be addressed and evaluated. Heat pipe envelope material, end-caps, welding materials, and the wick structure would be studied for compatibility with potassium (both separately and as a combination). The impact of component cleanliness and materials used for component fabrication (for example, fill materials to make a 
wick structure) and not completely removed can be pronounced, so these issues would be studied in detail.

At the end of this task, the set of materials and requirements for material manufacturers would be generated and used as guidance for future efforts.

\subsection{Design of the heat pipe}

In this phase, detailed analysis of the heat pipe (both mechanical and performance) would be performed. The working fluid to be used for the baseline analysis is potassium; however, as these heat pipes would be used in test fixtures with a surrogate fluid (most likely water), the performance and structural integrity would be analyzed for water as a working fluid as well.

The condenser of the Rankine cycle loop must be an integral part of the heat pipe design; therefore heat pipe performance would be analyzed together with the performance of the Rankine cycle condenser. The internal and external designs of the condenser would be created.

A fluid distributor design would be developed, and material compatibility studies for the flow distributors would be performed. The internal and external design of flow distributors would be created. One of the main parts of this task's effort is the identification of manufacturing techniques and approaches suitable for heat pipe fabrication that provide necessary compatibility, cleanliness, and overall quality. At the end of this task, a complete set of design drawings would be generated. This package would be suitable for manufacturing the entire experimental hardware package.

\subsection{Fabrication of heat pipes and flow distributors}

Two $\mathrm{Nb}-1 \% \mathrm{Zr}$ heat pipes would be fabricated during this task. These heat pipes would have identical design, except that one heat pipe would be fabricated with the Rankine cycle condenser on the heat pipe evaporator and another without the Rankine cycle condenser. Four flow distributors would be fabricated as well. All documentation required for the fabrication of the hardware be prepared under this task, and all required tooling and handling fixtures would be produced.

\subsection{Charging and testing of the potassium heat pipe}

After completion of the previous task, one of the heat pipes (without the condenser) would be charged with potassium for performance testing. At the completion of this task, the complete mapping of the heat pipe performance would be available. It is recommended that tests be performed at variable powers, temperatures, tilts, and charges. After completion of these tests, the potassium heat pipe would be set up for freeze/thaw and then accelerated life testing.

\subsection{Charging and testing of the surrogate fluid heat pipe}

The second heat pipe fabricated (with the Rankine cycle condenser) would be tested with a surrogate working fluid. This test would envelop the heat pipe performance during the ground and microgravity tests. The condensing potassium vapor in the Rankine cycle would be simulated with a hot fluid pumped through the Rankine cycle condenser. It is recommended that tests be performed at variable powers, temperatures, and heat pipe tilts. 
The ability of the flow distributor to restrict vapor penetration beyond the Rankine cycle condenser would be verified during this test as well.

As an objective of this test, a complete understanding of heat pipe performance with a surrogate fluid would be obtained. This knowledge would be used for planning of future experiments at the Rankine cycle loop level with a surrogate fluid.

\subsection{Fabrication of two additional heat pipes}

A study of the parallel condenser behavior needs to be performed on at least three identical condensers connected in parallel and equipped with flow distribution devices. In order to support this study, at least two more heat pipes of identical design would be fabricated and charged with the surrogate fluid.

\subsection{Parallel condenser testing - surrogate fluid}

Load sharing and cross-talking of condensers would be studied, and possible failure modes simulated. This test would be performed with the heat pipes charged first with a surrogate fluid and then with the actual working fluid - potassium.

This activity includes assembly of the test article, which includes three heat pipes equipped with Rankine cycle loop condensers and flow distributors. Routing of the manifolds would represent the worst-case scenario for a flight radiator configuration.

The test article would be connected to a boiler, which would be producing a vapor/liquid mixture simulating turbine exhaust conditions. The test plan includes steady state performance testing with uniform and non-uniform gravity conditions on the flow distributors, and uniform and non-uniform cooling applied to the heat pipes. The test program would also investigate transient limitations of the parallel condenser design (power up and power down, temperature up and temperature down). These transients envelop the possible real-life operation of the parallel condenser.

One very important part of this testing is an NCG injection test. A certain amount of NCG, corresponding to the maximum NCG amount that can be expected to be generated in the Rankine cycle potassium loop at the end of life (EOL) would be injected into the flow of the two phase fluid used to simulate the condensing potassium vapor in the Rankine cycle. The system response to the NCG injection would be monitored and studied. The result of this test could provide the ultimate answer regarding the applicability of flow distributors in the flight system. This test would be repeated several times with different amounts of NCG, exceeding the amount previously calculated for the EOL. The point at which the system starts failing to perform as expected determines the design margins for the condenser/flow distributor combination. Upon completion of this test, the condenser and flow distributor design may need to be updated.

After successful completion of the parallel condenser test with the components charged with surrogate fluid, the test article should be cleaned and outgassed in preparation for potassium filling.

\subsection{Parallel condenser testing- potassium}

All three heat pipes would be charged with potassium, and the parallel condenser section would be connected to a closed potassium loop. 
The test program performed on the test article while it was filled with a surrogate fluid would be repeated using potassium. Power and temperature levels during this test correspond to the actual loads expected during the flight. The number of tests and their sequence and parameters would be determined after completion of the surrogate fluid test.

The intent is to simulate prototypic circulation of potassium through the Rankine cycle loop, especially when the NCG test is be performed.

\subsection{Freeze-thaw behavior of potassium heat pipe}

After the completion of the single potassium heat pipe test, the heat pipe would be checked for NCG content. This should give a good understanding of the NCG levels expected in the potassium heat pipe at the end of the NEP actual mission. After the heat pipe is checked for NCGs, it would be charged with a predetermined amount of NCG (TBD). After the heat pipe is charged with the NCG, it needs to be pre-conditioned by uniformly heating the entire length and then cooling it uniformly to a temperature below the freezing point of potassium. This allows potassium to distribute itself evenly so the heat pipe does not have any difficulty starting for the first time.

The freeze-thaw test would be performed for at least 5 or 6 cycles. Afterward, the heat pipe would be started, operated for a while at full power, and then brought to a temperature below freezing in a flight-representative manner.

Repeating this test several times and monitoring any differences in the heat pipe behavior should demonstrate the applicability of freeze-thaw protection which has been demonstrated on a number of heat pipes with different fluids and different capillary structures, but never with potassium and a fibrous wick combination.

\subsection{Long-term testing of potassium heat pipes}

At least three potassium heat pipes would be tested on a long-term basis. A program to destructively examine individual heat pipes at several time intervals during the testing process would be used to determine the long-term durability and performance of these heat pipe designs. Analysis of the heat pipes includes material transport, wick integrity, and NCG generation.

\subsubsection{System Start-up/freeze/thaw}

The potassium-Rankine system startup sequence may be difficult and must be verified experimentally whenever possible. There are several critical moments in the sequence where phase changes must begin to occur and flow directions must be controlled by design or directed by hardware. These transitions must occur smoothly while component temperatures are kept within acceptable levels and flow instabilities are avoided. Several critical areas that require experimental verification and hardware component development are described below.

\subsubsection{Low-power Flow Direction}

In the absence of gravity, the vapor does not have a preferential flow direction. The only available driving force is the very small pressure difference produced by the TEM pump. The most critical feature of the startup routine is the ability to preferentially move the potassium vapor out of the boiler exit and condense it in the start loop radiator, effectively pulling it 
through the pump. The ability to increase the vapor flow rate until enough motive power is available to turn the main pump and the alternator must also be demonstrated.

Flow through the start loop could possibly be maintained by placing a flow check valve between the boiler exit and start loop radiator. As vapor production occurs in the boiler, the pressure increases and forces flow through the check valve toward the start loop radiator. During the startup process, it may be possible to pump the start loop with this method and remove the need for a secondary-side TEM pump.

\subsubsection{Radiator Startup}

When the main pump begins to turn, vapor flow from the boiler can be initiated through the bypass path around the turbine to the condenser. The turbine bypass flow dumps directly into the condenser and warms and initiates the operation of the radiator heat pipes. Up to this point, the heat loss has been minimal because the heat pipes in the radiators are frozen and not operating. This is important at startup because it limits the temperature required in the boiler to raise the condensing leg of the condenser above the melting temperature of the working fluid. The ability to systematically initiate radiator operation, including thawing of the heat pipes and a gradual increase in the portion of the condenser that is active, must be demonstrated experimentally.

\subsubsection{RFMD Requirements}

The RFMD is required in the initial phase of the startup for phase separation; however, it may be useful in initiating working fluid flow when the diverter valve is initially opened. The RFMD is driven from the alternator when sufficient electricity is available, and it is possible that the current supplied to the RFMD can be used as trim control on the secondary system working fluid flow rate.

An RFMD may not be required for separation of gas and liquid from the condenser, but it still may be required to supply NPSH to the pump. If the system is sufficiently clean and NCGs are not being produced in the working fluid, then it may be possible to design the system with sufficient subcooling out of the condenser to preclude cavitation at the main pump.

It is also possible that cavitation could be designed as normal operation for the main pump at full power, and an RFMD may not be required. In fact, such a system has been proposed as the operating scheme of a $300-\mathrm{kW}(\mathrm{e})$ liquid metal system. If NPSH is not maintained, then the pump would cavitate and flow would be reduced. Low flow may result in increased vapor pressure in the boiler, which ultimately increases the pressure at the condenser exit. The increased pressure causes the voids in the pump to compress, allowing the pump to move liquid through the system again.

\subsubsection{Flow direction control hardware (valving)}

To start the system, the flow must be directed to the proper location at various phases of the startup sequence. Specifically, flow must be directed through the start loop and restricted through the turbine, turbine bypass, and alternator coolant loop pump initially. As the system begins to increase in power, flow has to be diverted first to the turbine bypass loop and then through the turbine. Once the main pump is turning, the startup loop can be shut down. Vapor diverter valves 
and isolation valves would be required to direct flow. Development of the diverter valve is an important development issue. It is possible that the valve could be passive (a bi-metallic strip that opens as a function of temperature). Also, a three-way diverter valve could be used that progressively increases and varies the flow to the pump and the turbine across all reactor power settings from a single actuator. The coordinated use of multiple valves is also possible.

\subsubsection{Boiling stability}

Boiling instability, especially during startup, has been observed in a liquid metal test loop developed as part of the MPRE program. Various strategies were developed to overcome the problem, including mechanical forming of nucleation sites onto heat transfer surface areas and the addition of restrictions to flow channel entrances. There has been essentially no work performed on flow instability of liquid metals in micro-gravity. Critical issues that need be addressed relate to the degree of superheat that can occur before boiling initiates under low-flow conditions and how it might impact the startup sequence.

\subsubsection{Condenser flow balancing and scavenging}

Flow into and out of the condenser is controlled passively through design by tapering the flow channel cross-sectional areas. Shear flow and viscous forces are required to pull the liquid through the system and balance that flow over the available parallel heat pipe channels. The ability to operate the condenser at all required power levels needs computational analysis and experimental verification.

\subsubsection{Potassium Loop Facilities}

Development of the Rankine cycle would be most economically accomplished by the use of two distinct types of test facilities. One type of facility would be devoted to the development testing of suitable bearings, seals, and couplings for use in the power turbine, alternator, and turbopump. The second type of facility would be devoted to testing of the full-scale rotating machinery: the power turbine, the alternator, the turbopump, and other loop components such as the boiler, condenser, and RFMD.

Initial potassium loop development should focus on re-establishing capabilities to handle and operate potassium systems. This may be accomplished by operating and testing at lower temperatures. If temperatures are maintained below approximately 1100 to $1000 \mathrm{~K}$, tests may be performed in a stainless steel system, and vacuum systems would not be necessary to protect the refractory metal systems that would have to be used at higher temperatures. This can greatly simplify the development process as operational issues are re-learned. These temperatures allow tests to be performed at prototypical temperatures on the low side of the Rankine cycle system, the condenser, RFMD, heat pipes, etc. Additionally, because the bearing system operates at 750 $\mathrm{K}$ or below, initial bearing and seal testing would be amenable to this type of facility. Also, although $1300 \mathrm{~K}$ temperatures could not be achieved with a stainless steel system, the boiling process could still be studied, although at a somewhat reduced pressure. After operating procedures are developed using a stainless steel system, they could be easily adopted for highertemperature operation in refractory systems; this would require the added complication of operation in vacuum. 
The small component test facility is expected to consist of a heated potassium supply or loop consisting of a small storage tank, a small E-M pump, and suitable electrical heating elements. Potassium could be supplied in small quantities to special test rigs that would provide for load and speed simulation of an actual turbine. Drive motor power would be limited to about $10 \mathrm{hp}$. Since the potassium inventory is small, the facility could be located in a populated area with adequate safety precautions. Several such facilities existed in the 1960s. Sketches of the test apparatus used at the time for testing bearings, seals, and couplings are still available. A flow diagram for such a facility is given in Fig. 7.3.

Testing of the potassium Rankine rotating equipment and other Rankine cycle components requires the development of a completely new test facility. Suitable test facilities existed in the late 1960s; however, insofar as can be determined, they have all been deactivated and demolished. A top-level flow diagram for a suitable facility is shown in Fig. 7.4. Proposed plans are to test the power turbine, alternator, and turbopump simultaneously during the prototype testing stage. Provisions are included to test the different components, namely independent drive motors for the alternator and pump, separately. The diagram illustrates the major disadvantage of using refractory materials, - that they are generally not compatible with oxygen and sometimes not compatible with other gases and must therefore be tested in a vacuum.

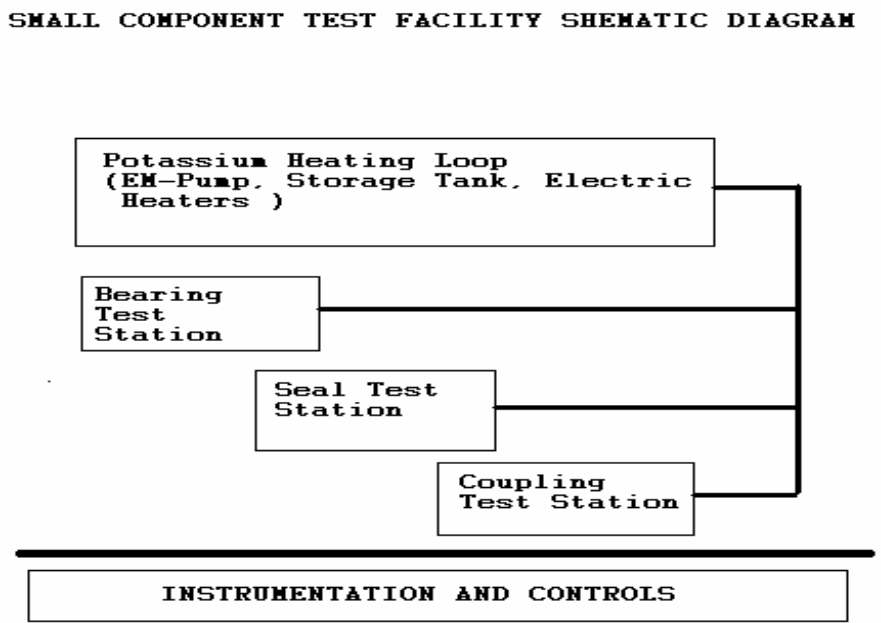

Fig. 7.3. Description of small component test facility.

The large component test facility consists of six major elements:

1. A gas-fired potassium boiler

2. A vacuum-jacketed turbine/alternator test stand

3. An auxiliary drive motor package for the test stand

4. A vacuum pumping facility for the turbine test stand

5. An air-cooled condenser

6. A vacuum-jacketed boiler feed pump test stand

7. A vacuum pumping facility for the feedpumps

8. Instrumentation and controls 
A boiler is required to produce boiling potassium for testing the power turbine. Natural gas firing appears to be the most convenient method of producing the heat required to boil the mass of potassium expected to be required. The temperatures involved are considerably higher than are used in steam generation applications, and the use of refractory materials for the boiler tubes would be required. TZM appears to be a satisfactory candidate alloy for the boiler tubes and piping between the boiler and the power turbines. TZM should provide the corrosion resistance for operation in air as long as the boiler is fired with a reducing flame. An oxidizing flame may cause rapid oxidation of the boiler tubing. A similar unit was constructed and operated successfully by Atomics International in the early 1960s.

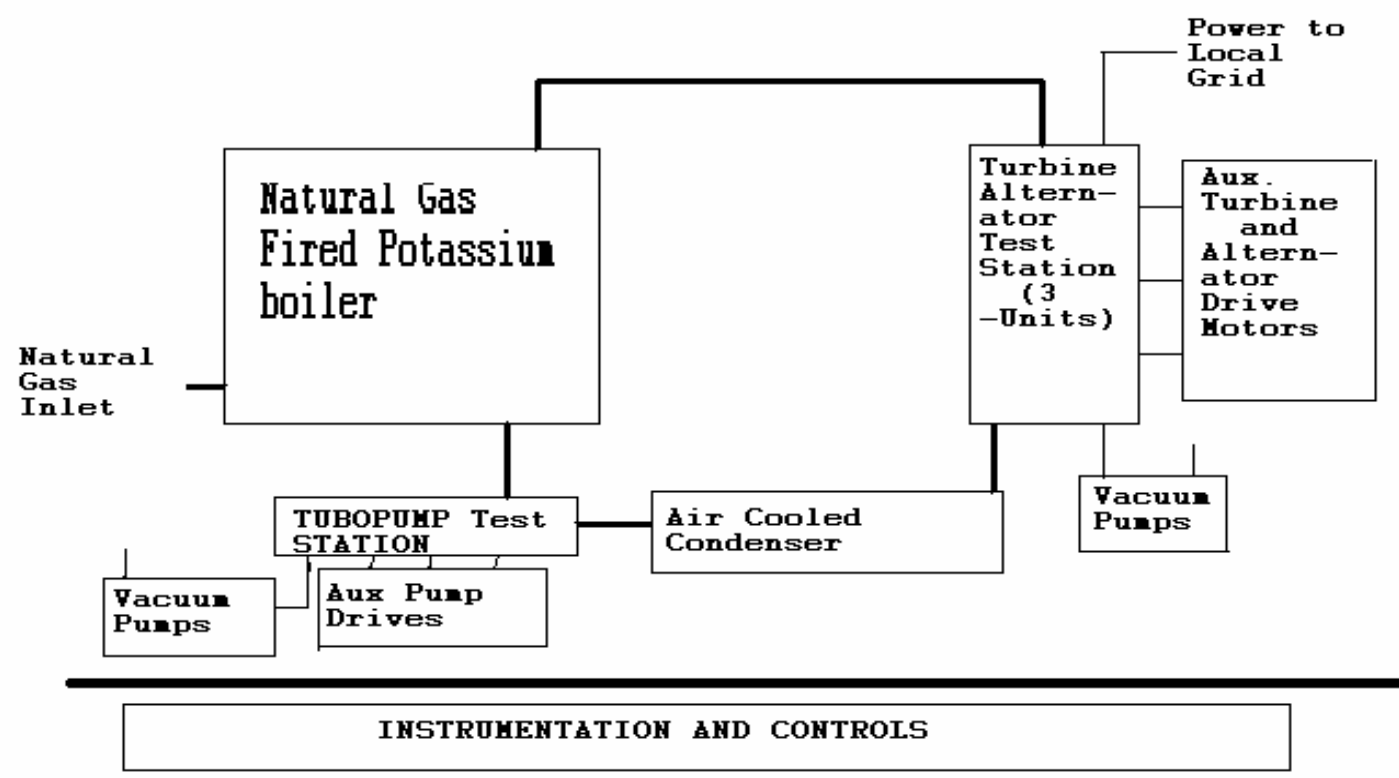

IARGE COHPONEHT TEST FACILITY SCHEHaTIC DIAGRAH

Fig. 7.4. Description of large component test facility.

The actual turbine testing would be conducted in a large compartmented vacuum chamber. Each test cell in the vacuum chamber would be large enough to accommodate both the test turbine and a generator. The generator would be replaced by a flight design alternator at the start of prototype endurance testing. Otherwise, the main purpose of the generator is to generate electrical power for sale to the local utility in order to offset the cost of fuel for the potassium boiler. Separate drive motors for the alternators would be provided to permit alternator testing independently of the turbine. This is expected to be useful during the pre-engineering model phase of the development program

Potassium effluent from the power turbines would be passed to an air-cooled condenser for conditioning (condensed to liquid phase) prior to being returned to the boiler. The use of air cooling for the condenser recommends itself since cooling fans are easily regulated and the unit should therefore be simple to control. Several large air-cooled - liquid metal heat exchangers were built and successfully operated at Atomics International during the 1960s and 1970s. 
Effluent from the condenser is pressurized by the boiler feed pump and returned to the gas-fired boiler. The boiler feed pump can be electric motor or turbine driven as appropriate. A vacuum chamber, which contains the turbopumps, is included. The flight-type turbine-driven pump would be tested in conjunction with testing of the main power turbines and alternators. Three pumps would be tested simultaneously with the power turbines

A vacuum pumping facility featuring both roughing pumps and high-vacuum pumps would be required to maintain vacuum conditions on the turbine and on the pump test stations as required.

Instrumentation and control would be located remotely from the test articles in order to provide operator safety. Appropriate fire control systems would be provided to contain the results of a potassium spill. Berms or a below-grade location would provide blast protection for the public in the event of a major accident. A description of this facility is shown in Fig. 7.4.

\subsubsection{Microgravity Testing}

The micro-gravity test program is designed to confirm operation of the Rankine cycle under micro-gravity conditions. Several Rankine cycle components operate under two-phase conditions and rely on effective control of the two phases to ensure proper component operation. The component design philosophy is to design so that these components are essentially gravity independent, by relying on other mechanisms such as inertial, surface tension, or centripetal forces to control the liquid and vapor interfaces. However, control must be maintained for both off-normal as well as normal operating conditions, and operational margins must be understood to design these systems. Confirmation of the designs under long-term micro-gravity conditions are necessary to achieve a TRL of 6 for these components. As noted in Section 6, the boiler and condenser systems are the major components that operate under microgravity conditions. Additionally, proposed plans are to incorporate a device or system in the design at the condenser exit to separate and recondense any vapor carryunder in the condenser and to be capable of separating NCGs (if necessary) from the system. In the baseline system, this is accomplished through the use of an RFMD; however, other devices may be considered in the future. In general, the rotating equipment in the cycle operates at high enough rotational speeds that micro-gravity testing is not warranted, so micro-gravity testing concentrates on the boiling and condensing equipment in the system.

Because of the difficulty of long-term micro-gravity testing using potassium as the working fluid, the micro-gravity testing program is divided into two major phases. The first phase uses surrogate fluid testing to characterize the two-phase behavior of the Rankine cycle. It is designed to use existing experimental platforms on either the space shuttle or the International Space Station. The second phase of micro-gravity testing uses potassium to confirm the surrogate fluid experimentation and to investigate additional issues unique to potassium, such as freeze/thaw behavior in engineering geometries and the procedures to start, shut down, and restart from the frozen state. It is expected that this experimentation would be performed using commercial launch systems.

\subsubsection{Surrogate Fluid Testing}

\subsection{Surrogate fluid ground testing}


The surrogate fluid experimentation is initiated with a ground test design. The initial portion of this task is to identify surrogate fluids that can be used to simulate the performance of potassium. This effort requires identification of appropriate non-dimensional groupings that describe the fluid behavior in each component. Once groups are identified, the surrogate fluid is selected by matching the appropriate non-dimensional numbers developed for the actual Rankine cycle potassium systems with those of the surrogate fluid. This exercise defines both geometry and power levels required (both heating and cooling) for testing. This process would proceed in parallel with identification of potential flight formats, so that both the fluid and format are consistent. It is expected that the boiler and condenser would be the major components identified for testing.

The ground test design uses component geometries like those to be used in the flight experiment. The test apparatus would be designed to be capable of operating in several orientations to define the parameter space where gravitational effects are important. Instrumentation may be more extensive on the ground test unit than on the flight test design. Ground test results would be compared with data gathered during micro-gravity testing. Ground testing may also include a test program using either aircraft trajectories or drop tower experimentation, depending on the exact test program required.

The ground test program consists of three separate phases: ground test system design, experimental construction, and ground testing. It is estimated that this program can be completed in approximately 2.5 years. Completion of this program would provide baseline data to compare with flight test results.

\subsection{Surrogate fluid flight testing}

At least two surrogate fluid flight experiments are anticipated. These experiments are anticipated to use the same flight format and most of the same flight hardware. Multiple experiments are anticipated because testing the full parameter range of all components may not be possible in one experiment.

Based on results from the ground test system, a flight design would be developed using existing flight formats. This system would be designed to confirm ground test results under micro-gravity conditions and investigate the component operational limits. Two separate design phases are anticipated, since results from the first flight test may require design changes for the second.

Multiple surrogate flight tests would be used to confirm ground test results and establish a database for potassium subcomponent testing.

\subsubsection{Potassium Subcomponent Testing}

\subsection{Potassium subcomponent ground testing}

Full-scale potassium micro-gravity testing is not possible because of the large power requirements. It is therefore be necessary to test on the subcomponent level. This may mean testing a single boiler tube, for instance, or even smaller-scale devices. The objective in this testing is to confirm component operation with potassium, and develop techniques for operation of potassium systems in space. Areas that should be studied include the startup, shutdown, and 
restart sequences that would be required by the full-scale Rankine cycle, as well as normal and off- normal operational performance.

The initial phase of subcomponent testing is the design of a ground system that matches the one to be tested in a micro-gravity flight. As with the surrogate fluid tests, this experiment would be used to test in multiple orientations to benchmark the flight data. In addition, this experiment would be used to confirm the operation of the instrumentation package to be used on the flight system.

\subsection{Potassium subcomponent flight testing}

It is expected that multiple potassium test flights would also be necessary to cover the entire parameter range of interest. Two separate commercial flights are explicitly identified in this proposed plan. These experiments are anticipated to use the same flight format and most of the same flight hardware.

The flight design process would use information developed in the ground test phase to develop a final flight design. Two separate design steps correspond to the two flight test tasks. The second design phase is expected to be less intense than the initial design because it would require only moderate changes in the original flight experiment.

Flight testing and the resulting data would be used to benchmark design codes and algorithms so that a final Rankine cycle design may be developed.

The scheduling exercise associated with this task does not include NASA-required safety analysis to be compatible with manned flights.

\subsubsection{Analysis}

An analysis task exists throughout the thermal/fluids program. It is designed to improve Rankine cycle performance predictions as new information becomes available and to develop and exercise codes that would be required to complete the Rankine cycle design. Examples of topics are identified in the following paragraphs.

\subsubsection{System Analysis}

System analysis codes would be developed, updated, and improved as necessary to incorporate design changes as they warrant, and modified as necessary to remain current with new information as it becomes available.

\subsubsection{Reliability Studies}

In order to ensure that the 15 -year mission is accomplished with a high probability of success, reliability studies are required. Some of these studies are

1. Effect on the overall system reliability of the number of units and the power of each unit (comparing systems with $1 \times 100 \%, 2 \times 100 \%, 3 \times 100 \%, 2 \times 50 \%, 3 \times 50 \%, 4 \times 50 \%$, $3 \times 33 \%, 4 \times 33 \%, 5 \times 33 \%$, etc.). The effect of operating all of the units at the same time or having some shut down.

2. Study and comparison of different startup schemes from the point of view of reliability. 
3. Reliability studies for the different components of the system - turbine, alternator, turbopump, condenser, radiator, PMAD, valves, startup system, and control systems - including operating strategies (such as connecting one idle unit after failure of the operating unit), interconnections, and common cause failures.

\subsubsection{Dynamic and Static Stability Studies}

Multiple types of instabilities may exist in a two-phase loop system if appropriate engineering care is not exercised in the design of these systems. The instability behavior for the potassium Rankine cycle loop must be evaluated to ensure a successful design. Two types of instabilities would need to be evaluated: static-type instabilities that affect the multiple-tube, once- through boiler, and dynamic instabilities that affect the entire loop behavior and are dependent on specific loop design. Existing codes and techniques would be identified and/or developed and used as necessary to begin this evaluation process.

\subsubsection{Two-phase System Analysis Code}

An analysis package(s) must be identified or developed as necessary to examine twophase thermal and fluid behavior in the Rankine cycle components. Analysis capability is necessary to determine the local heat transfer and pressure drops, especially in components such as the boiler and condenser. A complete review of potential software is warranted to ensure that the most efficient path is followed. Once a code selection is made, modifications may be necessary to ensure that it has the appropriate capabilities (liquid metals, $\mu$-gravity analysis capability, etc.).

\subsubsection{Structural Analysis}

Structural analysis is required on multiple levels: analysis at the component and sub-component level, analysis at the system level, analysis of launch loads, fatigue analysis of components, etc. This effort requires assessment of a variety of codes, development of specialized models, and other tasks in order to ensure system success.

\subsubsection{Freeze/Thaw Analysis}

Calculations of the freeze/thaw process in the system piping or accumulator are necessary to help evaluate start, restart, and shut down schemes. A combination of thermal conduction, radiative heat transfer, and external heating sources (electrical, small heat pipes, etc.) is expected to play a role in these processes. Analysis tools must be assembled in this task to help evaluate these processes and develop design solutions.

\subsubsection{Safety Analysis}

Safety analysis of the Rankine cycle system is necessary to identify potential issues. Also, because the cycle interfaces with the nuclear system and is the heat sink for the reactor, deterministic analysis would be necessary as well. 
These topics are examples of the types of analysis that would be necessary to design a Rankine cycle system. A complete identification of this effort should be performed early in the development process.

\subsection{SCHEDULE}

The schedule presented assumes a notional 10-year development program. It is assumed that facilities would be shared among different parts of the program; however, the level of detail in this evaluation did not permit resolution of schedule conflicts that might be present. The schedule assumes a program start date of July 1, 2004, and full funding throughout the program.

Some of the scheduling assumptions were

- A 10-year development plan is assumed.

- It is assumed that an appropriate PMAD test facility already exists.

- Potassium facilities would be shared among tasks requiring loop operations.

- In general, a standard engineering model, qualification and flight development programs are assumed.

- An accelerated endurance testing program could be developed that would satisfy mission requirements.

An estimated schedule for completing the Technology Development Program follows. 


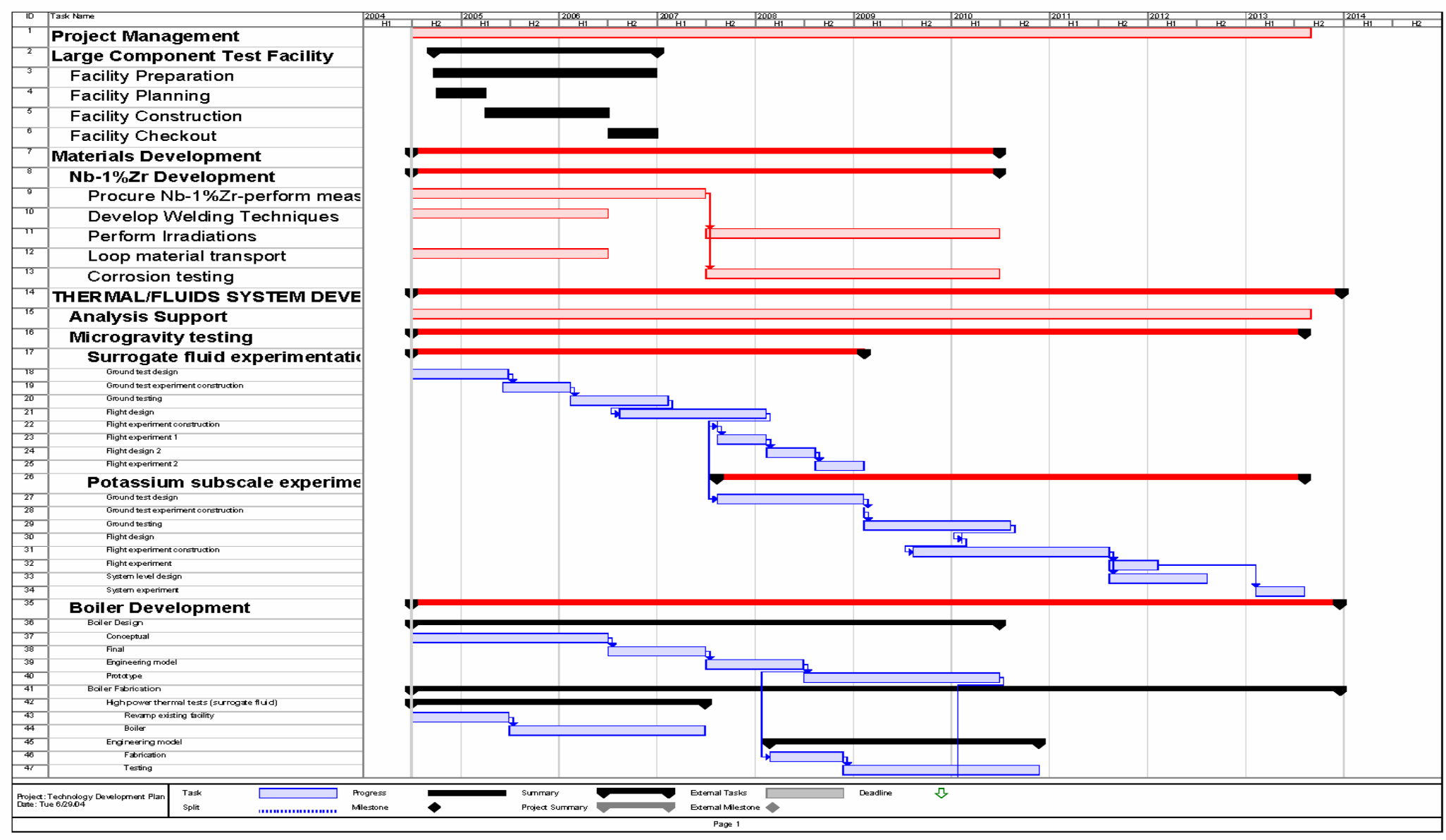




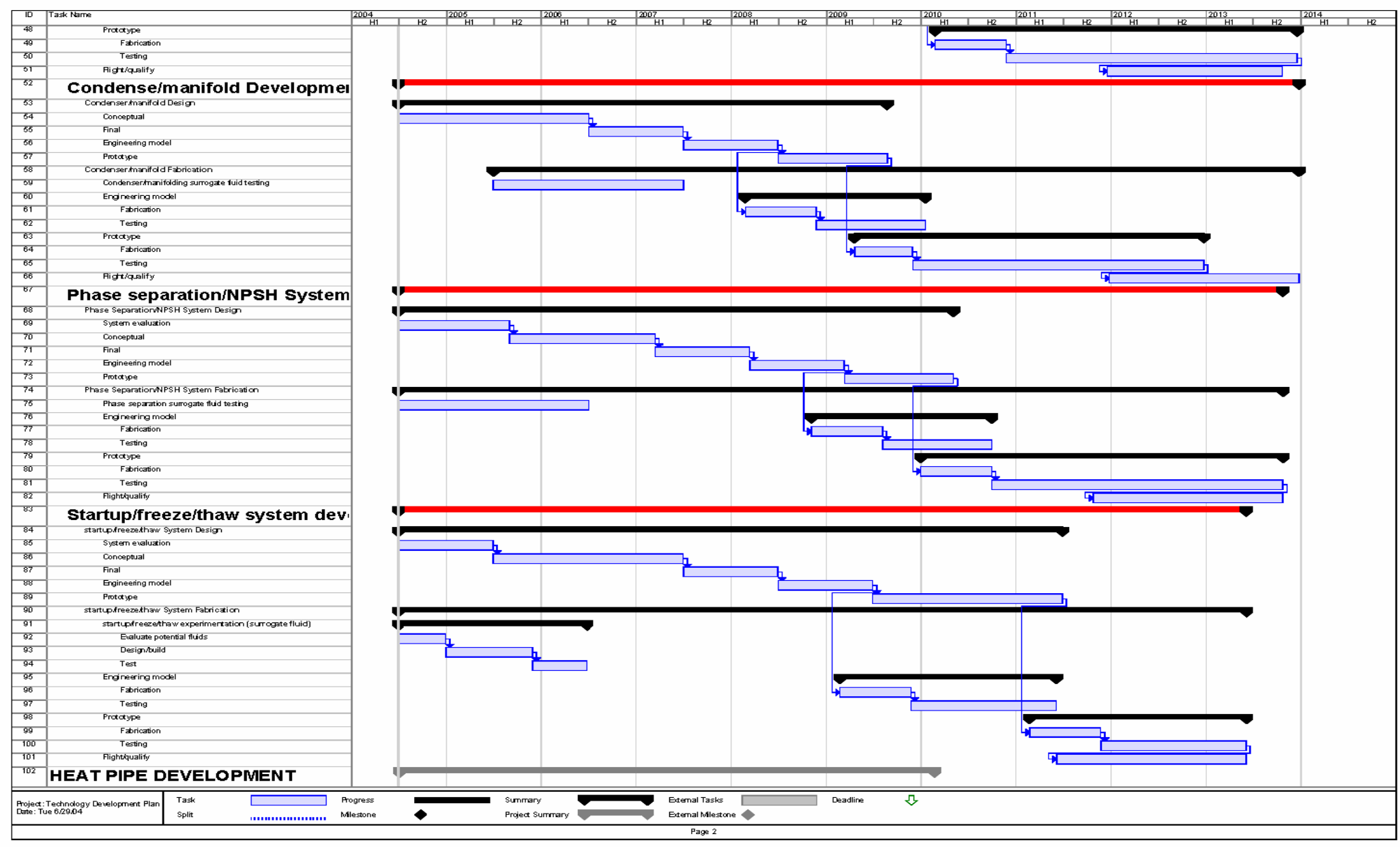




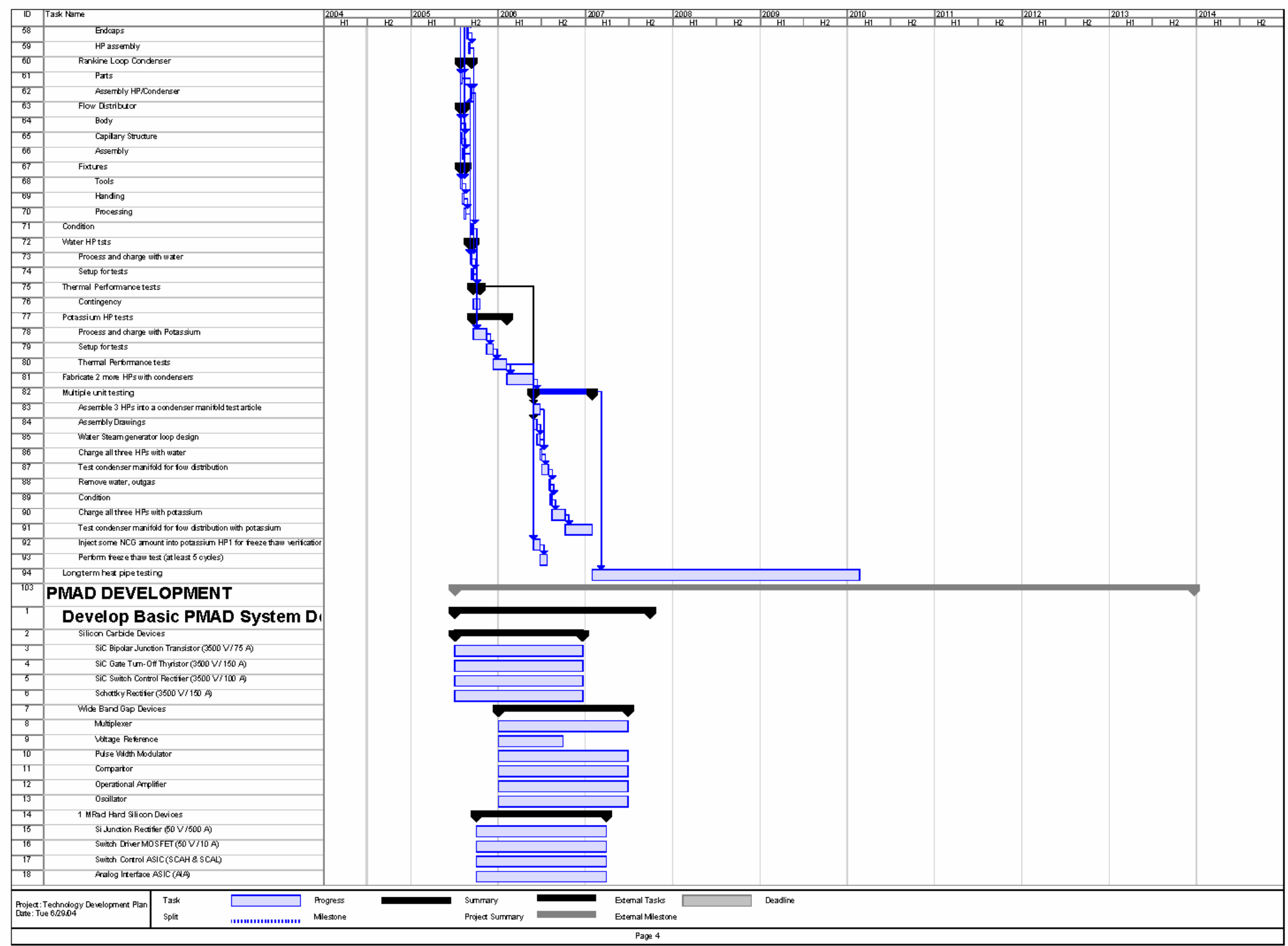




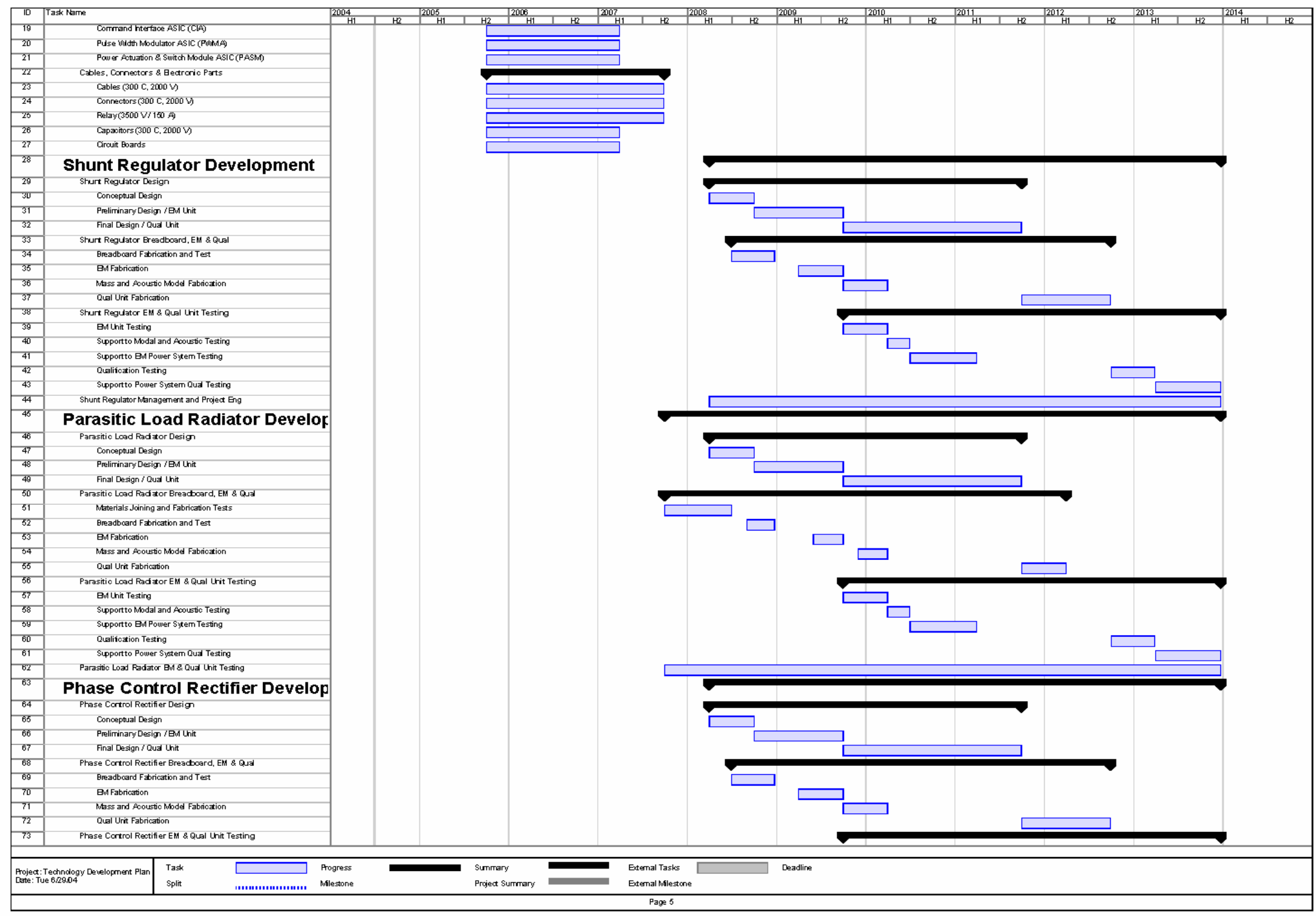




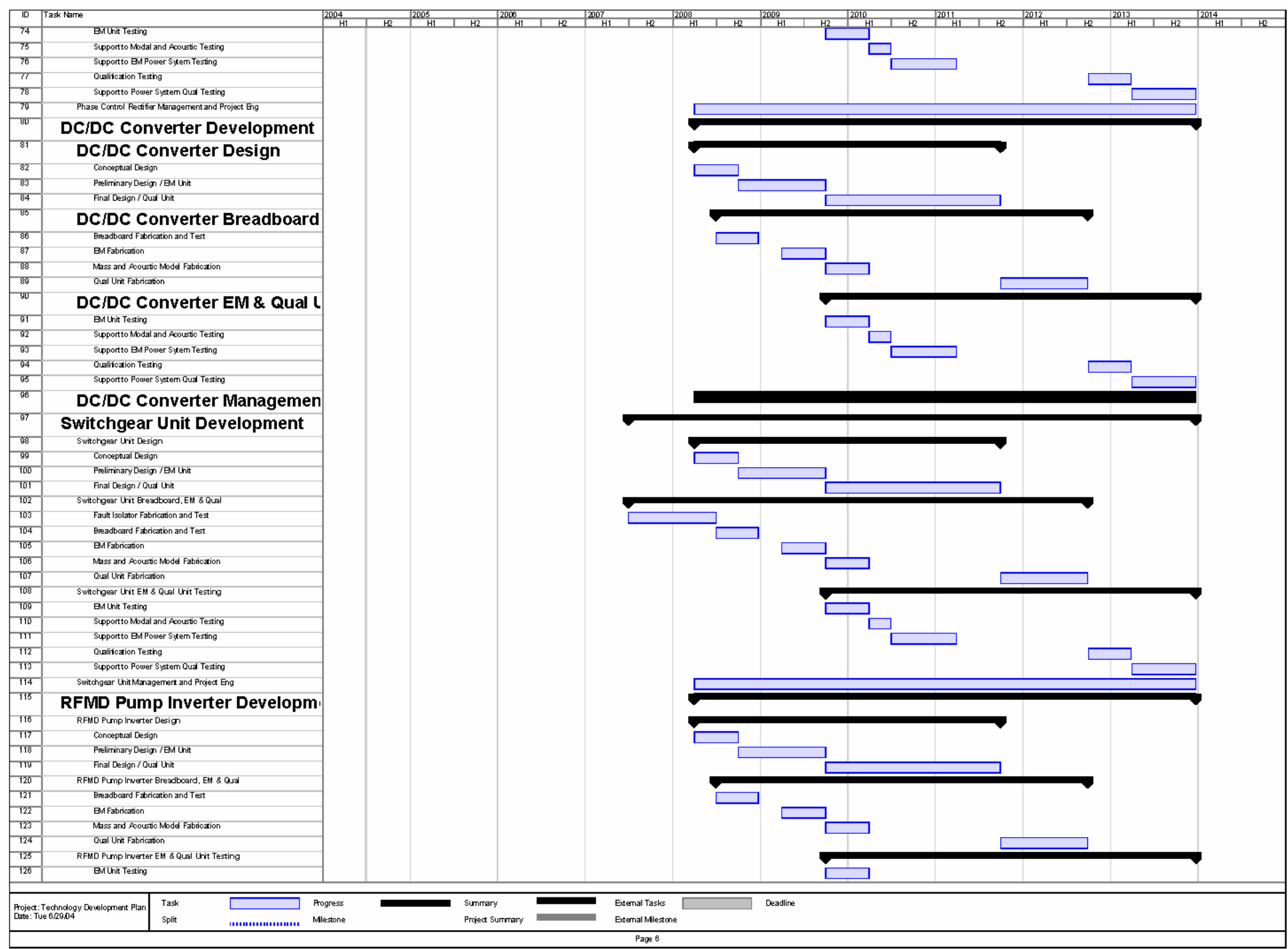




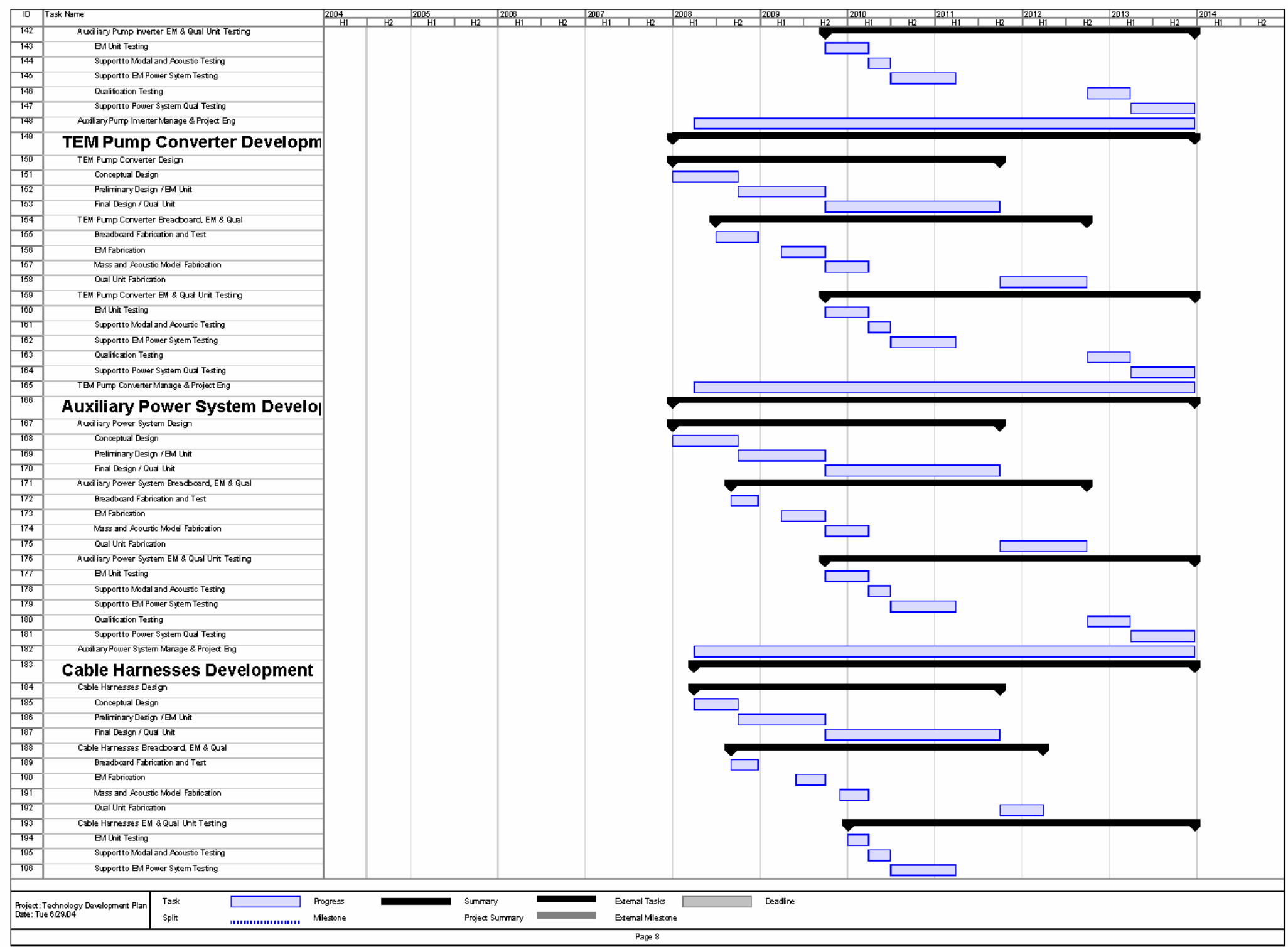




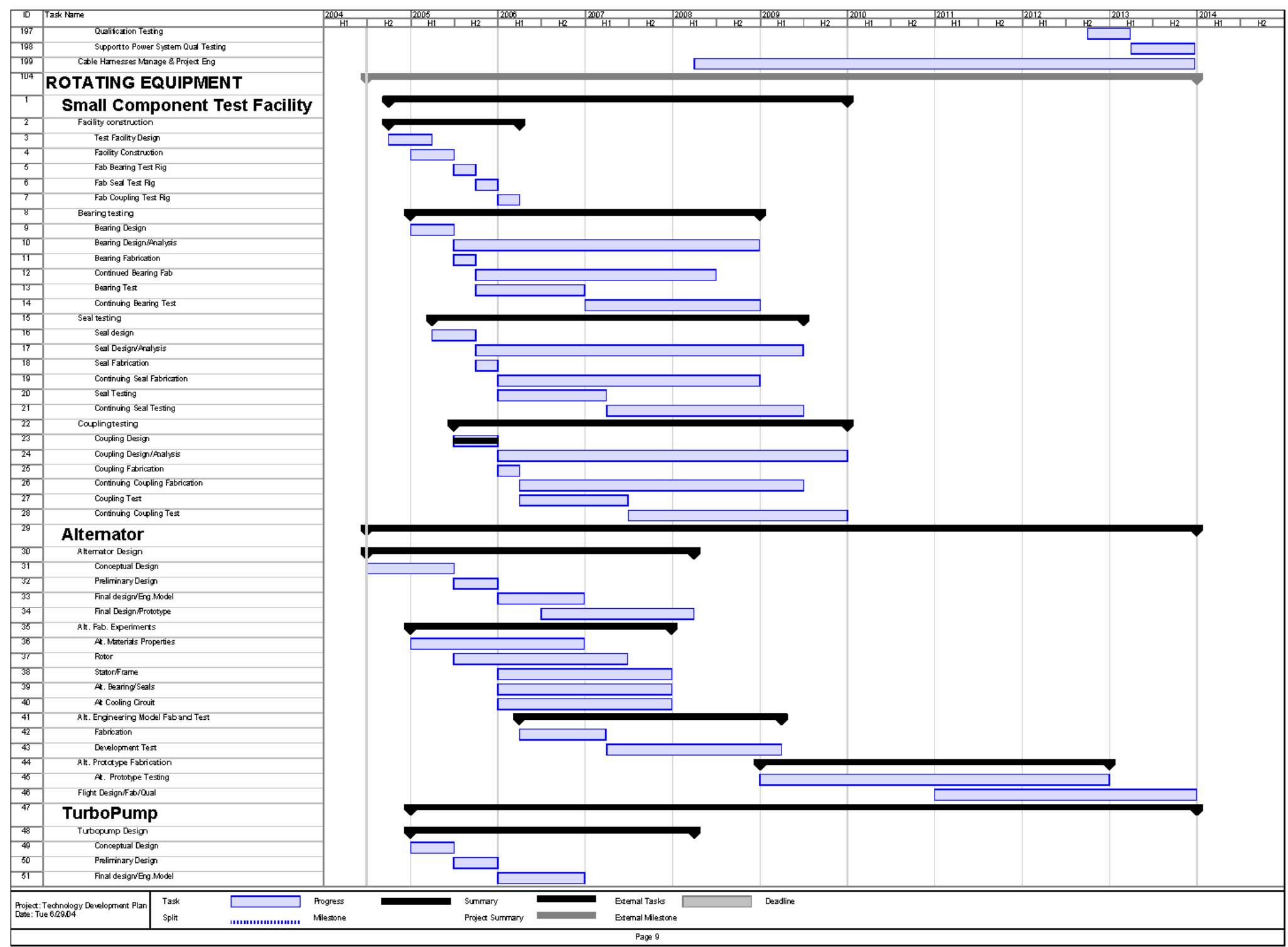




\section{REFERENCES}

1. SNAP-50/SPUR Program Summary, Pratt and Whitney Aircraft, October, 1964

2. A. P. Fraas, Summary of the MPRE Design and Development Program, ORNL-4048, Oak Ridge National Laboratory, June 1967.

3. H.C. Young and A. G. Grindell, Summary of Design and Test Experience with Cesium and Potassium Components and Systems for Space Power Plants, ORNL/TM-1833, Oak Ridge National Laboratory, June 1967.

4. J. R. Peterson, High-Performance “Once-Through” Boiling of Potassium in Single Tubes at Saturation Temperatures of $1500^{\circ}$ to $1750^{\circ} \mathrm{F}$, Report NASA CR-842, National Aeronautics and Space Administration, August 1967.

5. Potassium Rankine Cycle Power System for Nuclear Electric Propulsion (NEP), BC 90-56, RockWell International, June 1990.

6. J. A. Bond and G. L. Converse, Vaporization of High-Temperature Potassium in Forced Convection at Saturation Temperatures of $1800-2100^{\circ}$ F, NASA CR-843, General Electric Co., July 1967.

7. J. C. Moyers, and J.P. Nichols, “ALKASYS, A Computer Program for Studies of Rankine-cycle Space Nuclear Power Systems”, ORNL Report, ORNL/TM-10427, Oak Ridge National Laboratory, September 1987.

8. Requirements Definition for 100-kW(e) Advanced Potassium Rankine Power Conversion System, unpublished ORNL report, April 17, 2003

9. G. W. Bersin, J. Horan, and D. Costales, Forced Convection Boiling Potassium Experiments, Report PWAC-430, December 1964.

10. T. T. Robin, Design of Boiler-Superheater Units for Representative Cesium and Potassium Space Power Plants, ORNL-TM-2080, Oak Ridge National Laboratory, September 1968.

11. Jones, J. K., R. E. MacPherson, and A. M. Smith, "Development of Integrally Finned DryerSuperheater Tubes for Potassium Rankine Cycle Boilers," ORNL-TM-3383, Oak Ridge National Laboratory Report, June 1971.

12. Jack A. Heller, Thomas A. Moss, and Gerald J. Barna, Study of a 300-Kilowatt RankineCicle Advanced Nuclear-Electric Space-Power System, Report NASA TM X-1919, National Aeronautics and Space Administration, November 1969.

13. J. R. Peterson, R. N. Weltman, and M. U. Gutstein, "Thermal Design Procedures for Space Rankine Cycle System Boilers,” pp. 313-328, Proceedings of the Intersociety Energy

Conversion Engineering Conference, Vol. 1, IEEE, 1968

14. J. A. Angelo and D. Buden, Space Nuclear Power, Orbit Book Company, 1985

15. RELAP5 Code Development Team, “RELAP5/Mod 3.2 Code Manual,” NUREG/CR-5535, INEL-95/0174, Idaho National Engineering Laboratory, 1994.

16. Brayton Power Conversion System Study to Advance Technology Readiness for Nuclear Electric Propulsion - Phase I Report, Contract Number: NAS3-02204

17. V. Havens and D. Ragaller, Study of Toluene Rotary Fluid Management Device and Shear Flow Condenser Performance for a Space-Based Organic Rankine Power System, National Aeronautics and Space Administration, Contractor Report 180885, July 1988.

18. R. McKenna, R. Niggemann, and P. Thollot, "Solar Dynamic Power For Space Station," Proceedings of the 1984 SAE Aerospace Congress and Exposition, October 1984. 
19. G. L. Sorensen, R.E. Niggemann, M.W. Reck, and W. D. Kenney The 1980 Technology Status of The Dynamic Isotope Power System, American Institute of Aeronautics and Astronautics, Inc., 1980.

20. Johnson, G. A., "Potassium_Rankine Power Conversion Subsystem Modeling for Nuclear Electric Propulsion (Task Order 18)," NASA Report CR-191134, National Aeronautics and Space Administration, 1993.

21. A. A. M. Delil, J. F. Heemskerk, O. Mastenbroek, A. Pauw, P. A. G. van Put, R. G. H. M. Voeten, R. H. M. Jacobs, R. Muller, W. D. Ebeling, and M. M. Beckmann, High-efficiency, Low Pressure Drop TwoPhase Condenser - Final Report, NLR Contract Report CR 96002 L, October 28, 1996.

22. J. E. Fredley and C. E. Braun, "A Low Pressure Drop Heat Exchanger With Integral Heat Pipe," Proceedings of the 1988 ASME National Heat Transfer Conference, July 24-27, 1988. 23. S. G. Sawochka, Thermal and Hydraulic Performance of Potassium During Condensation Inside Single Tubes, National Aeronautics and Space Administration Contractor Report CR-851, 1966.

24 W. Bienert et al. "Experimental Study of Loop Heat Pipe Behavior in the Presence of Noncondensible Gas," Proceedings of the $10^{\text {th }}$ International Heat Pipe Conference, Stuttgart, Germany, 1997.

25. Yu. Maidanik et al. "Theoretical Basis and Classification of Loop Heat Pipes and Capillary Pumped Loops," Proceedings of the $10^{\text {th }}$ International Heat Pipe Conference, Stuttgart, Germany,1997, 
Appendix A

Changes to the ALKASYS Code 



\section{Appendix A: Changes to the ALKASYS Code}

\section{Version 1 of ALKASYS-SRPS}

This version of ALKSYS-SRPS was released in August 2003. This version has a new reactor module implemented. A detailed description of the new reactor module follows. Some parts of the original reactor model of ALKASYS were not modified; in particular, the following models have not been changed:

1. The average and peak rod burnup calculation based on peak pellet burnup

2. Lithium circuit calculations (pressures and flows)

3. Lithium final pitch calculation

4. Potassium boiling core calculation

5. Temperature distributions inside cladding and fuel rod

6. Fission gas release and plenum length calculations

7. Calculation of the initial and the final core diameter and height

8. Calculation of the initial mass and volume of uranium based on burnup

9. The criticality equations

10. The calculation of the radial control drums

The new reactor module that has been implemented requires the following additional input variables:

1. Maximum heat flux (variable QOA) in $\mathrm{W} / \mathrm{cm}^{2}$

2. Peak burnup (variable BUPP) in $\%$

3. Theoretical density of the fuel (variable RHOUN) in \%

4. Power peaking factor (variable $\mathrm{PF}$ )

5. Central control rod option (variable NOCON, with $1=$ yes, $0=$ no)

Small reactors normally do not require the central control rod, since the peripheral control drums provide sufficient negative reactivity to shut down the reactor ( $\mathrm{NOCON}=0$ option).

The new reactor module has 3 options for reactor types (variable RTYPE). The original ALKASYS code had only two options: RTYPE $=0$, for the potassium boiling reactor and RTYPE $=1$ for the lithium cooled reactor/potassium boiler with two loops.

The new option, RTYPE=2, is for the lithium reactor, two-loop, but employing the $\mathrm{Nb}-1 \% \mathrm{Zr}$ material, independently of the reactor maximum temperature.

For RTYPE 0 or 1 of the new reactor module, the reactor material properties (including density and structural properties used in calculating thicknesses of the vessel, fuel plenum, and boiler) are selected based on the maximum reactor temperature and the material limit temperature (TMAT). Two materials are available: ASTAR for high temperatures and $\mathrm{Nb}-1 \% \mathrm{Zr}$ for low temperatures. The ASTAR option has been removed in version 2 of ALKASYS-SRPS and replaced by $\mathrm{T}-111$. The temperature to switch from $\mathrm{Nb}-1 \% \mathrm{Zr}$ (for low temperatures) to $\mathrm{T}-111$ (for high temperatures) is $1350 \mathrm{~K}$ in version 2 of the code, unless the RTYPE=2 option is used, for which the material is $\mathrm{Nb}-1 \% \mathrm{Zr}$ independent of the temperature. 
The overall logic of the new reactor module follows an iterative procedure until a satisfactory solution is achieved. The logic of the new reactor module follows these steps:

1. Calculation of average and peak rod burnup (unchanged from original model).

2. Calculation of lithium circuit and boiler (unchanged from original model).

3. Calculation of initial mass and volume of uranium (as the original program), using the total thermal power, total reactor life, and average fuel burnup for the mass calculation, and using the uranium mass and the percent of the theoretical density of uranium for the volume calculation.

4. Calculation of fuel rod and fuel pin diameters using a new model employing the volumetric heat generation rate, the peaking factor, and the maximum rod heat flux. The fuel rod diameters are constrained to a minimum of $0.635 \mathrm{~cm}$ and a maximum of $1.9 \mathrm{~cm}$. The same cladding thickness (variable TKCLAD $=0.0635 \mathrm{~cm}$ ) and tungsten thickness (variable $\mathrm{TKW}=0.0127 \mathrm{~cm}$ ) of the original program are employed in this calculation. These two variables are NOT part of the input.

5. Calculation of temperature distributions inside the cladding, tungsten, and fuel as the original program (using heat fluxes and radial dimensions).

6. Calculation of fission gas releases as the original program.

7. Calculation of the initial core diameter and height, and fission plenum length as the original program. The initial number of fuel rods is calculated based on the total uranium volume (from number 3 ), the fuel rod diameter (from number 4 ) and the initial core height.

8. Calculation of lithium reactor rod pitch as the original program

9. Calculation of the number of assemblies and rods per assembly that closely matches the initial total number of rods calculated in part 4. For small power reactors (thermal power under 1200 $\mathrm{kWt}$ ), a minimum of 6 assemblies (or 7 if a central control rod is not employed) with a minimum of 7 rods per assembly and a maximum of 91 rods per assembly can be selected. Therefore, assemblies may contain 7, 19,37, 61, or 91 rods per assembly.

For large reactors, the minimum number of assemblies is 18 with 61 rods per assembly for a total of 1098 rods. The switch from the small to the large reactor assembly configuration was set when the thermal power of the reactor was $1200 \mathrm{kWth}$.

This logic was modified in version 2 of the code, switching when the initial total number rods is 1098 or larger instead of at a power of $1200 \mathrm{kWt}$.

10. Calculation of the potassium boiling core (as the original program).

11. Calculation of the final core dimensions based on the number of rods and assemblies selected in part 9. Since the total number of rods selected with the assembly configuration is different from the initial number of rods, the final core dimensions would be different from the ones 
calculated in part 7. A smaller final diameter (and a larger height) would result if the final total number of rods is smaller than the initial number of rods, and vice versa.

12. Calculation of core neutronics and criticality constants. The absorption cross section of the structural material is adjusted depending on the material (ASTAR/T-111 or Nb-1\%Zr) employed in the core. The material can be selected by input $(\mathrm{Nb}-1 \% \mathrm{Zr}$ for RTYPE $=2)$ or can be selected by the code based on the reactor operating temperature. The fuel enrichment (variable UENR) is calculated by the code using the criticality equations.

If the enrichment is calculated to be less than or equal to $95 \%$ (maximum value for enrichment), the neutronics calculation is completed and the calculation proceeds to the next step, calculation of control drums and control rod assemblies.

13. If the calculated enrichment (UENR) is more than $95 \%$, the program goes back to step 3 . The initial mass and volume of uranium that were calculated based on burnup considerations are increased by a factor of $\{\mathbf{0 . 9 *}$ UENR/95.0 , and all the calculations after step 3 are repeated again. If the calculated enrichment this second time is still above $95 \%$, the recalculated mass and volume of uranium are increased again by a factor of $\{\mathbf{U E N R / 9 5 . 0 \}}$ and this process is repeated again up to 7 more iterations. A solution is normally achieved before the 8 iterations are completed. If the final enrichment printed by the code is slightly over 95\% (95.01 is the value used by the code to end the iterations), this is an indication that the 8 iterations were completed without reaching the $95.01 \%$ enrichment goal.

14. After the calculated enrichment is at or below $95 \%$, or the 8 iterations are completed, the module adjusts the peak and average burnup (based on the new mass of uranium) and continues to calculate the control drums and additional control rod assemblies if needed.

The calculation of additional control assemblies has been revised to correct some problems of the original code. If central control rod assemblies are required, the calculation of the core dimensions is repeated again.

15. Finally, weights for each component are calculated, employing the appropriate dimensions and density for each material (structure, fuel, cladding, liner, and coolant).

\section{Version 2 of ALKASYS-SRPS}

This is the final version of the code, and it has a long list of changes, modifications, and additions incorporated. This list is below. The models or changes have been incorporated as new models became available or as problems were discovered in the code after running some special cases.

The modular architecture of ALKASYS-SRPS, with separate and independent models, facilitated these changes and modifications into the code.

The components that are not explicitly modeled in the code are the radiator for the EM pumps and the condenser, including its potassium inventory. However, the total system mass calculated by the final version 2 of the code is deemed to be accurate (within the accuracy of the ALKASYS-SRPS code), since some components (like the PMAD and the high-temperature radiators) have been modeled with redundant/excessive mass that may account for the masses of the components that are not explicitly considered in the code. 
Also, the code does not have shielding variables as part of the input. These variables could also be added to the input variables. The code employs the following fixed values for shielding calculations:

Reactor to dose plane (variable DISPL): $15 \mathrm{~m}$

Diameter of the payload dose plane (variable DIAPL): $7 \mathrm{~m}$

Gamma radiation dose at the payload (variable DGAM): $10^{6}$ rads

Fast neutron fluence at the payload (variable DNVT): $10^{13}$ neutron $/ \mathrm{cm}^{2}$

List of changes/additions/modifications to Version 2 of ALKASYS-SRPS:

1. Variable XBOIL added into COMMOM block AVA1 to transfer its value properly to other subroutines.

2. The Boeing-Rocketdyne turbine and turbopump model added. The original ALKASYS turbine and turbopump models are still available.

3. Two new generator models: a revised Boeing-Rocketdyne model and the model of the code MNRANK (Reference 2). For the MNRANK model, an upper limit of 80,000 rpm has also been implemented. The original ALKASYS alternator model is no longer an option in the code. The MNRANK model is used together with the ALKASYS turbine model as an option, and the other option is the Boeing turbine/turbopump/alternator.

4. New high-temperature radiator models from Swales Aerospace have been added: potassium heat pipes (HP) with $\mathrm{Nb}-1 \% \mathrm{Zr}$ with two different lengths; $1.5 \mathrm{~m}$ and $0.5 \mathrm{~m}$; potassium $1.5-\mathrm{m}$ heat pipes with TZM and Inconel; and mercury loop heat pipes (LHP) with TZM and Inconel. The original ALKASYS model is also available. Therefore, five different options are available for the radiator.

5. Two low-temperature radiators added: one at $600 \mathrm{~K}$ using mercury heat pipes (based on extrapolation of a Swales model, it uses a mass of $4.8 \mathrm{~kg} / \mathrm{kW}_{\mathrm{t}}$ and an area of $0.2 \mathrm{~m}^{2} / \mathrm{kW}_{\mathrm{t}}$ ) to remove the alternator heat losses $(\sim 10 \%$ of alternator power) and auxiliary loads (bearings), and one at $400 \mathrm{~K}$ using water heat pipes (based on Swales model) to cool the PMAD.

The bearings have a typical cooling load of $\sim 107 \mathrm{~W}$ for a $100 \mathrm{~kW}_{\mathrm{e}}$ net system; they need to be cooled to a temperature of $750-800 \mathrm{~K}$. A portion of the main potassium condensate flow (which is at about $850-880 \mathrm{~K}$ ) would be cooled down to $750 \mathrm{~K}$ using the $600 \mathrm{~K}$ radiator to cool the bearings. The $400 \mathrm{~K}$ radiator weights $15 \mathrm{~kg}$ to remove $6.5 \mathrm{~kW}_{\mathrm{t}}$, typical value supplied by Boeing/Rocketdyne for a $100-\mathrm{kW}_{\mathrm{e}}$ net $\left(114 \mathrm{~kW}_{\mathrm{e}}\right.$ gross $)$ system.

6. Option added to have a reheater by selecting the reheat temperature (vapor superheat over saturation temperature) of the vapor after the reheater. Masses are adjusted by multiplying the turbine mass by 1.8 , multiplying the boiler mass by 1.5 , and adding the piping mass from the turbine to the reheater (lines 1 and 2 of ALKASYS are duplicated).

The vapor to be reheated is saturated vapor taken from the exit of the mid-stage of the turbine. For instance, if the turbine has 7 or 8 stages, the vapor to be reheated is taken at the outlet of 
stage 4 . Reheating can be accepted by the code only when there are four or more stages in the turbine. This number of stages requires a sufficient temperature difference between the boiler exit (variable TBOILK) and the condenser (variable TCONK).

Since the reheater is assumed to be located at the exit of the main boiler, there is also a limit in the maximum reheating temperature that can be achieved. The maximum temperature of the vapor after reheat has been set at $100 \mathrm{~K}$ below the boiler exit temperature (variable TBOILK). If a very large reheat delta $\mathrm{T}$ is input, the temperature of the vapor after reheat is set to the maximum value of TBOILK-100.

7. Added the option to have superheated vapor (employing qualities larger than 1.0). When a quality over 1.0 is used, both the saturation temperature and pressure are recalculated by the code and the cycle calculations are adjusted.

8. Corrected the pressure drop calculations in the boiler by incorporating P/D values and twophase multipliers and also pressure drop calculation for single-phase potassium vapor.

9. Corrected the lengths of the boiler tubes to $91.5 \mathrm{in} .(232.4 \mathrm{~cm})$ and reduced the amount of potassium vapor that can be generated by each tube to a more conservative value of $0.03 \mathrm{~kg} / \mathrm{s}$ from the original value of $0.038 \mathrm{~kg} / \mathrm{s}\left(\mathrm{G}=34.1 \mathrm{lb} / \mathrm{ft}^{2} / \mathrm{s}\right)$. Boiler mass is calculated more realistically, including structures and tube separators/baffles inside the shell.

10. Calculates the inventory (volume and mass) of liquid potassium in the system, including boiler, piping, and heaters.

11. Added a new PMAD mass calculation, including control systems and auxiliary power. Calculations for systems with one power conversion system (PCS) unit (1/1) and with two PCS units with only one operating (2/1) are available.

12. Added a calculation for the RFMD and accumulator masses. This calculation is a modification of the model employed by the MNRANK code (Reference 2). The jet pump that was available in the original ALKASYS can be deactivated via input (large value for variable JETRAT).

13. Modified the calculation of control rod assemblies. A problem that was discovered in the code has been fixed.

14. Changed the switch in the core from small to big assemblies (for small to big cores). The switch that was before at a power level of $1200 \mathrm{kWt}$ has been changed to the number of fuel rods of 1098 (for 18 assemblies with 61 rods/assembly).

15. Three different materials, $\mathrm{T}-111, \mathrm{Nb}-1 \% \mathrm{Zr}$, and stainless steel, can be used in the secondary system with the option of selecting one specific material or automatically selecting the material based on temperature (for a total of 4 options). The temperature ranges are: 1500 $1350 \mathrm{~K}$ for $\mathrm{T}-111,1350-1000 \mathrm{~K}$ for $\mathrm{Nb}-1 \% \mathrm{Zr}$, and below $1000 \mathrm{~K}$ for stainless steel. For the primary system, two materials can be selected, $\mathrm{T}-111$ and $\mathrm{Nb}-1 \% \mathrm{Zr}$, and the selection can be 
done by the code automatically based on the maximum temperature of the primary $(1350 \mathrm{~K}$ is the switching temperature). There is the additional option of using $\mathrm{Nb}-1 \% \mathrm{Zr}$ in the primary system independent of the operating temperature. The subroutine calculating structural properties has been modified also. Stresses are calculated for each material as a function of temperature and lifetime. If a material is used outside its range of applicability, a warning is given by the code, but the calculation is completed for the selected material. Employing a material out of its range of applicability may yield erroneous results (very thick walls may be calculated as the material has reduced strength). Equations used for material strength calculations (stainless steel, Nb$1 \% \mathrm{Zr}$, and $\mathrm{T}-111$ ) are presented in Appendix D.

\section{Modified/added some input:}

added an input for the superheat temperature of the reheater, added an input variable for the number of units (to divide the total power) and removed the input from the number of lines (which are the same as the number of units), added an input variable for selecting the material of the secondary (three options), added an input variable for selecting the turbine/alternator model (two options), added an input variable for selecting the radiator type (five options).

17. Modified the input to be in SI units ONLY, and modified the output with most variables (with the exception of the thermodynamic cycle points, heaters, turbine-generator, and some radiator variables) printed in SI units, and with some variables printed in dual units. Also the output provides new lines indicating the reheater temperature, the material selected for the secondary, the temperature to switch radiator materials in the ALKASYS radiator option, the turbine/alternator option used, and the radiator option used.

18. Added the option to calculate system mass with a single reactor and with dual PCS at $100 \%$ capacity each, including two boilers, two turbines, two turbopumps, two generators, two piping sets and heaters, and two radiators.

19. Modified the moisture separator model in the turbine for low pressures (below 3 psia or $20.6 \mathrm{kPa})$ by reducing the pressure drop in the separator to $0.5 \mathrm{psia}(3.4 \mathrm{kPa})$ from the original value of $1.5 \mathrm{psia}(10.3 \mathrm{kPa})$ that still applies for high pressures. 


\section{Appendix B}

$100 \mathrm{~kW}_{\mathrm{e}}$ piping dimensions 



\section{Appendix B: $100 \mathrm{~kW}_{\mathrm{e}}$ piping dimensions}

\author{
Component \\ Core \\ Core hardware \\ Pressure vessel and piping \\ Control elements \\ Li pump \\ Li inventory \\ Boiler \\ Shield \\ Turbo-alternator \\ Turbine \\ Generator \\ Turbo-pump \\ RFMD \\ Power conditioning (shared between units) \\ PMAD \\ Auxilliary power \\ Instrumentation and control \\ $\mathrm{K}$ inventory
}

Mass (kg per unit)

108

22

52

35

4

10

831

17

41

3
463

112

129

3
Dimensions

$21 \mathrm{~cm} \mathrm{D} \times 30 \mathrm{~cm} \mathrm{I}$

$0.4 \mathrm{~cm}$ thick

$7.6 \mathrm{~cm} \mathrm{w} \times 11 \mathrm{~cm} \mathrm{~h} \times 2.4 \mathrm{~m} \mathrm{I}$

$97 \mathrm{~cm} \mathrm{D} \times 51 \mathrm{~cm} \mathrm{I}$

$13 \mathrm{~cm} \mathrm{D} \times 16 \mathrm{~cm} \mathrm{I}$

$20 \mathrm{~cm} \mathrm{D} \times 40 \mathrm{~cm}$

\section{Piping Dimensions}

Boiler to turbine

Turbine to condenser

Condenser to RFMD

RFMD to boiler feed pump

Boiler feed pump to boiler
$2.8 \mathrm{~cm} \mathrm{D} \times 0.06 \mathrm{~cm} \mathrm{t}$

$12.6 \mathrm{~cm} \mathrm{D} \times 0.05 \mathrm{~cm} \mathrm{t}$

$1.3 \mathrm{~cm} \mathrm{D} \times 0.05 \mathrm{~cm} \mathrm{t}$

$1.3 \mathrm{~cm} \mathrm{D} \times 0.05 \mathrm{~cm} \mathrm{t}$

$1.3 \mathrm{~cm} \mathrm{D} \times 0.05 \mathrm{~cm} \mathrm{t}$ 



\begin{abstract}
Appendix C
Listing of possible system connections of the integrated

Rankine system design
\end{abstract}




\section{APPENDIX C: Listing of possible system connections of the integrated Rankine system design.}

\author{
Component
}

1

Boiler

2

Control valves

3

Turbine

Condenser header

$5 \quad$ Condenser manifold

6

Liquid return

7

RFMD

Pump

9 TEM pump

10

Startup radiator
Total number

1

lithium outlet

vapor outlet

vapor outlet

Startup liquid inlet

Startup liquid inlet

2

control valve inlet

control valve outlet

control valve outlet

2

turbine main flow inlet

turbine outlet

liquid extraction line

bearing cooling inlet

bearing coolant outlet

2

inlet

inlet

outlet

2

inlet

outlet

2

outlet

inlet

2

inlet

inlet

inlet

outlet

2

vapor inlet

vapor outlet

liquid inlet

liquid outlet

bearing coolant outlet

alternator coolant loop outlet

inlet

outlet

inlet

outlet
Destination

reactor vessel outlet reactor pump inlet control valve inlet control valve inlet TEM pump outlet TEM pump outlet

boiler vapor outlet turbine inlet turbine pump inlet

control valve outlet condenser header

RFMD inlet

bearing coolant radiator

RFMD inlet

turbine outlet startup shut off valve

condenser manifold

condenser header

liquid return

RFMD inlet

condenser manifolds

liquid return

turbine liquid extraction rotor coolant loop return pump

pump inlet

control valve outlet

startup shut off valve

RFMD outlet

boiler main flow inlet

bearing coolant loop radiator

alternator coolant loop radiator

startup radiator

boiler startup inlet

startup shut off valve

TEM pump 
11 Startup loop shutoff valve

12 Alternator cooling loop radiator

13 Alternator cooling loop pressure drop

14 Rotor cooling loop return pump
2

inlet

outlet

outlet

1

inlet

outlet

2

inlet

outlet

2

inlet

outlet turbine pump vapor outlet

startup radiator

condenser manifold

pump alternator coolant

outlet

alternator stator coolant loop

alternator stator coolant loop outlet

alternator rotor coolant loop

alternator rotor cooling loop outlet

RFMD inlet 
Appendix D

$250 \mathrm{~kW}_{\mathrm{e}}$ piping dimensions 


\section{Appendix D: $250 \mathrm{~kW}_{\mathrm{e}}$ piping dimensions}

$\begin{array}{lcc}\text { Mass Details } & & \\ \text { Component } & \begin{array}{c}\text { Mass } \mathbf{( k g} \\ \text { per unit) }\end{array} & \text { Dimensions } \\ \text { Core } & 265 & 30 \mathrm{~cm} \mathrm{D} \times 40 \mathrm{~cm} \mathrm{I} \\ \quad \text { Core hardware } & 42 & 0.4 \mathrm{~cm} \text { thick } \\ \quad \text { Pressure vessel and piping } & 74 & \\ \quad \text { Control elements } & 77 & \\ \text { Li pump } & 16 & \\ \text { Li inventory } & 21 & 17.5 \mathrm{~cm} \mathrm{D} \times 20 \mathrm{~cm} \mathrm{~h} \times 2.5 \mathrm{~m} \mathrm{I} \\ \text { Boiler } & 1403 & 112 \mathrm{~cm} \mathrm{D} \times 92 \mathrm{~cm} \mathrm{I} \\ \text { Shield } & & \\ \text { Turbo-alternator } & 40 & 20 \mathrm{~cm} \mathrm{D} \times 25 \mathrm{~cm} \mathrm{I} \\ \quad \text { Turbine } & 150 & 30 \mathrm{~cm} \mathrm{D} \times 40 \mathrm{~cm} \\ \quad \text { Generator } & 7 & \\ \text { Turbo-pump } & & \\ \text { RFMD } & & \\ \text { Power conditioning (shared between } & 903 & \\ \text { units) } & 164 & \\ \quad \text { PMAD } & 168 & \\ \quad \text { Auxiliary power } & 8 & \\ \text { Instrumentation and control } & & \\ \text { K inventory } & \end{array}$

\section{Piping Dimensions}

Boiler to turbine

Turbine to condenser

Condenser to RFMD

RFMD to boiler feed pump

Boiler feed pump to boiler

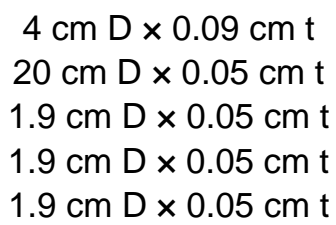



Appendix E

Design stress equations used in ALKASYS-SRPS 



\section{Appendix E: Design stress equations used in ALKASYS-SRPS}

The design stress equations for stainless steel and $\mathrm{Nb}-1 \% \mathrm{Zr}$ used in ALKASYS-SRPS were developed by curve fitting Figs. 1 and 2, respectively in ref. 1. The T-111 information was assembled from ref. 2. Each design curve was made up of multiple curve segments. Plots of the final design equations are shown for each material. In the low-temperature region, this was generally $1 / 3$ of the ultimate stress. In the mid-temperature portions of the figures, the curves were established by radiation limits; and in the higher-temperature portions of the figures, the design limit was established by $2 / 3$ of the creep limit. For stainless steel, the baseline creep limit was taken as the $1 \%$ creep value ( 10 years). For $\mathrm{Nb}-1 \% \mathrm{Zr}$ and T- 111 , it was taken as the creep rupture value $\left(10^{5}\right.$ hours). Creep rupture values were used for analysis of $\mathrm{Nb}-1 \% \mathrm{Zr}$, since for $\mathrm{Nb}$ $1 \% \mathrm{Zr}$, the rupture stress is significantly less than $10 \%$. Additionally, since these limits are used for piping, the tolerance on these components is not critical. Additionally, because pressures are so low in the Rankine cycle system, most of the piping thicknesses are limited to a minimum thickness established by fabricability instead of stress limits. This minimum piping thickness has been taken as $0.5 \mathrm{~mm}$, in order to allow the materials to be welded and formed. A factor, using the Larson-Miller parameter, has been added to the creep-limiting portion of these curves that accounts for time at temperature, allowing the final equations to be used for different mission times (not shown in the figures).

\section{E.1. Stainless Steel (973 K maximum temperature)}

\begin{tabular}{|c|c|}
\hline \multirow{2}{*}{\multicolumn{2}{|c|}{ 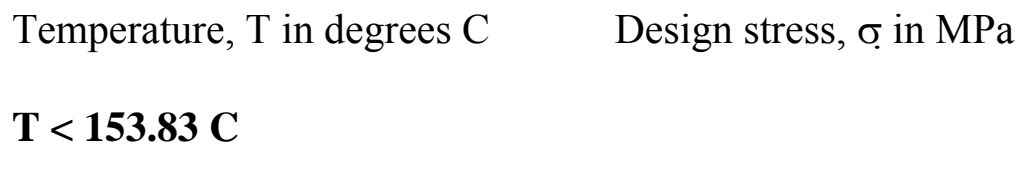 }} \\
\hline & \\
\hline$\sigma=147.5$ & \\
\hline $153.83 \mathrm{C}<\mathrm{T}<547.97 \mathrm{C}$ & \\
\hline$\sigma=a(T-b)^{-c}$ & \\
\hline$a=440.71893$ & \\
\hline $\begin{array}{l}b=50.09179 \\
c=0.23580479\end{array}$ & \\
\hline $547.97 \mathrm{C}<\mathrm{T}<700 \mathrm{C}$ & \\
\hline $\begin{array}{l}\sigma=\left\{\mathrm{a} \mathrm{e}^{-\mathrm{bT}}\right\}\left\{[\mathrm{C}+5] /\left[\mathrm{C}+\log _{10}(\mathrm{t})\right]\right\} \\
\mathrm{a}=20922.404 \\
\mathrm{~b}=0.0097169439 \\
\mathrm{C}=18 \\
\mathrm{t}=\text { lifetime in hours }\end{array}$ & \\
\hline
\end{tabular}




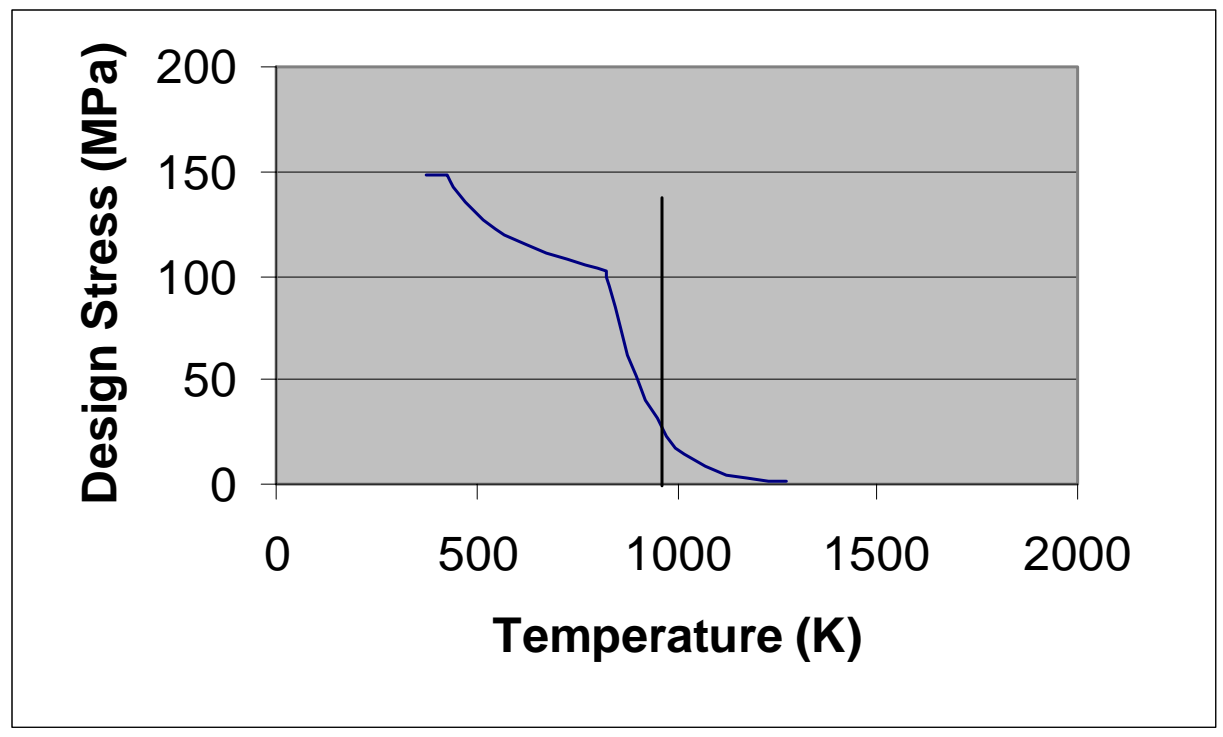

E.2. Nb-1\% Zr (1350 K maximum temperature)

Temperature, $\mathrm{T}$ in $\mathrm{K} \quad$ Design stress, $\sigma$ in $\mathrm{MPa}$

$\mathrm{T}<658.364 \mathrm{~K}$

$\sigma=a b^{T}$

$\mathrm{a}=121.32044$

$\mathrm{b}=0.99908316$

$658.364 \mathrm{~K}<\mathrm{T}<1023.521 \mathrm{~K}$

$\sigma=a T^{b}$

$\mathrm{a}=19.536391$

$\mathrm{b}=0.18833769$

$\mathrm{T}>1023.521 \mathrm{~K}$

$\sigma=\left[\mathrm{a}+\mathrm{b}^{*} \mathrm{~T}+\mathrm{d}^{*} \mathrm{~T} * \mathrm{~T}\right]\left[\{\mathrm{C}+5\} /\left\{\mathrm{C}+\log _{10}(\mathrm{t})\right\}\right]$

$\mathrm{a}=511.70094$

$\mathrm{b}=-0.6163561$

$\mathrm{d}=1.8253547 \mathrm{e}-4$

$\mathrm{C}=15$

$\mathrm{t}=$ lifetime in hours 


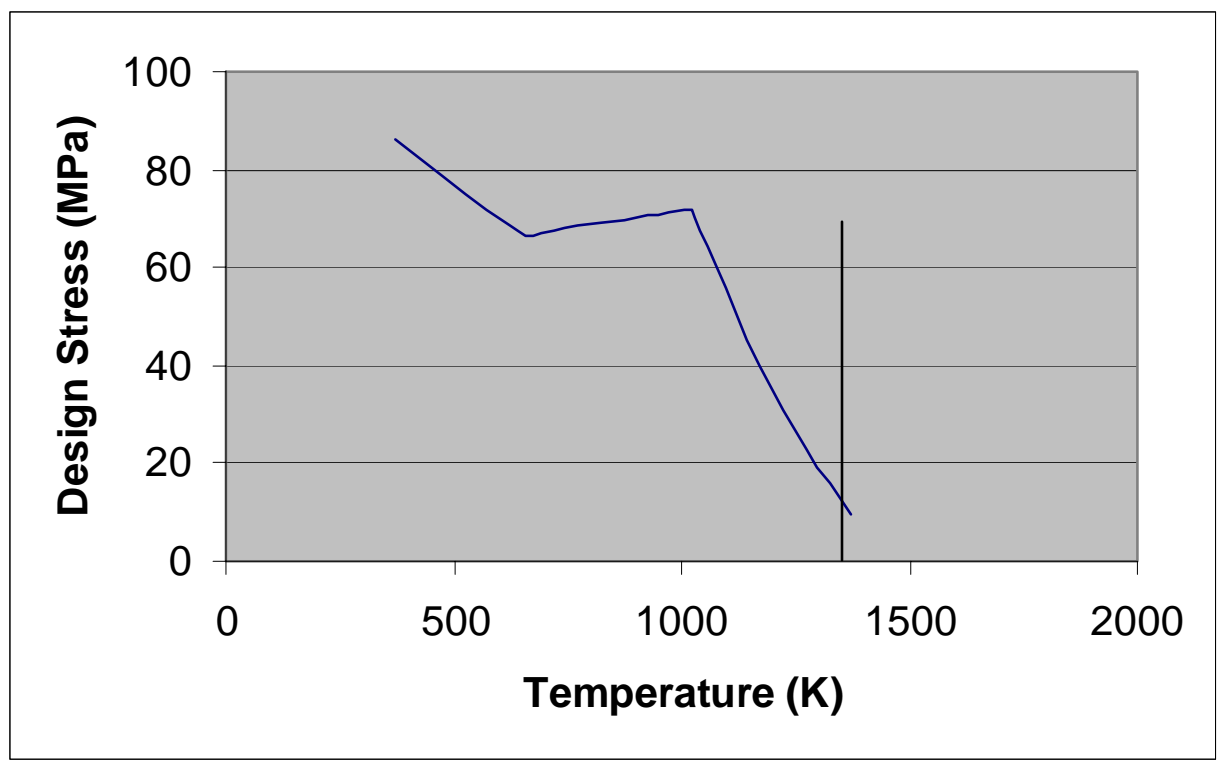

\section{E.3. T-111 (maximum temperature $1500 \mathrm{~K}$ )}

Temperature, $\mathrm{T}$ in degrees $\mathrm{C} \quad$ Design stress, $\sigma$ in $\mathrm{MPa}$

$\mathrm{T}<924.47 \mathrm{C}$

$\sigma=\left(612-1.743 * \mathrm{~T}+0.003585 * \mathrm{~T}^{2}-0.000003076^{*} \mathrm{~T}^{3}+0.0000000008819 * \mathrm{~T}^{4}\right) / 3$

924.47 C < T

$\sigma=\{\exp (-0.0073 * \mathrm{~T}+11.297)\}\left\{[\mathrm{C}+5] /\left[\mathrm{C}+\log _{10}(\mathrm{t})\right]\right\}$

$\mathrm{C}=12$

$\mathrm{t}=$ lifetime in hours

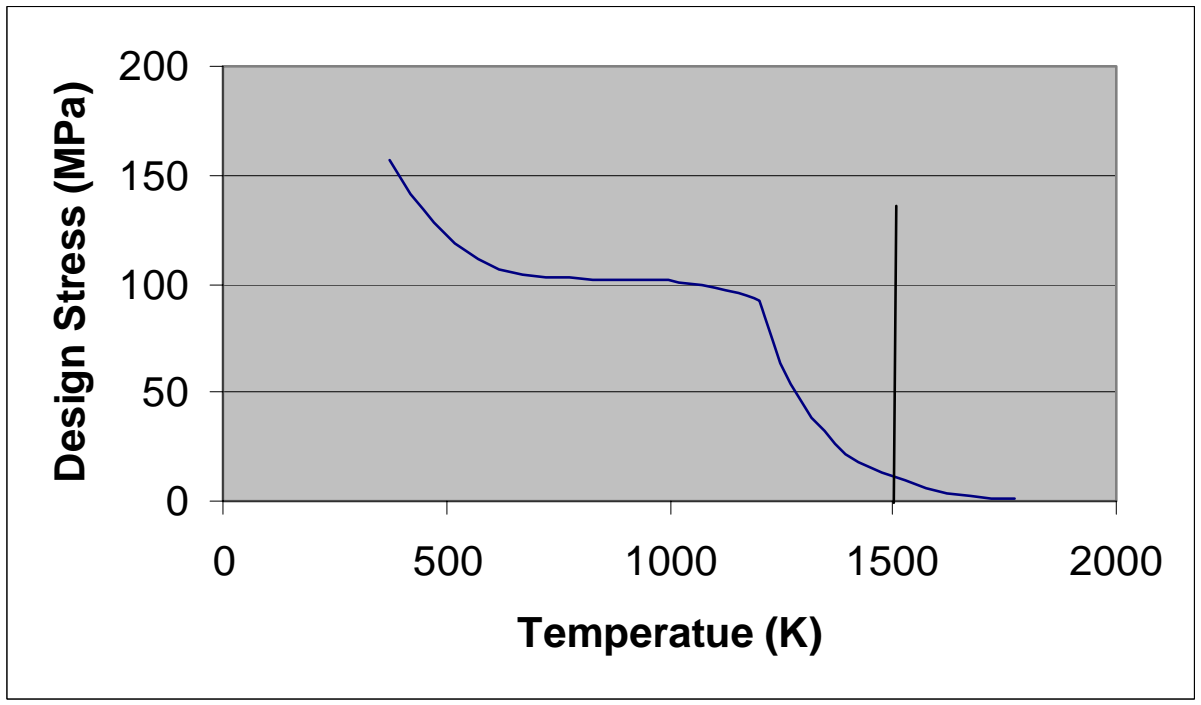


1. Zinkle, et al., "Overview of Materials Technologies for Space Nuclear Power and Propulsion". Space Technology and Applications International Forum-STAIF 2002 (AIP Conf. Proc. Vol. 608), M.S. El-Genk (ed.), American Institute of Physics, 2002, pp. 1063-1074.

2. Zinkle, et al., Thermophysical and Mechanical Properties for Ta-8\%W-2\%Hf, unpublished ORNL Document. 